\title{
INDIGENOUS ORGANISING \\ IN GLOBAL CONTEXTS
}

by

\author{
Steven John Finlay
}

\author{
A thesis \\ submitted to the Victoria University of Wellington \\ in fulfilment of the \\ requirements for the degree of \\ Doctor of Philosophy \\ in Management
}

2011 


\begin{abstract}
Drawing from social phenomenology, this thesis builds a grounded theory of indigenisation from two cases in their respective global and historical contexts: Te Wānanga o Raukawa in New Zealand and The Iona Community in Scotland. The theory describes indigenous organising as a process, showing how leaders develop strategies for their organisations to recover, enact and update indigenous knowledge. The theory of indigenisation also shows how actors use this knowledge to rebuild identity and overcome the effects of globalist practices, illustrating the dialectic of how globalisation as a large scale social process may be declining as differing cultures and their ways of organising emerge.
\end{abstract}




\section{Acknowledgements}

This thesis is dedicated to my long suffering family. In completing the thesis I have been given support by many others. Not least of these are: the gracious staff, volunteers and students of Te Wānanga o Raukawa; the members, staff, guests and volunteers of the Iona Community; and especially the staff of the Victoria Management School, and in particular my supervisors Professor John Brocklesby and Dr Deborah Jones. I also thank Professor Coin Campbell-Hunt for his initial support and supervision. Professor Graham Hingangaroa Smith, Professor Manuka Henare and Māori M.P. Hon. John Tamihere also provided invaluable guidance at the early stages of the journey. Professor Whatarangi Winiata and Kathy Galloway have guided my steps along the way. John Ralston Saul was a worthy encourager as the end drew near.

Your graciousness in tolerating gaps in my own knowledge, and sharing your own knowledge so fully, is deeply appreciated. I owe a significant debt of gratitude to you all. 


\section{Contents}

$\begin{array}{ll}\text { Abstract } & \text { ii }\end{array}$

$\begin{array}{lll}\text { Acknowledgements } & \text { iii }\end{array}$

Contents $\quad$ iv

Figures $\quad$ xi

Tables $\quad$ xii

CHAPTER 1: INTRODUCTION 1

1.1 Introduction 1

1.2 The Research Question 2

1.3 Positioning the Research 3

1.4 Positioning the Researcher 6

1.5 Why Social Phenomenology? 9

1.6 Social Phenomenology: A Naturalistic Theory 10

1.7 Social Phenomenology in OS 13

1.8 Naturalistic Research Methods, Naturalistic Generalisation 14

$\begin{array}{ll}1.9 \text { Cases } & 18\end{array}$

1.10 Definitions of Terminology 19

1.11 Thesis Summary 22

CHAPTER 2: DEFINING INDIGENEITY IN GLOBAL CONTEXTS 28

2.1 Introduction 28

2.2 Indigeneity in the Context of Globalist Practices 28

2.2.1 Globalisation Fragments Indigenous Knowledge 33

2.2.2. Alienation: The Seeds of Globalisation's Demise 39

2.3 Indigenous Organisations: Surviving in Global Contexts. 44

2.4 Indigenous Organisations Enacting Indigenous Knowledge $\quad 50$ 
2.5 Indigenous Leadership and Identity

2.6 Defining Indigeneity in Wider Literatures

2.6.1 Objective Colonialism: Positional Superiority

2.6.2 Postcolonial Identity Constructed by the Coloniser

2.6.3 Objective Anthropology

2.6.4 Indigeneity in Global Agencies; Challenging Nation States

2.6.5 Constructing Indigeneity in Anthropology

2.6.6 Authentic Indigenous Identity

3.1 Introduction

3.2 Social Phenomenology in Philosophical Context 
4.3.1 Naturalistic Case Study Methodology and Selection $\quad 122$

4.3.2 Case Study Selection

\section{CHAPTER 5: CONSTRUCTING INDIGENEITY IN GLOBAL CONTEXTS}


5.2.1 Tangata Whenua: The People Are the Land 
$\begin{array}{lr}\text { 6.3.2 A Celtic Institution? } & 198\end{array}$

6.3.3 George MacLeod: The Visionary Celtic Environmentalist 199

6.3.4 Founding Purposes and the Celtic Imaginary 200

$\begin{array}{lr}\text { 6.3.5 The IC Today } & 204\end{array}$

$\begin{array}{lr}\text { 6.4 Discussion } & 209\end{array}$

$\begin{array}{lr}\text { 6.5 Summary } & 211\end{array}$

\section{CHAPTER 7: DEFINING AND ENACTING MĀORI KNOWLEDGE 213}

$\begin{array}{ll}7.1 \text { Introduction } & 213\end{array}$

$\begin{array}{ll}\text { 7.2 Preparing Cultural Competence } & 213\end{array}$

$\begin{array}{lr}\text { 7.2.1 Approach to TWoR } & 215\end{array}$

7.2.2. Defining Māori Knowledge - Māori Worldviews 221

7.2.3 Defining Indigeneity - Constructing Identity 223

$\begin{array}{ll}\text { 7.2.4 Boundaries and Rules: The Theory of Wānanga } & 228\end{array}$

$\begin{array}{lr}\text { 7.2.5 Theory of Wānanga Session } & 229\end{array}$

7.2.6 Māori Knowledge and Life Projects in Social Context 231

7.2.7 Experiencing Colonialism and Postcolonialism 233

7.2.8 Māori Knowledge at Individual Levels 235

$\begin{array}{ll}\text { 7.3 Discussion } & 238\end{array}$

$\begin{array}{lr}7.4 \text { Summary } & 239\end{array}$

CHAPTER 8: DEFINING AND ENACTING CELTIC KNOWLEDGE 240

$\begin{array}{lr}\text { 8.1 Introduction } & 240\end{array}$

8.2 Iona Programme 2003: On the Move $\quad 240$

8.2.1 Celtic Knowledge - Celtic Liturgy 245

$\begin{array}{ll}\text { 8.2.2 Defining Indigeneity } & 247\end{array}$

$\begin{array}{ll}\text { 8.2.3 Defining Celtic } & 251\end{array}$

8.2.4 IC: Recovering and Enacting Celtic Knowledge 257 
8.3 Experiencing Celtic Knowledge and Plotting Boundaries

8.3.1 Boundaries - Drawing from the Benedictine 265

8.3.2 Celtic Knowledge: Building Community 266

8.3.3 Historical and Neocolonial Impositions on Celtic Knowledge 273

8.4 Discussion: Indigeneity Defined and Enacted in a Celtic Context 276

$\begin{array}{lr}\text { 8.5 Summary } & 277\end{array}$

\section{CHAPTER 9: ORGANISING WITH INDIGENOUS KNOWLEDGE 281}

$\begin{array}{lr}9.1 \text { Introduction } & 281\end{array}$

9.2 Māori Organising: Constructing a Tikanga Māori Organisation 281

9.2.1 Overcoming Knowledge Challenges 283

9.2.2 Autonomy in Decision Making: The Academic Board 287

9.2.3 Māori Knowledge: Continuity and Adaptiveness 290

9.2.4 Māori Knowledge Coordinates Organising 293

9.2.5 Māori Organising at the Social Level 295

$\begin{array}{lr}9.3 \text { Summary } & 297\end{array}$

9.4.1 Challenging Celtic Knowledge inside the IC 302

9.4.2 Challenging Celtic outside the Community 303

9.4.3 Celtic Knowledge: Continuity and Change 305

9.4.4 Constructing the Celtic Christian Holistic Cosmology 309

9.4.5 Celtic Knowledge Coordinates Organising 311

9.4.6 Celtic Knowledge at the Social Level $\quad 312$

$\begin{array}{lr}\text { 9.5. Summary } & 312\end{array}$

CHAPTER 10: INDIGENOUS ORGANISING IN GLOBAL CONTEXTS 315

$\begin{array}{ll}10.1 \text { Introduction } & 315\end{array}$

10.2 Defining Indigeneity from Holistic Cosmologies 315

10.3 Comparing and Theorising Indigenous Organisations 320 
10.3.1 The Indigenous Organisation in Global Contexts 
Figures

$\begin{array}{ll}\text { Figure 1: Thesis Structure } & 27\end{array}$

Figure 2: Impacts of Colonisation on Aboriginal Health 38

Figure 3 : The Flow of Naturalistic Inquiry, Applied to a PhD Context 123

Figure 4: The Abductive Process 139

Figure 5: NVivo Full Interview Example 140

Figure 6: Example Page from The Book of Kells 164

Figure 7: Iona in Historical and Physical Location 167

Figure 8: Te Raupara and Interior of Rangiātea Church, Otaki. 181

Figure 9: The Iona Abbey, MacLeod Centre, Refectory and Guests 198

Figure 10: TWoR and Professor Winiata 218

Figure 11: Iona Abbey 242

Figure 12: Appraching the MacLeod Centre 243

Figure 13: The Aronga Model 286

Figure 14: Māori Organising as a Process 323

Figure 15: Celtic Organising as a Process 324

Figure 16: Indigenous Organising as a Process 325

Figure 17: The Iterative Cycle of Indigenous Adaptation 332

Figure 18: Effects of Globalist Practices on Indigenous Knowledge 338

Figure 19: Indigenisation in Globalising Contexts 340 


\section{Tables}

Table 1: Summary of Indigeneity and Globalist Terms 22

Table 2: Definitions of Indigeneity Applied $\quad 81$

Table 3: Definitions of Indigeneity Assessed 83

Table 4: Mapping 'Indigeneity' at Three Levels 84

Table 5: Theory, Premises and Research Methods at Three Levels. 90

Table 6: Māori Constructed in Differing Contexts 160

Table 7: Celtic Defined In Differing Contexts 178

Table 8: Indigenous Communities of the Scottish Celtic and Māori Compared 211

Table 9: Self Definitions of Indigeneity in Two Contexts 318

Table 10: A Constructionist Assessment of Indigeneity 319

Table 11: Components of the Indigenous Organisation 320

Table 12: Two Indigenous Organisations Compared 322

Table 13: Effects of Globalist Practices on Two Indigenous Communities 339

Table 14: Indigenous Knowledge Effects on Indigenous Peoples 340

Table 15: Assumptions of Indigenisation and Globalisation Compared 341

Table 16: Summary of Thesis Contribution at Three Levels 354 


\section{Chapter 1: Introduction}

'E kore au e ngaro, he kãkano i ruia mai Rangiātea' [I won't be lost, a seed broadcast from Rangiātea] ${ }^{1}$ (Te Wananga o Raukawa Charter, p.1).

\subsection{Introduction}

In this chapter I introduce the topic of the indigenous organisation in global contexts, pose the research question for the thesis and position the researcher relative to the research. I also introduce social phenomenology and its use in Organisation Studies (hereafter OS). Naturalistic research methods are applied in two case studies, using key terms of indigeneity, globalist practices and the organisation, all of which draw from critical constructionists. Finally, the thesis is summarised.

Rangiātea is known as both the ancient source of indigenous Māori knowledge and the $12^{\text {th }}$ level of heaven within a Māori cosmology. The quote heading this chapter is central to the identity of the Māori University Te Wānanga o Raukawa (hereafter TWoR) at Otaki, New Zealand. It summarizes hope and confidence in the ongoing survival of Māori knowledge and people emanating from their sacred origins of Rangiātea.

\footnotetext{
1 Māori terms are translated in square brackets on first use. These are also referenced in the glossary, in Appendix 1.
} 
In this thesis I generate an innovative organisational theory which illustrates how Indigenous Peoples construct an organisation in the face of fragmenting practices of globalisation ${ }^{2}$. These battles between symbolic universes carry significant implications for individual and organisational identity. Indigenous organisations such as TWoR are rich sites which magnify and play out these knowledge tensions. Two indigenous organisations are theorised in global contexts: a Māori University in New Zealand, and the Iona Community (hereafter IC), a Christian community based on the Isle of Iona and Glasgow in Scotland.

\subsection{The Research Question}

The thesis poses and answers a central question: "what is an indigenous organisation, as seen in global contexts?' The aim is to contribute to OS with a working theory of indigenous organising. This theory draws from social phenomenology to show how actors use and update indigenous knowledge systems or holistic cosmologies to rebalance the negative effects of globalisation, and goes on to show how they define indigeneity and construct worlds of local meaning at individual, organisational and social levels, thus enacting the indigenous organisation.

\footnotetext{
${ }^{2}$ The terms globalisation and indigeneity are summarized on p.22 and fully developed in Chapter 2.
} 


\subsection{Positioning the Research}

This innovative international research travels beyond the traditional objective definitions, research approaches, cases and findings to explore new definitions and applications of indigeneity and the indigenous organisation. To forewarn the reader of the unique approach this thesis takes in theory, method, cases and findings, I position both the research and the researcher before outlining the unique features of social phenomenology which are applied to answer the thesis question.

Social phenomenology ${ }^{3}$ is defined as the study of how actors and groups experience, construct and transmit social knowledge (Berger and Luckmann, 1966; Schutz, 1967, 1970, 1973). I use this theory to focus on knowledge as the main working concept, but understanding how it is used by living actors who are the carriers, constructors and guardians of this knowledge in use. This research approach brings strengths and limitations in its focus, treatment of bias and definition of knowledge. Each is dealt with in turn.

I generate innovative research by focusing the research lens on the organising methods of indigenous actors. Like Schwartzman (1993) I draw from OS constructionists such as Karl Weick (1979) who commends OS researchers to focus on the 'organizing processes out of which a sense of organization unfolds

\footnotetext{
${ }^{3}$ Social phenomenology is dealt with fully in Chapter 3 .
} 
and is enacted, instead of continuing to examine organizations as objective, concrete, material, and unproblematic entities' (Schwartzman, 1993 p.36). A working theory of indigenous organising is developed which illustrates how actors organise using knowledge, methods and practices to co-create the organisation, drawing from constructionist definitions of both organising, and the organisation (Clegg and Hardy, 1996). This working theory can be tested by theorists and readers in wider contexts, themselves cognisant of their own context of theoretic application. The deep descriptive cases within this thesis offer the context of development (Lincoln and Guba, 1985).

I use extant literatures as artefacts to guide the analysis of local actors who pragmatically define polyvocal and local definitions of indigeneity for themselves. This research reveals similarities and differences without the comfort of collapsing these local definitions into a single fixed and universally applicable definition which glosses either local differences or the tools required for collective inter-subjective agreement, as outlined in Chapter 3. Without a single fixed definition implied or expected, a constructionist analysis shifts to asking who is defining indigeneity, for whom, and for what purpose? I explore the pragmatic definitions of Māori and Celtic, and how these definitions aided or hindered the communities studied. This research does recommend that researchers and communities reflect on both the constructionist definitions herein, against their own definitions to open new avenues for exploration, as well as reconfirming and updating useful working definitions in their own context. 
Similarly, no analysis of a fixed indigenous organisational structure is undertaken as this assumes an objective and unproblematic organisation. Again, this research invites organisational actors and researchers to reflect on organising processes in their own social contexts. This research indicates that knowledge plays a fundamental role in constructing both the organisation and the wider context. But knowledge requires actors who together script their own shared stories and choose the stage where the organisation is enacted. This thesis shares the stories of two organisations, told by a management researcher who also brings prior knowledge to the stage.

Social phenomenology suggests that both the researcher and the research project are inexorably linked. Rather than an objective method which attempts to reduce bias, a naturalistic method encourages the articulation of prior experiences, influences on the topic, case selection, method and resulting theory. This way, readers are informed and can judge for themselves the propositional theory, supported by an awareness of the tacit knowledge, which is defined as the lived experience of the researcher (Lincoln and Guba, 1985 p.195).

Social phenomenology places the accent on actors' lived knowledge by defining knowledge as finite providences of meaning which works for actors in local contexts, and is transferred from teachers, parents and local leaders (Schutz, 1973 p.7). Stocks of knowledge are culturally based (what works in each cultural context), transmitted through language and enacted by reference to organisational 
purposes and rules (Heritage, 1984; Schutz, 1967, 1973). I examine the key actors and leaders who articulate knowledge as strategy, and how this enables organising as a process. This definition is also aligned to working concepts of indigeneity, and fully covered in Chapter 2. Indigenous knowledge is defined as actors' stocks of knowledge held within holistic cosmologies that are passed from previous indigenous generations to guide action and form collective identity (Fischer, 1999; Friedman, 1994a,b; Muehlebach, 2001). Foreshadowing Chapter 4, I next bend back to self-reflect and briefly describe my own tacit knowledge which influenced the topic, theory, method and cases (Altheide \& Johnson, 1998; Guba, 1990).

\subsection{Positioning the Researcher}

One must live the life one wants to change (Feyerabend, 1994 p.305)

I bring a personal philosophy and background which has been shaped by my own formative search for a Scottish holistic cosmology in the context of globalisation and the search for Scottish national political autonomy. I grew up in a small rural community on the West Coast of Scotland where my father was a Community Development Officer for over 25 years. I learned through experience how socalled impoverished communities both develop and decline in the face of seemingly global pressures, losing connections to Celtic knowledge and Gaelic language as generations of our family moved from our own historic Highland Clan lands and Celtic beliefs and into the Scottish industrialised cities to find work following the Highland clearances. 
As a critical postmodern student studying management at The University of Glasgow Business School, I learned much about globalisation, its promises and effects with the tools of critique but without the balancing skills of a creative appreciation of my own Celtic Scottish worldview. The Isle of Iona is the site of St Columba's original Celtic Christianity which dates from A.D. 563. The Isle is also the burial place of 27 Scottish and Scandinavian kings and the site of a $13^{\text {th }}$ Century Benedictine monastery which was rebuilt by the IC in 1938. Iona is a historical storehouse of Celtic Scottish culture and knowledge, which, together with the IC programmes run on the Isle and the mainland, encouraged a reconnection to Celtic Christianity which shaped my own identity and worldview during three years of vacation work experience from 1994 to 1997. During this time I also met my now wife, a third generation Pākeha New Zealander of Scottish descent who introduced me to aspects of Māori culture. At that time the IC also hosted First Nation guests who presented American Indian worldviews. I found the many rich parallels between these holistic cosmologies intriguing.

The debate on sovereignty from the Scottish perspective in the 1990s piqued my interest in the study of organisations that have their antecedents in local cultures. Worker co-operatives and alternative organisational models provided academic insights in undergraduate OS classes, feeding my vacation work with the IC. After I migrated to New Zealand in 1997, I made connections with Māori as tangata whenua, the people of the land, through my role as Ecumenical Lay Chaplain at Victoria University, where I also drew from my lived knowledge and 
experience of Celtic Christianity. As a visitor being welcomed onto the marae [tribal centre] at Parihaka in 1998, I was especially moved by the karakia [prayers of welcome].

I have been inspired and humbled to learn how indigenous communities look first to their own knowledge. I seek to understand how actors recover indigenous cosmologies from globalist effects and how this recovered knowledge builds strength by enabling individual, organisational and social action. In so doing, I reflect my own passions and philosophies, aspirations and dreams that maintain the belief of the sacred in people and in creation, core principles of a Celtic cosmology.

This thesis integrates and reflects academia and community-centred organisations; Scotland and New Zealand; and indigeneity and globalisation. It intentionally traverses these parallel physical and cultural worlds of learning, living, and worldviews. It critically challenges notions of globalisation and seeks to hone the counterbalancing skills of local knowledge analysis, appreciation and application. It takes full measure of the fragmenting effects of globalisation but illuminates the relationships which are reconnected as actors recover their own knowledge traditions. Taken together, these polyvocal narratives lend weight to the arguments that we are witnessing a major rebalancing: that the large-scale economic project of globalisation is revealed for what it is, and that indigenous 
ways of organising are powerfully re-emerging (Ralston Saul, 2004, 2005). These narratives suggest that there is much to relearn.

\subsection{Why Social Phenomenology?}

I use social phenomenology to challenge the notion of a singular globalist world and its claims of universalism. I theorise actors' ongoing constructions of local social worlds or indigenous holistic cosmologies. I show how these worlds are maintained and continually updated. This is a process-based approach which seeks to acknowledge the living nature of knowledge as a process, rather than the final and fixed properties of indigeneity as a universally applicable definition. As a result (and a potential limitation of this research approach) no universal theory is concluded. Instead, a working theory is proposed which can be tested by other researchers in their own contexts.

I have experienced the effects of a Celtic holistic cosmology during my time with the IC, and sought a theory to research organising using holistic cosmologies. Social phenomenology was chosen to critically challenge notions of a singular worldview and the universal assumptions contained therein, and to examine how actors live, experience, enact and transfer knowledge to create and co-create worlds of local meaning, applied at three key levels of analysis throughout the thesis: individual, organisational and social. This lens reveals the powerful role actors play in articulating and enabling action to overcome globalisation effects, hence there is an equally strong focus on leadership and their strategies 
throughout the thesis to reflect the actors and their actions as carriers and guardians of indigenous knowledge.

\subsection{Social Phenomenology: A Naturalistic Theory}

To further forewarn the reader of the naturalistic approach this thesis uses, and the significant differences, strengths and limitations which this brings, the research assumptions of a positivist method are contrasted with a hard application of social phenomenology and its tenets which question the objective dualism ${ }^{4}$ of a single reality and focus the lens on how actors construct multiple realities through language (Lincoln and Guba, 1985 p.37).

Initially developed by Alfred Schutz, and later by Berger and Luckmann in the 1966 classic 'The Social Construction of Reality', social phenomenology and its progeny social constructionism are ideally suited to theorize how actors use knowledge to enable (legitimize) and disable (de-legitimize) individual identity, and agency in social and historical context. Garfinkel's ethno-methods also derive from social phenomenology and are used to explore members' methods in-situ to maintain organisational coherence (Heritage, 1984). Social theorist Schutz (1967, 1970) and naturalistic researchers Lincoln and Guba (1985) and Guba (1990) suggest that a positivist approach assumes a single external reality which can be broken into parts and studied independently of context to reveal linear cause and

\footnotetext{
${ }^{4}$ These technical terms are explained in Chapter 3.
} 
effect relationships which can then be universally applied. The truth of a single and fixed objective definition is guaranteed by method, where the detached researcher seeks to remove any bias which may interfere with independent findings which are referred to extant literature, and assumed to apply universally, regardless of context. Research subjects are engaged with dispassionately. Knowledge construction and application remains the sole domain of the researcher, who is vested with scientific authority to guarantee the truth of theory.

Naturalistic researchers Lincoln and Guba (1985) suggest that this approach fails to account for the historical and political conditions of the researcher and those researched. They suggest claims of objectivity and universalism subtly mask the power relationships between the researcher and the researched. The superior position of the researcher is maintained as the guardian of scientific method. Rather than objective, external facts awaiting discovery by the dispassionate researcher, Lincoln and Guba claim that the researcher's gaze and prior knowledge are implicit in the construction of knowledge.

Lincoln and Guba (1985, p.37) describe propositions of a naturalistic approach which both guides and limits the application of social constructionism

1. That actors themselves construct realities, through their own minds.

\footnotetext{
${ }^{5}$ Social phenomenology is one theory in this larger family, all of which basically assume that actors construct reality, but they do have subtle differences between them.
} 
2. Since there are an almost infinite number of possible constructions, there are many realities.

3. While one singular reality is questioned, if it does exist it can never be fully known and no amount of inquiry can fully capture it. However, tangible external entities do exist, and actors' definitions of these are more or less related.

4. The guiding factor in establishing any 'truth' is the degree of consensus in which actors collectively agree on definitions, which are by nature only ever partial, and are context dependent.

5. Rather than a universal application, a working hypothesis articulates findings as holistic phenomena in their local context, described as rich case studies. This 'working theory' is tentatively proposed, to be tested by others sensitive to the context of discovery, through 'thick description' of cases and their own context of application.

6. The credibility of these findings is tested not by reference to a single externally existing reality or literature which is assumed to hold universally, but by reference back to actors' own understandings and the context of construction.

All of the above tenets are fully applied in this thesis, resulting in deep case descriptions seen in historic context, tentatively applied findings and local open definitions which articulate processes of knowledge in use, rather than knowledge as a fixed universal. I next describe how social phenomenology can support this 
application, as one of a number of OS researchers who have used social phenomenology and its progeny social constructionism.

\subsection{Social Phenomenology in OS}

Social phenomenology is not new to OS, influencing the broader interpretive (Czarniawska, 1997; Prasad and Prasad, 2002) and related social constructionist literatures (Gergen, 1985, 1992; Weick, 1995). These studies take a critical stance against the social status-quo by challenging received social orders and explore meaning-making of organisational members (Deetz, 1996; Prasad and Prasad, 2002). Critical OS theorist Deetz (1996) suggests that this approach supports the discovery and exploration of themes outside the traditional boundaries of empirical science and dualism by opening fixed and reified definitions for new exploration (Deetz, 1996 p.202). Constructionist OS researchers often voice concerns over the grand claims of universalism in OS, and the value-free status of positivist knowledge, and question how OS theory which is developed in the American historic context is assumed to apply globally, glossing the context of knowledge development and ignoring the context of application (Jacques, 1996; Reed, 1996).

While objective definitions of indigeneity can and do enable indigenous communities in specific contexts and times, such as in the creation of legal definitions in order to begin redress, universal generalisation can also constrain the evolving nature of indigeneity and the ways in which local actors 
pragmatically redefine their own working knowledge to enable community growth. Objective approaches have also masked historical and political agendas of powerful colonial actors and countries keen to constrain indigenous communities, by fixing their identity as inferior and underdeveloped. I examine the limitations of objective approaches to indigeneity in Chapter 2, and the balancing limitations of social phenomenological research in Chapters 2 and 10.

Others use phenomenology to good effect. Stablein (2002) uses existential phenomenology to study members' changing experiences of a work group over time. He commends phenomenology as a response to both the limitations of positivism and the extremes of postmodernism which can refute the foundations of knowledge, fragment claims to knowledge continuities and undermine the identity of the researcher. To enable a process-based approach which supports the the study of knowledge continuities by the positioned researcher, a complementary set of research methods have been selected.

\subsection{Naturalistic Research Methods, Naturalistic Generalisation}

In-depth naturalistic research methods (dealt with fully in Chapter 4) are used to explore the research question in situ. For constructionists, research goodness does not depend on accurately capturing an externally existing social reality. Instead good research is critical, i.e., it challenges prevailing assumptions; plausible, i.e., it develops the reader's current knowledge; and as authentic as possible, i.e., it conveys the vitality of everyday life in the research setting. To support this 
vitality, Chapters 7 to 9 are described as auto-ethnographic present day confessional accounts, to describe the immediacy of my research experience (Altheide and Johnson, 1998; Golden-Biddle and Locke, 1993; Van Maanen, 1998).

This position does not deny the ability to transfer knowledge. Processes of naturalistic generalisation propose that intended audiences are able to generalise for themselves which elements of a working theory apply or not, in their own time-bound and locally understood context (Denzin, 1997; Lincoln and Guba, 1985). Since the research does not claim to hold for a universal singular reality, the findings as a working theory are framed in the context and time of the study, as constructed by the researcher and those researched (Lincoln and Guba, 1985).

The researcher engages with the respondents in ways which place the emphasis on the relational spaces between the researcher and the communities of research. Rather than being dispassionate, neutral and objective, naturalistic researchers seek to enable trust in the research relationship through an empathetic communitarian stance (Denzin, 1997; Lincoln and Guba, 1985). Drawing from feminist poststructuralism, this approach assumes that researchers and respondents both exist as part of their wider communities, with knowledge, ethics and morality emerging from and relating to this ongoing dialogue of local communities. The measure of goodness of knowledge is not how knowledge is reduced to a singular universally applicable definition, but how the researcher 
reflects the long-term aspirations, visions and aesthetics of the researched communities in ways which enable and encourage the fulfilment of these.

Under this approach, respondents shape what questions should be asked, and cocreate the findings that emerge. The living community becomes the arbiter of the ultimate value of the research. Especially relevant in many indigenous contexts, the living community are the guardians of knowledge. Kaupapa Māori methods ${ }^{6}$ support and direct how knowledge is developed, respected and protected, including who benefits from this knowledge. These kanohi kitea (L. Smith, 2000, p.242) or face to face human commitments challenge either the extreme of the objective researcher hidden behind one-way glass reifying indigenous subjects, or the other extreme of the disappearing author. Through these conversations treasure houses of holistic cosmologies can be shared, but not plundered, supported and policed by local and ongoing commitments between OS researchers and indigenous practitioners.

To effectively engage in this community dialogue, the researcher self discloses to respondents in ways which allow trust to develop, through revealing their own political and philosophical commitments, hopes and weaknesses. Thus, throughout the research process I spoke to Māori participants as a positioned, located researcher, learning as much Te Reo Māori as time allowed, and

\footnotetext{
${ }^{6}$ Fully dealt with in Section 4.3.4.
} 
acknowledging local and cultural protocols (Cramm, 2001; G. Smith, 2000; L. Smith, 1999, 2000). Wearing a kilt also helped, as did the Scottish accent, my own authentic voice which dispelled suspicions voiced to me as "we thought you were just another Pākeha who doesn't understand us.”

Beginning with pilot fieldwork in the Māori context, I was profoundly struck by how local worlds were constructed and maintained through language, becoming explicitly aware of both respondents' and my own processes of meaning construction, the goal of interpretive research (Czarniawska, 1997; Shwandt, 1996; Yin, 1990). Māori actors were describing and enacting practices through korero [conversations] using Māori knowledge and Te Reo [the Māori language] socially constructed within and between actors, and revealed in situated social action. My limited knowledge of Te Reo and my status as a Pākeha ${ }^{7}$ [European] researcher brought up many challenges in gaining access or doubts in understanding what I was given access to. To overcome these, I pragmatically drew from my own prior search for Scottish Celtic identity on Iona. Sharing this context with participants proved critical in building research trust, and gaining respondents' own insights into their own construction of meaning. Similarly, during the IC casework, I drew from learnings and insights developed from TWoR.

\footnotetext{
${ }^{7}$ Pākeha is the Māori-derived term many New Zealand Europeans apply to themselves; see Ranford (2006) for a short discussion of the term.
} 


\subsection{Cases}

The first case, TWoR, is a wānanga or Māori university in New Zealand close to where I now live. The second, the IC, is a Celtic Christian community on the Isle of Iona and in Glasgow, Scotland. On first view these cases may not appear comparable but they do share many similarities. Both of these organisations claim continuities with their ancient indigenous knowledge and 'houses of learning' which taught this knowledge. They each currently enact and teach indigenous knowledge in ways which seek to overcome profoundly negative environmental and historic effects in global contexts. How they do this differs in their contexts, including their treatment of indigenous languages, their definitions of indigeneity and the unique ways in which they each express self-determination in the face of imperial and colonial projects that have imposed external control by variety of legal, political and military means, which themselves share similarities. These similarities include: legislating for English as the language of growth against Gaelic and Te Reo [the Māori language]; military force repressing nationalistic uprisings; tribal collectives becoming fragmented by globalising notions of individualism and collective bases of land ownership being transferred to private titles, amongst other things. In the face of this, competing sovereign nationhood has been fought for, alongside the recovery of language and the formation of political parties and institutions to further their own aims (Devine, 2000; Henare, 1995). These two indigenous organisations are summarised in Table 8 (p.211) and Table 9 (p.318). 
It is important to acknowledge the limits of the comparison. My cross case comparison of Scottish and Māori indigenous organisations was not met by universal accord. Many Scots do not identify, nor are they as readily identifiable, as indigenous, choosing identities based on the Scottish national imaginary, as some in the IC did, challenging the term indigenous as well as any links to Celtic that Iona has. However others in the IC did strongly identify as indigenous. By contrast, TWoR has intentionally developed, and policed, consensus over its identity as a Māori organisation, but it is also not without its tensions. In Chapter 2 the politics of self and collective identity are more fully discussed.

\subsection{Definitions of Terminology}

Constructionist OS defines the organisation as a site of situated action with purposes, rules, histories and boundaries (Clegg \& Hardy, 1996; Shafritz \& Steven Ott, 1987). Organising is defined as situated social action embedded within local conversations drawing from distinct cultural and ethnic practices (Clegg and Hardy, 1996). I follow Alvesson, (2002, p.3) and Schutz (1970, p.80) in defining culture as a cohesive system of meanings and symbols drawing from socially derived knowledge containing shared rules governing social interaction and the means whereby they are expressed. Organisational culture describes the symbolism, rituals, stories and the assumptions of social reality of organisational actors, which are shaped by the groups within which they live (Alvesson, 2002 p.3), applied in this context as indigenous knowledge. 
Indigeneity and globalisation are two broad rubrics with significant debates surrounding each and the confluence of both. Chapter 2 examines these rubrics in selected literatures, as artefacts which inform and add to this thesis project, and Chapter 5 examines the use of these terms in each historic case context. In summary form, the theorists used are cited together below, but they differ in important ways.

Indigeneity as the abstract noun of the term indigenous illustrates how the term has been objectively constructed to infer the identity of colonial people and projects as developed and Indigenous Peoples as tribal or backward (Rattansi, 1997; Said, 1978, 1994). Secondly, the term illustrates how Indigenous Peoples construct themselves. Constructionist definitions illustrate how actors use indigenous knowledge continuities to rebuild positive identity and overcome globalising influences, emphasising indigenous knowledge continuities within a holistic cosmology, the working definitions I pragmatically explore in two local contexts (Fischer, 1999; Friedman, 1994a,b; Muehlebach, 2001).

Similarly, globalisation is explored in two ways. Critical social theorists Lash and Friedman (1992) and Ralston Saul (2005) describe how economic and consumption relationships construct actors' social identity and agency by actively devaluing indigenous knowledge and collectivist practices. For postcolonial OS scholars, these processes of neocolonialism are interwoven with the colonial project, which continues cultural control which began in the formative stages of 
colonial contact (Banerjee, 1999; Banerjee \& Linstead, 2001, 2004; Prasad, 2003).

Secondly, globalisation posits how consumption creates alienation that in turn results in an increased awareness of difference, enabled by global connections formed through trade-based relationships. These effects are claimed to support a reorientation towards local practices and knowledge, even to the point of globalisation's demise, definitions I also pragmatically explore in two local contexts (Friedman, 1994b; Ralston Saul, 2004, 2005; Robertson, 1995; Sklair, 2002).

I test these claims in the cases to critically examine if and how actors use indigenous knowledge continuities to overcome effects of the globalisation project. I then use social phenomenology to theorise how new ways of organising are re-emerging, and the roles that key organisational actors take in articulating local indigenous visions and strategies. Table 1 below summarises these positions, with references removed for brevity. 
Table 1: Summary of Indigeneity and Globalist Terms

\begin{tabular}{|l|l|l|}
\hline Term & 'Objective' / Colonial & Critical Constructionist \\
\hline Indigeneity & $\begin{array}{l}\text { Colonial processes construct } \\
\text { indigenous as backward. }\end{array}$ & $\begin{array}{l}\text { Indigenous knowledge } \\
\text { within } \\
\text { holintic cosmologies. }\end{array}$ \\
\hline Globalisation & $\begin{array}{l}\text { Devalues indigenous knowledge } \\
\text { as undeveloped; maintains } \\
\text { Western hegemony and } \\
\text { legitimises globalist practices of } \\
\text { consumerism as the logic of } \\
\text { development. }\end{array}$ & $\begin{array}{l}\text { Increased awareness and } \\
\text { connectedness to other } \\
\text { Indigenous Peoples } \\
\text { through technology, } \\
\text { economic practices } \\
\text { adopted within recovered } \\
\text { cosmologies. }\end{array}$ \\
\hline
\end{tabular}

\subsection{Thesis Summary}

Chapter 1 introduced the topic of the indigenous organisation in global contexts and posed the research question. I positioned both the researcher and the research. I introduced social phenomenology and its use in OS, and naturalistic research methods. I introduced the two case studies where these methods will be applied. The thesis was summarised.

Chapter 2 reviews literature on the dialectic between globalist practices and indigenous knowledge which are compared for their effects on the indigenous organisation at social, organisational and individual levels. Definitions of indigeneity in colonial postcolonial and anthropological literature are evaluated. Constructionist anthropological definitions are described alongside a rationale for their use as artefacts to support the purpose of the thesis.

In Chapter 3 I introduce social phenomenology and describe how local knowledge underpins individual and group identity. I illustrate how concepts handed down 
from previous generations are transmitted through language. These concepts can be artfully drawn on in order to organise, and to construct the wider organising context. However, mechanisms and functions, including those of the leader, are required to maintain knowledge validity at the social level, where competing knowledge claims seek to challenge the validity of local knowledge.

In Chapter 4 I describe a grounded theory approach using naturalistic case study methods to select key case studies of organisations which purposely use indigenous knowledge in two differing settings. I describe the ethnographic methods that are used in the field to gather data, while following Kaupapa Māori protocols. Finally I then describe the methods of data analysis, and the criteria I propose for the goodness of the thesis.

Chapter 5 describes how indigeneity has been defined in the face of globalist practices. Section 5.2 covers the Māori of Aotearoa New Zealand and their status as Tangata Whenua, despite the colonial and globalist practices which have sought to fragment Māori knowledge. Despite the signing of The Treaty of Waitangi, land confiscation, knowledge loss and language loss have occurred. Māori challenges brought The Treaty Act and subsequent claims and settlements. Recovering Te Reo language and Māori knowledge began with the Kohanga Reo and Whare Wānanga movements, culminating in Māori political autonomy and representation. Section 5.3 discusses the early Celtic and Scottish national identity, before Scotland was assimilated in the United Kingdom. Despite land 
clearances and powerful globalist fragmentation, Celtic knowledge survived in the Western Isles, and is currently experiencing a revival in the context of Scottish political autonomy.

Drawing from archival case material, as well as primary and secondary data, Chapter 6 describes how indigenous leaders use indigenous knowledge to create organisational purposes which attempts to overcome the fragmenting effects of globalist practices. Section 6.2 describes TWoR in the context of The ART Confederation and earlier rangatira such as Te Rauparaha. As founder, Professor Winiata recovers and embellishes Māori knowledge, to underpin the organisation. Section 6.3 describes the IC in the historic context of the Columban Celtic Mission. As founder, George MacLeod formed the purposes of the IC by drawing from the Columban and Celtic imaginary to overcome globalist practices. It describes aspects of the IC today which reflect these Celtic Christian themes within an ecumenical missonary context.

Chapter 7 examines at the individual level how boundaries and rules support actors to enact Māori knowledge and how this action creates polyvocal definitions of indigeneity in the face of fragmenting globalist practices. It ethnographically describes how I approached TWoR. It describes how local actors define Māori knowledge, identity and indigeneity, and how boundaries and rules support this positive identity and life projects of members. It covers members' experiences of 
fragmenting globalist practices, and of colonialism and postcolonialism. The data on individual Māori identity is discussed and compared with extant literature.

Chapter 8 examines at the individual level how boundaries and rules support actors to enact Celtic knowledge. This action also creates polyvocal definitions of indigeneity in the face of fragmenting globalist practices. It shows how the IC has sought to recover and enact Celtic Christian knowledge, which supports the life projects of members to rebuild community and overcome fragmenting globalist and historic practices which have affected Celtic Christian knowledge. The data on individual Celtic identity is discussed and compared with extant literature.

Chapter 9 examines actors' indigenous organising processes as seen in situ, but viewed in social and global contexts. The chapter illustrates how leaders' strategies and practices encourage members to create and enact an indigenous organisation which overcomes knowledge challenges. These organising practices encourage the departments and family groups to define, enact and update Māori and Celtic knowledge through the organisation, as well as supporting the construction of Māori and Celtic holistic cosmologies at the social level. The data on indigenous organisational identity as seen in global contexts is discussed and compared with extant literature.

Chapter 10 discusses and compares polyvocal Māori and Celtic definitions of indigeneity and indigenous organisations which are enacted from recovered 
holistic cosmologies, in the face of fragmenting globalist practices. These case studies illustrate indigenous organising as a process and the key roles that the leaders play in enabling organising from indigenous knowledge. Contrary examples are included. Overcoming internal and external challenges, leaders and actors maintain the validity of indigenous knowledge. These processes of indigenisation support the recovery of individual and organisational identity and a wider holistic cosmology. This theory of indigenous organising is compared with the OS literature at three levels, and with assumptions contained in globalist literatures. Limits of this research and a social phenomenological approach are noted. Future research agendas are proposed. The thesis structure is summarised as a whole in Figure 1 (over). 


\section{Figure 1: Thesis Structure}

\begin{tabular}{|c|c|c|c|c|c|c|}
\hline $\begin{array}{l}\text { (Level of } \\
\text { Analysis) }\end{array}$ & $\begin{array}{l}2.2 \text { Globalist Lits. } \\
\text { Globalist Effects } \\
\text { on Indigenous } \\
\text { Knowledge. } \\
\text { (Social Level) }\end{array}$ & $\begin{array}{l}\text { Globalist Effects on } \\
\text { Indigenous } \\
\text { Organisations. } \\
\text { (Social Level) }\end{array}$ & $\begin{array}{l}2.4 \text { OS Lits. } \\
\text { Role of Indigenous } \\
\text { Knowledge in } \\
\text { Indigenous Orgs. } \\
\text { (Organisation Level }\end{array}$ & $\begin{array}{l}2.5 \text { OS Lits. } \\
\text { Indigenous } \\
\text { Knowledge \& } \\
\text { Role of Leader. } \\
\text { (Indiv Level) }\end{array}$ & $\begin{array}{l}2.6 \text { Indigeneity } \\
\& \text { Polyvocality. } \\
\text { Assessment. } \\
\text { Links to Social } \\
\text { Phenomenology. }\end{array}$ & $\begin{array}{l}\text { 10. Theory Building. } \\
\text { Indigeneity Defined. } \\
\text { The Indigenous Organisation } \\
\text { in Global Contexts. }\end{array}$ \\
\hline $\begin{array}{l}\text { Research } \\
\text { Process \& } \\
\text { Research } \\
\text { Question: } \\
\text { What is an } \\
\text { indigenous } \\
\text { organisation } \\
\text { in global } \\
\text { contexts? }\end{array}$ & \multicolumn{2}{|c|}{$\begin{array}{l}\text { 2. OS Definitions. } \\
\text { An organisation is a site of } \\
\text { situated action with histories, } \\
\text { purposes, boundaries and rules. } \\
\text { Organising is situated action } \\
\text { within local conversations } \\
\text { drawing from distinct cultural } \\
\text { and ethnic practices. }\end{array}$} & $\begin{array}{l}\text { 3. Theory. } \\
\text { Social Phenomenology at } \\
\text { Individual, Organisational and } \\
\text { Social Levels. } \\
\text { Organising from Local } \\
\text { Knowledge. Protecting } \\
\text { Knowledge from Social \& } \\
\text { Global Pressures. }\end{array}$ & \multicolumn{2}{|c|}{$\begin{array}{l}\text { 4. Method. } \\
\text { Naturalistic Inquiry, } \\
\text { Grounded Theory. } \\
\text { Case Study Approach, } \\
\text { Ethnography and Fieldwork. } \\
\text { Kaupapa Māori Protocols. } \\
\text { Data Analysis, } \\
\text { Theory 'Goodness'. }\end{array}$} & $\begin{array}{r}\text { Indigenous Organising } \\
\text { as a Process } \\
\text { Links to } \\
\text { Social Phenomenology. } \\
\text { Indigenous Leadership. } \\
\text { Globalist Effects on } \\
\text { Indigenous Practices. }\end{array}$ \\
\hline $\begin{array}{l}\text { Case Study } \\
\text { Fieldwork }\end{array}$ & $\begin{array}{l}\text { 5. Defining } \\
\text { Indigeneity in } \\
\text { Māori and } \\
\text { Scottish Historic } \\
\text { Contexts. } \\
\text { (Social Level) }\end{array}$ & $\begin{array}{l}6 \text {. Forming the } \\
\text { Indigenous } \\
\text { Organisation \& } \\
\text { The Role of } \\
\text { Leadership. } \\
\text { (Individual Level) }\end{array}$ & $\begin{array}{l}\text { 7. Defining and } \\
\text { Enacting Māori } \\
\text { Knowledge. } \\
\text { (Individual Level) }\end{array}$ & $\begin{array}{l}\text { 8. Defining and } \\
\text { Enacting Celtic } \\
\text { Knowledge. } \\
\text { (Individual Level) }\end{array}$ & $\begin{array}{l}\text { 9. Māori \& Celtic } \\
\text { Organising in } \\
\text { Global Contexts } \\
\text { (Organisational \& } \\
\text { Social Levels) }\end{array}$ & $\begin{array}{l}\text { Theory of Indigenisation. } \\
\text { Conclusion. } \\
\text { Limitations and Areas for } \\
\text { Future Research. }\end{array}$ \\
\hline
\end{tabular}




\section{Chapter 2: Defining Indigeneity in Global Contexts}

The challenge today may be that we are now not only at the end of the globalism period but also at the end of Western rationalism and its obsession with clear linear structures on every subject. Perhaps we are living the beginnings of a major rebalancing in which other cultures with more complex ideas of what makes up a society are moving to the fore (Ralston Saul, 2005 p:278).

\subsection{Introduction}

This chapter introduces indigenous organisations in the context of globalisation. It assesses the dialectic of historic and ongoing effects of globalist practices on indigenous holistic comologies. Drawing from exemplar OS literature, it also assesses the effects of both globalist practices and indigenous knowledge on the indigenous organisation at social, organisational and individual levels. The chapter then examines how either globalist or indigenous knowledge defines indigeneity covering colonial, postcolonial and anthropological literatures, before finally explaining the definitions of indigeneity and indigenous knowedge used and how these artefacts support the purpose of the thesis.

\subsection{Indigeneity in the Context of Globalist Practices}

Indigeneity is the abstract noun derived from the term indigenous which has been formed in English from the Latin roots 'indu' or within and 'gignere' meaning to beget. The term begotten carries a number of meanings, one of which is to father. When this concept is linked to indu, it expresses the condition of being birthed from within. The goal of Indigenous Peoples to rebirth identities, organisations, communities and indeed universes from the seeds of their own knowledge is the topic of this thesis. This seed - as expressed in Māori at the beginning of the 
introduction - has faced significant pressures from the global environment. Critical globalisation theorists such as Ralston Saul (2004, 2005) and Friedman (1994ab) describe a dialectic where globalisation has offered many false hopes and promises of growth, but has instead fragmented indigenous cosmologies and devalued their knowledge guardians. These effects have produced profound alienation which has accelerated the demise of globalisation as a large scale social theory and helped bring about a new awareness of other cultural practices, with a deeper respect for the complex ways of organising that are birthed from ancient indigenous holistic cosmologies, as the opening quote suggests. For Canadian social theorist and globalisation critic Ralston Saul (2004, 2005) globalist practices are defined as:

an inevitable form of internationalism in which civilisation is reformed from the perspective of economic leadership provided not by people but by the innate force of economics, the marketplace (Ralston Saul, 2005 p:19).

Ralston Saul (2005) avoid the pitfalls of a specific definition of globalisation, instead offering a context-based description of its claims, which include notions that: the power of the state is weakening; that global markets are strengthening, and with them the fortunes of all including the developing peoples and countries; that growing markets will be serviced by equally growing multinationals who will effectively lead civilisation out of boom and bust cycles of history (Ralston Saul, 2005 p.17).

From the earliest expansion of colonial markets, these globalist practices have attempted to fragment indigenous holistic cosmologies and subvert the process of 
Indigenous Peoples' identity which drew from indigenous knowledge, community, land and a holistic cosmology, to being in relationship to the objects and processes of consumption. Friedman (1994a) analysed how traditional identities were formed within holistic cosmologies, but that globalist practices sought to replace this cosmology with processes which encourage apparently autonomous individuals, able to define themselves in relation to ever changing consumerism (Friedman, 1994a p.150). Friedman (1994) claims globalist practices actively target holistic cosmologies, within which stable identity formation took place, and instead attempts to assert the modernist identity of the autonomous self.

\begin{abstract}
The emergence of modernity lies in the crossing of a threshold in which the individual subject emerges as an autonomous subject representing his or her self as a selforganising, self-motivated being. This requires a dissolution of the previous structures that might be characterized as holistic, ascribed and totalizing, with respect to the individual subject. This dissolution is a complex process but historically has been most clearly represented by the process of commercialisation as a penetration of the network of obligations typical of kinship societies (Friedman, 1994a p:213).
\end{abstract}

Friedman (1994ab) suggests the emerging self seeks integration with community and society through possession of products as a substitute, which is intentionally never complete. An incessant quest for the next better product forms the context of socialisation, alongside an increasing discomfort with - and rejection of holistic cosmologies. Ralston Saul (2004, 2005) suggests globalist practices sought to replace the agency of long held ways of being at the local level: 'in practical terms [globalisation] has meant demoting the values - ethical and moral - of community in favour of the certainty that humans are driven by self interest' (Ralston Saul, 2005 p:97). For Friedman too, being modern is not knowledge of 
the ancients or a self which is identifying with community knowledge continuities, but rather the active and constant search for Western brands, logos and products:

The stable cultural situation of [Western] hegemony is one in which areas incorporated into the system maintain a value hierarchy commonly described in terms of the devaluation of local culture and the necessity of identification, where possible, with the dominant Western model which is defined as the modern. Colonial mentality and the consciousness of the colonized are both formed in this context (Friedman, 1994a $\mathrm{p}: 173)$.

Globalisation's deceptive promise was to deliver an unprecedented era of wealth creation, where unfettered trade and the principles of economics alone could solve most if not all social ills, by amongst other things: increasing wealth for developing and developed nations, including those in rural locations; releasing regions to trade more effectively, unfettered by the (apparently) declining nation state and creating greater economic participation by an increasing number of global consumers with increasingly sophisticated tastes (Ralston Saul, 2004, 2005). Such globalisation arguments were not new; but merely a reworking of free trade economic theory iterated in the early 1800s, such as that proposed by advocate Richard Cobden.

We have a principle [in free trade] established now which is eternal in it's truth and universal in its application, and must be applied to all nations and throughout all times, applied not simply to commerce, but to every item of the tariffs of the world...[A law which prevents free trade is a] law which interferes with the wisdom of Divine Providence, and substitutes the law of wicked men for the law of nature (Ralston Saul, 2005 p:41).

Notions of universal trade were often legitimised by the Christian ethics and morality of the time, a 'natural' order which presided over the decimation of the First Nation Peoples of The United States from a population of over 5 million at 
the start of the 1800 s to 250,000 by 1900 (Banerjee and Linstead, 2001; Ralston Saul, 2005). This decimation was symptomatic of the global effects of this new order on Indigenous Peoples and their knowledge. Globalisation as the universal spirit of capitalism was grasped by a nascent American nation keen to rid itself of its own repressive British colonial heritage (Jacques, 1996; Ralston Saul, 2005). For critical OS theorist Jacques (1996), the services of science legitimised the new settler capitalism, and hid the cultural and historic American context behind these values. The cultural ideological practices of capitalism could then be exported as universal practice.

These globalist practices immediately sought their global and colonial mission fields. They promised a brave new world to the under-developed other but instead delivered the physical and spiritual destruction of Indigenous Peoples, their identity and holistic cosmologies. Globalist practices subtly redefined participants' identities in the global context as demanding economic consumers. At the zenith of globalisation in the mid 1990s, American economic evangelists such as Ohmae (1995ab) championed the case.

\footnotetext{
Larger numbers of people have come forward from every part of the globe to participate. They have left behind centuries, even millennia, of obscurity in forest and desert and rural isolation to request from the world community - and global economy that links it together - a decent life for themselves and a better life for their children... They have economic demands to make (Ohmae, 1995a p:1).
}

Development expanded the processes of globalist practices which are fundamentally driven by consumerist logics (Ralston Saul, 2005; Sklair, 2002). As a result host communities and their holistic cosmologies have declined into consumerism, which is the cultural-ideological practices of globalising capitalism 
(Friedman, 1994b; Sklair, 2002). By encouraging and, in some cases forcing trade, neocolonial expansion sourced raw materials from developing nations, often at lower than equitable levels (Banerjee and Linstead, 2001). Globalisation's promise instead delivered logics which reframed members of communities as consumers and nations or regions as markets for Western value-added products, which were first created in and then resold to developing regions. With the postmodern turn creating economies of sign and space, it is now not just consumption of the product, but the symbol which is sold and consumed (Banerjee and Linstead, 2001; Friedman, 1994 ab; Lash and Urry, 1994).

\subsubsection{Globalisation Fragments Indigenous Knowledge}

With new technology accelerating the penetration and reach of global brands, globalisation seeks to ascribe higher status to Western products and symbols than local knowledge. American Globalisation evangelist Ohmae (1995a) suggests that this process (known as homogenisation) occurs where media influences educate cross-cultural groups into having similar tastes and preferences. Ohmae concedes or celebrates how consumerism can fragment and weaken the underlying nexus of local culture.

Social borders are starting to give way to the information and technology driven processes of convergence that have already turned political borders into largely meaningless lines on economic maps...As societies move up the economic ladder of development...there is a notable upward ratcheting in the speed with which the lifestyles of the people grow more and more alike. The effects of this acceleration reach, to some extent into the underlying nexus of culture (Ohmae, 1995a p:225). 
Consumerism replaces local knowledge continuities with the latest Western products and status symbols. This project seeks the discontinuity of knowledge from one generation to the next, penetrating and separating the social connections which hold and transmit knowledge continuities, a process best described not by critical social theorists, but by the very champion of this economic orthodoxy.

The critical balance is beginning to shift: children and teenagers are, at deep levels of sensibility and worldview, becoming much more like their counterparts in other societies than like the older generations in their own cultures. The essential continuity between generations, on which every society necessarily depends, has begun to fray (Ohmae, 1995a p:225).

Rather than being the promised tide that would lift all ships, globalist practices have delivered a massive increase in the gap between the richest and poorest nations and regions (Amin, 2004; Ralston Saul, 2005). The measure of success becomes the level of assimilation to developed or Western levels (Dhaouadi, 1994; Durie, 2000; Munck, 1984). Under this regime, any under-developed community must struggle to reach Western levels despite poverty which is often a by-product of the colonial and consumerist West, caused by inequitable historic World Bank debt repayments (Friedman, 1994a; Wallerstein, 1974).

For critical development theorists such as Munck (1984) development entails the unfettered mobility and exploitation of capital, mineral resources and goods across geographic boundaries. This exploitation maintains the hegemony of a purely Western view of history which 'robs people of different cultures the ability to conceive of and articulate for themselves their own forms and practices of social life within their own histories and cosmologies' (Munck, 1984 p:22). As 
Ralston Saul (2005) notes, the zealots of globalisation assume the same answer applies to every problem. For example, when commenting on local indigenous underdevelopment at the 2001 Knowledge Wave Conference in New Zealand, economic guru Michael Porter pointed to positivist research on raising the economic outcomes of individuals. Results of these studies, applied universally, would suggest that the best way for indigenous communities to increase their wellbeing is to move to the cities where the jobs are (Porter, 2001).

As Jackson (2001) notes, the deep nuances of locality and context can get subsumed under the catch-all panaceas that such gurus offer. Porter's (2001) analysis fails to consider the historic processes of urbanisation which have left many indigenous communities fragmented and separated from their tribal lands, and also the promise of wealth which were never delivered. In the 1980s gaps in the labour market for lower skilled positions were filled by rural Māori (Durie, 1998). Subsequent structural changes to the New Zealand economy resulted in much higher than average unemployment for Māori who bore the brunt of economic restructuring. Urban Māori were left without economic resources during the next phase of 'economic re-adjustment', as well as connections to tribal communities and their community resources. Interestingly these outcomes closely match similar urbanisation processes within Scotland, another so-called developed Western nation (Devine, 2000). What gets lost in the grand claims of globalisation and development is what is undeveloped in such practices. 
Critical theorists have long understood the hidden effects of globalist development. For instance, Dhaouadi (1994) argues both cultural and psychological under-development becomes accelerated by economic development, a consequence which often remains hidden in mainstream discourse. Dhaouadi's (1994) four factors are considered in relation to Scotland and New Zealand:

1. Linguistic underdevelopment occurs where widespread use of another language marginalizes the local language. Within New Zealand use of the Māori language dropped from full usage by the Māori population in 1820 to a position of slow recovery. For instance in 2001 eight percent of the Māori adult population were highly fluent. Of these, seventy one percent were aged forty five or over (Te Puni Kokiri, 2001); thirty five percent had a medium comprehension while thirty percent of the adult population had very low comprehension levels.

While Gaelic was reported to be widely spoken in many northern regions in the pre-1700s (Chapman, 1978) the Gaelic language was rapidly lost in most northern areas, as economic migration and changes aligned with progress rapidly replaced the local language with the Lowland English (Devine, 2000). By 1991 only one point four percent of Scotland's total population could write or speak Gaelic. However, local pockets of fluency still remain. Within the Western Scottish Isles, this figure rises to sixty six percent (1991 Census of Population, General Registry Office, Scotland). 
2. Local knowledge systems underdevelopment is created by dependency on Western knowledge. Māori health and education providers have only recently reinstituted indigenous knowledge and practices to reconnect to previously alienated communities. This recent revival in indigenous knowledge has often worked in parallel processes with Western scientific health and education models (Henare, 2001). In Scotland there has been a recent strong revival of interest in Celtic knowledge systems which have also been in decline for some time (Bradley, 1994).

3. Cultural value systems underdevelopment. Dhaouadi proposes that increasing assimilation of Western values can marginalise indigenous cultural value systems. Within New Zealand, an early BERL report on barriers to economic development advises Māoridom to engage in entrepreneurial behaviour within an unquestioning acceptance of the need for adoption of Western paradigms (Rose, Sanderson, Morgan, Stuart \& Andrews, 1997). These analyses often overlook the fact that pre-1850 many Māori were themselves highly entrepreneurial, but from within their own cosmologies (Love and Waa,1994).

4. Cultural inferiority, which is a deep rooted sense of inferiority towards one's own identity and knowledge. Dhaouadi points to two facets that emerge against a dominant other, a negative perception towards one's own language and culture and an eagerness to adopt Western cultural norms and methods. Discussing 
indigenous vulnerabilities in the context of Australian colonisation, Cunningham and Stanley (2003) map the interrelationships between identity fragmentation and poor health outcomes in Figure 2 below.

\section{Figure 2: Impacts of Colonisation on Aboriginal Health}

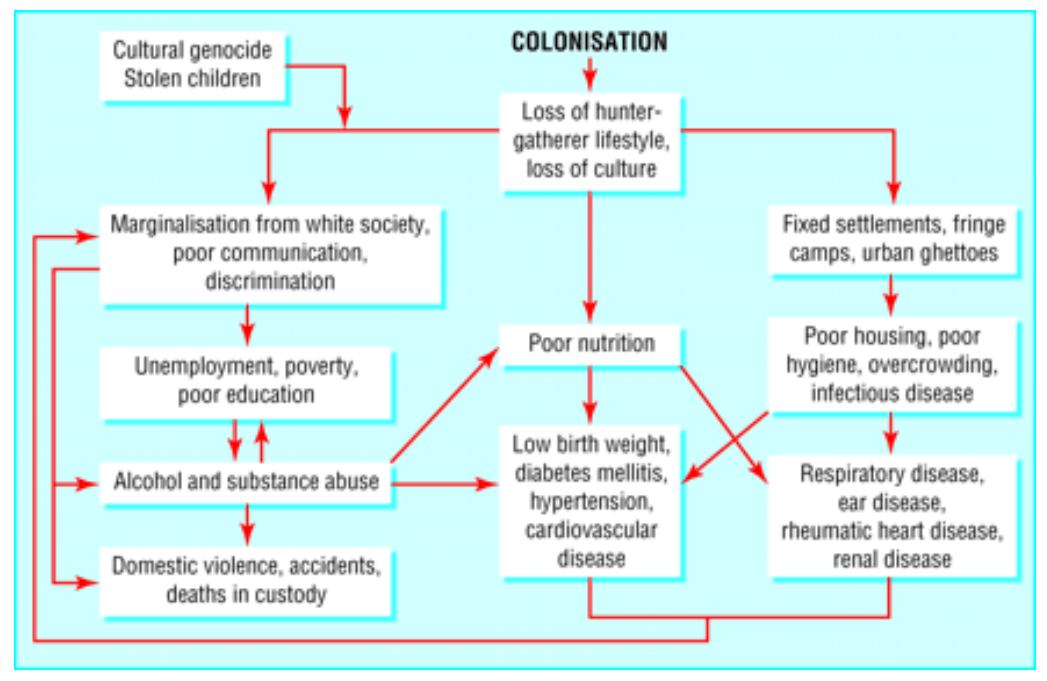

(Cunningham \& Stanley, 2003 p:403)

As the findings in the Australian context above suggest, globalist practices have been theorised to intentionally fragmented holistic cosmologies and the indigenous knowledge they contain, with impacts on Indigenous Peoples' identity and health (Banerjee, 1999; Cunningham and Stanley, 2003 p.403).

Globalism's great promise of progress has delivered unprecedented wealth to the developed elite for whom the services of science and economics have helped open the gates for their Trojan horse. What has spilled out has been a forceful and unprecedented assault on the very fabric, resources and structures of the host people, all repackaged as both resource and recipient for Western products, brands and knowledge. Despite appearances, this assault is not flawless in design. 


\title{
2.2.2. Alienation: The Seeds of Globalisation's Demise
}

Critical social theorists have deeply questioned the assumptions underpinning globalist practices as the stable expansion of Western logics and processes. They strongly suggest the concept of linear economic growth and development has become profoundly unstable (Friedman, 1994a; Jacques, 1996; Lash and Friedman, 1992; Nustad, 2003; Ralston Saul, 2004, 2005). These theorists have powerfully argued for some time that knowledge and values are not fixed by global economic forces but instead created by local culture.

No longer is progress and infrastructure-led development a self evident reality. The denaturalization of doxa naturally leads to its relativization. And relativization substantiated is culture (Lash and Friedman, 1992 p:26).

In the search for deeper market penetration globalist practices have created the perhaps surprising conditions for a renewal of interest in local knowledge. Friedman argues that modernity's separation of identity from cosmology and construction of individualistic autonomous subjects experience little more than profound alienation.

\begin{abstract}
Alienation belongs to the logical core of modernity. The separation of the subject from any fixed identity is itself the definition of the problem. The search for identity, for a meaningful construction of selfhood in a meaningful existence, is predicated on the ultimate arbitrariness of modern identity (Friedman, 1994a p:219).
\end{abstract}

He argues that movements of capital and wealth are the underpinning drivers for increases in spatial and technological connectedness. These processes within modernity can support local knowledge and identity, albeit through unintended consequences. Robertson (1995, 2002) and Robertson and Giulianotti (2004) have also argued that globalist practices have unintentionally provide an increased awareness of heterogeneity, which is knowledge of diversity, and posit that 
'glocalisation' is an universalisation of particularism which involves the valorisation of particular ethnic identities.

Globalization [is] characterized by two distinct processes. Social actors possess greater senses of 'globality': that is increasing subjective consciousness of the world as a whole; a heightened awareness of the world as a 'single place' characterized by a global intensification of social and cultural 'connectivity' through telecommunications (Robertson and Giulianotti, 2004 p:546).

Similarly for Friedman (1994a) high modernity creates specific forms of ethnicity.

This modernist construction sees ethnic membership and the vast ways and means

that produce and transmit meaning in the contested field of social existence reduced and flattened to the term 'culture ${ }^{, 8}$. This reduction goes to biological origins as a form of social construction, which replaces formal citizenship as markers of belonging.

As the private self becomes the only reality the only kind of ascription possible is what can be attributed to the body. Difference becomes inscribed as phenotype and culture is reduced to nature. Cultural identity, language, religion, common history and origins, that is roots, could easily be transformed into a powerful force since such identity could be reduced to blood, to race, to absolute difference irrespective of the vagaries of social mobility. This new ethnicity is a specifically modern phenomenon insofar as the ethnic group is defined as the sum of those individuals who carry the marks of identity (Friedman, 1994a p:218).

This modernity-produced alienation ultimately creates the reverse effect: a desire for individuals to actively transfer their individual life projects back again to a social group, such as the new social movements, which emerged in the absence of, and as a replacement for the stable identity provided by holistic cosmologies.

\footnotetext{
${ }^{8}$ This argument supports the absence of the over-determined term 'culture' in this section of the thesis. The specific term organisational culture (Alvesson, 2002 p.3) is used later to describe the symbolism, rituals and stories of organisational actors and the interpretation of events and assumptions of social reality shaped by the groups within which they live, in this context drawing from indigenous knowledge.
} 
Movements provide a synthetic solution to the disenchantment as well as the alienation of the modern subject. The identity of the member consists of the self-willed replacement of his personal project by that of the group, the active fusion of self with the larger social undertaking, and the reconstitution of social reality that it entails (Friedman, 1994a p:219).

Critical theorists Crossley (2003) and Sklair (2002) have also argued these new social movements are rapidly appearing as a reaction to the failings of globalisation. These movements have emerged articulating both anti-globalisation protests and calls for a stronger sense of ecological respect (Crossley, 2003; Sklair, 2002). While these new social movements are theorised to refer to a new post-industrial society they have also powerfully articulated the limitations of globalisation, for example the failure of World Trade Organisation agendas, especially in so-called developing nations (Crossley, 2003 p.3).

Others describe differing reactions to globalist practices. Barber (1996) claims Western consumerism or 'McWorld' co-creates an equal and opposite reactive 'Jihad', both using globalisation to gain traction (Barber, 1996). However Smith and Ward (2000) and Merret (2001) argue that reducing all communities to either McWorld or Jihad is a binary reduction which ignores the multitude of indigenous possibilities and social projects which act as counterpoints to globalising practices, but within their own holistic cosmologies (Merrett, 2001; Smith and Ward, 2000 p.36). Robertson and Giulianotti (2004) suggest local cultures use elements adapted from a global environment to suit their own projects.

Globalization is marked culturally by processes of 'glocalization', whereby local cultures adapt and redefine any global cultural product to suit their particular needs, beliefs and customs (Robertson and Giulianotti, 2004 p:546). 
Ralston Saul (2005) proposes that a reorientation to locality and local knowledge systems stem from 'an incapacity to recover from the loss of our pre-modern social structures' (Ralston Saul, 2005 p:247). Indigenous worldviews are not only a source of refusal of globalist practices, but also the source of a re-identification with place. He argues the fall globalisation and alternatives to it emerged - in part at least - in New Zealand, which was seen as the original poster boy of globalist practices in the 1980s.

\subsubsection{Indigenous Knowledge: Recovery and Protection}

An increasing acknowledgement of place occurred through the actions of Māori who began to reassert both themselves and their culture. The colonial immigrants soon began to do the same, to think of themselves as 'of the place'; conceiving of themselves in terms of a non-European egalitarianism and inclusivity (Ralston Saul, 2005 p:212). This move against globalisation, and a rearticulation of new social relations began from principles buried deep within indigenous knowledge.

Each society has to find the strength to say no from within its own experience. The New Zealander's growing integration with their place, tied to the [Indigenous] idea of an eternal natural presence, was perhaps the foundation for the self confidence that would help them change direction (Ralston Saul, 2005, p:213).

While for many such as Ralston Saul the high point of globalisation may have passed, for others its ability to change form to maintain the positional superiority of powerful Western interests remains indelibly present, not least in its own response to indigenous knowledge and guardians (Banerjee and Linstead, 2001; Greene, Banerjee Bannister and Brush, 2004). Rather than view indigenous knowledge as a source of resistance, powerful globalising agencies such as 
pharmaceutical companies realise there still is much to mine from indigenous knowledge, especially in relation to indigenous medicine.

Globalisation transforms the power-knowledge nexus in its relation to other knowledge: while colonialism generally served to undervalue or invalidate other knowledge, transnational capitalism seeks to own, exploit and profit from other knowledge as highlighted by the current debate over patenting and intellectual property rights concerning 'traditional ecological knowledge' of indigenous communities all over the world (Banerjee and Linstead, 2001 p:691).

So even as indigenous knowledge is posited as the source of resistance to globalisation, more than ever it remains a target for commodification and valuemining by current powerful globalist actors, thus requiring constant vigilance by knowledge guardians and, when required, recourse to protection.

If the claims from critical globalisation theorists are warranted - and I seek to show in later chapters that they are - then high modernity's attempt at the fragmentation of holistic cosmologies and the separation of self from social structures produces individuals who experience profound alienation. This unintended consequence paradoxically propels individuals to recover and rebirth what was lost. They seek to create stable identities and develop meaningful social projects, even if the modernist replacements for these integrative canopies of meaning are biological ethnicity and new social movements. Rather than being decimated by modernity, holistic cosmologies seem to have been partially revived by modernity's attempts at their destruction.

In the next section, I evaluate exemplar OS research to test if and whether all the above forces continue to powerfully exist in the external environment that many 
indigenous organisations seek to survive within, as well as the significance of holistic cosmologies to organising and the organisation. I assess the OS literature at three levels used throughout the thesis. For alignment with the previous section I begin in Section 2.3 at the social level and track through the organisational in Section 2.4, before moving into the level of the individual organisational leader and actors in Section 2.5. I finish the chapter in Section 2.6 with a summary of how indigeneity has been defined in a number of literatures, and describe the rationale for the social constructionist definitions chosen for the purposes of this thesis.

\subsection{Indigenous Organisations: Surviving in Global Contexts.}

In postcolonial OS, researchers have also examined the troubled relationships between the promises of development and the ongoing effects of globalist practices on indigenous communities and organisations. Introducing postcolonial OS, Prasad's (2003) definition of postcolonial studies focuses on how indigenous identity is constructed within and against colonial projects.

[Postcolonial theory is] an attempt to investigate the complex and deeply fraught dynamics of modern Western colonialism and anti-colonial resistance, and the ongoing significance of the colonial encounter for people's lives both in the West and the nonWest (Prasad, 2003 p:5).

Banerjee and Linstead (2004, p:227) define neocolonialism as 'a continuation of Western colonialism without the traditional mechanism of expanding frontiers and territorial control but with elements of political, economic and cultural control'. Neocolonialist or globalist practices creates powerful methods of cultural control of indigenous knowledge and identity as an extension of the political control 
gained in colonial projects (Banerjee, 1999; Banerjee and Linstead, 2001; Gopal,

Willis and Gopal, 1999; Prasad, 2005). Indigenous knowledge is marginalised and

subsumed under the catch all panacea of development:

This was a scientific and technological process that subsumed difference in culture, transforming people into variables in the grand equation of 'progress' validating the assimilative imperatives of development in the name of national interest. This regime depended solely on the modern Western knowledge system, and rejected and marginalized non-Western forms of knowledge (Banerjee, 1999 p:11).

A significant effect of such knowledge domination is maintaining the means to define reality for everyone else caught in the capricious web of development:

If the history of development is to be seen as a history of imperialism and colonialism, it is the power-knowledge nexus that can illustrate how development came to be seen as a version of reality and entrenched as the only normative reality (Banerjee, 1999 $\mathrm{p}: 11)$.

Banerjee and Linstead (2001) claim that globalisation as development continues neocolonial control by separating the economic from the social to the detriment of local populations:

'Development' was seen as economic development: once wealth was created, nation states could address social aspects of development. The separation of economic development from social development was typical of a Western capitalist world view and its imposition on non-Western cultures led to a host of problems: displacement of rural populations, unemployment, urbanization and environmental destruction (Banerjee and Linstead, 2001 p: 687).

They are also fully aware of the global reach that these relationships have, where notions of democracy become quickly transfigured into the underlying nexus of global capitalism which requires the continual growth of consumers.

The structural power inherent in such a discourse effectively reconceptualizes democracy as global capitalism, which is sustained by transforming citizens into consumers and where the role of the polity is to protect the world trade system. Thus, globalization becomes the new global colonialism, based on the historical structure of capitalism where trans-national corporations become identified as carriers of democratic values and practices to the Third World (Banerjee and Linstead, 2001 p:694). 
Further and significantly these relationships are not driven by force but by much more subtle and pervasive means, including direct challenges to indigenous holistic cosmologies.

The new forms of colonialism do not rely solely if at all on force to rule peoples neocolonialist structures and thinking have permeated all corners of the globe. Exclusions, co-optations and continuing epistemic violence characterize this process through the exercise of Western regimes of representation and thought upon the rest of the world (Banerjee and Linstead, 2001 p: 694).

Neocolonial practices challenge the authenticity of indigenous groups who choose to adopt global tools and technologies. Banerjee and Linstead (2004) examine how in a significant paper, Whiteman and Cooper (2000) portray the Cree's use of new technology in the place of 'traditional' practices, which renders them inauthentic:

Echoes of romanticism appear in the idea of an 'authentic' or more authentic version of the native within the native population itself, as shown in Whiteman and Cooper's references to the snowmobile and other technologies having replaced the traditional forms of hunting trapping and 'walking out'. This desire for what Wolfe (1999) calls 'repressive authenticity' is probably more reflective of the ethnographers' desire to construct the authentic indigene by attracting attention to authentic and traditional symbols without realizing that Indigenous Peoples all over the world have always used post-contact technology to sustain their communities - whether it be four-wheel drives, harpoon guns or dynamite (Banerjee and Linstead 2004, p:230).

Other postcolonial OS scholars note the colonising effects of new technologies and their capacity to standardise processes within elitist Western systems which benefits often White American owners. However they also note opportunities which exist by critically adopting global technologies for Indigenous Peoples and knowledge.

The necessity for the reinvention of [ICT] for the larger indigenous context, which would call for a privileging of indigenous knowledge systems, is rarely felt. That the recovery of indigenous knowledge systems for and through the inventive use of ICTs might actually sever Western bonds and might rekindle a technological dialogue amongst equals is hardly considered (Gopal Willis and Gopal 1999, p:33). 
Powerful global forces are easily identifiable. Foley (2004) found that indigenous

entrepreneurs operate in a global environment which is far from neutral.

Indigenous Australian entrepreneurs have operated within an oppressive social environment, rejected the negative social stratification within Australia's social order and become successful in their business pursuits. To illustrate the lack of financial assistance from government agencies, only three of these participants received any financial support from ATSIC. The rest began business with nominal credit after often using a credit card for working capital (Foley, 2004 p:11).

Even agencies apparently set up to help Indigenous Peoples are permeated with neocolonial power structures, and operate through the lens of economics alone, as the answer to indigenous communities' problems:

Contemporary discourses of aid and development agencies are related to notions of progress and civilization that inform colonial anthropology and continue to permeate society through neocolonial modes of political authority... [These] agencies operate on the assumption that economic progress leads to social progress and that development can solve poverty and social problems on a global scale (Banerjee, 1999 $\mathrm{p}: 11)$.

Banerjee (1999) articulates how large scale economic interests in the Australian context underpinned business agendas which were used by Australian government negotiators to ignore objections put forward by the Aboriginal Mirrar people through The Land Councils, their representative body:

Traditional owners require a system in which they can negotiate their future and the Land Council is culturally closer to Aboriginal communities than governments and mining companies. However, the neocolonial structures of bureaucratic organisations direct the ways Land Councils can be governed and accountability is established through capitalist and neocolonial frameworks. The 'postcolonial' [Australian] government's policy of dealing with Aboriginal people is in effect the same as the colonial policy but employs much more sophisticated means of control (Banerjee, 1999 p:18).

Given these powerful global forces, efforts to voice a competing conception of reality from the Aboriginal cosmology could not be voiced. If they were, they landed on deaf ears. The Land Council settled on a pragmatic approach: 
The Land Council's approach was to make the best of a bad deal: get legal land title and negotiate decent royalty payments. This was seen as a pragmatic approach with the quite reasonable assumption that if they were not part of the negotiations, the process would go on without them which would be even more harmful (Banerjee, 1999 p:17).

Banerjee (1999) describes how the institutional context for negotiations was underpinned by principles and practices which could not accept the articulation of an indigenous cosmology.

The economic view prevailed because the alternative view, an Aboriginal view of land, could not be effectively articulated within the economic rationalist and corporate government rationalist structures in which the negotiations were conducted. The Land Council, supposedly representative of Aboriginal views and aspirations has to operate and implement policies in a legislative framework that is designed to serve nonAboriginal interests (Banerjee, 1999 p:18).

Banerjee (1999) confirms how colonial and neocolonial power relations marginalise and silence indigenous voices and cosmologies. Banerjee also accepts the seemingly paradoxical situation where postcolonial theory itself has limits in supporting indigenous positions and agendas:

The position of Indigenous Peoples in contemporary postcolonial theory continues to be unspeakable and invisible... Contemporary postcolonial theory is especially problematic in accounting for anti-Colonial struggles such as the struggles of the peoples of the Fourth World to negotiate with and survive colonial conditions in countries like 'postcolonial' Australia where Aboriginal peoples are consistently denied their rights (Banerjee, 1999 p:4).

Henare and Lips-Wiersma (2002) also note how the all encompassing logic of markets and attendant self-interest causes problems for the articulation of indigenous worldviews and values.

The tendency of the Anglo-West to reduce human motivation to that of self-interest and monist utilitarianism and the construction of moral structures to reinforce the tendency is a problem for Māori and other Indigenous Peoples (Henare and LipsWiersma, 2002 p:11). 
However, when space is made to consider alternative notions of development from an indigenous perspective, purposes are revealed which seeks a profound reconnection to social aspects in deep relationship to indigenous knowledge.

Henare's findings are that Māori traditions and values profoundly affect the perspectives of and approaches to sustainable economic and business development in which the aim is to develop businesses that will manage tribal estates and resources, mobilize the kinship system towards an ethos of commercial self-reliance and wealth creation (Henare and Lips- Wiersma, 2002 p:11).

Māori culture is seen as a prime driver of sustainable indigenous development, operating from the premise of remaining profoundly connected to context.

Māori culture is fundamental to the success or otherwise of a vision of an indigenous sustainable economic development model. Māori, like other Indigenous Peoples, do not see businesses and the economy as distinct from society but are embedded in society and, that these economic institutions exist to protect society and enhance culture (Henare and Lips-Wiersma, 2002 p:11).

At the social level I seek to place a central lens on indigenous knowledge but view this knowledge in each global context to theorise indigenous organising in terms which illuminates global pressures. More significantly, I use social phenomenology to address how these pressures are managed and overcome, describing how indigenous worlds as holistic cosmologies are maintained and updated, whilst adaptation to the global context occurs. The result of this theorising seeks to understand indigenous organising not as a reductionist set of psychological states to be universally adopted, but rather a working theory which frames organising in terms of a reconnection of people, land and holistic cosmologies in deep relationship to historic context, rather than away from it. I offer this working theory and theoretic principles to support the development of indigenous voice and theory within OS. The next section summarises exemplar OS literatures at the organisational level. 


\subsection{Indigenous Organisations Enacting Indigenous Knowledge}

This section summarises the effects and limits of globalist knowledge on the organisation, as well as the coordinating role of indigenous knowledge. OS theorists have long known that objective organisational theorising glosses the American context of theory development to claim universality (Jacques, 1996). They have also recently called for organisational theory which acknowledges indigeneity, and organising processes without imposing a single notion of organisational structure.

When we examine forms of organizations, or structure, the notion of structure is itself structured from a Western standpoint. We must actively examine indigenous organizations and read about them maybe through illustrative cases about the Native American tribal organization, or a tribe in Bastar, India. What about discussions of forms of organization such as the tribal organization of a tribe in Africa, such as the Zulu or the Nuer, or the tribe in remote Bastar in Madhya Pradesh in India, or the workings of Native American society and uncover the organizing features of these forms of organization? What insights can we extract from all this? (Jaya, 2001 p:231).

Postcolonial organisational theorists advance the use that postcolonial theory has in challenging the long held assumptions prevalent in much management and organisational theory:

Postcolonial theoretic insights can develop a fresh understanding of [many] important developments including globalization, and a new international division of labour [and] an eroding faith in the universality (and infallibility) of the master narratives of Western modernity (Prasad, A. in Prasad and Prasad, 2005 p:33).

Postcolonial OS theorists also call for a fundamental reworking of theory, which begins to reincorporate the social and community aspects of local realities back into organisational understanding: 'is it possible to theorize a non-capitalist form of globalisation? If so, what will this look like?' (Banerjee and Linstead, 2001 p:

714). While Banerjee and Linstead (2001, p.713) cite examples such as small 
family businesses, and icons of resistance such as Ghandi, their view of possibilities remains constrained by the all-embracing economic reach of globalism.

Similarly, in a paper challenging the universal application of postmodernity in organisational theory, Alvarado (1996) uses health organisations in Guatemala to argue that notions of modernity, postmodernity, and pre-modernity have developed in the context of industrialised countries. He proposes that 'using the notions of margins of modernity means recognizing that constructing theory from outside the limits of conventional organizational language is a first step to questioning it' (Alvarado,1996 p:679). However he goes on to propose that 'admitting knowledge generated at the margins, as well as studying organizations and the 'outside' margin in their own terms takes us beyond comparison and into discovery' (Alvarado,1996 p:679).

Others have sought discovery in OS from ancient knowledge. Bartenuk and Necochea (2000) have used the holistic cosmology of the Inca to theorise notions of kairos within organisational theory. Indigenous organisations figure briefly in third world contexts. Vargas-Cetina uses postcolonial theory to address the misrepresentation of indigenous organisations in the Chiapas regions of Mexico (Vargas-Cetina, 2001).

Indian organizations in Chiapas are actively engaged in the geography, the writing of the world. The contents of their writing, however, continue to be influenced and censured by distorted perceptions of "the Indian" and indigenous societies (VargasCetina, 2001 p:76). 
At the end of an extensive paper she uses a single example of a small weaving cooperative as an authentic example of an indigenous organisation.

Mujeres en Lucha is a small weavers' co-operative with its headquarters in the municipal center of Tenejapa. The members of this organization are eighteen women from the municipalities of Tenejapa and Chamula. They all take turns looking after their store, where they sell the work of all the cooperative's members. As their clientele is mainly indigenous, they sell acrylic-colored items along with textiles made using natural dies (Vargas-Cetina, 2001 p:77).

Vargas-Cetina (2001) notes the communal practices and adaptive techniques which are used to learn managing practices which are pragmatically useful to the operation of the cooperative:

They have learned organization techniques at workshops sponsored by the government and by weavers' organizations, taking what they find useful from these forms of instruction. The cooperative has survived since 1982 to date, providing its members with an income that helps them support their families. I believe that this type of selfdriven organization is a good example of what indigenous organizations can be in Chiapas (Vargas-Cetina, 2001 p: 77).

Beyond my own developing work (Finlay, 2001, 2002, 2003, 2005, 2006, 2008) there is a paucity of work in OS examining any type or form of Scottish or 'Celtic' organisation, save for an early undergraduate strategy textbook which writes up the IC as a case (Johnson \& Scholes, 2001).

By contrast there has been a strong and growing literature framing Māori organisations, and their relationship to Māori knowledge and 'global' contexts. For example, Henry (1994, p:151) considers the history behind many Māori organisations, signalling:

the importance of tribal cohesion as the foundation for economic development of Māori in the nineteenth century [in the face of] the impact that loss of land and resources, internecine conflict, disease, poverty and social dislocation had on that development. 
Henry (1994) also notes that the vast majority of organisational forms have developed as a result of legislative or government based institutional initiatives. These include the tribal runanga, which were 'formed in the aftermath of Te Urupare Rangapu (1989) to facilitate the devolution of resources to iwi... Runanga were set up in anticipation of dealings with the Crown when the Runanga Iwi Act was passed in 1990.' (Henry, 1994 p:160). Quoting research into Māori managers, Henry (1994) describes the notion that a barrier to effective management from a commercial perspective was:

an insufficient understanding of business or successful management practice which has led to a lack of internal controls and difficulties in addressing technical and business matters in an efficient and timely manner (Henry, 1994 p:154).

Recent early doctoral research examines four case studies of contemporary Māori organisations and the relationship between organisational form and cultural dissonance (Wolfgramm, 2001). Classifying: traditionalists; hybrid traditionalists; hybrid capitalists; and entrepreneurs, Wolfrgramm (2001) reports the highest levels of cultural dissonance within hybrid traditionalists who exhibit the greatest tension between traditional culture and mainstream economic ideologies: 'resentment builds within and throughout the organization, leading to low cultural and scial assimilation towards both traditional and mainstream cultures' (Wolfgramm, 2001 p:7). Significantly, those organisations which seek the most globally adaptive stance find themselves:

unrestrained by traditional roles... there appears to be a cultural and social assimilative shift towards this global culture... Congruence with the values and belief systems of a dominant global economic ideology leads to low levels of cultural dissonance (Wolfgramm, $2001 \mathrm{p}: 8$ ). 
For those Māori organisations that maintain what she terms a traditional culture 'a psychological, social and spiritual contract remains embedded within the collective at the most fundamental level'(Wolfgramm, 2001 p:7). The study highlights 'the important role traditional Māori culture plays in the development of organisational cultures in contemporary Māori organisations' (Wolfgramm, 2001 p:7). Other Māori business research in New Zealand has also described the adaptability and entrepreneurialism which historically characterised Māori before European contact, with inter-tribal trade existing in the context of a holistic cosmology imbued with obligations of reciprocity. Love and Waa (1994, p:22) indicate that gift exchange:

Depends on socially-governed ethics regarding such issues as honour, prestige, mana, hospitality, generosity, and the value placed on particular items to dictate the exchange equation.

Love and Waa (1994) note how imposed colonial educational structures fragmented Māori knowledge and customs:

With the advent of European schooling, traditional values, beliefs and customs steadily declined. Not being able to adequately adjust to this new educational system, Māori self esteem and direction waned dramatically (Love and Waa, in Deeks and Enderwick, 1994 p: 37).

Without theorising in-depth cases themselves, Henry and Pene (2001) introduce Kaupapa Māori organisations in the educational context which have been established to redress the effects of colonial educational structures noted above.

Grassroots Māori educationalists have advocated for, and created, an alternative Māori educational system, operating alongside the mainstream. Kohanga Reo ['language nests'] are early childcare educational centres in which infants are introduced to Māori language and culture. The centres are managed by whanau [families] and paid staff, and operate as non-profit, community-driven enterprises (Henry and Pene, 2001 $\mathrm{p}: 239)$. 
In the paper they introduce whāre wānanga [houses of higher learning], and note,

like Henry (1994), the institutional legal structures within which they are embedded:

Whāre wānanga is Māori for 'houses of higher learning'. Today, the name is used to define Māori language universities, set up in tribal areas [as] fully funded tertiary institutes, yet they are under-resourced and geographically isolated from much of the intellectual academy. They have been constructed by drawing on a bicultural partnership model with the Pakeha (Anglo) mainstream, a relationship that mirrors the original Treaty of Waitangi partnership between Māori tribes and the British Crown (Henry and Pene, 2001 p:239).

These Kaupapa Māori projects seek to directly challenge the dominance of the neocolonial Western academy and instead develop academies which instead reflect and construct a Māori worldview.

Kaupapa Māori recognizes the political, cultural and intellectual capital that universities 'own' and 'distribute'. Thus, for Māori, the Western 'university' is as problematic as the knowledge it constructs and perpetuates. Māori seek to establish an 'academy' that is more representative of our traditional world view (Henry and Pene, 2001 p:239).

Henare and Lips-Wiersma (2002) describe how Māori knowledge underpins

Māori business and describe some elements of this knowledge which is enacted to

ensure balance and harmony.

Studies of Māori business suggest that tradition and culture play a role in shaping present-day Indigenous Peoples perspectives and practices. [Examples are:] a concern about living according to Māori customary values and practices (tikanga and ritenga); The enhancement of Māori kinship groups in which individuals may prosper; and the social good or common good of all human endeavours. Underpinning all values and behaviour is a Māori spirituality (wairuatanga), which must be nurtured to ensure there is harmony and balance in individuals, in groups, in organizations, and society as a whole. (Henare and Lips-Wiersma, 2002 p:10).

Henare and Lips-Wiersma (2002) describe how this worldview underpins not just the form of organisation but also the identity of Māori who are embedded in wider social and cultural milieu. 
When Māori come together in any form of organization the power of traditional and contemporary collective values become more explicit and provide the context for both the individual and group identities and their spirituality (Henare and Lips-Wiersma, 2002, p: 11).

They go on to note a belief in the health of the organisation itself and how this health can directly contribute to the broader social context.

Māori believe that organizations as collective expression of its members, has an inherent spirituality of the organization itself. The health of this institutional spirituality may have a significant bearing on the spirituality of the individuals and groups within the organization and it's ability to contribute to society (Henare and Lips-Wiersma, 2002, p:11).

Henry and Pene (2001) challenge theorists to create space for alternative theorising of organisations such as those who operate from within a Māori cosmology, to not just recognise and name colonisation, but to contribute to alternative positive constructions.

The Kaupapa Māori challenge calls for an ongoing creation and maintenance of space for intellectual traditions flourishing in parallel institutions operating alongside the mainstream; and the recognition that the academy has a role, as a location for 'decolonization' and the development of counter-hegemonies, not just to pay lipservice to alternative ways of knowing and being, but to embrace and celebrate them (Henry and Pene, 2001 p:240).

At the organisational level this thesis aims to complement the above literature by theorising how the indigenous organisation is enacted. Rather than in structural objective terms, the organisation is seen through an established lens of OS and viewed as a whole; the object of the exercise is to view the working uses of indigenous knowledge and the organising processes and practices which may emerge from this (Jaya, 2001). How these indigenous organisations orient themselves to, and enact indigenous knowledge in current contexts is offered as a discovery of an alternative theoretic space to the all-encompassing domain of 
globalisation or the dominance of Western institutions (Alvarado, 1996; Banerjee and Linstead, 2001, 2004; Jaya, 2001) or as an alternative to indigenous studies where the global domain is entirely absent (Whiteman and Cooper, 2000). Two in-depth studies of indigenous organisations and a whāre wānanga in particular contribute to existing OS research in Māori organisations. The case reveals how a Māori university constructs the Māori spiritual worldview which underpins organising to create an organisational culture which controls and disseminates Māori knowledge, while challenging the dominance of Western institutions (Henare and Lips-Wiersma; 2002; Henry, 1994; Henry and Pene, 2001; Wolfgramm, 2001). The thesis also adds to OS by describing a Celtic organisation. The thesis examines how indigenous organisations adapt to broader social contexts, while maintaining indigenous knowledge as central, creating coherence between organisational identity and adaptation (Vargas-Cetina, 2001; Wolfgramm, 2001). The next section interrogates the OS literature at the individual level to examine how actors survive in the context of globalist pressures, but that individual and organisational choices remain as to the strategic focus and purpose of the indigenous organisation, underscoring the significant role that founding leadership has, even if this leadership may be weakened by the unending external pressures that is seeks to mitigate.

\subsection{Indigenous Leadership and Identity}

An important topic in an emerging indigenous OS is the notion of agency, which, for the purposes of the thesis, is defined as the life-projects of indigenous actors. I 
focus on the agency of individual leader's actions to enable organisational action.

For Jaya (2001) notions of indigenous leadership can be rethought by drawing on wider ideas of the context of leadership and the aspirational examples which can

be used as leadership cases.

In leadership, [we must] examine the discussion of leadership, from the ideas of the leadership of a clan, a tribe, and biographies of people like Gandhi, Nasser, Castro, Sadat, Desmond Tutu, Nelson Mandela and others (Jaya, 2001 p:231).

Exemplar OS researchers Whiteman and Cooper (2000) have observed how indigenous holistic cosmology underpins managerial beliefs.

Cree managerial beliefs are strongly infused with a non-anthropocentric sense of spirituality, in which all earthly entities are perceived to be alive with spirit: "We're taught that everything is alive, even the rocks. Every single thing around us came from the earth in some shape or form. An elder once told me: There's not one thing you see around me that hasn't come from the earth." (Whiteman and Cooper, 2000 p:1271).

The management practices of the Cree emerged through the ongoing enactment of indigenous knowledge within the Cree environment, to the extent that management practices and the environment become synonymous with one another.

The [Cree] management practice was a daily elaboration of the Walking Out Ceremony. Even when [Cree] did not walk (and instead used snowmobiles), their location was a compelling characteristic of their management practice. The natural environment was not an abstract entity removed from management practice. In this way, the [Cree] management practice was "natured" in a physical sense. This physical characteristic is a key dimension of the [Cree's] ecological embeddedness (Whiteman and Cooper, 2000 p:1278).

The goal of these management practices for the Cree was not profit, but in

Whiteman and Cooper's terms finance to sustain subsistence activities.

The goal of trapping for trade did not appear to be profit. Rather, the goal was to sustain the subsistence activities that now require a certain level of cash income; for example, gasoline for chainsaws and snowmobiles has to be purchased. Yet the fieldwork also provided some reports of Cree hunters serving as guides to non-native fishermen and hunters. It is unclear how such individuals resolved market pressures for fur with traditional Cree beliefs (Whiteman and Cooper, 2000 p:1279). 
Whiteman and Cooper (2000) describe how indigenous knowledge underpins

Cree management practices and leadership roles, in contrast to profit maximisation.

[Cree] managed from within an eco-spiritual worldview that privileged the earth as a living and sentient force that requires respect and care. [Cree] believed that they had a spiritual relationship with the land and the animals that also lived there. They believed their role as managers was to maintain reciprocity with the land, to show respect for all that lived there and to take care of ecological health and animal populations. Ecological actions took the form of not maximizing hunting or trapping output, not overharvesting, enacting spiritual ceremonies, giving tobacco as thanks, disposing of bones in a respectful way, and not laughing at or mistreating the natural and spiritual world (Whiteman and Cooper, 2000, p:1276).

Whiteman and Cooper (2000) report how leadership in the Cree context is legitimised by practicing indigenous knowledge, in this case of the land, which was built up over many generations, identifying and enacting the knowledge continuities which have been handed down:

Several [Cree] reported that "walking out" was a basis for managerial legitimacy and leadership: "The [Cree steward] is chosen for this job because he has proven that he has these skills. He knows his land because he walks and talks with it all year round. He is a full-time trapper." (Whiteman and Cooper, 2000 p:1271).

Whiteman and Cooper (2000, p:1267) describe management practices in the Cree context under the terms 'ecological embeddedness' which is defined as the extent to which a manager is on, and learns from, the land. The paper theorises how indigenous identity and the development of management practices are intimately connected to the land:

[Cree stewards] strongly identify with the land. Their managerial approach had developed over regular interactions with specific places. "When you live in the bush all year long, watching over it, the land speaks to you. So when the tallymen speak, it is the land speaking. Life is the land. And the land is the people" (Whiteman and Cooper, 2000 p:1274). 
This deep connection to the land occurs over many generations and is intimately connected to indigenous knowledge which is framed as traditional ecological knowledge. Whiteman and Cooper (2000) propose this knowledge is: holistic; built up from lived experience over time; inter-generationally transmitted; and underpins traditional life-projects framed in the natural environment.

Traditional ecological knowledge systems are a mixture of management knowledge, beliefs, and practices. These three elements operate in an iterative and holistic system that emerges over time, and across generations, and they are embedded in the lived experience of traditional pursuits, in activities or ways of life that take place in the natural environment (Whiteman and Cooper, 2000 p:1266).

Whiteman and Cooper (2000) also identify a key characteristic of this indigenous management approach.

Indigenous spirituality is a fundamental element of this management approach (Whiteman and Cooper, 2000 p:1266).

However powerfully Whiteman and Cooper (2000) portray indigenous Cree methods, for Banerjee and Linstead (2004), an absence of any reference in Whiteman and Cooper's (2000) study to globalist practices not only paints a false picture of a romantic noble savage, it also masks the effects of these globalist practices - allowing the insidious methods of cultural control to continue unchallenged. Instead Banerjee and Linstead (2004) have theorised how the identity of indigenous actors is constructed by engagement with neocolonial forces which also need to be acknowledged (Banerjee, 2000; Banerjee and Linstead, 2001, 2004).

Indigenous value systems need to be taken seriously and with respect. But we argue that this must entail a reflexive awareness of the ideological and historical conditions out of which and against which these systems have developed and struggled for their continued existence, and in interaction with which they have adapted, rather than solely the ecological systems within which they are embedded (Banerjee and Linstead, 2004 p:225). 
Banerjee (1999) examples the agency of indigenous leadership in the face of overwhelming global forces, describing Aboriginal elders caught in exhausted and exhausting resistance against seemingly immoveable and all powerful global structures engaged in a process of consultation over mining rights:

The consultations took place over 18 months... The last meeting was about consent. The senior [Aboriginal] owner was very sick at the meeting, he was so run down by the process that he couldn't sit, he spent most of it lying down, and finally at the end of that meeting when the question of consent was put, he got up and addressed the meeting: "I'm tired now, I can't fight anymore". That was consent. That was officially and legally all that was required to embody legal consent for a project to go (Banerjee, 1999 p:20).

Banerjee and Linstead (2004) claim Whiteman and Cooper (2000) fail to account for or theorise a global context for Cree managers, framing them in the same terms as most Western institutionalised managers. The assumption is that indigenous managers and leaders are able to draw from indigenous knowledge in terms akin to how Western managers draw freely from management knowledge. 'Indigenous ecology becomes represented as an abstract but pristine fountain of knowledge (to be appropriated unproblematically), separate from indigenous economy and society.' (Banerjee and Linstead, 2004 p:227). They challenge this de-mythologised portrayal of the Cree as synonymous with earlier colonial Evolutionist narratives which legitimised domination, and separated Indigenous Peoples from their own holistic cosmologies, which are deeply spiritual.

Whilst the evolutionist paradigm constructed a rationale for domination that accounted for the deaths of refractory savages, synchronic relativism recruited living subjects for colonial society by disqualifying them from a mythical parallel realm (Banerjee and Linstead, 2004 p:233).

In anthropology 'synchronic relativism' refers to how theories of development ascribe change to self-organising groups without any reference to their own 
historic contexts. As Wolfe (1999, p:52) notes: 'in regard to twentieth-century settler-colonialism synchronic relativism's principle ideological significance is as a suppressor of consequences'. The consequences being referred to here are the 'disruptions and incongruities involved in [colonially-imposed] historical change'.

Banerjee (1999) suggests history is often used as a means of constructing Western identity in advanced terms, seeking to maintain Western superiority in identity construction.

Studies of Aboriginal resistance are also theorised in relation to Western cultures and the dichotomies that result from this position (development versus no development; traditional versus modern; land use versus conservation) only serve to perpetuate Western notions of progress (Banerjee, 1999 p:30).

Banerjee (1999) acknowledges how relationships of indigenous identity are intimately connected with the land, but describes in detail how colonial and global forces have powerfully fragmented these relationships.

If the aim of colonialism was to control the people's wealth and resources in terms of what was produced and how it was produced, colonization of Aboriginal Australia was about controlling land - the real wealth (possibly the only one that matters) of Indigenous Peoples all over the world (Banerjee, 1999 p:8).

Banerjee and Linstead (2001) propose that it is an all pervasive global culture which instead constructs individual identity and culture 9 .

The production of culture is directed by the logic of late capitalism. This global culture is one of consumption, and the global consumer culture is one that consumes not only products and services, but increasingly signs and symbols and ideas (Banerjee and Linstead, 2001 p: 696).

\footnotetext{
${ }^{9}$ I draw from Alvesson, (2002, pp.3-6) and Schutz (1970, p.80) in defining culture as a cohesive system of meanings and symbols drawing from socially derived knowledge containing shared rules governing social interaction and the means where they are expressed.
} 
They also show how insidious global practices construct individual identity in relation to consumption, the defining action for social participation.

The primacy of the market and the 'democratic' principles it purports to possess effectively reconceptualize citizens as consumers. Once this process is set in place, when individuals become dependent on the market for the prostration and reproduction of their identities, everybody becomes a consumer (Banerjee and Linstead, 2001 p: 697).

Banerjee (1999) frames indigenous knowledge and identity as holistic, containing none of the dualities prevalent in Western knowledge systems, which, in the Aboriginal context, sought to separate Aboriginals from the land, and therefore from their own identity.

Indigenous identity and culture cannot be separated from the land - the nature-culture dichotomy, so prevalent in Western thought, is an alien epistemology for Indigenous Peoples. Dispossession of land was [to gain] control of Aboriginal culture which in turn impacted how self definitions of Aboriginality were constructed, definitions that are based on their relationship with the colonizer (Banerjee, 1999 p:8).

For the Australian Aboriginal, the effects of this identity fragmentation are not small. Banerjee (1999) describes these effects in detail, where the historic imposition of economic development separated Aboriginal communities from the land and instead brought

a legacy of bad health, no houses, no infrastructure [and] no employment. It has brought them not economic independence, but ecocide - a sense of powerlessness. Alcohol consumption in this area is synonymous with powerlessness. People anaesthetize themselves to what they see around them to their inability to be able to control their lives. That's led to other poor health outcomes, poor educational outcomes, poor employment outcomes (Banerjee, 1999 p:19).

Foley (2004) researched 25 Aboriginal entrepreneurs, to find that they retained indigenous practices despite losing a connection to their indigenous knowledge.

Indigenous Australian entrepreneurs stated generally that 'traditional values' for them no longer existed, yet they continue to base themselves in a kinship or quasi-kinship arrangement and identified the provision for family as their dominant intrinsic motivator in business. They made adjustments to their social and cultural life to 
achieve this as their primary concern was the improvement of their respective Indigenous family's condition in a modern society (Foley, 2004 p:6).

Despite these knowledge gaps, the purpose or agency of their work was based on kinship relationships.

Their driving force in striving for business success has been identified as the contemporary kinship value. The intrinsic motivator is to provide for their families, to give their children a better life than they had (Foley, 2004 p:11).

These effects included devaluing and fragmenting indigenous knowledge, making connections to this knowledge a fraught task. Amongst the 25 urban indigenous entrepreneurs studied, the majority

treated traditional spiritual knowledge as if it was largely irrelevant or dead. Most of this group did not know their traditional culture. It was something they had lost or their parents or Elders had not taught them. They were either members of the stolen generation, children of the stolen generation, or parents/grandparents who were institutionalized in Missions. In short, most of the study group lost control of or contact with their traditional land, culture and kin (Foley, 2004 p:7).

This was not the only legacy of colonialism. In studying the 25 entrepreneurs,

Foley found that

twenty-three of the twenty-five participants are the children of stolen generation victims who have suffered (to some degree) the emotional traumas of their parents. Twelve of the twenty-five Australian participants were also taken from their families and placed in institutions as children. The majority of these twelve Indigenous Australian entrepreneurs not only were institutionalised themselves, so where their parents (Foley, 2004 p:10).

Another feature of these entrepreneurs was their dissatisfaction with Western educational systems 'the majority of this group obtained tertiary qualifications as mature aged students after their non-completion of high school' (Foley, 2004 p:11). 
Postcolonial and critical OS theorists have also framed individual indigenous practices in terms of their resistance to the ongoing effects of colonialism, which inevitably dispossess (Elmes and Prasad, 2005; Prasad and Prasad, 2005). These theorists also draw from postcolonial studies to describe indigenous workplace resistance (Elmes and Prasad, 2003) and the relationship of postcolonial studies in OS to the broader topic of workplace resistance in management writing (Prasad and Prasad, 2005). In the Mohawk context, indigenous knowledge continuities serve to support indigenous 'imaginings' against almost overwhelming economic practices:

[Mohawk Ironworkers] used their work in high places to talk back to and redefine....aspects of colonial discourse. Working atop skyscrapers in Manhattan, ironworkers have remarked that they can see and, in one sense, reclaim, all the land that was once Mohawk and the home of their ancestors (Elmes and Prasad, 2005 p:18).

The central themes of postcolonial studies in OS evidence how neocolonialism continues to fragment indigenous identities. At the individual level, identity construction is deeply interwoven with the coloniser, despite the acknowledgement that indigenous knowledge continuities remain to offer rich alternatives.

This thesis theorises and describes how indigenous knowledge underpins agency in the life-projects of members. As part of this, indigenous leadership is positively examined in each case to theorise actions and legitimising effects in the context of each indigenous organisation and the global pressures it faces (Jaya, 2001). Each holistic cosmology or in Wolfe's terms 'mythic parallel realm' (1999, p:53) is explored in its historic context to reveal the disruptions and incongruities of 
colonial history and globalist practices, but also the recovery and enactment of each. The recovered effects of indigenous knowledge on indigenous identity and health are explored in the context of globalist practices. In the last chapter section, I assess indigenous identity definition as it is constructed in four main literatures, summarising the strengths and weaknesses of each literature and definition, before articulating the pragmatic definitions used for this project.

\subsection{Defining Indigeneity in Wider Literatures}

Indigeneity has been defined in colonial, postcolonial, anthropological and constructionist literatures, generating differing foci of attention. I summarise and provide a constructionist assessment of the exemplar theorists in each literature, before finishing with a summary of the strengths and weaknesses of these definitions, alongside the constructionist definitions I have chosen for the pragmatic purposes of this project.

\subsubsection{Objective Colonialism: Positional Superiority}

Indigeneity has been defined in the English Canon to carry the value-free authority of tradition, which reflects a colonial marker of native to the term. The $17^{\text {th }}$ century Latin definition of indigenous, quoted in 2003, examples the colonial English usage:

[indigen-us born in a country, native (f. indigen- $a$ a native, 1697) 1. Born or produced naturally in a land or region; native or belonging naturally to (the soil, region, etc.). Used primarily of aboriginal inhabitants or natural products. (Shorter Oxford English Dictionary, 2003 p:1357). 
The term 'native' was a descriptor for being backward, undeveloped and in need of civilising, while the colonial project was legitimised as bringing developmental benefits to the natives as much as a duty as anything else (Rattansi, 1997; Said, 1978, 1994). As late as 1894, Said (1978) illustrates colonial legal arguments that proposed: 'regions of the earth designated 'uncivilised' ought to be annexed or occupied by advancing powers' (Said, 1978 p:210). The duty of the coloniser was to develop and educate the other in Western ways and customs. As part of this, the coloniser denied the cognitive status and legitimacy of indigenous knowledge, replacing it with colonial knowledge, political projects, and sovereign rule which was deemed legitimate under the 'natural' duty of the advancing colonial project.

\subsubsection{Postcolonial Identity Constructed by the Coloniser}

Postcolonial studies have sought to open the margins to reveal hidden power relations in the construction of identity, with the aim of empowering those in the margins to articulate their own reality. As a significant theoretical tradition which has informed many literatures, not least those in OS outlined earlier, it offers many important insights into indigenous identity construction. While they differ in theoretical approach and content, postcolonial theorists such as Said and Spivak have addressed how indigenous identity has been formed (Said 1978, 1994; Spivak, 1987ab, 1988, 1993). They propose that indigenous identity has been essentially fixed as tribal peoples who are both backward and in need of development in colonial and neocolonial contexts. This critique has revealed the binary reduction of white settler dominant and developed versus the non-white 
indigenous tribal barbarian. Rattansi (1997) argues that processes of identity formation within the colonial encounter are central features of postcolonial studies. Imbrication is defined as:

the mutually constitutive role played by coloniser and colonised, centre and periphery, the 'metropolitan' and the 'native' in forming in part the identities of both the dominant power and the subalterns involved in the imperial and colonial projects of the West (Rattansi, 1997 p:481).

Postcolonial theorists suggest essentialism is: 'a belief in the real, true essence of things, the invariable and fixed properties which define the 'what-ness' of a given entity' (Fuss, 1989 p:xi). The ability of actors to use language to fix identity is a major strategy used by the coloniser to create superior identity claims by proposing universally-fixed meanings to define the colonised. Said (1978) argues that the complete self-identity of the West was forming as advanced, based on a contrast with so-called backward races.

The whole question of imperialism, as it was debated in the late nineteenth century, by pro- imperialists and anti-imperialists alike carried forward the binary typology of advanced and backward (or subject) races, cultures and societies (Said, 1978 p:206).

In this way the identity of both coloniser and colonised were constructed in the fulcrum of colonial expansion and tribal repression. Indigenous Peoples in this context were pejoratively constructed and essentially classified to connote inferiority and assign undeveloped status to the natives. These claims were used to legitimise the hegemonic supremacy of the colonial development project.

Postcolonial writers have proposed differing terms for the construction of identity based on authentic terms, instead stressing the ongoing construction of subjectivities based on their experience of engagement with repressive political 
structures. By paying attention to colonising processes, notions of indigenous are revealed and written into a marginal position. In the Indian colonial context, for example, Spivak $(1987 \mathrm{ab} ; 1988)$ theorises imbrication of the subaltern tribals by strategies of both misrepresentation and essentialism. She defines indigenous identity as the 'silent silenced centre such as the tribals; the illiterate peasantry and the lowest strata of the urban sub-proletariat' (Spivak, 1988 p:283). Strategic essentialism uses an understanding of the tools of essentialism by tribal peoples themselves to create an awareness of the formation of their tribal self in relation to fixed specificities in culture, language and political positions, including institutions.

What your self represents is that kind of a[n] ... agency, a history, a culture, a position, an institutional position. But, via that persistent critique you may be aware that this is merculating [acting on like a cause] you as you speak, rather than you speaking in unmediated identity. Of course that awareness is always beside, before, after the point, but that's life. The essence of life... This is the strategy by which history plays you, your language plays you... It's not a question of choosing the strategy (Spivak, 1993 $\mathrm{p}: 6)$.

Researching the Indian context, Spivak (1987) proposes that the subaltern collective consciousness is interwoven with not only the ongoing colonial imbrication, but also a tribal community.

Subaltern consciousness is a consciousness of the collective - a community. [The tribe's] consciousness of itself as a body of insurgents was indistinguishable from its recognition of its ethnic self (Spivak 1987, p:206).

Consciousness is theorised to be the ground from which the self emerges, in 'disclosures', where consciousness is inexorably co-constructed in the colonial encounter, and never appropriable back to a fully indigenous state.

Consciousness is the ground that makes all disclosures possible. Subaltern consciousness is subject to the cathexis of the elite, it is never fully recoverable. 
Consciousness is not of the being of the subaltern, but of that of the oppressors (Spivak, 1987 p:202).

Subaltern identities can be constructed from their fragmented essence, in the interests of what Calas and Smircich (1999) call the agency for struggle, which aims to progress political feminist and subaltern agendas against the dominant coloniser. Critical anthropologists have also drawn from postmodernism to open the margins and challenge the legitimacy of anthropological science, which has hidden powerful political agendas behind its objective gaze.

\subsubsection{Objective Anthropology}

Rather than being the dispassionate voice of material fact, objective anthropologists have been the willing partners in colonial imbrication through their own essentialist classifications of Indigenous Peoples. Critical anthropologists have revealed how the terms native and tribe have been classified by 'objective' anthropologists, who were themselves profoundly engaged in colonial projects (Rosaldo, 1993; Wolfe, 1999). For example, in the Australian context Wolfe (1999) cites how colonial ethnographer Baldwin Spencer helped construct the Aboriginal as inferior, proposing and legitmising by science policies which were adopted by the Australian Government which resulted in assimilation (Wolfe, 1999 p.10). For objective anthropologists, the term 'native' is closely linked to the terms aboriginal and tribe which related 'not only to a type of society, but also a stage of evolution' (Beteille, 1998 p:187). These 'objective' terms describe and classify the inferior status of Indigenous Peoples. 
This essential classification: 'skirts the issue of a formal definition and merely stands for a set of communities listed in an official schedule' (Beteille, 1998 p:188). Anderson (1983) suggests colonial empires were claimed, legitimised and grown through methods of reality definition which assimilated and classified native territory which was in need of Western development (Anderson, 1983). Terms such as native and primitive have been challenged by the resurgence of the term indigenous, 'where one spoke in the past of the tribal population of a country one speaks more and more of its Indigenous Peoples' (Beteille, 1998 p:188). Noting the lack of definition, Beteille (1998) differentiates between indigenous and tribal, so that the term indigenous

acquires substance when there are other populations in the same region that can reasonably be described as settlers or aliens. A significant dimension of the identity of the populations correctly designated as 'Indigenous' derives from a particular history of settlement and usurpation (Beteille, 1998 p:189).

In this way Beteille (1998) also defines indigenous by way of engagement with the colonial settler. This definition excludes any notion of indigenous that could be constructed in the West and if we go by these new anthropological conventions, Western Europe will be the only region in the world without any significant presence of Indigenous People' (Beteille, 1998 p:188). Perhaps unsurprisingly, Beteille's definitions have faced strong challenges within anthropology.

Beteille is concerned not with the thinking of Indigenous Peoples but with a distant how best to define them. Such defining, he argues, should adopt a detached social science perspective unaffected by the alleged emotionalism of anthropologists who [are] responsible for the idea of indigenous (Childs and Guillermo Delgado, 1999 $\mathrm{p}: 211)$. 
Sillitoe (1998) argues that material concepts within the global knowledge society construct, in part at least, the indigenous knowledge renaissance. Sillitoe frames indigenous knowledge as folk knowledge which, in part, reflects the global emphasis on knowledge, and articulates the indigenous case for the protection of bio-diversity in the light of advances in genetic modification (Sillitoe, 1998).

By contrast, Childs and Guillermo Delgado (1999 p: 211) argue that indigenous as a term has been used by 'numerous communities of Indigenous Peoples themselves'. However this process of self-definition is not without its own challenges. A new set of universal indigenous self-definitions have emerged, supported by international development agencies which have championed the legal and social justice case of Indigenous Peoples, beginning with their rights of self-definition.

The next section assesses and outlines the definitions chosen for the pragmatic purposes of this thesis. Taken together these definitions were selected because they share a focus on how Indigenous Peoples define themselves in relation to sacred land, sacred communities and larger holistic cosmologies, in the context of articulating new 'indigenous imaginings'. 


\subsubsection{Indigeneity in Global Agencies; Challenging Nation States}

The United Nations (U.N.) has recently sponsored and advocated for Indigenous Peoples to define the term indigeneity for themselves, in an effort to counter colonial definitions and usurpation, and to establish a basis for redistributive justice. Indigenous delegates have used the U.N. as a forum to challenge what they regard as the dominant destructive economic and political orders, and to restate, by contrast, their own claims to ancient settlement and articulate these within their own sacred cosmologies. As a forum to articulate these claims The United Nations Working Group on Indigenous Population (WGIP) was formed in 1982 (Muehlebach, 2001). These definitions locate indigenous identity as continuously connected with pre-colonial peoples and territory.

Indigenous communities, peoples and nations are those which, having a historical continuity with pre-invasion and pre-colonial societies that developed on their territories, consider themselves distinct from other sections of societies once prevailing in those territories or parts of them. They form at present non - dominant sectors of society and are determined to preserve, develop and transmit to future generations their ancestral territories, and their ethnic identity, as the basis of their continued existence as peoples, in accordance with their own cultural patterns, social institutions and legal systems ( Muehlebach, 2001 p:421).

The aims and goals of indigenous projects are empowered by notions of the continuity of stewardship of indigenous land and knowledge to be protected and transmitted to future generations to ensure the continuity of existence. Precolonial indigenous knowledge continuities support and enable these purposes. Muehlebach (2001) describes how, despite differences, Indigenous delegates have developed remarkable consistency in using the definitional opportunities of the WGIP. They articulate a shared vision based on "values and types of being in the world' (ontology), which sees 'territory as the fundamental and multidimensional 
space for the creation and recreation of the ecological, economic, and cultural practices of communities' (Muehlebach 2001, p: 416). Muehlebach (2001) also argues that Indigenous Peoples express their own strategic essence within and through connections between holistic cosmologies and the land itself. They are thus historically grounded, embedded in, and enabled by, specific meaningful practices and activities containing epistemologies that share commonalities of: 'interconnectedness, morality, myth belonging and sacredness which are as old as colonialism itself’ (Muehlebach, 2001 p:417).

Indigenous knowledge continuities also underpin claims to self-determination. Meuehlebach (2001) suggest the morality of self-determination comes out of historical experiences of ancient settlement and colonial usurpation. From this to the more recent environmental relationships that claim to be a counterpoint to the destructiveness of global business agendas, Indigenous communities ground claims to autonomy and self rule in the continuity of connections to the land and indigenous knowledge which challenge and problematise existing legal-political notions of nation states (Muehlebach, 2001).

For Anderson (1983), connecting to local knowledge provides the basis of resistance to superimposed notions of 'nationhood'. Ethnic Christianities such as the Batak Church became fortresses from which ethnic nationalistic impulses could be launched (Anderson 1983, p.170). Friedman (1994a) has described how Indigenous Peoples have redefined the cognitive status of indigenous knowledge 
continuities which have legitimised claims to an earlier Indigenous 'nation' and strengthened a collective indigenous Hawaiian identity within the larger US Nation State (Friedman, 1994a). However holistic cosmologies do not only provide grounds for resistance and nation building: 'cultural elements and the logic that binds can and do act as tools of resistance, yet their power derives from their unifying quality, a quality based at least as much on continuity as on resistance to an Other' (Fischer, 1999 p:488). The integrative and coordinating features of indigenous knowledge continuities are fully explored in later case study chapters.

Unsurprisingly perhaps, nation states have responded by seeking to re-impose fixed national political-legal constructs which emphasise the existing status quo, whilst negating any alternative claims Indigenous Peoples have. Further as Durie (2003) notes, although more and more nations are ratifying these WGIP definitions and statements, they remain at best moral directives, which have no basis in nation states' own legal jurisdictions (Durie, 2003). These selfdefinitions of indigenous in the activism context have proved problematic not just to nations, but also to Indigenous Peoples themselves. Debates between many of the member participants contest the terms by which indigenous is defined. In an effort to emancipate, the very term indigenous can become itself exclusive, as:

the question has been raised whether Indigenous Peoples need to be first peoples in the narrow sense, and whether there is not a need to go beyond 'beyond the Columbus context' and into histories of non-Western Colonisation (Muehlebach, 2001 p:430). 
Despite this, newcomers to the scene at the WGIP are redefining the territory for debate, and refocusing on the critical engagement with the legal-political construction of the nation state. Nor are these relationships essentially fixed: 'the people inhabiting these places are presented as mobile rather than immobilized, their identities relational rather than bounded, and their loyalties overlapping rather than linked to bounded territories only' (Muehlebach, 2001 p:440).

\subsubsection{Constructing Indigeneity in Anthropology}

Constructionist anthropologists have examined how Indigenous Communities build indigenous identity using indigenous knowledge to create political agency within the milieu of globalisation. Drawing from notions of strategic essentialism, Greene, Banerjee, et al. (2004) theorise indigenous identity, where Indigenous Peoples represent themselves as an essentially fixed point of identity upon which indigenous politics are strategically based. In this case, Indigenous Peoples construct their own histories from sub-national ethnic identities as a basis from which political engagement occurs, in the fulcrum of globalisation.

Indigenous Peoples publicly embrace the virtues of indigenous cultures in ways that portray them as relatively fixed and identifiable wholes associated with delimited ethnic collectives / territories and specific histories [which gives] validity to the historically specific sub-national ethnic identities on which much global indigenous politics is based (Greene, Banerjee et al., 2004 p:213).

Relatedly, Benedict Anderson (1983) defines an imagined political collective as a nation, which, for the purposes of this thesis, supports a theorising of an indigenous national imaginary.

In an anthropological spirit, then, I propose the following definition of the nation: it is an imagined political community - and imagined as both inherently limited and 
sovereign. It is imagined because the members of even the smallest nation will never know most of their fellow-members, meet them, or even hear of them, yet in the minds of each lives the image of their communion. (Anderson, 1983 p:5).

Fischer (1999) sets out to show how indigenous Mayan identity has been constructed in relation to globalisation. However, almost to his surprise, Fischer instead finds indigenous identity is not formed in reaction to globalising impulses as Sillitoe (1998) suggests, but by reference to indigenous knowledge continuities, in this case a Mayan holistic cosmology, which is ancient in source, and territorially located. He found Indigenous Peoples in the Mayan context ground their indigenous identity in deep indigenous knowledge continuities to reclaim a strategic essentialism in the form of an authentic essence. Fischer locates indigenous knowledge continuities - what he calls the 'cultural logic' of the group - as the stable vehicle through which identity is inter-generationally transmitted and constructed. Comparing the Mayan with a number of other cultures, the cultural logic of indigenous identity construction for Fischer 'appears to be based on conceptions of metaphysical balance and a sacred covenantal relationship between individuals and cosmic forces' (Fischer, 1999 p:488). Cultural logic is defined as 'generative principles expressed through cognitive schemas that promote inter-subjective continuity and are conditioned by social, political, and economic contingencies' (Fischer, 1999 p:474). Indigenous identity is theorised to be constructed by individuals applying indigenous knowledge to the contexts of their own lived experience.

Maya culture is dynamically constructed. At the same time, innovation is constrained by aspects of an internalised cultural logic - a logic that is itself subject to change but that changes much more slowly than surface markers of identity (Fischer, 1999 p:488). 
In this way individually-experienced social change continues within stable indigenous holistic cosmologies. This continuity has been theorised in notions of authenticity.

\subsubsection{Authentic Indigenous Identity}

Within anthropology concepts of authentic identity are developed in relation to notions of indigeneity. These concepts underpin strategic and political purposes by both colonial elites and Indigenous Peoples. Wolfe (1999) proposes repressive authenticity as a strategy of representation. Colonial elites render Indigenous Peoples 'inauthentic' by comparing them to a romantic construction produced by the elites to locate authentic Indigenous Peoples as only inhabiting 'natural' indigenous spaces which also happen to be other than the settler inhabited economic and social centres of power (Wolfe, 1999 pp.173-181).

Authenticity also centrally explores the subjective construction of identity by Indigenous Peoples themselves. For Friedman (1994a) authenticity is defined as the subjective construction of identity through identification between the individual and a broader social life-project, a key definition used for this thesis. He posits authenticity in the positive as being in relation to the ongoing construction of subjectivity, which is 'the existential relation between subjects and the constitution of a material world' (Friedman, 1994a p:145). What he terms a traditional identity forms with the aims and goals of the individual's life project 
emerging within a social structure that is intimately connected to a broader holistic cosmology.

Where the modern has his self, or ego, as the locus of his life project's authority, the tendency in traditional societies is that the project and its authority exist external to the human subject, in the larger social network and its cosmological principles (Friedman, 1994a p:172).

Fischer's (1999) term cultural logic describes the development of authentic subjective experience in the relationship between the individual and a larger social project. In this fulcrum indigenous knowledge is learned, enacted, adapted but also constrained. Indigenous knowledge, when enacted in life-projects, builds authentic identity for Indigenous Peoples, the aspects of which, whilst continuous, are adaptive to each social context.

Fischer's (1999) study also reveals that indigenous knowledge and not global contexts form indigenous identity, knowledge which is not fragmented, as Spivak (1987ab, 1994) has proposed, although indigenous knowledge does underpin strategic and nation-building political agendas. Instead, the continuity of indigenous knowledge underpins the essence of identity, learned and enacted within life-projects increasingly connected to a holistic cosmology emphasising harmony and balance between the people and the land. This is a key working definition which is used for the pragmatic purposes of this thesis taken from these artefacts, as it aligns most succinctly with social phenomenology by describing how indigenous knowledge continuities forms identity and coordinates action. I also draw from other constructionist anthropologists. 


\subsection{Indigenous Definitions Used in This Thesis}

Exemplar constructionist theorists Anderson (1983), Fischer (1999), Friedman (1994ab) and Muehlebach (2001) suggest indigenous actors define their identities by profound connection to relegitimised holistic cosmologies and not global or colonial contexts. These definitions emphasise actors' reconnecting in powerful ways to holistic cosmologies, their own land and communities in living relationships to both their own history and future. Indigenous actors use knowledge and identity to provide resistance to both globalising pressures and the imposition of political-legal 'national' constructs, as well as a unifying source of 'collective' indigenous imaginings (Anderson, 1983; Fischer, 1999). Despite claims that these identity constructions are a new essentialism Muehlebach (2001) argues that in living communities where identity is constructed and defined as a matter of course, it is dynamism and not stasis that characterises indigenous identity construction. For the purposes of the thesis I use definitions of indigeneity which draw from constructionist anthropology and align with social phenomenology to examine how indigenous knowledge and identity is formed by Indigenous Peoples themselves. I focus on how knowledge continuities or 'cultural logics' within holistic cosmologies builds indigenous identity and directs social agency, while exhibiting both continuity and change. Table 2 below illustrates a sample of the key definitions chosen as artefacts for this thesis, but the reader is encouraged to follow these key authors to understand each definition in its original context. 
Table 2: Definitions of Indigeneity Applied

\begin{tabular}{|c|c|c|}
\hline Indigeneity & Key Concept & Specific Definition \\
\hline $\begin{array}{l}\text { Authentic. } \\
\text { (Friedman,1994a) }\end{array}$ & $\begin{array}{l}\text { Authenticity is defined as the } \\
\text { subjective construction of identity } \\
\text { through identification between the } \\
\text { individual and a broader social } \\
\text { life-project, within a holistic } \\
\text { cosmology. }\end{array}$ & $\begin{array}{l}\text { Authenticity is 'the existential relation } \\
\text { between subjects and the constitution of } \\
\text { a material world' (Friedman, 1994a } \\
\text { p:145). 'The project and its authority } \\
\text { exist external to the human subject, in } \\
\text { the larger social network and its } \\
\text { cosmological principles' (Friedman, } \\
\text { 1994a p:172). }\end{array}$ \\
\hline $\begin{array}{l}\text { Strategic essence. } \\
\text { (Muehlebach, } \\
\text { 2001). }\end{array}$ & $\begin{array}{l}\text { Indigenous Peoples express their } \\
\text { strategic essence within and } \\
\text { through connections between } \\
\text { holistic cosmologies and the land } \\
\text { itself. }\end{array}$ & $\begin{array}{l}\text { 'interconnectedness, morality, myth, } \\
\text { belonging and sacredness which are as } \\
\text { old as colonialism itself' (Muehlebach, } \\
2001 \text { p:417). }\end{array}$ \\
\hline $\begin{array}{l}\text { Coordinating } \\
\text { functions of } \\
\text { indigenous } \\
\text { knowledge. }\end{array}$ & $\begin{array}{l}\text { Knowledge continuities which are } \\
\text { the stable vehicle through which } \\
\text { identity is inter-generationally } \\
\text { transmitted and constructed. } \\
\text { Coordinating and integrating } \\
\text { features of indigenous knowledge. }\end{array}$ & $\begin{array}{l}\text { Cultural logic is 'generative principles } \\
\text { expressed through cognitive schemas } \\
\text { that promote inter-subjective continuity } \\
\text { and are conditioned by social, political, } \\
\text { and economic contingencies' (Fischer, } \\
1999 \text { p:474). } \\
\text { 'conceptions of metaphysical balance }\end{array}$ \\
\hline $\begin{array}{l}\text { Covenantal } \\
\text { relationships. } \\
\text { (Fischer,1999) }\end{array}$ & $\begin{array}{l}\text { Covenantal cosmological } \\
\text { principles which guide action } \\
\text { towards ecological harmony and } \\
\text { balance. }\end{array}$ & $\begin{array}{l}\text { and a sacred covenantal relationship } \\
\text { between individuals and cosmic forces' } \\
\text { (Fischer, } 1999 \text { p:488). }\end{array}$ \\
\hline $\begin{array}{l}\text { National } \\
\text { imaginings. } \\
\text { (Anderson, 1983) }\end{array}$ & $\begin{array}{l}\text { An imagined political collective } \\
\text { as a nation, which supports a } \\
\text { theorising of an indigenous } \\
\text { national imaginary. }\end{array}$ & $\begin{array}{l}\text { 'the nation... is an imagined political } \\
\text { community.. because the members of } \\
\text { even the smallest nation will never know } \\
\text { most of their fellow-members, meet } \\
\text { them, or even hear of them, yet in the } \\
\text { minds of each lives the image of their } \\
\text { communion.'(Anderson, } 1983 \mathrm{p}: 5 \text { ) }\end{array}$ \\
\hline
\end{tabular}

Having seriously considered the alternatives, these definitions were selected for the purpose of this thesis because:

a) they prioritise Indigenous Peoples' own self definitions as the major focus of attention;

b) they align with social phenomenology in focussing on knowledge continuities or holistic cosmologies as the working dynamics which underpins indigeneity;

c) they support an enabling theorisation of indigeneity in an ongoing way; 
d) they do not presuppose a single universal definition to apply to every context, which has been shown to be problematic; and

e) they suggest a process-based approach to explain the construction of indigenous identity, and the indigenous organisation, within the context of a holistic cosmology.

Other definitions were considered from both colonial and postcolonial theorists. The literatures presented suggest colonial anthropology has classified a fixed definition and inferior status to the natives, legitimising assimilation as the most efficient means of development. Within postcolonial literatures indigenous knowledge and identity has been theorised to be constructed within the colonial encounter, and has been subject to inferiorisation. This literature suggests empowerment can be achieved through this awareness alone. Objective anthropology has classified stages of development to tribal and Indigenous Peoples, and has proposed fixed universal definitions, which have also become exclusive or problematic. Table 3 (below) assesses the strengths and weaknesses of each literature, while Table 4 (after) summarises indigeneity at the three levels used throughout the thesis. 
Table 3: Definitions of Indigeneity Assessed

\begin{tabular}{|c|c|c|}
\hline $\begin{array}{lll}\text { Indigeneity } & \text { Defined } & \text { in } \\
\text { Literatures } & & \end{array}$ & Focus & $\begin{array}{l}\text { Strength }(\mathrm{S}) / \\
\text { Weakness }(\mathrm{W})\end{array}$ \\
\hline $\begin{array}{l}\text { Colonial and Imperial: } \\
\text { 'Native' 'Aboriginal' } \\
\text { (Said, 1978;1994; Wolfe, } \\
\text { 1999) }\end{array}$ & $\begin{array}{l}\text { Primitive and barbarian } \\
\text { nature of } \\
\text { 'native' as opposed to the } \\
\text { civilising influences and } \\
\text { advancement of the settlers. }\end{array}$ & $\begin{array}{l}\text { S: To fix identity. } \\
\text { W: Devalues and denigrate } \\
\text { epistemologies, to classify as } \\
\text { backwards to legitimise } \\
\text { colonialism as development. }\end{array}$ \\
\hline $\begin{array}{lll}\text { Postcolonial: } & & \\
\text { 'Oriental' } & \text { 'Tribal' } & \text { and } \\
\text { 'Subaltern' } & \text { (Said, } & 1978 ; \\
\text { Spivak, 1987ab;1988) } & \end{array}$ & $\begin{array}{l}\text { Identity construction by the } \\
\text { colonial. }\end{array}$ & $\begin{array}{l}\text { S: Reveals colonial identity } \\
\text { imbrication. Claims space for } \\
\text { the indigenous. } \\
\text { W: Indigenous constructed by } \\
\text { the coloniser. }\end{array}$ \\
\hline $\begin{array}{l}\text { Anthropological: } \\
\text { 'Native', 'Aboriginal' } \\
\text { (Beteille, 1998; Sillitoe, 1998) }\end{array}$ & $\begin{array}{l}\text { Classification of stages of } \\
\text { development: primitive to } \\
\text { civilised. }\end{array}$ & $\begin{array}{l}\text { S: to fix identity, to support } \\
\text { distant construction of 'other'. } \\
\text { W: reinforces colonial 'nation' } \\
\text { supremacy. }\end{array}$ \\
\hline $\begin{array}{l}\text { Constructionist: } \\
\text { 'Authentic' 'Indigenous' } \\
\text { (Anderson, 1983; } \\
\text { Fischer,1999; } \\
\text { Friedman,1994ab, } \\
\text { Muehlebach, 2001) }\end{array}$ & $\begin{array}{l}\text { Knowledge continuities in } \\
\text { context of land, community } \\
\text { and holistic cosmologies. } \\
\text { Adaptive 'cultural logics' } \\
\text { update indigenous } \\
\text { knowledge. }\end{array}$ & $\begin{array}{l}\text { S: to reclaim adaptive identity } \\
\text { through holistic cosmologies. } \\
\text { W: To create ongoing processes } \\
\text { of indigeneity, avoiding fixed } \\
\text { definitions. }\end{array}$ \\
\hline
\end{tabular}

Table 3 (above) summarises indigenous definitions as seen in four main literatures, describing the major focus and strengths and weaknesses relating to how these applied definitions could support the theorisation of the indigenous organisation. As discussed, constructionist definitions were chosen because they align most closely with social phenomenology and can therefore illuminate the ongoing processes of organising and how they are updated by Indigenous Peoples themselves. This constructionist lens enables the theorisation of the agency of Indigenous Peoples as a living empowered community as the central focus, rather than as peoples constructed by a dominant other or within a single all encompassing objective definition which is fixed in language. 


\title{
Table 4: Mapping 'Indigeneity' at Three Levels
}

\author{
Indigeneity at the individual level in OS and wider literatures:
}

Identity constructed in relation to coloniser; identity fragmentation causes poor health outcomes (Banerjee, 1999; Banerjee and Linstead, 2001, 2004).

Leaders framed in terms of: exhausted resistance (Banerjee, 1999); protecting fragile 'traditional' practices in ecological settings (Whiteman and Cooper, 2000).

Individual agency framed in terms of: workplace resistance (Prasad, 2003; Elmes and Prasad, 2005); adaptation despite colonial effects (Foley, 2004); maintaining traditional practices (Whiteman and Cooper, 2000).

Indigenous knowledge: enacted in relation to traditional individual practices (Whiteman and Cooper, 2000); fragmented by colonialism (Banerjee, 1999; Banerjee and Linstead, 2001; Banerjee and Linstead, 2004); remains a source of indigenous imaginings in resistance and identity continuity in neo-colonial contexts (Elmes and Prasad, 2005).

'Indigeneity': defined in postcolonial (Said, 1978, 1994; Spivak, 1987ab,1988,1993) and anthropological literatures (Battiste, 2000; Beteille, 1998; Fischer, 1999; Muehlebach, 2001; Wolfe, 1999).

\section{Indigeneity at the organisational level in OS}

Theory: Remains a missing voice in OS research (Ghopal, 1999); Theories and in depth cases of organisational indigeneity called for (Henry, 1994; Jaya, 2001);

Celtic organisations: small case study (Johnston \& Scholes, 2001); gap in literature. Māori organisations: often historically formed through Government directives (Henry, 1994); exhibits historic and current adaptiveness and entrepreneurialism (Love and Waa, 1994); are permeated by spirituality linked to a holistic cosmology (Henare and Lips-Wiersma, 2002); exampled through the Kura Kaupapa and Wānanga projects (Henry and Pene, 2001).

International research: indigenous entrepreneurs dealing with racist business practices (Foley, 2004); 'traditional' Cree management practices struggling to maintain their authenticity (Whiteman and Cooper, 2000); an uncritical perspective on 'global' environments (Banerjee and Linstead ,2004).

\section{Indigeneity at the social level in OS and wider literatures}

Indigeneity in OS at social levels: overwhelmed by powerful global forces (Banerjee, 1999; Banerjee and Linstead, 2001); faces continuities of colonial practices (Prasad, 2003); is continually affected by poor community health outcomes (Banerjee, 1999); has lost links to indigenous knowledge through colonialism (Foley, 2004); uses indigenous knowledge to: imagine reclaimed indigenous landscapes (Elmes and Prasad, 2005); build community capacity and capability (Henry and Pene, 2001).

Indigeneity as understood in globalisation and critical globalisation literatures: Globalisation: fragments holistic cosmologies; constructs identity as consumer (Friedman, 1994ab; Lash and Friedman, 1992; Ohmae,1995ab); is itself in decline (Ralston Saul, 2004, 2005).

Critical: holistic cosmologies are re-emerging with a 'sense of place' and ecological principles: are increasingly being recovered and enacted in reaction to globalisation (Crossley, 2003; Ralston Saul, 2004, 2005; Sklair, 2002). 


\subsection{Summary}

During the rise of globalisation indigenous knowledge and identity has been subsumed within economic solutions of development which have profoundly fragmented holistic cosmologies, to be replaced with consumerism and the always-incomplete search for the use of the next product (Friedman, 1994ab; Lash and Friedman, 1992; Ralston Saul, 2005). As a result of this separation, alienation has resulted in a renewed search for ethnicity and social projects, even if these are the modernist equivalents of the prior holistic cosmologies. Reconnections to indigenous knowledge and place have been posited as signs of an emerging 'globalisation's other', which, taken together with new social movements, articulates new forms of relations based beyond the economic (Ralston Saul, 2005). Even here, globalising forces remain to commodify and profit from indigenous knowledge. Seen in social context, globalist practices remain pervasive, and often define the terms of development for indigenous organisations. Countering this, OS researchers have called for alternative spaces which recast positive alternatives to globalisation (Banerjee and Linstead, 2004). Positive cases of indigenous organisation and leadership have been called for (Jaya, 2001). While little research exists on the Celtic organisation, researchers have identified how Māori knowledge and spirituality underpins the Māori organisation, despite its often institutional origins (Henare and Lips-Wiersma, 2002; Henry, 1994). Kaupapa Māori cases, notions of indigeneity and Whāre Wānanga in particular have been introduced to OS but not yet fully theorised (Henry and Pene, 2001). Exemplar OS researchers theorise indigenous identity to 
be constructed within a holistic cosmology and through ongoing relationships to the land (Whiteman and Cooper, 2000). However accounting for history reveals incongruities and impacts of neocolonialism which continues to fragment relationships to holistic cosmologies, and land (Banerjee and Linstead, 2001, 2004).

In the following chapters the above literatures as artefacts are used to explore indigenous identity construction, with a specific focus on the relationships found within holistic cosmologies. The later chapters also explore the underlying relationships between these cosmologies and the historic and current contexts, examining processes of change, following constructionist definitions of indigeneity. Notions of authenticity are examined to understand the effects of, and pressures on, indigenous knowledge at the organisational level. These are examined not only for any evidence of colonial imbrications but also for evidence of how indigenous knowledge acts to enable organisational coherence. These chapters finally review competing identity claims to explore sites of alternative indigenous imaginings. The next chapter proposes a theory which describes how holistic cosmologies provide knowledge and practices which guide action at the organising level, and form identity for all cultural groups, supporting the working definitions of indigeneity in the later case study research. 


\title{
Chapter 3: Organising Knowledge
}

\begin{abstract}
Man [sic] is born into a world that existed before his birth; not merely a physical but also a socio-cultural one. The latter is a pre-constituted and pre-organised world whose particular structure is the result of an historical process and is therefore different for each culture and each society (Schutz, 1970 p:79).
\end{abstract}

\subsection{Introduction}

In this thesis I use constructionist definitions of indigeneity to illustrate how indigenous actors use knowledge continuities to underpin identity, organising and social action. Indigenous knowledge is defined as the inter-generationally transmitted knowledge of indigenous communities (Fischer, 1999). As the above quote from Schutz (1970) suggests, this use of knowledge is common to each culture and society. This chapter aims to describe social phenomenology, and how actors use knowledge to organise at three levels: from an individual's identity; to the artful means of organising; and up to the creation and transmission of holistic cosmologies at the social level. At each level the theory premise is linked to method, discussed in full in the next chapter.

I firstly introduce social phenomenology and describe how local knowledge underpins individual and group identity. I then illustrate how concepts handed down from previous generations are transmitted through language. These concepts can be artfully drawn on to organise, and to construct the wider organising context. However mechanisms and functions, including those of the leader, are required to maintain knowledge validity at the social level, where competing knowledge claims seek to challenge the validity of local knowledge. 


\subsection{Social Phenomenology in Philosophical Context}

Phenomenology in its philosophical form is a complex set of ideas loosely defined as a tradition which 'holds consciousness to be the matrix of all phenomena' (Burrell and Morgan, 1979 p:232). This multi-faceted philosophical tradition, ranging from Husserl to Heidegger, Jean-Paul Sartre and Maurice Merleau-Ponty, has a broad commitment to understanding the complex taken-for-granted lifeworld of lived experience from the point of view of those who live it (Popkin, 1999; Shwandt, 1996). The major premise of this position is that the lifeworld is itself constructed by social actors through whom meaning-making processes occur (Burrell and Morgan, 1979).

For phenomenologists such as Husserl, the ontological (the nature of being) and epistemological (the nature of knowledge) basis of a singular objective reality and externally existing knowledge is problematic. Instead individual or social subjectivity and consciousness is theorised as the basis of the construction and development of knowledge. Husserl's individual phenomenology begins with the premise of transcendental idealism, or that the origins of knowledge are an original idea (Nantson, 1970). This position has been widely criticised as tending towards 'radical subjectivism' or the belief that any subjective reality is as valid as any other, reducing the world to meaninglessness (Burrell and Morgan, 1979). Schutz rejects Husserl's radical subjectivism and proposes a pragmatic solution to the origins and maintenance of knowledge, called inter-subjectivity. Knowledge does not reside outside of social groups in a supposed transcendental realm but is 
constructed and adapted within and between members. Knowledge is the ongoing assessment of what works in each socially defined environment, based on actors' collective, inter-subjective experiences: hence social phenomenology. I use this concept in the thesis to frame indigenous knowledge and explore it within its social context. I next unpack social phenomenology in more detail, with an accent on its application.

\subsubsection{Social Phenomenology in Application}

Schutz (1970) proposes that individuals are born into pre-constituted worlds essentially different for each culture. Actors are socialised into their local versions of the world and receive knowledge of and about this world. Schutz' social phenomenology describes this source of knowledge in local contexts as epistemology (the nature of knowledge), and how such worlds are knowable as ontology (the nature of being) addressing the meaning-making processes at work in enacting local knowledge (Schutz, 1964, 1967, 1970, 1973). Social phenomenology theorises interconnected levels of individual, group or organisational and social knowledge. I deploy social phenomenology at these three levels to frame indigenous knowledge and identity construction, as well as challenging the validity of taken-for-granted assumptions within global knowledge. At the highest level, I describe indigenous knowledge as epistemologies, or for the purposes of the thesis, holistic cosmologies, placing indigenous knowledge in its largest form within cultural, social and political 
contexts. This use of social phenomenology is illustrated in Table 5 (below)

noting the heuristic separation of levels of analysis shown with a dashed line.

Table 5: Theory, Premises and Research Methods at Three Levels.

\begin{tabular}{|c|c|c|}
\hline Theory Level & Theory Premise(s) & Research Methods \\
\hline $\begin{array}{l}\text { Individual: Identiy } \\
\text { Berger and Luckmann } \\
\text { (1966), Schutz (1967, 1970, } \\
\text { 1974). }\end{array}$ & $\begin{array}{l}\text { Individual knowledge: } \\
\text { received and expressed } \\
\text { through language, co- } \\
\text { constituting identity and } \\
\text { individual action within } \\
\text { lifeplans. }\end{array}$ & $\begin{array}{l}\text { Individual interviews, focus } \\
\text { groups } \\
\text { participants exploring } \\
\text { making construction and } \\
\text { enactment of 'being } \\
\text { indigenous. }\end{array}$ \\
\hline $\begin{array}{l}\text { Organisational: Organising } \\
\text { Berger and Luckmann } \\
\text { (1966), Garfinkel (Heritage, } \\
\text { 1980), Schutz (1967, } 1970 \\
\text { 1974). }\end{array}$ & $\begin{array}{l}\text { Organising as a process } \\
\text { constituted through meaning- } \\
\text { making processes using social } \\
\text { stocks of knowledge enacted } \\
\text { and updated through accounts } \\
\text { and accounting practices. }\end{array}$ & $\begin{array}{l}\text { Interviews, participant } \\
\text { observation, archival } \\
\text { analysis exploring how } \\
\text { meaning is constructed and } \\
\text { maintained by actors at the } \\
\text { organisational level, } \\
\text { observing and theorising } \\
\text { how indigenous knowledge } \\
\text { underpins both organising } \\
\text { and the organisation. }\end{array}$ \\
\hline $\begin{array}{l}\text { Social:Holistic Cosmologies } \\
\text { Berger and Luckmann } \\
\text { (1966) Schutz (1967, 1970, } \\
\text { 1974). }\end{array}$ & $\begin{array}{l}\text { Knowledge strategies: } \\
\text { Legitimising } \\
\text { delegitimizing } \\
\text { inside and outside the } \\
\text { organisation. }\end{array}$ & $\begin{array}{l}\text { Interviews, observation, } \\
\text { archival analysis assessing } \\
\text { how indigenous knowledge } \\
\text { legitimises and is } \\
\text { delegitimised by actors in } \\
\text { their social and historical } \\
\text { contexts. }\end{array}$ \\
\hline
\end{tabular}

\subsection{Individual Knowledge Construction and Transmission}

Schutz (1970) proposes that consciousness constitutes knowledge, as each individual experiences and co-constitutes the lifeworld in the context of the social group to which they belong. Schutz (1973) defines knowledge as the accumulated (but never total) build up of prior 'sedimented' (internalised) experience of the individual. Knowledge is simply 'what works' for the individual within their situated local community as they share and update their taken-for-granted local knowledge: 
Understanding of the world is based at any given time on a stock of previous experience: my own immediate experiences as well as such experiences as are transmitted to me by my fellow men and above all by my parents, teachers, and so on (Schutz, 1973 p:7).

Schutz (1973) posits that knowledge of the world is pre-given and pre-interpreted to individuals who, through socialisation, internalise not only the socially constructed and maintained epistemology of the group, but also the interpretive schema within which these epistemologies reside. He defines these experiences collectively as the stock of knowledge "which serves me as the reference schema for the actual step of my explication of the world' (Schutz, 1973 p:7).

Individuals construct and experience meaning through interpretation, which Schutz (1967, p: 84) defines as the 'referral of the unknown to the known'. Lived experience is interpreted by reference to local knowledge as the source of meaning-making materials. This premise frames a focus on members' intergenerationally transmitted indigenous knowledge, explored using qualitative methods.

In the case study one example of this is how TWoR defines Māori knowledge. Mātauranga Māori as a concept defines not only knowledge for the university, but also the way Māori knowledge is used, embellished and updated through such use. This definition works in the context of being a university, but also maintains the active and adapted use of the term 'mātauranga' in the process. 
Schutz proposes that epistemologies are transmitted and internalised primarily through three central and connected ideas: 1) typification as the process whereby individual experience is made typical (made a type), 2) language as the medium of communication and construction of typifying objects, and 3) inter-subjective agreement as the means where objectifications are commonly agreed. Each of these is taken in turn.

\subsubsection{Typification}

Schutz (1973) proposes that human consciousness typifies (makes typical) the systems of relevances central to any social group. Typification is defined as 'a relation of determination' (Schutz, 1973 p:230) which is the process of naming and classifying an object and inscribing it with properties. These processes select what socially-derived knowledge is relevant to a community (what works) and how they suggest action. Over time the object and its properties become socially accepted based on its ability to offer practical solutions to problems at hand. This classification then becomes removed from the original context of meaning and held in type. Redefinition can take place where hidden aspects of meaning in the original definition become clearer, or where the original definition no longer works. This premise is used to examine how differing groups in differing contexts have made typical (defined) their understanding of being indigenous but with very different practical outcomes based on each definition and the properties attached. These definitional strategies have been used to both legitimise and delegitimise a variety of practices. 


\subsubsection{Language: Constructing and Transmitting Worlds}

Typifications are not externally existing objects to be described in language, but are socially accepted objectifications constituted through language. If typification is a central process to knowledge construction, then it is through actors' language that knowledge is transmitted: 'the typifying medium par excellence by which socially derived knowledge is transmitted is the vocabulary and syntax of everyday language' (Schutz, 1970 p:96).

In the vernacular of everyday life lies not only named things and events but also the very typifications that generalisations refer to: the relevance systems of the group. Within these systems reside the named and commonly agreed objectifications of the group. Language contains within it a treasure house of preconstituted types within socially derived epistemologies, awaiting application in the concrete ontic particulars of each situation.

This premise is used to examine deeper knowledge accessed through language. For those advancing in their studies at TWoR, deeper language capabilities allowed for deeper access to Māori knowledge: at higher and higher levels in the university more and more sophisticated use of Te Reo was both expected and required. Knowledge of Māori concepts were transmitted through this language and internalised and realised in the concrete realities of each situation, ranging from discussing classroom assignments, through to the inter-tribal negotiations required to gain acceptance and develop marae-based studies. Returning to theory, 
Schutz (1970) reconciles the question of the existence of individual versus socially derived group knowledge without presupposing an objective reality that validates and sustains knowledge.

\subsubsection{Inter-subjectivity}

Schutz (1970) posits that socially derived or pre-constituted knowledge which is transmitted through language assumes and requires inter-subjective agreement between people. This agreement between differing subjectively experiencing individuals is solved in a practical, mundane and ongoing fashion by actors in social settings who make two central assumptions, that:

1. Their views and experiences within their own unique spatio-temporal positions, if they were to swap with someone (in the same position) would be roughly the same as the other, and

2. Until proven otherwise, the differences in their unique biographic histories are irrelevant for the purposes at hand. They have both selected and interpreted the same 'empirical objects' in a manner sufficient for practical purposes.

Despite actors never having the same subjective experience of anything, they routinely assume that their experiences, and interpretations, are similar and act as if they are identical for all practical purposes. Remaining essentially within social phenomenology, Schutz (1970) proposes that there still is no guarantee of an externally-existing common world beyond these practical assumptions. 
This premise is used to examine how consensus at the organisational level was dependent on the strategic and practical aims and goals of the organisation being met. However, competing strategies were often also proposed. Ultimately agreement was based on consensus after discussion, but the goal of practical and pragmatic outcomes were a driving force in gaining and sustaining intersubjective agreement.

\subsubsection{Epistemologies}

Inter-subjectively agreed knowledge is socially transmitted as an epistemology. This technical concept supports the working term holistic cosmology, which is defined by Ladson-Billings (2000) as the living use of indigenous knowledge in its largest form. For Schutz (1970, p:82) epistemologies are 'systems of relevancies and typifications'. These are socially-defined interpretive schemas of what works, which are embedded and transmitted as part of the social heritage handed down in the education process to members of a group or community (Schutz, 1970 p.20). Local stocks of knowledge are expressions of, and in continuity with, epistemologies that are passed down from generation to generation, by individuals routinely assuming that this knowledge holds for all practical purposes.

Epistemologies are the everyday stocks of knowledge of the world as it is coconstituted, and experienced, named and transmitted through social, historical and linguistic contexts. Schutz (1970) assumes knowledge is prioritized according to 
situated practical or theoretical interests, which selects and constitutes the stock of knowledge at hand. These local knowledge traditions, or 'folkways' (1970 p:80) contain central ideas about a cosmology and the place of humanity within it. Schutz (1970) posits that principles contained within cosmologies establishes the socially accepted course of actions for individuals and groups: 'the social world constitutes the folkways of the in-group, which are socially accepted as the good ways and the right ways for coming to terms with things and fellow men[sic]'(Schutz, 1970 p:80).

Epistemologies contain many assumptions about how actors define and relate to the local environment. These recipes for action ensure that the values and social ideals of the group are handed down: 'this includes ways of life, how to come to terms with the environment, efficient recipes for the use of typical means for bringing about typical ends in typical situations' (Schutz, 1970 p:96).

Epistemologies ultimately define and describe a whole social world of fully differentiated perspectives, describing what is important, how the environment is interacted with and what the common and typical solutions to common or typical problems are. Accessed via qualitative methods, I focus on how indigenous groups in each context define themselves in relationships to their environments, which are imbued with a living essence. Relationships to the environment, in a literal sense, define many actions and principles. Not only are rules for actions and interactions handed down, but also the very schemes of interpretation. 
These folkways constitute the social heritage which is handed down to children born into and growing up within the group. This is so, because the system of folkways establishes the standard in terms of which the in-group defines its situation (Schutz, $1970 \mathrm{p}: 80)$.

Epistemologies are transmitted through various forms, from parents, kin based relationships, systems of symbol and meaning, and institutional forms of social organisation.

The social world into is experienced by him as a tight knit web of social relationships, of systems of signs and symbols with their particular meaning structure, of institutionalised forms of social organisation, of systems of status and prestige, etc. (Schutz,1970 p:80).

Institutions play a key role in transmitting and protecting this knowledge. In Section 3.7 the roles of institutions (and the leadership roles that accompany these) are more fully dealt with, underpinning a specific focus on indigenous leadership in this thesis.

\subsubsection{Identity}

Our identity (how we construct 'us' as selves) happens through the often takenfor-granted phenomenological reflection on our own ontic reality in relation to epistemologies transmitted by those around us, which are subsequently internalised and objectified as reality. Passing on interpretive schemas through socialisation gives individuals not only the knowledge of what a social group defines as significant, but also the very resources from which their identity, understood as their own experienced biography, is developed.

For the social construction of biography, not only the typifications of biography itself are relevant, but also the valuing interpretations of the social world superimposed on them in the system of typifications; they are expressed in legitimations of social institutions, laws, recipes for acts, and govern social action on various levels of anonymity (Schutz, 1973 p:93). 
Thus, at the base level of identity formation, the very categories of biographical articulation 'are not really categories of inner duration but are rather... intersubjectively constructed categories handed down within the relative natural world view'(Schutz, 1973 p:94).

While individuals always operate with free will (non-essentialism), their 'biographic horizon' is indelibly constructed and inscribed with, and from, these socially derived influences. Extending this concept of identity, the individual and the socio-cultural environment are mutually co-constructing (Berger and Luckmann, 1966 p.194). The individual is constructed by the social relations around them, while they co-constitute these very social relations by accepting them as legitimate or otherwise. Social systems emerge as the sum total of individual identities that together play a greater or lesser role in defining, or redefining systems. Further since identities are themselves constructed within a cosmology, reference to identity cannot be understood as separate to the overarching cosmology through which they are constructed (Berger and Luckmann, 1966 p.195).

The above premise frames a discussion of identity construction, focussing on the individual phenomic experience of - and relationship to - indigenous knowledge, accessed via qualitative methods. Simply put, this thesis examines how members are constructed by, and themselves co-construct holistic cosmologies. At TWoR, for example, Māori students became reoriented to their Māori identity through the 
Te Reo Māori [the Māori language] and mātauranga Māori [Māori knowledge]. Within each of these, customs and practices enacted through genealogical rituals (whakapapa) routinely strengthen and embellish indigenous identity, as well as, by extension, co-constructing the world of Māori knowledge and tradition.

Thus individuals learn about and internalise socially derived knowledge and categories of knowledge within their socialised local contexts through language. Individuals remain free to choose knowledge as it meets their practical and theoretical interests, but such selections remain at the pre-theoretic level: knowledge deemed relevant is always knowledge chosen at the mundane level to solve practical and everyday problems at hand. Within these typifying schemas lie assumptions about socially legitimate actions that are valued and verified within tradition in terms of relationships to self, other and environment, within a holistic cosmology.

\title{
3.4 Enacting Knowledge at Group Levels
}

\begin{abstract}
Man finds himself at any moment of his daily life in a biographically determined situation, that is, in a physical and socio-cultural environment as defined by him, within which he has a position... not only his physical position or his status, but also his moral and ideological position (Schutz, 1970 p:79).
\end{abstract}

As the quote above, suggests, social groups define and make typical the nature and types of action deemed to be significant to the group including roles of significance and social problems (Schutz, 1970 p.120). These interests become subsumed within an individual's lifeplan to direct consciousness to maintain and 
develop certain aspects or domains of partial knowledge. The typifications deemed significant by the social group inexorably influence individuals. In Chapters 7 and 8 this premise frames research on the question of how indigenous knowledge is defined and experienced, accessed through active in-depth interviewing. Increasing exposure to, and enactment of, indigenous knowledge directs lifeplans of individual members. Within each case, I was struck by the reordering of individual's lifeplans as they became more deeply exposed to the principles within each holistic cosmology. These lifeplans profoundly changed from previously individualistic projects to those concerned with local group or community development.

\subsubsection{Group Membership}

Membership of a group depends on familiarity with a social stock of knowledge and the 'right' actions which emerge from this, 'the subjective meaning the group has for its members consists in their knowledge of a common situation, and with it common system of typifications and relevances' (Schutz, 1970 p:82). To gain access to a socially defined world means becoming familiarised with the principles and practices that are typified and why they are significant (Schutz,1970). Showing themselves competent to understand and enact common solutions to problems as knowledge within these typifications deems people competent to operate within the group. In each case this 'walking the talk' became a criterion for gaining membership and progression. 


\subsubsection{Knowledge Validity}

Because social phenomenology brackets a singular externally existing reality, notions of the validity of local knowledge are simply that it is proved to be working knowledge in each context. Schutz calls stocks of knowledge in their largest form a finite providence of meaning. These providences of meaning (for example the everyday lifeworld, the world of dreams, the world of science, and the world of religious experience) are not separately-existing equally or less equally valid versions of the reality. They are not objects whose truth is a function of their ontic existence, 'the orders of reality do not become constituted through the ontological structure of the objects but rather through the meaning of our experience'(Schutz, 1973 p: 23).

Enacting knowledge within such meaning experiences produces internally coherent actions, or a particular way of living or being consisting of internal regularities which flow from practice to principle and iteratively back to practice.

All experiences that belong to a finite providence of meaning point to a particular style of lived experience, viz a cognitive style. In regard to this style they are all in mutual harmony and are compatible one with another (Schutz, 1973 p:7).

The validity of the stock of knowledge is maintained through enacting 'what works' to provide consistency and compatibility between one's actions and the principles contained within a holistic cosmology. Members assume that this world will continue as it has been transmitted to them. 
The validity of knowledge is based on the ability of actors to repeatedly enact the past successful knowledge which was given, 'so long as the structure of the world can be taken as constant, and as long as my previous experience is valid, my ability to operate within the world in this way or that remains in principle preserved' (Schutz, 1973 p:7). Since these different providences of meaning do not achieve validity through their own ontic reality, the source of their authenticity for the individual rests on a fundamental ability of each providence to maintain unity or cohesion within each system of meaning. Consequently, any one providence of meaning cannot dominate or impose criteria for validity over another with regards to its criteria of harmony or compatibility: 'there is no possibility of reducing one finite providence of meaning to another with the help of a conversion formula'(Schutz, 1973 p:24).

Moving between providences of meaning is not impossible, but requires 'a leap which is nothing other than the exchange of one lived style of experience for another'(Schutz, 1973 p:24). The acceptance of a differing providence requires nothing less than the full relinquishing of the unities of a prior knowledge system and the adoption of the new. Such leaps are neither difficult, nor uncommon; throughout an ordinary day many of these transitions are made. Keeping an individual in one providence and not another is based on an individual's motivations within their life-plan.

Only when we are motivated by our life-plan to accept another attitude... only when we experience a specific 'shock' that bursts the limits of that which is for us momentarily 'real' must we transfer the accent on reality (Schutz, 1973 p:24). 
The biographically-determined practical or theoretical interest within the lifeplan of the individual directs and maintains the cognitive schemas of one providence or another, in the always present group context. This premise frames how 'multiple worlds' are concurrently engaged with, how members may enact principles and practices associated with 'global' practice and knowledge at the same time as operating in a larger indigenous holistic cosmology.

The member's interest foregrounds specific (but always questionably) relevant stocks of knowledge for the practical purposes of the task at hand, all the while seeking the ongoing concrete interpretation of a socially learned category to the specifics of a local situation. However, the application of knowledge as it is applied to new situations is never complete.

\subsubsection{Updating Stocks of Knowledge}

Missing, lost, or incomplete knowledge only becomes apparent when situations appear that the current stock of knowledge cannot solve (Schutz, 1973). This happens when the theoretical or practical interests of individuals within a society encounter situations outside their conceptual and interpretive schemas. Individuals within these situations learn and adapt their own stocks of knowledge. The actor has prior historic knowledge which has been learned through each member's own prior experience but this actor further faces an indeterminate and open future. The encountering of new situations requiring action illustrates the fragmentary and incomplete nature of knowledge. Through either conflict or 
comparison with other people's stocks of knowledge, gaps in one's own knowledge appear. Such gaps and learning involve the comparison with other sources of knowledge and their credibility. Amongst many different knowledge transfers Schutz (1973, p:176) identifies restorable knowledge, which is defined as 'prior knowledge that has either been lost or hidden by other knowledge', leaving its kernel. By contrast, the meaning context in which an element of knowledge exists can get lost although individual determinations of the object of experience remain. Logical connections between elements that were once established get lost (Schutz, 1973 p.176). Attainable knowledge is defined as:

Graduated according to its degree of attainability... it is established according to whether one can trace back specific gaps in one's own stock of knowledge... it is classified according to one's present state of interest (Schutz, 1973 p:177).

Lost, missing or hidden knowledge can be regained by the awareness of the gap, the level of interest in the attainment of the knowledge and the relative closeness of the knowledge to be recovered. This premise frames research into how indigenous knowledge is tested, updated, and challenged alongside competing knowledge claims, through participant observation and active interviewing. In both cases many instances occurred where the environment required actions which illustrated gaps in the current knowledge. Individuals with relevant global competence sought solutions from this knowledge. Conflict occurred where these solutions were deemed inauthentic in relation to the principles and practices of the holistic cosmology and identity of the institution. The institutions themselves, however, also challenged groups in their own knowledge updating processes. Each case challenged entrenched practices with innovative concepts to work 
better, leading to the creation of new, valid indigenous knowledge within broader communities of practice. Actors' understanding is constituted and transmitted through language which contains the typifications of the cumulative knowledge and interpretive schema inherited from the social group. This knowledge is dialectically passed through socialisation and through internalisation, constructs the individual.

This knowledge includes assumptions directly bearing on social action through individual lifeplans, and the future projections of action contained therein. The knowledge-action dialectic constructs, through internalisation, identity. In resolving how knowledge is maintained Schutz answers the issue of intersubjectivity by assuming that actors manage differences by two main assumptions of interchangeability and of interpretive congruence, to achieve ongoing practical action. Knowledge is never complete, for individuals or groups. Individual interest and proximity can recover hidden or lost knowledge. Having covered knowledge in some detail I now briefly turn to Garfinkel (1967) whose challenge to the Schutzian tradition, takes the focus to the mundane and ongoing accomplishment of how social definitions of reality are achieved at the organisational level, developing notions of consensus and dissensus which are never far from organisational realities. 


\subsection{Garfinkel and Ethno-methodology: Members' Methods}

In his major study of Garfinkel and Ethnomethodology, Heritage (1984), suggests Garfinkel opened his research agenda in 1967 with an emphasis of both consensus and dissensus, addressing one of the major difficulties in using a Schutzian framework, that the assumptions of practical co-operation glosses dissensus.

Conflicts of interest may constitute the crucial impetus to undercut common understandings and to undermine the small print of the non-contractual elements of the contract. A network of commonly agreed typifications per-se cannot guarantee a social order (Heritage, 1984 p:73).

Heritage (1984) suggests Garfinkel (1967) finds neither approach of Parsons (1951) or Schutz (1967) is sufficient to explain the ongoing processes by which organisational actors produce and accomplish their own locally achieved social order. Parson's Theory of Action (1951) posits that individual actors internalise institutional rules and norms almost unquestioningly within their own motivational 'reward and punishment' frameworks. Schutz (1967) emphasises the ongoing inter-subjective agreement that results from the suspension of dissensus for practical purposes, albeit within prior commonly understood typifications within providences of meaning.

Garfinkel (1967) instead emphasises the artfulness by which local actors establish and maintain inter-subjectively-agreed meaning. Actors are neither judgmental dopes as Parsons (1951) claims, nor are they merely slaves to consensually agreed common meanings, as Schutz (1967) suggests. Garfinkel investigates a variety of means and methods by which actor's own context is both constituted and 
maintained (Heritage, 1984; Holstein and Gubrium, 1994, 2000). These 'ethnomethods' are what Heritage (1984) calls the routine, seen and unnoticed procedures for accomplishing, producing and reproducing perceived normal courses of action (Heritage, 1984 p:118). For Garfinkel (1967) a central question is how everyday actors legitimise the institutional order as meaningful and ethical. The ethno-method takes a phenomenological sensibility to address constitutive social practice using actors' own meaning-making processes (Holstein and Gubrium, 1994 p.264).

\subsection{Indexicality and Reflexivity}

Garfinkel (1967) proposes that it is through language that reality is constructed and maintained, where members produce and recognise adequate descriptive representations of ordinary affairs. Members create and sustain group memberships, amongst other things (Heritage, 1984 p.139). It is not just what is being said, but how, why and where it is being said that helps to inform an understanding of reality being constructed through language. In this way, accounts are indexical - that is they depend on context for meaning. In addition, the production of descriptions themselves creates and sustains the very context they refer to, i.e., they are also reflexive. Attention focuses on the artful way that members create and sustain reality, in the process using and adapting shared stocks of knowledge, which are often taken for granted (Heritage, 1984). Ethnomethods have been used to understand how native conversation itself constructs 
the cultural context (Watson, 1996) normally assumed to exist externally to the subject (Hammersley, 2003).

In this thesis ethnomethodological tenets frame research into how members themselves construct and sustain the indigenous organisation as a whole, accessed via participant observation and in-depth active interviews (Holstein and Gubrium, 1995). At the organisational level this thesis explores indigenous organising as a process, the situated social action deriving from the ongoing construction of indigenous knowledge.

Chapter 9 reveals the methods of how indigenous organising is created and sustained, exploring how everyday members create accountability structures, covering both consensus and dissensus. Members' methods create and maintain the valid enactment of indigenous knowledge not only to enact the indigenous organisation, but also to ensure the survival of broader holistic cosmologies in changing contexts, the hope articulated in opening quote of this thesis.

Taking an example from each case study, in the Iona context I explore how the Iona membership constitutes themselves as a community in sacred relationship to each other, God, and the environment. Through community worship services, and the enactment of The Rule, members constitute and sustain their realities. The TWoR case study explores how mātauranga Māori is constituted in a variety of contexts, from group teaching sessions through to the in-depth analysis of 
constructing the organisational Charter. In both cases organisational artefacts (mission statements, charters, rules and so forth) act as reference points for this ongoing enactment (Clegg and Hardy, 1996). These are examined, wherever possible, as they are used in situ.

\subsection{Transmitting and Protecting Social Knowledge}

Only with the appearance of a new generation can one properly speak of a social world (Berger and Luckmann, 1966 p:79).

Working alongside Schutz (1967), Berger and Luckmann (1966) suggest social institutions play a key role in enabling and transmitting habitualised actions within commonly agreed social domains, which supports the ongoing dialectic of externalisation and internalisation of individuals' and groups' norms and actions.

\subsubsection{Institutional Knowledge and Roles of Leadership}

Berger and Luckmann (1966) posit that the institutionalisation of knowledge occurs where any frequently repeated action gets habituated into a pattern, and can be repeated in the future with same economy.

Habitualised actions retain their meaningful character for the individual although the meanings involved become embedded as routines in his general stock of knowledge, taken for granted by him and at hand for his projects into the future (Berger and Luckmann, 1966 p:71).

Individual lifeplans are co-constituted by institutionalised knowledge to impose habituated patterns of activity on the individual biography: '[Institutions] by the fact of their existence, control human conduct by setting up pre-defined patterns of human conduct' (Berger and Luckmann, 1966 p:72). These patterns require the 
establishment of types of actors whose roles are to embody, and represent the institution and make its functions real (Berger and Luckmann, 1966 p.71). Hence leaders are key actors who represent social institutions, and create the means by which the transmission of action occurs.

In this thesis indigenous organisational leaders represent the means by which the very worlds themselves are able to be sustained through symbolic representation of holistic cosmologies. Put simply, families and communities look to the symbolic leaders in these contexts to guide the moral and spiritual development of their own actions.

As the opening quote of the section suggests, this increasingly habitualised world only becomes objectively real when it is transmitted to a new generation. This occurs through typification; the ongoing explanations and namings of not only the things as objects in life, but also the way things are done. Only with the transmission of the social world to a new generation - and the internalisation through socialisation - does the fundamental social dialectic appear in its totality. Taking examples from the formation of family habits, the transmission from one generation to another confirms objective reality as real. Elements named within language systems for the growing child are what they are named, but reality becomes, for parent and child, stronger. What was, for the parents within their own providence of meaning merely a result of their own habitualised actions becomes for the child the way the world is. This world is harder to change, given 
its more fixed ontological status: 'a world so regarded attains a firmness in consciousness; it becomes real in an ever more massive way that can no longer be changed so readily' (Berger and Luckmann, 1966 p:77).

Institutions are transmitters of knowledge, from which individual actors select and enact their lifeplans: 'the typification of habitualised actions that constitute institutions are always shared ones... reciprocal typifications of actions are built up in the course of a shared history' (Berger and Luckmann, 1966 p:72). The role of leaders representing these institutions allows the symbolic transmission of embodied actions and predefined patterns of conduct within a given society. A central function of the institution and its leadership is to provide coherence and unity to successive generations: 'the same story, so to speak, must be told to all the children' (Berger and Luckmann, 1966 p:79). The institutional order develops an overarching meta-narrative; a story that sustains and integrates the various providences of meaning of society as a whole.

[The] institutional order develops a corresponding canopy of legitimations, stretching over it a protective cover of both cognitive and normative interpretation. These legitimations are learned by the new generation during the same process that socialises them into the institutional order (Berger and Luckmann,1966 p:79).

Integrating canopies of meaning support individuals who find themselves within a social order. The often taken-for-granted legitimisation of institutions occurs through individuals.

[A] biography is a reflected upon whole in which the discrete actions are thought of, not as isolated events but as related parts in a subjectively meaningful universe whose meanings are not specific to the individual, but socially articulated and shared. Only by way of this detour of socially shared universes of meaning do we arrive at the need for institutional integration (Berger and Luckmann, 1966 p:82). 
The knowledge of the group becomes the criterion for membership by the individual. Commonly known recipes of practical interest underpin this knowledge on the pre-theoretical level. It is the "sum of what everybody knows about a social world, an assemblage of maxims, morals, proverbial nuggets of wisdom, values and beliefs, myths and so forth' (Berger and Luckmann, 1966 $\mathrm{p}: 83)$. This stock of knowledge has a significant function within the life of the institution.

Such knowledge constitutes the motivating dynamics of institutional conduct. It defines the institutionalised areas of conduct and designates all situations falling within them. It defines and constructs the roles to be played in the context of the institutions in question. Ipso facto, it controls and predicts all such conduct (Berger and Luckmann, 1966 p:83).

Stocks of knowledge allow individuals to gain access to the broader society: 'this is the knowledge that is learned in the course of socialisation and that mediates the internalisation within individual consciousness of the objectivated structures of the social world' (Berger and Luckmann, 1966 p:83). In this thesis the above premise frames how actors use indigenous knowledge to articulate community and indigenous imaginings (Anderson, 1983). The organisation as a legitimising institution supports the related nation-building projects members are engaged in at the social level. These institutions are both accepted by individuals as being legitimate, and through their own legitimations, continue the overarching integrative canopy of universe-meaning within a holistic cosmology, supported by processes of 'legitimation', Berger and Luckmann's (1966) unique term for commonly used legitimisation. 


\subsubsection{Legitimising Knowledge}

Legitimation produces new meanings that serve to integrate the meanings already attached to disparate institutional processes. The function of legitimation is to make objectively available and subjectively plausible the first order objectivations that have been institutionalised (Berger and Luckmann, 1966 p:79).

Individuals require that stocks of knowledge require integration. Codes of conduct posit what and how knowledge defines reality and directs action at the social level. If institutions are the product of socially habituated actions, and if, through successive intergenerational transmission, these origins become lost in history then: 'the institutional world requires legitimation, that is, ways by which it can be explained and justified' (Berger and Luckmann, 1966 p:79).

An institution gains legitimisation by 'ascribing cognitive validity to its objectivated meanings'(Berger and Luckmann, 1966 p:111). Legitimisation serves a co-ordinating function inasmuch as it makes the institutional order just by ascribing normative dignity to its practical imperatives. However it is not only in the normative (making normal) domain that legitimisation works. It also validates the cognitive knowledge that is held within the institution and wider society.

Legitimation not only tells the individual why he should perform one action and not another; it also tells him why things are what they are. In other words 'knowledge' precedes 'values' in the legitimation of institutions (Berger and Luckmann, 1966 $\mathrm{p}: 111)$.

Berger and Luckmann (1966) posit a variety of functions to achieve legitimisation. Firstly actors' use of language creates legitimacy. Typifications as they exist and are transmitted carry within their own existence-legitimating properties, called incipient legitimisation. Theoretical propositions such as 
proverbs and maxims constitute the second level, akin to the social stock of knowledge, which are frequently transmitted in poetic form. The third level is a more fully differentiated body of knowledge, as a mode of reference for institutional conduct. Typically these bodies of knowledge reside in elders of the social group, who together maintain and constitute this body of knowledge and increase its status as tradition. The fourth and final level is symbolic universes, or what I term here holistic cosmologies which are 'bodies of theoretical tradition which integrate differing providences of meaning and encompass the institutional order in a symbolic totality' (Berger and Luckmann, 1966 p:113). Through symbolic processes of signification which relate to realities other than the everyday, smaller providences of meaning are integrated within a totalising universal order, an 'all embracing frame of reference' (Berger and Luckmann, 1966 p:114) which constitutes a universe, because all of human activity takes place within it. This universe contains 'all socially objectivated and subjectively real meanings; the entire historic society and the entire biography of the individual are seen as events taking place within this universe'(Berger and Luckmann, 1966 p:114).

Meaning making through sacred knowledge relationships provides an ordering to existence: 'the individual can assure himself that he is living correctly. The correctness of his life programme is thus legitimated on the highest level of generality' (Berger and Luckmann, 1966 p:117). Akin to the changes that individuals experience in the direction of their lifeplans, integrative narratives 
place their own biographies in the context of a holistic cosmology. This legitimisation has profound effects on the level of identity which is: "ultimately legitimated by placing it within the context of a symbolic universe. The individual may know who he is by anchoring his identity in a cosmic reality' (Berger and Luckmann, 1966 p:118).

In this thesis this premise frames the connections between individual indigenous identity, lifeplans and a broader holistic cosmology, accessed through active interviewing using members' phenomic reflection. The recovery of indigenous identity is a significant part of the research underpinned by this premise.

Symbolic universes emerge as the ultimate and totalising reference points for relationships within these social groups. However these legitimisations or conceptual machineries of universe maintenance not only legitimise the individuals, but also the social order as a whole. The universe orders social memory and the ongoing story of the local community, as well as the expected future actions of such members.

With regard to the past, it establishes a 'memory' that is shared by all the individuals socialised within the collective. With regard to the future, it establishes a common frame of reference for the projection of individual actions (Berger and Luckmann,1966 $\mathrm{p}: 120)$.

In this thesis I use this premise of collective memory to underpin research into the history of each community's past, and the collective views on the vision of action for future action, gathered through individual and group interviews. 


\subsubsection{Delegitimising Knowledge}

Competing knowledge systems question the legitimacy of an existing symbolic universe, so that 'the appearance of an alternative symbolic universe poses a threat because its very existence demonstrates empirically that one's own universe is less than inevitable' (Berger and Luckmann, 1966 p:126). Elites maintain their own reality-defining power and dominance through various means, but the most successful 'will depend more on power than on the theoretical ingenuity of the respective legitimators. The issue has been [historically solved] through military might' (Berger and Luckmann, 1966 p:139). Dominant universal machinery ultimately comes with a monopoly position.

A single symbolic tradition maintains the universe in question. To be in the society, then, implies acceptance of this tradition... in such a situation the monopolistic tradition and its expert administrators are sustained by a unified power structure (Berger and Luckmann, 1966 p:139).

Those in power 'use their power to impose the traditional definitions of reality... potentially competing conceptions are liquidated or integrated within the tradition itself... if successful, the tradition becomes enriched and differentiated' (Berger and Luckmann, 1966 p:139). The dominant order assumes knowledge validity by claiming the practical interests of members can be met. Additional means of ensuring adherence include 'nihilation'. Whereas legitimisation 'maintains the reality of the socially constructed universe; nihilation, in its turn, denies the reality of whatever phenomena or interpretations of phenomena do not fit within that universe' (Berger and Luckmann 1966, p:132). Nihilation works where the 
dominant order questions the very ontic validity of another cosmology's knowledge.

The threat to the social definitions of reality is neutralised by assigning an inferior ontological and therefore a not to be taken seriously cognitive status to all definitions existing outside the symbolic universe (Berger and Luckmann, 1966 p:132).

Any knowledge with lesser cognitive status can be ignored or disqualified. Like assimilation above, nihilation can absorb knowledge within the parameters of the dominant order, thus protecting the order from any reality-defining challenge.

The deviant conceptions are not merely assigned a negative status; they are grappled with in detail. The final goal of this procedure is to incorporate the deviant conceptions within one's own universe, and therefore to liquidate them ultimately. The deviant conceptions must, therefore be translated into concepts derived from one's own universe (Berger and Luckmann, 1966 p:133).

Concepts of legitimisation frames research into strategies of knowledge legitimisation and delegitimisation, which in the thesis also relates to the terms authentic versus inauthentic knowledge, following postcolonial scholars covered in Chapter 2. In addressing the social contexts in Chapters 5 and 9 I pay attention to these strategies. In the historic context of Chapter 5 imbrications of Māori and Celtic knowledge are discussed as they are deemed of 'low cognitive worth'. In Chapter 9 these strategies are examined currently within the organisation, noting how practices are labelled 'inauthentic' alongside competing knowledge claims.

\subsection{Summary}

This chapter describes how social phenomenology can support the analysis of indigenous organisational actors who draw from, and update knowledge continuities to define identity and organise. The individual level addresses the 
transmission of knowledge through language. This begs the question of collective agreement of knowledge, given social phenomenology's anti-objectivist philosophical tradition. Schutz (1970) proposed to overcome this through the mundane inter-subjective agreement for practical purposes. The social level covers the origins and inter-relationships between individual and social knowledge. Local knowledge traditions both create and are created by local individuals who, through internalising and accessing their stock of knowledge, gain ethical, cultural and moral positions with regard to both themselves and their broader environment. This knowledge fundamentally defines and sustains the identity of individuals and groups. These stocks of knowledge are by their nature incomplete. Knowledge gaps can be recovered. The organisational level addressed Garfinkel's (1967) critique of a Schutzian typology. Organisational members maintain consensus and dissensus using methods which create and sustain their own organisational realties, including accountability structures. At the social level I address the role and significance of social institutions that transmit habitualised actions, and leaders who symbolise these institutions and their provinces of meaning which require methods and means of legitimacy, or ways by which these worlds can be explained. Creating totalising 'symbolic universes' subsumes and creates coherence for all previous levels, including social and individual identity and action, a theoretical term I apply to holistic cosmologies. Finally the social context addresses competing 'symbolic universes' which seek to assume a dominant position by de-legitimising other universes. 
The next chapter describes how I applied a social phenomological lens in the research settings to gather and analyse data to answer the research question. It describes this method in terms consistent with reflexive research practice, which seeks to apply the tenets of social constructionism to ourselves as positioned researchers, and to be 'confessional' in reporting our own research practice. As such, it reports in the past tense. 


\section{Chapter 4: Constructing Naturalistic Method}

The confessional attempts to represent the fieldworker's participative presence in the studied scene, the fieldworker's rapport and sensitive contact with others in the world described, and something of the concrete cultural particulars that baffle the fieldworker while he learns to live in the setting (Van Maanen, 1998 p:91).

\subsection{Introduction}

In this chapter I reflexively describe a grounded theory approach. Using naturalistic case study methods, I select and study organisations which purposely use indigenous knowledge in two differing settings. I then describe the ethnographic methods that are used in the field to gather data, while following Kaupapa Māori protocols. Finally I describe the methods of data analysis, and the criteria I propose for the goodness of the thesis.

\subsection{Reflecting on Method}

As opposed to objective and detached researchers standing behind one-way glass, reflexive researchers seek to be open to and reflect on the research process, sharing how our own values direct the research while presenting issues, problems and solutions that we negotiated in the field (Altheide and Johnson, 1998; Lincoln, 1990; Van Maanen, 1998). The voice I use in this chapter is intentionally reflexive and framed in the past tense, applying the tenets of social constructionism to reflect on method (Ellis and Bochner, 2000; Steier, 1991). The self-positioned researcher is especially significant in researching with indigenous communities, by actively co-constructing research outcomes with 'coresearchers', a term proposed to recognise and equalise researcher-subject power- 
relations (Tolich and Davidson, 2000). This reflexivity also provides part of the criteria proposed for validity of the trustworthiness of the research process (Altheide and Johnson, 1998; Golden-Biddle and Locke, 1993).

\subsection{Constructing Grounded Theory}

Grounded theory is recommended to study phenomena where little extant knowledge is available, and is intimately linked to the practical domain from which it is developed (Glaser, 1978, 2002). The grounded theory approach is 'research and discovery through direct contact with the social world studied, coupled with a rejection of a priori theorising' (Lincoln and Guba, 1985 p:344). While positivist theory building frameworks suggest deductive theory testing, grounded theory has been used to generate theory grounded in the data, an approach termed 'inductive' (Locke, 2001 p:34). Rather than hypotheticodeductive reasoning which begins with concepts and searches for confirmation in empirical data, a grounded theory approach begins with empirical observation and seeks conceptual theorising which emerges from grounded data. Grounded theory has been used within OS under a variety of epistemological commitments, ranging from positivist examples (Dyer and Wilkins, 1991; Eisenhardt, 1989) to interpretivist approaches (Bartunek, 1984; Gephardt, 1993). Constructivist grounded theory has been proposed as an alternative to the classical objective grounded theory methods (Charmaz, 2000; Glaser, 2002; Lincoln and Guba, 1985). While Lincoln and Guba (1985) warn against the epistemological commitments of positivist grounded theory work, they do suggest that certain 
elements of grounded theory might be usefully applied to allow exploration of the phenomena at hand. Naturalistic inquiry supports the in-depth research of phenomena within purposively-sampled cases (Lincoln and Guba, 1985). The naturalistic method is presented from Lincoln and Guba (1985, p.188) and adapted to fit the $\mathrm{PhD}$ research context, outlined in Figure 3, over.

\subsubsection{Naturalistic Case Study Methodology and Selection}

Case study methodology is an empirical inquiry that produces one or a few 'revelatory' case studies written up to describe and explain a contemporary phenomenon within its real-life context, using multiple sources of evidence (Stake, 2000; Yin, 1990). The descriptive accounts of purposively sampled case studies are tacitly theorised by the researcher and described to allow the reader to imagine the world of the actor in their natural setting. Researchers get as close as possible to actor's own meaning and experience, using tacit knowledge to coconstruct both the interview and the findings. This method also supports theorising which is grounded in the data, and is regarded as useful where little knowledge or information about a phenomenon is known (Holstein and Gubrium, 1995; Lincoln and Guba, 1985; Maykuk and Morehouse, 1994). 
Figure 3 : The Flow of Naturalistic Inquiry, Applied to a PhD Context

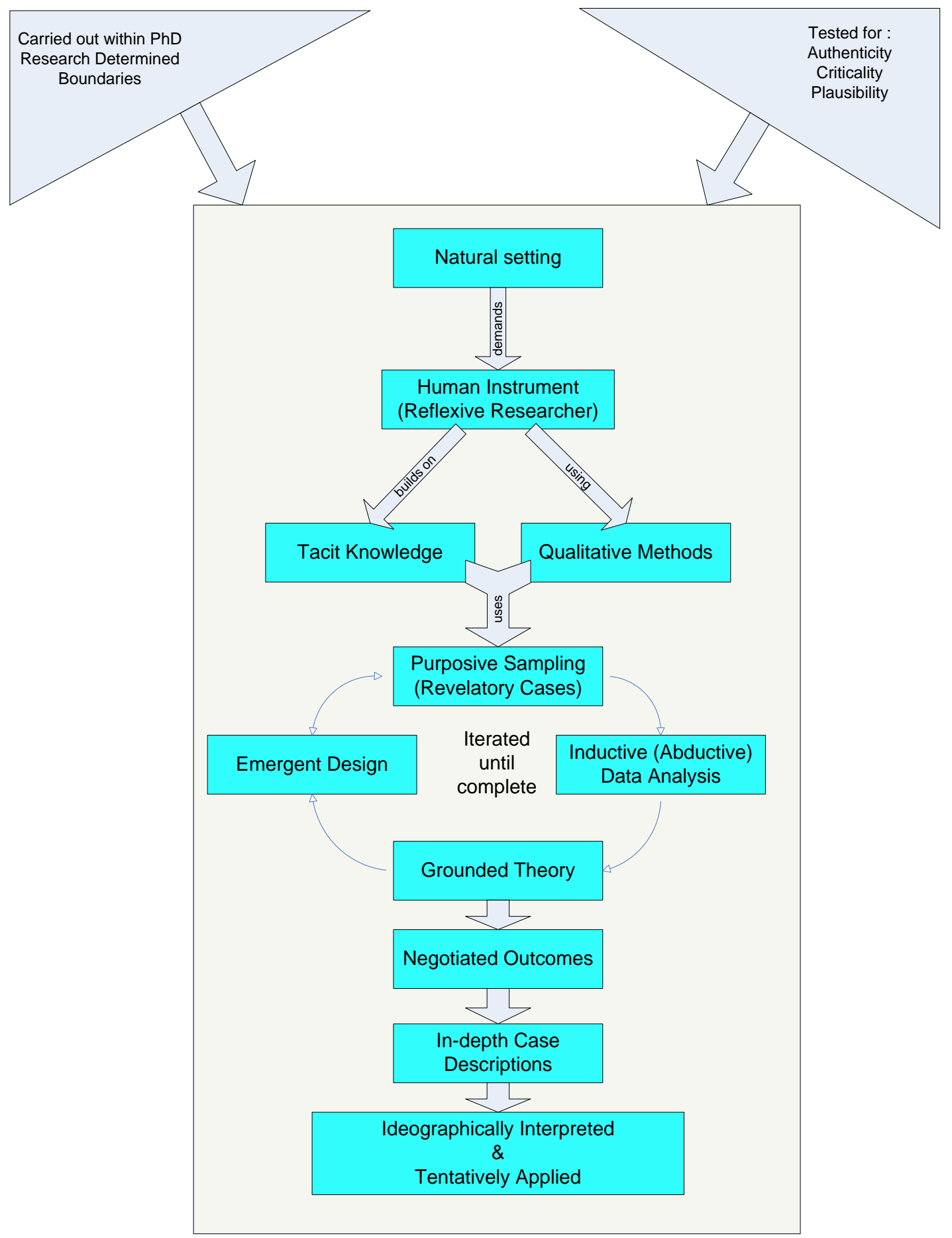

(Lincoln and Guba, 1985 p:188) 
Provisions applied within this naturalistic framework include grounded theory development in the natural setting; relating the questions to my own tactic knowledge and experience, (not just at the research question formation, but also at the interview level) and feeding theoretical conclusions back to each case, without claiming any pure fit. Since contexts change between data collection and analysis, and researchers' own tacit knowledge may differ from the experience of coresearchers in the field, I include feedback which also challenged and changed the original data gathered.

\subsubsection{Case Study Selection}

After formulating my tentative research questions outlined in the information sheet in Appendix 1, I purposively selected two organisations as natural settings to observe how they use indigenous knowledge to construct the indigenous organisation in two global contexts. Yin (1990) classes revelatory case studies where in-depth descriptions of unique phenomena are possible. Lincoln and Guba (1985 p.251) suggest prior ethnography as a way of fully exploring case contexts before fully developing the research approach. I used my prior knowledge of the IC, and early contact with Māori advisors to develop the initial $\mathrm{PhD}$ research proposal. The theoretic criteria for case selection was that each organisation shares a commonality of enacting indigenous knowledge out of local and historical contexts which have been riven by globalist practices, but each case uses indigenous knowledge differently. Case comparison allows a deeper analysis between contexts. Similarities and differences can be explored in ways which are 
excluded in a single case. Further the use of both of these cases illustrates what Lincoln and Guba (1985 p.84) call non-aggregatable multiple realities. These organisations each enact holistic cosmologies sharing legitimating features at the universal level (Berger and Luckmann, 1966; Lincoln and Guba, 1985). To convey the immediacy of my participative presence in the studied scenes, I describe the cases in an auto-ethnographic present day confessional account (Van Maanen, 1998 p,91). In describing the data of naturalistic inquiry, the tools of the ethnographic method are required (Lincoln and Guba, 1985 p.333).

\subsubsection{Ethnography and Fieldwork}

Although objectivists, Hammersley and Atkinson (1994) define ethnography as a form of richly descriptive social research using in-depth case analysis to explore phenomenon within one or two cases; open non-coded data at the point of collection; and explicit interpretation of meanings and actions, using rich verbal descriptions. Others in OS have used ethnographies to theorise cultures of control in high technology industries (Kunda, 1992), the construction of identity within and between Japanese and American cultural contexts (Kondo, 1990) and the construction of identity at work (Casey, 2002).

In anthropology, objective fieldworkers journeyed to exotic cultures to gain the native's point of view. Undergoing heroic tests, they returned with their hard won realist tales. By contrast, sociologist fieldworkers journeyed into their own urban local contexts to explore social meaning (Van Maanen, 1998). Epistemologies are 
not without consequence. Rosaldo (1993) illustrates how objective fieldworkers represented fixed 'primitive' cultures as backward, and ready to receive legitimised Western development. Rather than being devoid of political agendas, objective descriptions served to fix the identities of both researcher and those researched, legitimising colonial development and the supremacy of Western knowledge (Rosaldo, 1993). With increasing globalisation, both researchers and audiences are now no longer ivory tower Western or American academics, but increasingly those traditionally marginalised as 'other'. Indigenous researchers use and critique research tools and outputs for their own ends, studying adaptive cultures more akin to the heteroglossia of the garage sale than the hermetically sealed 'high cultures of monumentalism' (Rosaldo, 1993 p:44).

Through the research process I remained committed to the rigorous and critical use of constructionist practices, creating auto-ethnographic reflexive practice (Ellis and Bochner, 2000; Steier, 1991). I sought to balance my own tacit knowledge of Celtic and the IC with my obligations as a researcher and emerging academic, enabling one set of influences and obligations to creatively enhance the other. This does not mean, however, an uncritical stance. Within the naturalistic method the researcher's own context is opened to reveal its influence on the research process and product (Guba 1990, Lincoln and Guba, 1985). Rather than going native, I self-position as a Celtic researcher, as recommended in Kaupapa Māori literature dealt with next ( L. Smith, 1999). This thesis demonstrates how indigenous practices can benefit as much from serious academic engagement as 
the academic can benefit from serious engagement with the indigenous. To maintain cultural safety throughout, principles have been developed to assist both indigenous and academic communities to safely engage.

\subsubsection{Kaupapa Māori Research Protocols}

Māori research literature comments on objective research approaches which have been unhelpful to Māori (G. Smith, 2000; L. Smith, 1999, 2000). Negative outcomes for Māori resulted from epistemological clashes, of asymmetrical power relations during and after the research, of a lack of informed consent, and of forced participation (L. Smith, 1999, 2000). Because of this, Kaupapa Māori research protocols have been established which have been defined by Linda Smith as research which is 'culturally safe, involves the mentorship of Kaumatua [tribal elders], that is culturally relevant and done by Māori researchers' (L. Smith, 2000, $\mathrm{p}: 225)$. These principles seek to ensure that no harm comes to those who are researched. Researchers are encouraged to seek the permission and guidance of local knowledge guardians to check that practices are culturally safe ( L. Smith, 2000). Researchers who are self-positioned may align with Māori and undertake research with Māori if outcomes are sought that fit within a Kaupapa Māori model, or a project which benefits Māori (L.Smith, 2000 p.227).

\subsubsection{Applying Kaupapa Māori Research Protocols}

This research project seeks positive outcomes for Māori by: theorising how indigenous knowledge underpins organising to reverse the local effects of the 
colonial and globalist encounter; giving Māori written informed consent and rights of refusal within timeframes, which includes what the research will entail, in terms of time and process; enabling Māori guarantors to check that culturally safe practice exists for both parties; ensuring knowledge guarantors and research participants view any material contained within the study for its appropriateness and cultural safety; seeking permission and agreement on the research questions and protocols and providing the opportunity to feedback findings (within time and distance constraints) to honour the guardians of knowledge, without assuming a pure fit to a single external reality.

To check my initial approach, the Māori academic Professor Graham Hingangaroa Smith and Māori M.P. Hon. John Tamihere provided guidance on the early stages of research design and gave guidance on protocols. I also attended a Māori Leadership Conference held in Waitangi in 2001, where I discussed the project with Māori leaders and gained their insights and feedback. I also presented my early proposal to Māori scholars at the Auckland University Business School Māori Research Mini-Conference in 2001, led by Professor Manuka Henare. As my proposal developed I sought to develop cultural competence by attending a Te Reo language class. I was struck by how language conveys and constructs meaning. Not only this, the very interpretive schemas themselves were transmitted through language. During this exercise I was encouraged to deepen my own indigenous Celtic identity, by learning the Māori concept of whakapapa [genealogy] we were encouraged to locate ourselves within our own historic 
genealogy and geography. I learned the importance of sharing this during formal greeting protocols with Māori, known as mihimihi and insodoing constructing my own Celtic identity within a Māori context.

Using this knowledge of Te Reo, and my own tacit or lived knowledge from my time with the IC, I approached TWoR to seek permission to study there. I initially met with Professor Winiata and offered a mihimihi and whakapapa. Being a selfpositioned researcher I acknowledged and sought to protect the cultural safety of TWoR by being explicit about my own rationale for the study and the Kaupapa Māori outcomes I sought. I offered draft copies of the research proposal and research questions for their critical review. Co-researchers were given permission to accept or reject any part of the study within a time frame. Informed consent was obtained from each respondent, in individual and group settings (see sample information sheet in Appendix 1). With these agreements in place, I then continued my research by beginning fieldwork at TWoR, using the ethnographic fieldwork method outlined below. Interviews were taped, stored in a secure location and destroyed after the course of the research.

\subsubsection{Fieldwork}

The traditional tool of the objective ethnographer is fieldwork, which involves the systematic gathering and analysing of data in the field. As Yin (1990) suggests, fieldwork involves using multiple methods to gain the triangulation of a single point of focus under study. Consistent with constructionist practice, I used 
multiple methods such as: interviews; archival material; published sources; and referred experts to enable the articulation or crystallisation of multiple perspectives on my research topic (Richardson, 1994). Descriptive sketches and episodes in the first person illustrated organisational practices which somehow embodied or enacted indigenous knowledge. This evidence is not to confirm as valid a singular external reality, but to describe how members use methods to construct and maintain the very reality to which they purport to refer to, understand them as indexical and reflexive (Heritage, 1984; Holstein and Gubrium, 1994, 1995). These descriptions are the cornerstone of ethnographic practice.

\subsubsection{Ethnographic Descriptions of Culture}

The purpose of ethnographic descriptions are to 'recreate the varied forms of social organisation and interaction that months of study and observation have revealed' where 'the manifold symbolism every culture displays and the adaptiveness of people to their environment must somehow come to the page' (Martin, 2001 p:4). Martin (2001) reminds us that since reality is subjectively constructed researchers are compelled to pay attention to the inter-subjective frameworks of members. As mentioned previously, I draw from Alvesson, (2002, pp.3-6) and Schutz (1970, p.80) in defining culture as a cohesive system of meanings and symbols drawing from socially derived knowledge containing shared rules governing social interaction and the means where they are expressed. However I present no false picture of cohesion or consistency, but sketches which 
illuminated my fragmentary and inevitably incomplete experiences of their experiences. I next reflexively describe how I gathered and analysed this data in the field.

\subsection{Method in the Field: Interviews and Data Analysis}

To access co-researchers' experience, I interviewed between 16 to 22 key participants and undertook a focus group in each organisation, using the theory premises outlined previously in Table 5, p.90. Initial interviews were conducted with the leader-as-guarantor in each case and subsequent interviewees were recommended by the leaders, acknowledging their 'mana', and status as guarantors outlined in Kaupapa Māori research protocols. The material from leader-selected interviewees was referenced and acknowledged by citing the interviewee directly by name.

However the constructionist research literature warns against taking a unitarist view of leadership which may under-represent critical, opposing or alternative constructions (Alvesson and Deetz, 2000; Angrosino and Mays de Perez, 2000; Deetz, 1996). Conflicting or contrary data was also sought, using theory assumptions outlined in Table 5 to avoid a Schutzian gloss of inter-subjective agreement. Interviewees were sought from all levels of the organisation, from those new to the organisation and programmes to mid-level leaders and programme directors. Where there is no directly named interviewee citation, this indicates researcher-as-instrument selection. 
I began with a semi-structured interview schedule (summarised on the information sheet in Appendix 1), which was soon abandoned as co-researcher's answers to questions opened new lines of inquiry (Angrosino and Mays de Perez, 2000; Holstein and Gubrium, 1995; Lincoln and Guba, 1985). I then developed and cross-tagged an extensive fieldwork notes system to check levels of data and key emergent ideas during the subsequent interviews. This included asking coresearchers about their own historical, cultural and spiritual traditions and their relationship to indigenous knowledge. The philosophical position of the researcher and our own tacit knowledge is especially important within ethnographic relationships across cultures (Denzin, 1997; Fischer, 1999; L. Smith, 1999; Tolich and Davidson, 2000).

\subsubsection{Interviews -Tacit Knowledge and the Reflexive Researcher}

Tacit knowledge is defined as the experienced knowledge of the researcher, which precedes propositional knowledge (Lincoln and Guba, 1985 p.195). Sharing this experiential knowledge is theorised to build trust (Holstein and Gubrium, 1995). In the New Zealand context I sought to be a culturally-positioned researcher, as recommended by Kaupapa Māori research protocols. I used tacit knowledge of my Iona experience and personal spirituality to construct my role as researcher, balancing identities between researcher and 'native' ethnographer (Angrosino and Mays de Perez, 2000). 
In the interview context, revealing my own tacit knowledge actively constructed the context for the interviewees to explore their own indigenous experiences definitions and context (Holstein and Gubrium, 1995; Tolich and Davidson, 2000). These interviews lasted from 20 minutes to sometimes over four hours. Participant observation occurred in programmes, classroom settings and hui, lunch gatherings and car park conversations. Two 'in situ' focus groups were conducted containing a number of group members participating in the programmes. I observed activities, meetings and everyday interactions as a participant and research observer, spread over three months of both intermittent and fuller participatory contact with each organisation, observing how the leaders either ran programmes or facilitated leadership hui.

At TWoR, I felt that personal sharing my own tacit knowledge was culturally appropriate. If I missed this in the interview introductions, I was soon asked directly about it. My researcher and Celtic identity also countered my fears of being seen as an unwelcome outsider. I was told that Pākeha researchers "just didn't understand the way Māori do things". The literature, and research context, had forewarned me with plenty of examples of where misunderstandings have occurred (Tolich and Davidson, 2000). This self-positioning was taken as an authentic reason for me to be researching with Māori, by both Māori and Pākeha colleagues. A typical response by Pākeha was “they're letting you in because you are Scottish"; a typical response by Māori was "you're comparing Māori and Scottish? We've followed the Scottish Parliament debate". Being Scottish was 
seen as supporting Māori sovereignty, since support for self-government was and is part of my own historic Scottish social context.

In the IC my tacit knowledge also played a central role in gaining access. Being more of a cultural insider permitted easier access, although I ensured that the IC was offered the same permissions and reviews of the material as TWoR. However in the IC I had a prior-member identity. I emphasised my researcher identity but was also aware of the time that had passed since I was an active member and previous volunteer. Respondents gave me access to many interviews and archives, completing 22 IC interviews (again with all levels from visitor to leaders, to overcome positive representation) and nine days of full programme immersion in the 2003 IC Island programme. However having prior tacit knowledge was also a risk. Would I be too accustomed to miss the unique on Iona this time round? I bracketed my past experience as much as I was able to with a written part of the thesis prior to the research, which allowed me to focus on how co-researchers construct and maintain their own meanings. Over time I allowed my relationships to each context to naturally deepen, becoming a 'complete member' researcher, or 'those who study settings in which they are already members or with which they become affiliated during the course of the research' (Angrosino and Mays de Perez, 2000 p:677). With the above safeguards in place, my observations covered the three levels throughout: individual, organisational and social, summarised next. 


\subsubsection{Defining Indigeneity in Global Contexts}

I used social phenomenology to explore co-researchers experience of globalist and indigenous knowledge, asking them to define at the individual level their experience and understanding of both globalist practices and indigeneity, building a descriptive understanding of the effects and limits of globalist knowledge, and the effects of indigenous knowledge on individuals. I became sensitised to how meaning is achieved, constructed and legitimated within overarching holistic cosmologies transmitted through various means including language, symbol and archival case study materials.

I observed how co-researchers engaged with each community and directed their lifeprojects away from individualist and globalist concerns and towards what the organisation views as significant, a process which is central to individual and group identity formation processes. For Schutz (1970), the standing and identity of individuals with reference to group membership depends on their deepening familiarity with the social stocks of knowledge. In both cases members lifeprojects involved local community development and holistic cosmology recovery but with contextually significant differences. In each context I was struck by this relationship. Rites or tests of passage gave evidence by actions of individuals who could prove their familiarity with indigenous knowledge through situated social action, intimate indigenous knowledge was reserved for leaders who themselves socialised newcomers and mid-level leaders, and also acted as gatekeepers, guardians, and role-models of such knowledge. To my surprise, 
leaders also denied or repressed indigenous knowledge, creating conflict and confusion (see feedback, Chapter 10).

Projects for Māori individuals ranged from interviewing Kaumatua or developing capability assessing and building exercises for the iwi [tribe] and hapu [subtribe] of the area, or in the IC case, addressing urban regeneration, issues of peace and social justice. Running through both cases was an ethic of community that individuals were being re-orientated to, through organisational engagement. For others, their own motivating actions were seeking to re-integrate fragmented or missing family or genealogical knowledge. Indigenous knowledge profoundly influenced organisational and social levels also.

\subsubsection{Observing the Construction of the Indigenous Organisation}

At the organisational level, I ethnographically described how the indigenous organisation is constructed. Garfinkel's (1967) ethno-methods challenge Schutz' (1970) glossed assumptions of inter-subjective consensus. I used this lens to focus on how multiple actors constitute organising as a process, and hence the organisation. Remaining aware of my role as a critical researcher, but within Kaupapa Māori protocols, I sought poly-vocal interpretations. Differences in the legitimacy of indigenous or globalist knowledge allowed fruitful exploration of the tensions and claims of how either indigenous or globalist knowledge should underpin the organisation. 
Participant observation of strategy workshops and meetings gave me direct insight into how the organisation is a site of action using its history, purposes, boundaries and rules, creating artefacts using local accounts and accountabilities (Clegg and Hardy, 1996; Heritage, 1984). Gaining access to hui [gatherings] at TWoR and community events on the IC allowed me to observe in situ where and how these took place. In TWoR I observed how the leader enabled strategy development through rules as constitutive frameworks to allow actions to be made accountable. In the IC case study, archival analysis and interviews with the first senior management team who developed the early strategy in 1938 supported an analysis of strategy formation and the original leader's role. Observation and analysis of archival material and the IC leadership in 2003 was also undertaken.

I sought the inter-subjective knowledge of members and the meaning this knowledge has for them, illustrating how members perceive, reinterpret and adapt indigenous knowledge in the process of enacting the organisation. Thus indigenous organisational culture is an ongoing co-construction, through which the very notion of the organisation and indeed wider holistic cosmologies are constructed and maintained. What this means in simple terms is how material documents can both draw from a wider cultural context, and when referred to, themselves shape and construct that very context. For example the organisational charter of TWoR is not an objective document separated from context, but a living document which, when enacted, co-constructs the context it emerges from, supporting and constructing an indigenous organisational culture. 


\subsubsection{Social Context: Legitimising and Delegitimising Knowledge}

The legitimising and delegitimising strategies by each organisation and social actors and agencies beyond them were observed. At the social level I became alert to the devices of maintaining the survival of indigenous knowledge as well as strategies of repressive authenticity, both inside and outside the organisation which try to delegitimise indigenous knowledge. This is discussed using archival, published and interview sources historically in Chapter 5, and ethnographically in the case studies in Chapter 9.

\subsubsection{Data Analysis}

The constant comparison method was used to describe and explain indigenous organising by pattern building within each case, at individual; organisational and social levels. I was using extant theory tacitly to direct my attention to certain descriptions I had gathered, filtering for relevance and importance. This abductive method is adapted from Hansen (2003, p.8) and presented in Figure 4 (below), illustrating the moves between sensitising concepts, in this case social phenomenology and the ethno-data to create explanations of the phenomenon at hand. Given that induction can too often assume a questionable blank slate to the data, abduction instead openly uses the researcher's own tacit knowledge, awareness, hunches and feelings. I was now processing my own tacit knowledge of the cases with my tacit knowledge of the theory to develop propositional knowledge (Lincoln and Guba, 1985 p.195). Where data is coded in-vivo from the field, the constant comparison method covers the stages of data analysis: coding; 
categorising; and condensing until category saturation is reached (Marshall and Rossman, 1999).

Figure 4: The Abductive Process

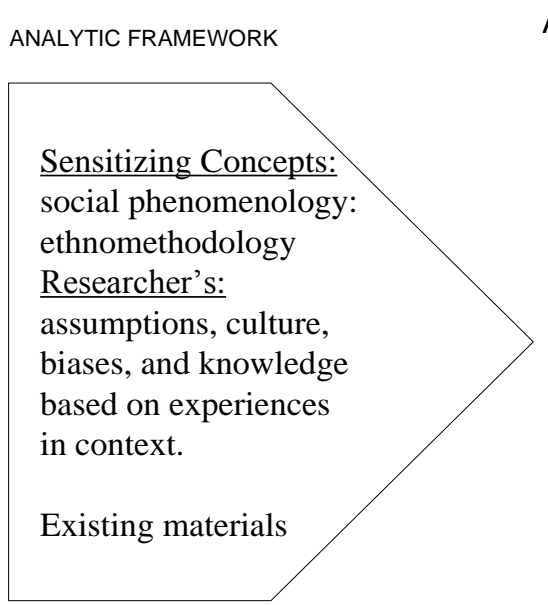

More deductive
Abductive Framework

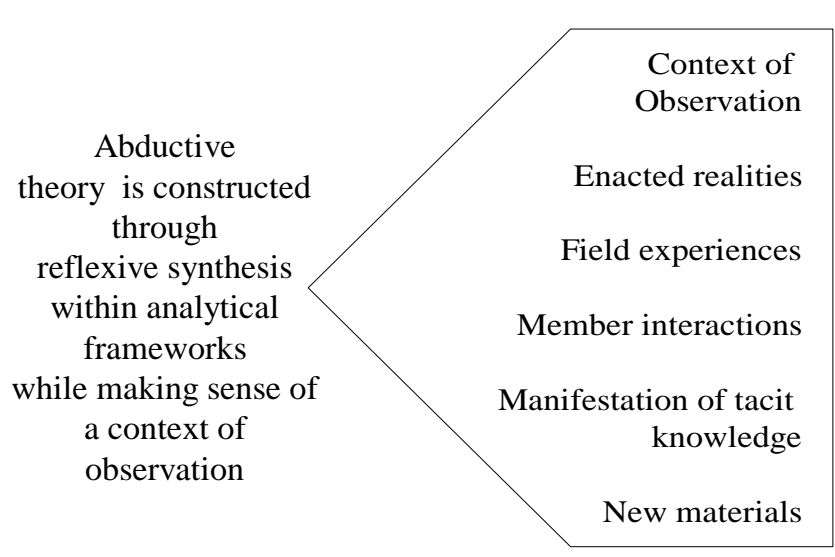

New materials

(Hansen, 2003)

Coding involves seeking patterns that emerge from the data using respondents own language and interpretive schemas. I used memoing to gather ideas. I analysed the data and noted key words, ideas and phrases during the interviews using my tagged system, cross-checked against transcripts. I used the NVIVO computer programme, exampled in Figure 5 below, to more fuly develop theoretic categories using coding on the right hand side of the program. I sorted the data by organisational levels and the uses of indigenous knowledge from multiple viewpoints reflected and crystallised by the data, archival materials and observations (Richardson, 1994). By using theory more explicitly to analyse the data, I was no longer working purely on induction with the data, but abducting. 


\section{Figure 5: NVivo Full Interview Example}

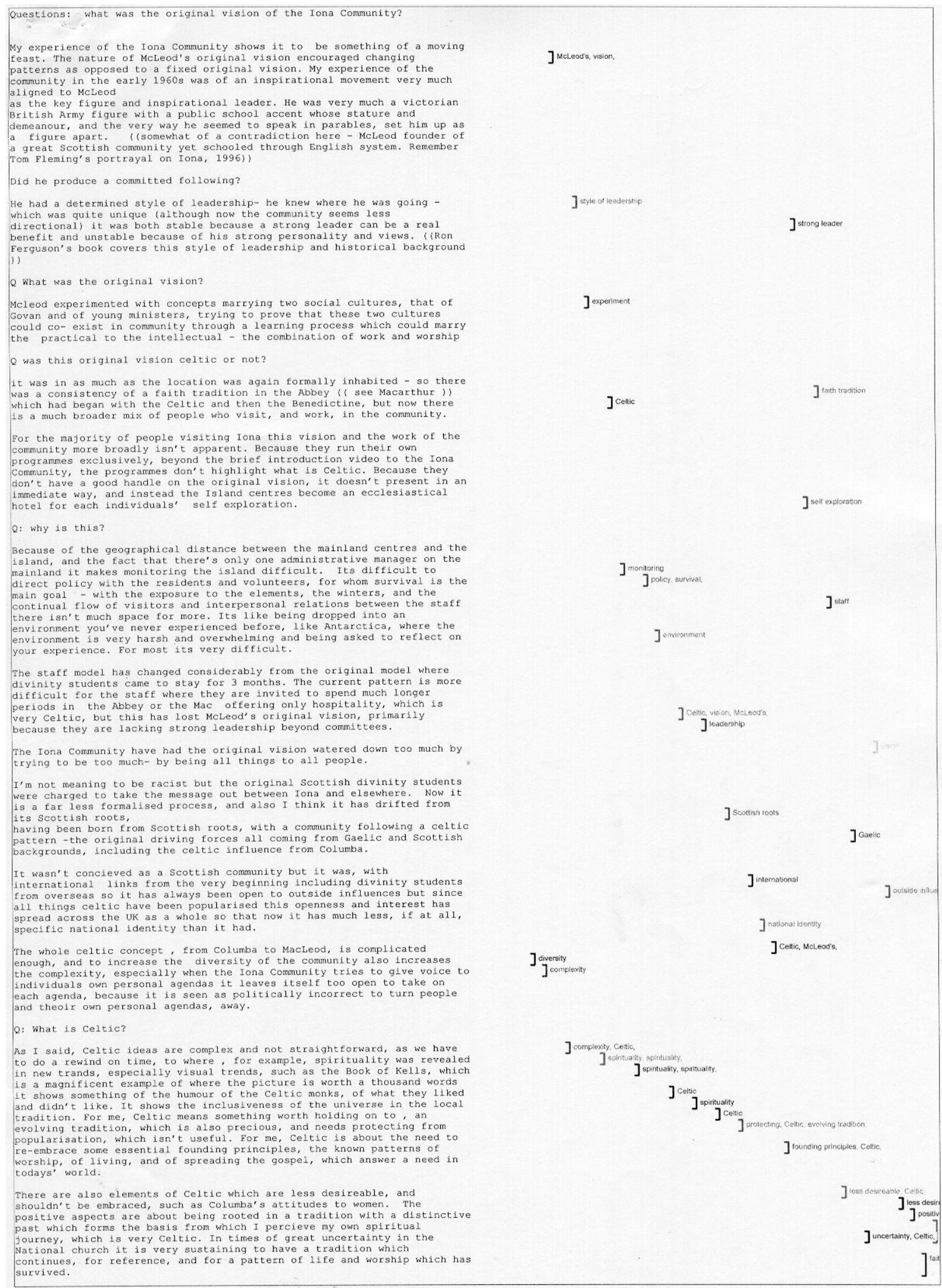


Categories emerged from which the essential properties for inclusion were defined. Pattern building was also tested by searching for negative instances (Charmaz, 2000). These themes and patterns rapidly emerged, and were ethnographically documented as I began each case write-up (Miles and Huberman, 1984; Yin, 1990). Integrating these categories brought clarity to the emergent propositions, which evolved from the rule for inclusion criteria. I described empirical observations from fieldnotes while undertaking in-vivo or in text coding, which was based upon my interpretation of respondents' ethno-data.

The most significant propositions were finally selected, condensed and fully described in the following chapters to develop propositional knowledge which answers the substantive research question of the thesis, within the context of each case and completing the within case analysis (Lincoln and Guba, 1985; Yin, 1990). These patterns are summarised and presented in Chapter 10 within each case and context before being compared across cases to explore similarities and differences (Yin, 1990).

At the individual level I condensed the data to prioritise how individuals define and experience indigenous knowledge. At the organisational and social level I condensed the data to build a pattern of indigenous organising as a process. I looked for examples of how the organisation was enacted and interpreted, and the social action that emerges from this, in social contexts which may also delegitimise indigenous knowledge. Data that didn't fit within the three levels of 
analysis or were less theoretically relevant were discarded. Miscellaneous codes were left aside, to be either later reincorporated or left aside (Lincoln and Guba, 1985; Marshall and Rossman, 1999; Maykuk and Morehouse, 1994; Yin, 1990).

\subsubsection{Cross Case Comparison}

Cross case analysis was finally used to deepen naturalistic generalisation, emphasizing case-context relationships as opposed to abstracting to context free generaliseability (Yin, 1990). Lincoln and Guba (1985) propose a working theory can develop from deep context description, which can be generalised to other contexts by researchers, practitioners and policymakers who generalise for themselves whether propositions fit or not by exploring these descriptive accounts and comparing their own tacit knowledge of their own contexts (Lincoln and Guba, 1985 p.297).

I sought to understand how the case in its context influenced how indigenous knowledge is enacted: how a Celtic Christian Community treats indigenous knowledge, as compared to a Māori university. Both similarities and differences were addressed, suggesting the significance that historical contexts, founding purposes and leaders have had on the organising methods and practices of each case. While I conducted the research using aspects of a full grounded theory the propositions remain firmly based within their time and contextual settings, which criteria for research goodness addresses. 


\subsubsection{Credibility Criteria for Naturalistic Research}

Since social phenomenology posits that notions of objective reality are problematic, I instead propose closeness to inter-subjectively constructed worlds as the primary credibility criterion for this naturalistic research. Amongst other things I use notions of authenticity; plausibility and criticality as qualitative criteria. Authenticity denotes the ability to convince the sceptical reader of the researchers' closeness and empathy to their subjects, 'conveying the vitality of everyday life in the research setting' (Golden-Biddle and Locke, 1993 p:599). Plausibility involves connecting two, or in this case three worlds: that the stories told of the two worlds of the thesis makes sense to the world of the reader. Finally critically suggests texts should challenge the taken for granted assumptions of readers (Golden-Biddle and Locke, 1993). In Chapter 10 I address how I claim the thesis meets these criteria, as well as addressing any fit claimed between theory and the lifeworld of the researched. I submit this chapter and reflexive sections throughout the thesis as evidence of reflexivity of method, as the literature commends (Altheide and Johnson, 1998).

According to Lincoln and Guba (1985, p.296), the researcher's construction of reality or the 'truth value' of theory is how closely the theory fits to the original constructors. The primary notion of validity is the authentic representation of the original research to the original research context. Representing the thesis back to the original participants does not guarantee any pure fit since time and organisational contexts change, as do the views of the respondents, such as with 
the IC leadership (see feedback, Chapter 10). The theory as a Powerpoint Presentation was presented to the Academic Board of TWoR in the first instance, fulfilling Kaupapa Māori Research protocols. The same Powerpoint Presentation was also presented back to current and past Iona leaders and volunteer members, and is also included in Chapter 10.

\subsection{Summary}

In this chapter I have reflexively described the methods used to apply the theory of Chapter 3 to describe and theorise an indigenous organisation. A naturalistic case study method was applied to gather and abductively analyse data at individual, organisational and social levels. A grounded theory illustrates indigenous organising as a process, showing how actors draw from indigenous knowledge to enact the indigenous organisation. Kaupapa Māori Research protocols underpin the research design, process and outcomes. Ethnographic methods of fieldwork were used to gather multiple sources of data, treating as central primary interviews with actors engaging with indigenous knowledge. From this fieldwork, notes were 'written up' describing my construction of their construction at three levels of analysis in Chapters 7, 8 and 9 respectively. These descriptions sought to privilege actor's uses of indigenous knowledge and their social action.

I used grounded theory methods to create 'within case analyses' at each level, interrogating the data according to iterative questioning that emerged whilst in the 
field. This allowed me to extend certain areas of inquiry within each case. Using the constant comparison method, patterns were built within each case, describing indigenous organising at three levels. Dis-confirmatory examples were included. Analysing similarities and differences between cases revealed if and how the context to each case affected how indigenous knowledge was enacted. Naturalistic criteria for generalisation were noted. Finally, qualitative criteria for the goodness of the theory were proposed, indicating notions of authenticity and plausibility within a critical stance that challenges readers' taken for granted assumptions. With theory and method described, I next turn to the historic contexts to each case to view how notions of indigeneity are constructed in the face of global pressures. 


\section{Chapter 5: Constructing Indigeneity in Global Contexts}

\subsection{Introduction}

This chapter describes the historic context to each indigenous organisation. It examines the globalist practices as illustrative backgrounds to the later case study chapters. Section 5.2 covers the Māori of Aotearoa New Zealand and their status as Tangata Whenua, despite the colonial and globalist practices which have sought to fragment Māori knowledge. Despite the signing of The Treaty of Waitangi, land confiscation, knowledge and language loss have occurred. Māori challenges sought redress, resulting in The Treaty Act and settlements. However, recovering Te Reo language and Māori knowledge began with the Kohanga Reo and Whare Wānanga movements, culminating in Māori political autonomy and Representation. Section 5.3 discusses the early 'Celtic' and Scottish national identity, before Scotland was assimilated in the United Kingdom. Despite land clearances and powerful globalist fragmentation, Celtic knowledge survived in the Western Isles, and is experiencing a renaissance in the context of recent Scottish Devolution.

\subsection{Constructing Māori of Aotearoa New Zealand}

Although the origins of Māori have been hotly debated by New Zealand historians (King, 1997), within Māoridom itself the narrative of voyages from Hawaiki, the ancient Polynesian homeland also known as Rangiātea, in 'waka' [canoes] in around the period 1200 A.D. is recounted in oral history. 
That people dwelt in Hawaiki. They planned to shape a canoe for themselves, in order to search for a new land of their own. That canoe was shaped. When it was finished... it was launched and loaded up... Then that canoe travelled forth, and made a crossing to this land (Naahe, 1860, cited in Henare, (1988 p:9))

Early Pākeha historians have produced accounts which King (1997) notes are so inaccurate as to be myths, such as the construction of Kupe as the first founder of Aotearoa in 1350 (King, 1997). While the Kupe narrative does exist in Māori oral tradition, there are many variations. Evidence of settlement has also been found from at least 800 A.D. (Salmond, 1991). Henare (1988) notes oral Māori origins go back many thousands of years. These oral histories attest to spiritual origins within a holistic cosmology.

Māori creation traces itself to Ranaganui the sky father and Papa-tu-a-Nuku the Mother Earth. The offspring of this coupling were the creators of all resources: they are the patrons of all things tapu. The close relationship of the people and the land, and the culture that they built around this relationship, stem from the religious belief of common ancestry (Henare, 1988 p:9).

From the oldest oral traditions Māori knowledge and whare wānanga figured prominently. The offspring of Ranganui and Papa-tu-a-Nuku, was Tane, who ascended to the $12^{\text {th }}$ or highest heaven, called Rangiātea

to receive the baskets of knowledge and the mauri (life force) of the whare wānanga (school of higher learning) which resides in two stones. These were received from Io, the supreme being of Māori tradition (Royal, Baker, \& Simpson, 1997 p:3).

This sacred knowledge and its use sets the parameters of maintenance and embellishment of mana [life energy/ spiritual pride], as defined by Rev. Māori

Marsden:

In the Māori sense, since authority is derived from the gods, mana as authority means 'lawful permission delegated by the gods to their human agent to act on their behalf and in accordance with their revealed will... it [also] denotes the ability to perform. Mana includes all these ideas, but essentially it means 'that which manifests the power of the gods' (Marsden, 2003 p: 4). 
Mana is closely associated with tapu [sacredness], being the potentiality for power inherent in mana (Shirres, 1997). In this way tapu directs, protects or makes manifest the mana of the gods through human actions. Shirres (1997) notes the connectedness of mana, tapu and people.

The mana which is the actualisation, the realisation of the tapu of the person is threefold, mana tangata, power from people, mana whenau, power from land, and mana atua, power from our link with the spiritual powers (Shirres, 1997 p:53).

These relationship between the gods, the people and the land figures as not only central in the construction of Māori history, but also Māori identity.

\subsubsection{Tangata Whenua: The People Are the Land}

The covenantal relationship of Māori with the land, for Henare (1988) is central to the construction and maintenance of Māori identity.

The land and people covenant has formed the source of identity for the tangata whenua, the people that are of the land, and indeed are the land. When reflecting on this relationship with the land, Māori see the generations of ancestors who have been the guardians of ancestors before them: the link to these predecessors is held by the land, and the land is the link to future generations: Toitu te whenua, whatungarongaro he tangata: the land remains forever, but the people pass on (traditional) (Henare, 1988 $\mathrm{p}: 8)$.

Māori tribal histories and genealogies evolved within Aotearoa from 1200 A.D. onwards, when larger landing parties took place. These tribal groupings formed a sacred covenant with the land in each area which was a continuity of the previous indigenous seafaring identification:

The meaning of words in Māoridom is illuminating. The word Maunga, for example, meaning mountain is also the word for island. As the ancient people settled here, they located themselves in relationship to the land around them. Thus 'this... is my mountain' in ritual introductions was a continuity of the island identification that would have occurred prior to settlement in New Zealand (Royal Interview, 2002). 
The identification with the sacred land of origin is reflected in naming Hawaiki in its other known form: 'E koro au e ngaro te kakano i ruia mai i Rangiātea: I shall never disappear, the seed which was sown from Rangiātea' (Walker, 1989 p:37). Precolonial Māori practices embody complex and advanced social structures revolving primarily around - in order of significance - the whanau, hapu and iwi (Love and Waa, 1994). Māori knowledge evolved in tribal localities, where tohunga [knowledge specialists] gathered and taught in whare wānanga according to the knowledge and ancestry of each area (Salmond, 1985). These wānanga were the tribal houses of learning, where suitable males where chosen to receive instruction from tohunga. However this knowledge was soon to experience powerful and fragmenting influences.

\subsubsection{Colonial New Zealand: Fragmenting Indigenous Knowledge}

The term 'Māori' was not in common usage until the arrival of British colonial settlers at the beginning of the $18^{\text {th }}$ Century. Previously, the inhabitants referred to themselves by separate iwi and hapu local categories. Māori or 'normal' as a term was developed to differentiate the Indigenous Peoples from the new settlers (Walker, 1989). Grice and Fleming (1999) locate Imperial British economics, the Industrial Revolution and wage slavery as major factors in migrants leaving Britain and immigrating to New Zealand. Settlers were bringing a capitalist worldview which was defining the new colonies all over the world. This worldview was legitimised by Christianity, as preached by the missionaries, which also fragmented Māori knowledge (Orange, 1989). To support this 
colonial vision the settlers co-constructed legal-political and religious structures adopted from their homeland to consolidate and protect the individualistic principles and practices (Grice and Fleming, 1999 p.325).

The colonial project established capitalist relations of production over indigenous communal orientations of Māori society. However the dynamic adaptation of iwi and hapu to the changing local environment - and worldviews - resulted in the colonial settlers meeting a great deal of heterogeneity (Salmond, 1991). Despite this, settlers immediately began constructing Māori knowledge as inferior and devaluing their guardians in contrast to their own settler knowledge and identity which was being formed as superior.

Savages were held to be intellectually inferior to civilised men, and so could only benefit from contact with the West, as J.L Nicholas declared in 1814: 'though the savage does posses all the passions of Nature, pure and unadulterated, and though he may in many instances feel stronger and more acutely than the man of civilised habit, still he is inferior to him in every other respect (Salmond, 1985 p: 255)

Settlers paid scant regard to the Māori cosmological principles like tapu which applied to rangatira [tribal chiefs]. The colonial settlers treated these people and their principles poorly, and their sacred land as a commodity to be used for personal gain (Walker, 1992 p. 2). Rangatira responses to colonisation differed. Some skilfully used relationships to their own material and military advantage while others fought for the maintenance and autonomy of Māori. In the early phases of colonisation Māori tribal relationships were proposing self-government, driven by concerns of increasing settler numbers (Henare, 1995). As a result, the 
Declaration of Independence was signed in 1835. This attempted to ensure some

legitimacy was given to Māori national imaginings:

By coming together to establish a tribal social compact and declaring to their own people and the world at large the freedom of Māori from any intended domination, the rangatira were founding a constitutional basis for Māori law making. Māori New Zealand was acknowledged as a sovereign and independent state (Henare, 1995 p:5).

This declaration was recognised by British legal statutes in 1817,1823 and 1828, a fact many current historians overlook (Orange, 1989). However this declaration was short lived. The early recognition of Māori sovereignty was supplanted via means of a contrary British claim.

\subsubsection{The Treaty of Waitangi}

The signing of the Treaty of Waitangi in 1840 is taken as the founding document of New Zealand (Orange, 1987, 1989). The understanding established between the British Crown and the majority of the Māori signatories varied significantly between the two versions which were produced, one in English and one in Māori. Critical differences revolved around understandings of kawanatanga [governorship] and tino rangatiratanga [full chieftainship]:

Whatever the truth, and we may never know, it is clear that William's (Māori) translation (of the Treaty) did not spell out the implications of annexation. Māori were being told only half the story. Not surprisingly, they expressed serious reservations, especially about the extent of kawangatanhga; but at Waitangi, if not elsewhere, Hobson gave assurances that the main need for a cessation of sovereignty (rendered as kawangatanga) was to better control Europeans. The cessation of power involved in sovereignty was muted and the likely intrusion on Māori independence minimised. Explanations presented the treaty as a protective instrument (Orange, 1989 p:13).

Further the often quoted words of Hobson, that 'we are one people'; or in Māori 'he iwi tahi tatou' 
should be understood in the Christian sense, less as an aspiration for a unified nation than as a covenant: Māori and European would be one in the one God. Heke spoke of the Treaty as the new covenant; and the idea was echoed at the Kaitia treaty signng.... 'if your [British] thoughts are towards Christ as ours are, we shall be one' (Orange, 1989 p:13).

For the colonists, assumptions were made about rights to Māori sovereignty being subsumed by the Crown. Māori assumptions of the separation between governorship and full chieftainship were very different. Kawangatanga would have implied a more limited concept of sovereignty than perhaps what the British ultimately had in mind (Orange, 1987, 1989). Pressures on Māori quickly increased.

\subsubsection{Land Confiscation and Language Loss}

Fragmentation of Te Reo, and matauranga Māori [Māori knowledge] mirrored the systemic dislocation and depopulation which carved a deep wound in the history of the Māori, post-Treaty (Belich, 2001). Forced land sales led to the Land Wars of 1864, with a Times newspaper headline summing up the position: 'All questions between the British colonists of New Zealand and the Māori are now merged in a war of sovereignty - probably of extinction' (Orange, 1987 p:159). The colonists embarked on a radical programme of native assimilation; subsuming Māori identity and customs within nascent Pākeha structures (Durie, 1998, 2000, 2003; Walker, 1989, 1992). In 1877 a legal judgement described the Treaty as a nullity 'since Treaties with primitive barbarians lacked legal validity' (Durie, 2003 p:181). The Tohunga Suppression Act in 1907 banned the specialised use and transmission of matauranga Māori. Military domination, legal 
institutional structures and the systematic devaluing of matauranga Māori by Pākeha capitalist practices were all forms of knowledge supremacy designed to ensure the dominance of one institutional system over another. The impact that colonisation had on matauranga Māori was prolonged and disastrous.

Rangatira were steadily overwhelmed by the tsunami of colonisation. From the outbreak of Pākeha - introduced diseases to the spread of muskets taken up and used in inter-tribal warfare, the signing of the Treaty of Waitangi in 1840 brought an apparent agreement for protection whilst giving rangatira a belief that their own leadership would be maintained. From the 1840s onwards, Māori knowledge and organisations, iwi and hapu populations receded drastically. The Māori population fell to a low point of 42,113 in 1896 from estimates of around 7090,000 in 1840 from over 140,000 previously (Lange, 1999). Stewardship of sixty-six million hectares of Māori land dropped to eleven million in 1896 (Lange, 1999). Whatever the numbers, the effect of colonisation on the collective spirit, health and welfare of Māori is beyond debate.

The widespread use of English marginalized and reduced the use of Te Reo which dropped from being fully spoken in 1820 to a point where, by the 1970 s its extinction was being confidently forecast, with the data supporting this prediction: $90 \%$ of Māori school children were fluent in 1913, by 1953 the figure dropped to 26\% while in 1975 it was less than 5\% (Durie, 1998, 2003). 
English was institutionalised as the language of progress. When English was known by the speaker, Te Reo was illegal in the courts, hospitals or schools up until as late as the 1970s. In a newspaper article dated as late as 1972, Mitchell argued for 'one nation' and that the revival of the Māori language would be a 'disaster' and that it would create isolation, whereas 'if we are to be one nation we must have one language: English - the international language of education and development'(Mitchell, 1972 p:1).

Globalist practices dislocated Māori from their holistic cosmologies and communities. From 1960 onwards, rural Māori were encouraged to move to the cities where the jobs were. This economic participation was short lived, as after the reforms of 1980 s rendered much of these businesses obsolete. Not only were many more Māori made redundant in the ensuing period than non-Māori, urban Māori were also dislocated from their own turangawaewae [ground of standing] and their own whakapapa in tribal locations.

\subsubsection{Māori Challenge and Redress}

Durie (2000) notes two main responses that emerged from 1900 against assimilationist practices. Firstly, adaptation within the institutional frameworks encouraged strong Māori cultural identity. The second supported the acquisition of Western knowledge and skills but towards Māori self-control and autonomy. The dominant theme in each has been the protection and nourishment of a strong and distinctive Māori culture. Māori leaders such as Ngatata, Pomare and Buck 
were among the first university-educated Māori. They soon formed the Young Māori Party to implement change from within the system.

Many Māori activists challenged colonial sovereignty. They proposed full control should occur through Māori processes and structures. Small victories began to relegitimise Māori knowledge within institutions (Orange, 1987; Walker, 1992). Māori Studies University Departments were formed in the 1960s to upskill Māori leaders for roles in tribal organisations and trust boards. In 1971 the first Māori was appointed to the position of Race Relations Conciliator. Legal challenge in 1975 led to The Māori Language Act 1987, which declared Māori an official language of New Zealand (Durie, 2000). However despite all this, the relationship was established of asymmetrical paternalism between The Crown and Māori. However The Crown eventually began to come to some level of protection and even redress for Māori.

\subsubsection{The Treaty Act and Settlements}

The forced sale of lands and clearances abated with the establishment of the Treaty of Waitangi Act of 1975 which was designed:

To provide for the observance, and confirmation, of the principles of the Treaty of Waitangi by establishing a Tribunal to make recommendations on claims relating to the practical application of the Treaty and to determine whether certain matters are inconsistent with the principles of the Treaty (The Waitangi Tribunal, 2004 p:1).

The Act established The Waitangi Tribunal which is, 'a permanent commission of inquiry charged with making recommendations on claims brought by Māori 
relating to actions or omissions of the Crown, which breach the promises made in the Treaty of Waitangi' (The Waitangi Tribunal, 2004 p:1). Treaty settlements from 1985 helped underpin larger economic and social Māori development goals. An ever increasing number of iwi have reached settlement with the Crown for land confiscation and emotional trauma caused, although amounts are far less than current market value of land confiscated (Wilson, 2001). The slow recovery of Māori language is also occurring. A 1986 Waitangi Tribunal Hearing sounded a dire warning on the decline of the language: 'Ka ngaro te reo, ka ngaro taua, pera i te ngaro o te Moa [If the language be lost, man will be lost, as dead as the moa]' (Durie, Latimer \& Basil,1986 p:1). It encouraged the state to recognise the language as a treasure and adopt it within the education system and as an official language. The Māori Language Act of 1987 did the latter but it was local community initiatives that began the process towards the former.

\subsubsection{Recovering Te Reo: Kohanga Reo and Whare Wānanga}

The Kohanga Reo [Māori language learning nests] movement began in 1981 . Immersion schools taught Māori by Māori according to tikanga Māori [Māori principles] within a Māori holistic cosmology. These language schools have not been limited to children's education. The re-establishment of wānanga has paralleled this desire for Māori self-determination. However these institutions began without any formal government funding or support. As grassroots organisations they grew on voluntary donations of resources and time until finally 
being recognised as Crown educational establishments in The Educational Amendment Act 1993.

Te Reo remained at relatively low levels. In 2001 statistics still showed only $8 \%$ of the Māori adult population were highly fluent. Of these, $71 \%$ were aged 45 or over (Te Puni Kokiri, 2001), 35\% showed medium comprehension while $30 \%$ of the Māori in adult population had very low levels. With initiatives such as Kohanga Reo, wānanga and the commencement of the Māori TV channel, which was launched after some controversy in 2003, support for the language is increasing (Durie 1998, 2000, 2003).

Wānanga are significant for the progression and protection of Māori knowledge. The early success of the kohanga reo/wānanga model encourages Māori self development by creating a model for a 'bicultural system of education provision and management' (Walker, 1992 p:15). At the 2002 International Development Studies Conference an international visitor asked Professor Mason Durie if there was a government department to 'safeguard Māori knowledge'. He replied "The kaitiaki or guardians of traditional knowledge would be the three wānanga. They are the protectors of Mātauranga Māori, and they also serve a function in expanding and safeguarding this knowledge whilst ensuring its quality". (M.Durie, personal communication, March $15^{\text {th }}, 2002$ ) 
Recent tribal settlements, the programmes of the three wānanga and the increasing ability of Māori to be effective in two worlds (the Māori and the Pākeha) has resulted in the Māori economy gaining in both recognition and capital (Comer and Sundakov, 2003). Despite this, many Māori still experience regular and structural marginalisation within many mainstream organisations who look to America or Japan for legitimate management knowledge. They tacitly devalue Māori knowledge because managers 'would not know how to find out about this knowledge and do not recognise its existence' (Tremaine, 1990 p:49). There is also a difficulty of communication that Māori themselves share, if their own comprehension of Māori knowledge is low (Tremaine, 1990).

Institutional power dynamics also place constraints on Māori to interact and share their knowledge freely. Many are discouraged 'because they are not sure they will be treated seriously' (Tremaine, 1990 p:49). Despite bicultural tokenism within many Government departments, mainstream organisational practice does not draw from Māori knowledge. No real cultural sharing goes on deeper than the veneer of Māori ritual adopted to abide within politically correct protocols (Tremaine, 1990 p:49). Organisational leaders in New Zealand remain reticent about trying indigenous ideas. Conversely they remain keen to borrow ideas that have not proved particularly successful in international contexts, implicitly legitimating globalist knowledge superiority (Tremaine, 1990 p.49). 


\subsubsection{Māori Political Autonomy and Representation}

While autonomy is practised by many Māori organisations, including iwi and hapu, seeking autonomy at the national level generates unease both within Māoridom and the state more broadly (Durie, 2003). While national Māori autonomy and governance remains a central goal, Durie (2003) argues that: 'much deliberation is required to ensure adequate representation of iwi and hapu interests are met within the state frameworks, if some form of devolved power were to be achieved' (Durie, 2003 p:178).

Moves towards greater political representation have engaged many Māori leaders. Professor Winiata, Tumuaki [chairperson] of TWoR was elected President of the newly formed Māori Party in June 2004, alongside the co-leaders, MP Tariana Turia and Dr Pita Sharples, academic and Māori Community leader, after its formation which was in part a response to The Foreshore and Seabed Act (2004). When asked on the position of the party on self-determination, Ms Turia responded that self-determination was a central concern for the party and the three tikanga houses model could be useful. Winiata and the Raukawa Runanga [tribal authority] developed this framework to example a three-tier power sharing constitution within the Anglican Church, who transferred decision-making autonomy to Māori. Winiata articulated how this model is based on a quality partnership of equality, not separatism:

It is certainly not separatism. It is rather unity, through a quality partnership, and equality in that two partners, notwithstanding the difference in their numbers, are making decisions together. It does not prescribe sovereignty for Māori, and that is a ground on which many Māori reject it. There are plenty of Māori around who want sovereignty, and that means Māori in sole charge. This is a partnership model, which 
aims at providing for each of the partners to develop within their own set of models.

Sovereignty does not fit this model (Milne, 1998: p.2).

Discussing power-sharing as the keynote speaker of the Waitangi Day Rua Rau

Tau Lecture Series in 2005, Winiata spoke of the hope that The Māori Party might, if elected to Parliament, bring notions of tino rangatiratanga and kawanatanga to balance competing Pākeha governance:

If the Māori party can succeed in gaining $10 \%$ of the Pākeha support then there is a very real chance that, for the first time in 200 years kawanatanga can be brought into more balance with tino rangatiratanga (Radio New Zealand National, 2005).

As the following chapters will demonstrate, working towards autonomy is a very significant process for TWoR at a range of levels. Table 6 below summarises the chapter's constructionist assessment of how both Māori and colonial settlers have constructed 'Māori' in historic and current contexts. From the context to the Māori case, I next briefly cover how notions of 'Celtic' have been constructed by both powerful 'others' and Celts themselves.

Table 6: Māori Constructed in Differing Contexts

\begin{tabular}{|c|c|c|}
\hline Māori defined by & Colonial Settlers & Māori \\
\hline Historic & 'Native' 'Aboriginal' 'Barbarian'. & Iwi and hapu + national movements. \\
\hline Purpose & $\begin{array}{l}\text { Delegitimise Māori knowledge as } \\
\text { primitive, assert legitimacy and } \\
\text { supremacy of Colonial project, } \\
\text { delegitimise Māori language \& Treaty } \\
\text { Partnership. }\end{array}$ & $\begin{array}{l}\text { Emphasise sacred connections to land and } \\
\text { unique tribal identities, emphasise tribal } \\
\text { genealogy Māori rangatiratanga: } \\
\text { autonomy. }\end{array}$ \\
\hline Current & 'Māori' 'Separatist'. & Iwi' 'Hapu' + national movements. \\
\hline Purpose & $\begin{array}{l}\text { Delegitimise alternative 'national } \\
\text { imaginings' and Māori education } \\
\text { emphasise Globalisation and First } \\
\text { World National development under } \\
\text { Pakeha structures: 'one nation' } \\
\text { emphasis delegitimise } \\
\text { Partnership. }\end{array}$ & $\begin{array}{l}\text { Relegitimise Māori language. } \\
\text { Reassert Māori knowledge. } \\
\text { Redefine Māori 'national imaginings' as } \\
\text { Māori Party, amongst others. } \\
\text { Re-emphasises Treaty partnership. }\end{array}$ \\
\hline
\end{tabular}




\subsection{Constructing Scottish 'Celtic'}

The signifier Celtic is ascribed to speakers of the later Celtic languages viz: Gaelic Irish; Gaelic Scottish; Welsh; the peoples of Brittany, Cornwall and the Isle of Man. Despite differences, they carried a similar culture and archaeological style, historically named La Tene. These peoples originally travelled from Greece, through Northern Italy to Eastern Europe and on to the Western Isles of Scotland (Meek, 2002). This signifier attributes Celtic to language, but without any reference to a larger holistic cosmology, or Celtic knowledge.

O'Hagain (2002) locates Keltoi as deriving from the Greek word 'Kel', meaning 'to strike' and suggests it indicates a warrior people who were indeed wide travellers (O'Hogain, 2002). Joyce (1998) suggest Keltoi meant others or strangers, a term used by Greeks in referring to the others they found in their travels of Europe from the $5^{\text {th }}$ Century B.C on (Joyce, 1998). A Greek trader Herodotus described the 'Keltoi' as peoples found to the north of Massalia in Greece in the $5^{\text {th }}$ Century B.C. (Arnold and Gibson, 1996 p.2). While Arnold and Gibson (1996) suggest these Celtic peoples close to the borders knew and used the term to describe themselves, others further from the border would not, using individual tribal names of their chiefdoms.

Their tribal structures and aristocratic cultures had extensive rituals and extended clan-based social relations. Fortified settlements were the political capitals of local chiefdoms (Arnold and Gibson, 1996 p.8). The leaders or family 'kings' had 
wide powers embedded within clan elites, and were backed by warriors to implement their policies. These chiefdoms became major political entities which were remarkably durable and fluid (Brun, 1996). Notions of Divine ancestry legitimised clan identity by conferring hereditary title and status. These clans (Gaelic for 'the children') later migrated to Ireland and Western Scotland around 600 B.C., being called the Pritani or those who paint themselves, again by the visiting Greeks in 325 B.C. (O'Hogain, 2002). The clans emphasised genealogy 'as a means of defining the tribe, and to establish the status of the members' (O'Hogain, $2002 \mathrm{p}: 17$ ). The descriptive writings of the Greeks, in the first century B.C. onwards, constructed the Celts in barbarous terms, emphasising by contrast the civilisation of the Greek mind:

Aristotle made references to them, praising them for their courage, but expressed the opinion that they were rash to the point of madness... To such writers the Celts could be portrayed as the opposite of the civilised Greeks in whatever way was opportune to mention (O'Hogain, 2002 p:18).

O’Hogain (2002) emphasises how the early Celtic leadership displayed hospitality to strangers as a mark of their chieftainship and a sacred rite. If they were harmed or defrauded in any way, the leader would lose influence and position.

Julius Caesar states that 'violation of guest friendship they regard as impious strangers who have visited them for whatever reason they protect from injury and hold sacred, and every man's house lies open and his food is shared with them (O'Hogain, 2002 p:22).

The zenith of Celtic civilisation in the $3^{\text {rd }}$ Century B.C. saw the Celtic peoples inhabit most of West, Central and Eastern Europe, having combined forces to sack the nascent Rome in 388 B.C., and attack Greece with a 50,000 strong army in 278 B.C. Subsequent defeats by the strengthening Roman armies pushed the 
Celts back to the fringes of Western Europe. Interestingly, O'Hagain (2002) suggests that the migrating Celtic tribes interbred with the non-Celtic population who were indigenous to Ireland, although a lack of historical sources means no clear picture emerges of who these pre-Celtic indigenous Irish people were (O'Hogain, 2002).

The Romans also constructed the Celts as uncivilised and brutish in contrast to their own orderly civilisation. The Celtic peoples of Europe were further pushed to the margins with the Romanisation of the once Celtic Gaul (being the Galatians that St Paul refers to). The Celtic female leader Boudicca led uprisings where the Celts describe themselves in terms of their courage and ability to hide in forests and swamps, surviving through their knowledge of local ecologies (O'Hogain, 2002). The Celtic kingships ultimately survived the Roman occupation and, with the fall of Rome in 410 A.D., began to flourish. Kingly families such as Niall had re-established themselves in Ireland (O'Hogain, 2002).

A captured slave who later escaped and returned established Christianity as the major cultural force in early Ireland. St Patrick's mission work in 432 A.D. created the first interweaving of indigenous Celtic customs and Christianity. The earliest Irish 'towns' formed centres of community, commerce, literature and agriculture from the early Celtic Christian monasteries which were simple wattle huts (Joyce, 1998), as was the later Celtic Monastery formed on Iona. 
The art work of this later period exampled in the Book of Kells, written by the Celtic Christian Monks on Iona in about 900 A.D., emphasises the themes of Celtic Christianity, the interwoven nature of all creation, reflecting God's energy, as shown in Figure 6, below (Folio 32V).

Figure 6: Example Page from The Book of Kells

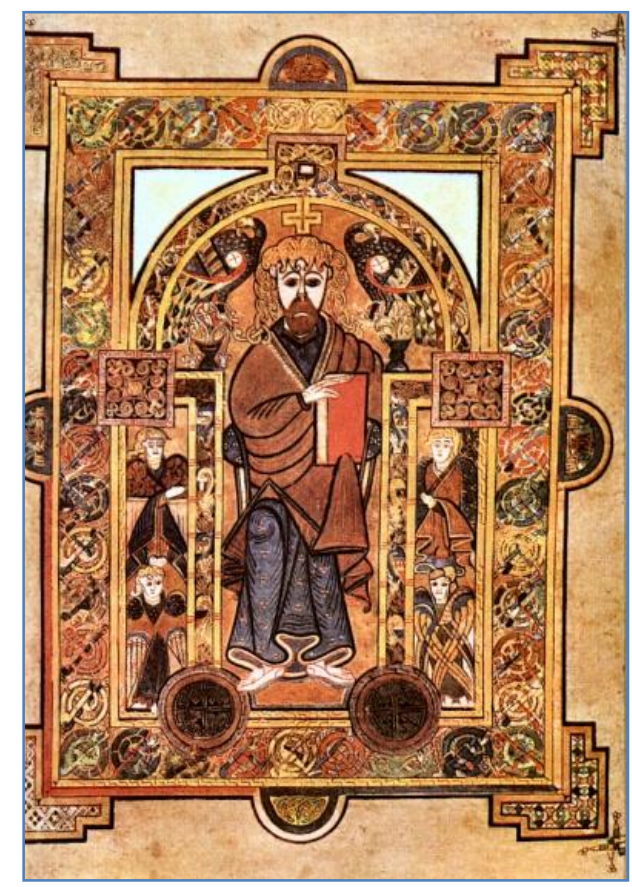

(Wikipedia, 2005)

The growing Irish Kingdom of Dalriada gained a foothold in the Scottish Isles through missionary expansion. Conall, granted the Isle of Iona to an Irish Monk Criomhthann, otherwise known as St. Columba, the great-great-grandson of Niall. From Iona the whole of northern Britain was slowly converted, and monastic centres were established in Lindisfarne and elsewhere. 
St Columba is attributed with many visions, the most significant of which is: 'In Iona of my heart, Iona of my love, instead of Monks voices will be the lowing of cattle, but ere the world come to an end, Iona shall be as it was.' (MacArthur, 1996 p:45).

\subsubsection{Early Celtic and Scottish National Identity}

St Columba helped create and expand the early Scottish nation, crowning - and therefore legitimise with Divine blessing - Aedan, King of Dalriada, in 574 A.D. (MacArthur, 1996). St Columba's life was later chronicled for political purposes by Adomnan, who emphasising his allegiance to God as opposed to any Ecclesiastical authority (MacArthur, 1996). This subtly stood against the Romaninfluenced Synod of Whitby in 664 which is widely, if mistakenly, held to have marginalised the Celtic Christian Church, given that the decline of the Celtic Church was already well underway (Bradley, 1994). Although the closeness to nature which characterises the Celtic Christian tradition can be overdone - their closeness to nature was a result of surviving in very harsh conditions - what is unquestioned is the unique sense of the Divine being present both in nature and at the centre of community life (Bradley, 1994). Further inasmuch as Christianity, it can be claimed, itself marginalised pre-existing indigenous beliefs:

If a world religion is to take root in a community, then it is inevitable that some degree of fusion or coalescence will take place between the new religion and the religious forms it seeks to replace. [In this way] pre-Christian religious paradigms and forms will certainly have governed the way in which Christianity was assimilated but also the types of Christianity that became established (Davies, O'Loughlin \& Mackay, 1999 $\mathrm{p}: 13$ ). 
Celtic Christianity was interwoven with, and acceptable to the peoples who were indigenous to Western Ireland and Scotland. Without dwelling too long on theological issues outside the scope of the thesis, enough evidence and scholarship exists to safely take the emergent 'Celtic Christianity' as collectively the 'indigenous worldview' of the Western Isles (Bradley, 1994; Davies, O'Loughlin et al., 1999; MacArthur, 1996; O'Hogain, 2002). For the purposes of the thesis it is taken as the ancient beliefs of a settled people located in historic and sacred relationship to place, and to each other.

Iona was significant as the focal (although not earliest) site for the emergence of Celtic Christianity. At the time, Iona was a strategic base for the expansion of the Kingdom of Dalraida, which was later to be united with the Picts in 842 A.D. by King Kenneth MacAlpin into the largest expression of an early united Scottish nation. Figure 7 (over) maps Iona in the historic and political context of Dalriada. 
Figure 7: Iona in Historical and Physical Location

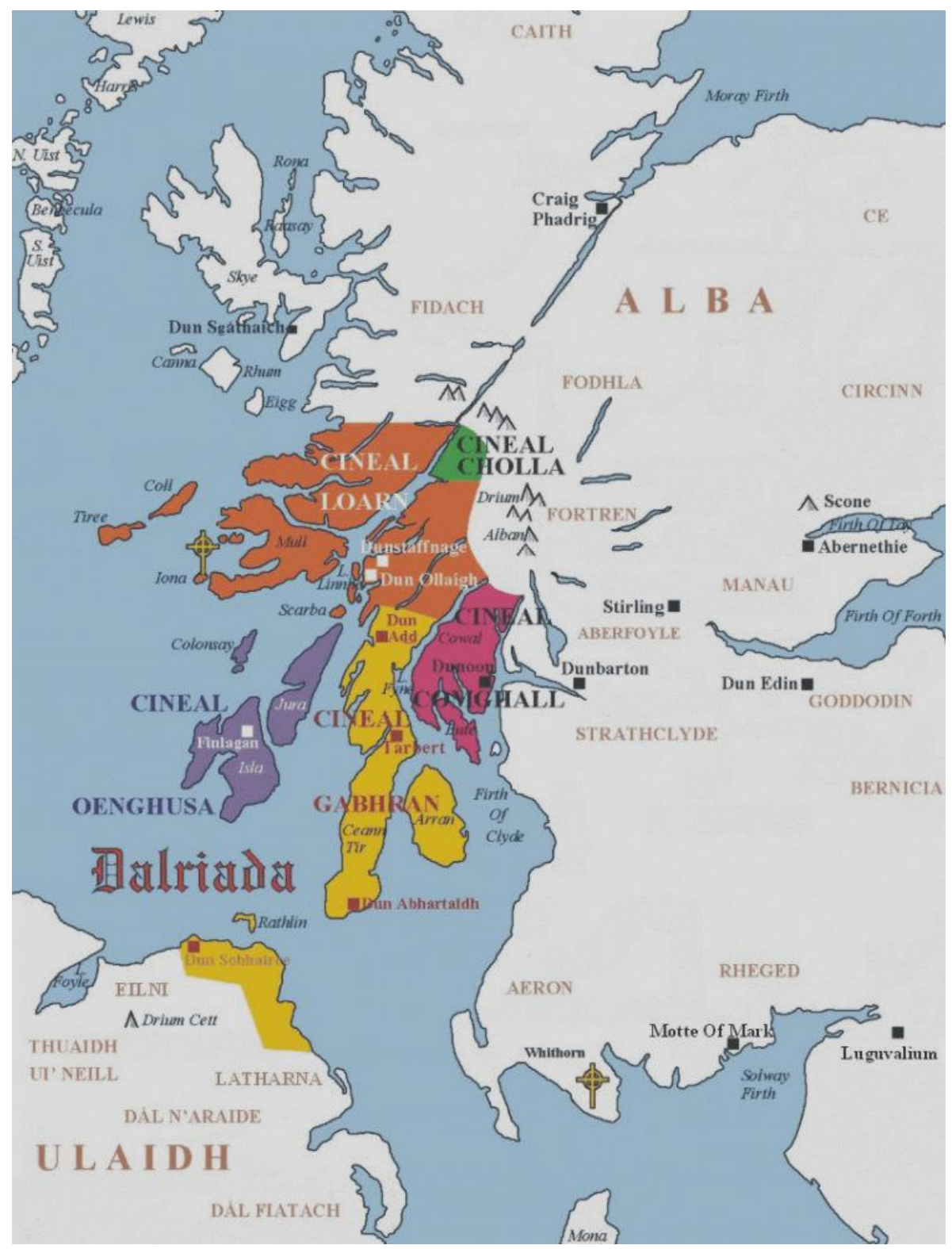

(MacDonnell of Leinster, 2006) 
During this period the Pictish language and culture went into decline, to be replaced with Gaelic Irish. Iona continued as a place of sacred reverence, being the burial place of many Scottish and Scandinavian kings. However the increasing influence and reach of the colonising Vikings pressured the Irish and Scots. The white sands of Iona were turned red with the massacre of Celtic monks by Viking raiders in the 9th Century, in the aptly-named Martyrs Bay. Iona remained a centre of worshipping and educational life up to and beyond the 12th Century, but many of the crosses adorning the Isle were removed by the Scottish Reformation of the $1600 \mathrm{~s}$, reflecting in microcosm the changes on the British mainland.

\subsubsection{Scotland Assimilated In Union}

Scottish Monarchs were subsumed by the militarily and numerically stronger English to the South. The Union of the Crowns occurred in 1603. English Sovereign Acts and Laws encouraged the denigration of Highland Scottish customs and culture. Successive English Kings sought full control over Scotland using patronage and land gifts to entice Scottish clans into English alignment.

In 1707 The Act of Union subsumed the Scottish Parliament in Edinburgh to the Parliament in London, and the inferiorisation of Scottish and Highland culture accelerated. After the 1745 Jacobite Uprising, The Disarming Act of 1746 forbade the wearing of highland clothes or any tartans. Devine (2000) suggests this Act was a direct attempt at economic and social assimilation. The mainland Scottish elite joined with the South in the denigration of the North, supporting economic 
and social development. The Industrial Revolution and the new economic orthodoxy had dramatic consequences on the Highland tribal clan system which was vibrant up until around 1700 A.D.

\subsubsection{Land Clearances and Celtic Cosmology Fragmented}

The clan elites rapidly succumbed to rising market prices for wool, sheep and intensive farming methods. It was lamented by many 'that profit was beginning to take precedence over ancient social responsibilities of the clan elites' (Devine, 2000 p:220). The land clearance policy enforced by the elites themselves forcibly removed crofters and tenants from the land to enable more profitable sheep farming. Bragg (2003) suggests this is direct evidence of the negative impacts of globalisation:

What we are seeing in this little microcosm is really the manifestation of global capitalism in the $19^{\text {th }}$ century. The landed classes had interests that stretched almost across the globe. In today's standards we are talking about billionaires (Bragg, 2003 $\mathrm{p}: 7)$.

When interviewed, Devine (2000, 2003) states globalisation unequivocally fragmented Scottish clanship, with notions of consumerism fragmenting communal ownership.

The death of clanship was very long drawn out process. A major factor was the growth of consumerism among the elite, which meant they had to start to adopt a more commercial attitude towards property (T. Devine, personal communication, July $15^{\text {th }}$ 2003).

Economic development legitimated fragmentation in its drive to create 'progress'.

Why could people have behaved in this way towards communities of their own ethnic kin group? There was a dominant assumption that for the better improvement of the society and the economy there had to be short term social costs, and they [the establishment] were prepared to bear these (Bragg, 2003 p:7). 
Imbricating the barbarians to the North as lazy and uncivilised helped legitimise the clearances to the mainland populace, and also to the chiefs themselves, who saw economic development as unquestionably better than the backward North.

Self styled intellectuals and the Church of Scotland threw up their hands and accepted that the crofting culture, which had survived for generations, was now, suddenly and inexplicably unsustainable: 'if they hadn't been so Celtic and feckless and dim, the Highlands wouldn't be in this mess' (Paterson, 2003 p:7).

Images within English literature recast and celebrated the wild Celtic Scottish warrior as brave and fierce, but now subsumed in support of the expansionist colonial project:

We find the confection of Scoto-British Celticism in the service of British military aggression. Ancient history has been overwritten with eighteenth century literary history. Ethnic distinctions are erased from historical consciousness. We see a British literary appropriation as the Scots language and literary revival of the eighteenth century is garishly... subsumed within the newfangled British Imperial myth of the 'fighting Jock' (Carruthers and Rawes, 2003 p:2).

The Highlander was constructed in less heroic terms in service of the identity construction of the Imperial project:

There was a long tradition of anti-Highland satire in both lowland poetry and song which can be traced back into the Middle Ages. References in works of such poets as William Dunbar and Sir Richard Holland caricatured the Gael as stupid, violent, comic feckless and filthy (Devine, 2000 p:232).

Bragg (2003) suggests the rationale for the demise of Celt was that they were lazy and prone to economic dependency: 'The [mainland] newspapers argue that this crisis has been brought upon by the racial inadequacies of the Celt which has helped to bring this catastrophe upon themselves' (Bragg, 2003 p:7). The capitalist worldview that was extending to America and New Zealand was also finding its place in Scotland, as evidenced by the ruling elite disavowing long held reciprocal obligations and instead emphasizing individualism. 
The gentry and landed-classes had accepted that communal agriculture was invalid. Individual control was good, the argument being that it released all the energies of ambition and initiatives, which according to this view were constrained or inhibited by communal agriculture. This was not simply in the Highlands but in the Lowlands as well. (Devine Interview, 2003).

This was an unquestioned challenge to a Celtic holistic cosmology which emphasised reciprocity and communal ownership:

It was a classic indication that under one family it was better done than the communal practices of the past. It was the implementation in terms of agronomy and the individualistic ethic. It was a powerful force, almost akin to an ideology in destroying communal structures (Devine Interview, 2003).

At times this imposition of a new spirit of individualism and profit maximisation by the clan chiefs was imposed by force if nothing else. 'It was established as part of improving agriculture. The old systems of joint tenancies were steadily and sometimes ruthlessly dismantled' (Devine Interview, 2003). The Duke of Sutherland forcibly removed up to 25,000 people, and in the Highlands as a whole between 1841 and 1861 a full third of the population was lost, becoming the settler migrants in New Zealand amongst other locations (Paterson, 2003). Commercialism as an 'economic fashion spelled the beginning of the end of a way of life' (Paterson, 2003 p:26). The local people were evicted, and the estates and lands were concentrated in the titled English landed gentry. Newly wealthy were also keen to emulate the life afforded to wealth and privilege. From the 1800s onwards the Highlands were reconstituted as 'sporting estates' that provided recreation for the nouveau riche and landed gentry (McIntosh, $2001 \mathrm{p}$ : 84). 
Another outcome of globalisation on the Highlands was the rapid erosion of spoken Gaelic. Although Census data wasn't available until 1891, in the century to 1991 , Gaelic use declined from 250,000 speakers to 66,000 (Devine, 2000). The clan system collapsed and communal lands were cleared for individual farming strips with rising rents. From 1745 to 1850 migration to the industrial lowland created rampant squalor and urban overcrowding. The urban population rose dramatically. However, the Act of Union often meant these areas were not protected from the major economic changes sweeping Europe.

\subsubsection{Celtic Knowledge Survives Globalist Fragmentation}

Pockets of both Gaelic as a spoken language and Celtic Christianity as the indigenous worldview survived in the Western Isles. Between 1855 and 1899 Alexander Carmichael, a Customs and Excise Officer travelled through the Isles, collecting Celtic prayers and songs in Gaelic. The Carmena Gadelica or 'Charms and Incantations of the Gaels' was published in 1900. Celtic knowledge began to recover the Celtic identity. MacInnes (1994) quotes Carmichael in 1905.

Let us show the world that our dearly loved people were not the rude, barbarous, creedless, godless ignorant men and women that prejudiced writers have represented them as it is to me heartbreaking to see the spiteful manner in which Highlanders have been spoken of (MacInnes, 1994 p.12).

These prayers and chants reflected the closeness to nature, prayers for everyday tasks, and 'chants to the faeries' which have at times been seen as nothing more than folklore or superstitious rubbish (MacInnes, 1994). Celtic Christian knowledge which was still intertwined with Gaelic continued to be taught and transferred between generations from the Bardic indigenous universities that 
flourished up to James IV and the oral traditions that gave rise to Carmichael's controversial collection (McIntosh, 2001). While Meek (2002) challenges whether the term Celtic can be applied to non-Gaelic speakers, he and MacInnes (1994) both locate the Celtic worldview within the Highlands and Islands of Scotland. Despite the continuity of Celtic Christianity in the practices of the Gaelic speaking peoples of the Western Isles of Scotland, globalisation increased the pressures on the indigenous worldview and language. Gaelic speakers on the island and mainland declined.

The decline in Gaelic, and the songs and stories that went with it, will have been keenly felt, by some at least. Others may well have been influenced by the prevailing ethos throughout the country, that the language had no useful place in this 'modern age' (MacArthur, 1996 p:145).

The Iona church had been left in ruins, and while being a popular location to visit for travellers to the Highlands, interest remained at the level of the historical monument. However proposals emerged for the rebuilding of Iona Cathedral to be a centre for the study of Celtic religion and Gaelic language, initially from wealthy American expatriates, The American Iona Society. These proposals were met with wary scepticism until a counter-proposal by a famous Scottish preacher and IC founder to rebuild the Iona Chapel as the first project of the new IC was agreed to by the Trustees of Iona in 1935 , as an intentional project to counteract the urban squalour of Glasgow (Ferguson, 1988, 1990).

\subsubsection{Current Context: Sovereignty and Nationhood}

Scots struggled for equitable representation under the Act of Union in 1707. Successive rule by London, although 'legitimate' in terms of the legal political 
structures of the United Kingdom, produced anomalies like the recent period of 1979 to 1997 where The Conservative Party were without a widely accepted social mandate, being un-represented in Scotland. A single Conservative Minister in Parliament represented Scottish peoples, whose allegiances were either with the Scottish Nationalist Party (SNP) or with Labour. These periods of directly unrepresentative rule were imposed by a country out-with the social and physical borders of Scotland. Indeed, the granting of a devolved Parliament to Scotland on July 1st 1999 strengthens the argument that this was the case.

The impetus for change came after long and sustained pressure from the Scottish National Party whose calls for devolution and independence were finally acknowledged by the then new Labour Government (Curtise, McCrone, Park \& Paterson, 2002). The Scotland Act, 1998 provided for the recreation of a Scottish Parliament which allowed for devolved decision-making in all areas except: the UK constitution; immigration and nationality; foreign policy; defence and national security; macro-economic and monetary and fiscal policy; regulation and employment. While full independence remains to be achieved, devolution has allowed Scottish policy to be developed around the core areas of: health; education and training; local government; social work; housing; planning; tourism, economic development and financial assistance to industry; some aspects of transport, including the Scottish road network, bus policy and ports and harbours; law and home affairs - including most aspects of criminal and civil law; the prosecution system and the courts; the Police and Fire services; the 
environment; natural and built heritage; agriculture, forestry and fishing; sport and the arts; and statistics and public registers (The Scottish Parliament, 2004).

One of the first acts to be passed was The Land Reform Bill (2001) whose purpose was to reverse the impact of the clearances and re-institute communal ownership, reaffirming the communal holistic cosmology that had prevailed for many centuries before 'to create new rights of access and of crofting community ownership' (Scottish Parliament Land Reform Bill, 2001 p:1). A number of infrastructure, language support, educational and health initiatives have resulted in the Highlands and Islands, which was once seen as the dim and feckless North, as being hailed as a model of success by Scotland's First Minster, Jack McConnell, speaking at a new Gaelic University which opened on Skye in 2004.

The Highlands and Islands renewal has occurred over 40 years and it has accelerated with devolved government. It has been underpinned by government action - local and national - not a coincidence or a series of accidents, but a deliberate choice to invest and modernise. Government has invested in infrastructure, in education, and in culture. And Government's have promoted individual enterprise and community responsibility with economic reforms and crucially, with land ownership reform (McConnell, 2004).

The change in status of the Highlands and Islands to the flagship model of regional development is for a new confident Scotland, means becoming free from the internalised inferiorisation associated with old imbrications, otherwise known as cultural cringe.

I want to see more Scottish communities and regions develop the confidence to grow just as the Highlands and Islands has grown. I want a Scotland welcoming Fresh Talent, just as the Highlands and Islands is doing as part of its renaissance and I want a Scotland where the Scottish cringe has given way to confidence and belief - just as the Highlands and Islands has overcome its lack of confidence and belief (McConnell, 2004). 
While the devolved Government has certainly achieved much, early analysis suggests that Scottish voters remain as wary of Scottish politicians as they were of those in Westminster (Curtise, McCrone et al., 2002). Further the ability of the Scottish Parliament to reflect Scots' own wishes and aspirations is an ongoing challenge, as recent cost escalations in the construction of the Scottish Parliament Buildings have shown.

\subsubsection{Gaelic Renaissance}

Devolution brought a dramatic increase in funding and support for the revitalisation of Gaelic. A vision was articulated for Gaelic at the heart of Scotland.

As a foundation stone in the building of the new Scotland, the Gaelic language will be an integral and dynamic component of a robust and self-assured community with economic and social stability and pride in its linguistic and cultural identity. The intrinsic value of Gaelic and the benefits of bilingualism will be increasingly recognised. Gaelic culture will be at the heart of confident and thriving communities. After a transitional period in which the decline of the language will be arrested, it will move into an exciting phase of regeneration and renaissance (Macpherson, Cunningham, MacInnes, MacKay, \& MacSween, 2000 p:b7).

The Report to the Scottish Executive noted that, despite the low numbers

currently speaking Gaelic, it was remarkable the language had survived at all.

It's a tribute to its tenacity, if not a miracle, that Gaelic has survived thus far. Within an overall ideology of linguistic assimilation and the stranglehold of a dominant language and powerful external forces, Gaelic has been neither an official nor promoted language. At worst it was discouraged, sometimes by restrictive legislation including Education Acts, and at one time it was even proscribed (Macpherson et al. 2000 p:b7)

The 2001 Census showed that the largest percentage of Gaelic speakers over the age of three live in the Western Isles, where $71.56 \%$ of the population are Gaelic speakers. Despite this, Gaelic speakers mainly reside in the lowlands and 
mainland Scotland, following industrialisation, and are mainly ageing, being in the 65 and over age group. However this trend is reversed in the outer Isles.

In the Isle of Ornsay, the incidence of Gaelic was stronger in the 3-24 age-range than amongst the older population - the likely result of the estate policies of Fearann Eilean Iarmain which uses Gaelic as the language of business and daily administration. (Macpherson et al. 2000 p:b7)

Where Gaelic is spoken as the everyday language in the community its use increases past the elder rate of attrition. New centres for the study and fostering of spoken Gaelic have also emerged. The Scottish Executive increased funding of Gaelic in the forms of the Gaelic Television programming, Gaelic language nests in schools and two specifically Gaelic learning centres: one 'Sabhal Mor Ostaig', the Gaelic College on Skye and the other the Columban Centre on Islay. Gaelic is not the only aspect of indigenous Scottish culture to have experienced a revival.

\subsubsection{Celtic Revival}

An upsurge of interest in Celtic Christianity has also occured (Pearson, 2002). A litany of popular and new age books have emerged which emphasise a return to the themes of interconnectedness and the relationships to the sacred Earth. While Meek (2002) critiques the more popular of these as romantic and historically suspect, since any unified notion of a 'Celtic' Church never existed, there is renewed interest in the academic study of Celtic Christianity (Bradley, 1994, 1999). This has increased interest in the IC, being the current tenants of Columba's historic site (Bradley, 1994, 1999). Table 7 below summarises the chapter's contructionist assessment of how Celtic and the Scottish national project have been constructed in historic and current contexts. 
Table 7: Celtic Defined In Differing Contexts

\begin{tabular}{|c|c|c|}
\hline $\begin{array}{l}\text { Celtic } \\
\text { defined by }\end{array}$ & Colonial and Imperial & Celtic \\
\hline $\begin{array}{l}\text { Historic } \\
\text { Purpose }\end{array}$ & $\begin{array}{l}\text { 'Native' 'Barbarian' 'Celts' } \\
\text { Delegitmise indigenous knowledge } \\
\text { as primitive, assert legitimacy and } \\
\text { supremacy of Union project , } \\
\text { delegitimise Gaelic language \& } \\
\text { nation Imbricate 'Celtic Warrior' } \\
\text { for Imperialist project }\end{array}$ & $\begin{array}{l}\text { Family 'Clans' + national movements } \\
\text { Emphasise sacred connections to land } \\
\text { and unique tribal identities,emphasise } \\
\text { tribal genealogy, seek autonomy }\end{array}$ \\
\hline $\begin{array}{l}\text { Current } \\
\text { Purpose }\end{array}$ & $\begin{array}{l}\text { 'Scottish Nation' } \\
\text { Accept limited self development } \\
\text { agenda. } \\
\text { Devolved decision making to } \\
\text { reinstated Scottish Parliament }\end{array}$ & $\begin{array}{l}\text { Regions + national movements } \\
\text { Reassert national autonomy } \\
\text { Relegitimise Gaelic language } \\
\text { Reassert Celtic knowledge+ worldview } \\
\text { Herald highlands region as flagship for } \\
\text { a new devolved Scotland }\end{array}$ \\
\hline
\end{tabular}

\subsection{Summary}

This chapter has covered notions of indigeneity and globalist practices in each historic case context, backgrounding the following case study chapters. Section 5.1 and 5.2 examined Māori constructions describing how colonial actors defined Māori knowledge and identity as the savages who could only prosper from Western contact. The Tohunga Suppression Act in 1907 legislated against Māori knowledge holders. Section 5.3 showed how Celtic peoples were constructed as barbarians by the civilising Greek and later imperial English powers, whose identities were co-created by such a contrast. Globalist pressures also fragmented the Gaelic language and Celtic cosmology. Despite this, the Celtic cosmology and Gaelic language survived through the Western Highlands of Scotland in particular. In the next chapter I explore the formation of two indigenous organisations whose leaders sought recovery from the effects outlined above. 


\section{Chapter 6: Exploring Two Indigenous Organisations}

\subsection{Introduction}

This chapter describes how the formation and purpose of each indigenous organisation emerged, positively describing indigenous leaders' agency and uses of indigenous knowledge to overcome the fragmenting effects of globalist practices. Section 6.2 describes TWoR in the context of The ART Confederation and earlier rangatira such as Te Rauparaha. The founder, Professor Winiata is profiled, focusing on how the purposes of TWoR sought to recover and embellish Māori knowledge, and how this activity continued in 2003, illustrating how Māori knowledge underpins the organisation. Section 6.3 describes the IC in the historic context of the Columban Celtic Mission. It describes how the founder, George MacLeod formed the purposes of the IC by drawing from the Columban and Celtic imaginary to overcome globalist practices. It describes aspects of the IC in 2003 which reflected Celtic Christian themes within an ecumenical missonary context. The chapter uses archival, secondary and, where necessary, some primary sources for each case.

\subsection{TWoR in Context: The ART Confederation \& Te Rauparaha}

TWoR presents itself as the latest in a series of joint ventures that emerged from the tribal confederation of the ART: Te Ati Awa, Ngati Raukawa, and Ngati Tourunguatira. The confederation originally formed under the leadership and activities of the rangatira of Ngati Toa, Te Rauparaha (Ramsden, 1951; Royal, 
Baker and Simpson, 1997; Taepa, 1968). Known as a fierce warrior and strategist, Te Rauparaha expanded his tribal domain by leading war parties from their base in Taranaki down to the top of the South Island. Kapiti Island, off the coast of Otaki, was Te Rauparaha's base, where both battles and retaliatory actions of utu were launched.

After being incarcerated by Governor Grey in 1849, Te Rauparara was said to have had prophetic visions, in the same manner that other rangatira such as Te Whiti had claimed in guiding their people through difficult times (Royal, Baker et al., 1997). Upon his return to Otaki, Te Rauparara challenged his tribe to accept Christianity, and to do so by building a church called Rangiātea. Te Rauparahu could see the necessity and benefit of adapting to the emerging colonial environment by his tribe adopting Christianity, although he never did. In this way he sought to free the people from the excessive practices of utu [reciprocal return, either positive or negative] and other ancient tribal customs (Royal, Baker et al., 1997). 
Figure 8: Te Raupara and Interior of Rangiātea Church, Otaki.
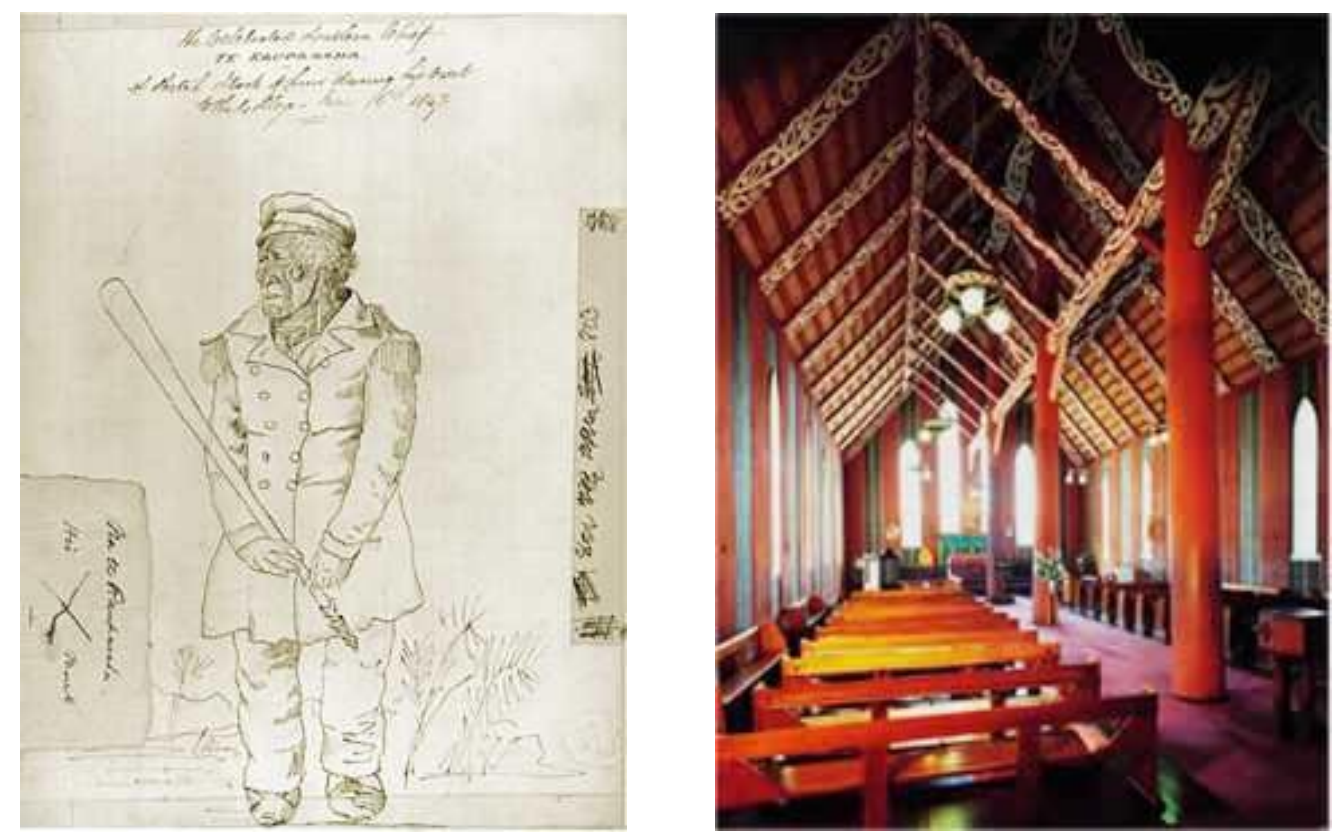

(National Library of New Zealand, 2001 pp:E3, E1)

The church was named Rangiātea after the original Rangiātea, wānanga and homeland of tribal origins. The integration of indigenous spirituality and Christianity was far less disruptive than missionary engagements and beautifully exampled in the style and decoration of the building (see Figure 8, E1 above). Karakia lifted the tapu from the foundation trees and sacred soil from Rangiātea is said to be buried at the altar (Ramsden, 1951; Royal et al., 1997; Taepa, 1968). From the 1850 s onwards the church became a focus for the region. In 1860 the Otaki Māori Racing Club was the first of many ART confederation projects. In 1905, the Otaki Māori Boys Club opened to educate local Māori boys. In 1936, the Raukawa Marae Trustees were established, which led on to the Otaki and Porirua Trust Board in 1943. These alliances gifted or leased lands and buildings, 
and provided scholarship, which benefitted TWoR's founder. The principle of positive utu was exampled in Professor Winiata who himself went on to provide significant educational opportunities for all Māori through the inception of TWoR.

\title{
6.2.1 Generation 2000: Reclaiming Māori Knowledge
}

In 1975, Winiata launched 'Whakatupuranga Rua Mano: Generation 2000': a 25

year major capability rebuilding project. This sought to reverse the negative effects of 150 years of contact with Pākeha. The TWoR founding charter describes these effects on Māori and knowledge.

\begin{abstract}
Māori teaching and learning has been through a period of extreme disarray in the ART region. This condition is a consequence of incessant and increasing pressures from institutions rooted in Tikanga Māori from local and national bodies which have not been able, or have chosen not to embrace Tikanga Māori in their institutions and teachings.The tikanga and Mătauranga of the iwi and hapu [of the ART] is not incorporated in the curricula of the educational bodies which serve these iwi and hapu. It follows that they are unable to ensure the advancement, dissemination and maintenance of the tikanga and Mātauranga of these iwi and hapu through teaching and research (TWoR Charter, 2001 p:5).
\end{abstract}

The confederation sought to reverse low living standards and educational achievements which were half the national levels. No one under 30 could speak Māori, knowledge of Māori identity as expressed by iwi and hapu affiliation was low, and the Marae were in poor condition. 'I think we realised that change, from where we were, to where we wanted to be, like restoration of the language and rebuilding of Marae, would take time' (Winiata, 2000 p:134).

Drawing from his accountancy background, Winiata used external knowledge tools and adapt these for culturally appropriate metrics to measure tribal health. 
He saw how local iwi capability reports were reflecting financial values and priorities of the mainstream, bearing little resemblance to the cultural and spiritual worldview of Māori (Loomis, 1998). This created metrics and measures which were reconstituted within the mātauranga Māori framework. The metric framework located health in terms of : the number of active members of the iwi or hapu; the number of members who have extensive knowledge of whakapapa of the iwi or hapu and can produce it simultaneously; the depth and strength of wairuatanga [spirituality] of the iwi or hapu; the depth and strength of Whanaungatanga [familiness] of the iwi or hapu; the ability of the iwi or hapu to explain and defend their kawa [practices] and tikanga; the strength of Te Reo within the hapu or iwi; the number of active and effective kaumatua within the hapu or iwi; the state of health of hapu or iwi members; the breadth, depth and general state of the books or manuscripts of the iwi or hapu; the condition of the Marae facilities of the iwi or hapu; the number and significance of the taonga [treasures] owned and controlled by the iwi and hapu; the amount of land owned collectively by the iwi and hapu; the size and number of stocks of the hapu or iwi fisheries; the size and state of financial assets of the hapu or iwi; and the value of any radio spectrum parts owned or vested in the iwi or hapu (Winiata, 2000 $\mathrm{p}: 137)$.

These criteria gave the confederation self-defined metrics by which their own health could be assessed, creating impetus to reverse the areas of central concern; a need to recover and embellish Māori language skills, and Māori knowledge 
(Loomis, 1998). Given the above experience of Pākeha institutions (both educational and other) failing to incorporate Māori tikanga, a mission emerged to educate both Pākeha and Māori. in the process recovering and re-legitimising Māori knowledge:

We were running monthly residential seminars, to teach ourselves about ourselves, for our young people, to encourage them to raise their sights. We also ran a lot of programmes for Pākeha - school teachers, parliamentarians, local bodies, and so on called the Pākeha Mission. The idea was that Pākeha were making of decisions for us, and needed to be better informed - that we should encourage them to see things Māori as being valuable. The seminars began to reveal that we needed to be thinking about long-term reinvigoration (Diamond, 2003 p:63).

This long term regeneration coalesced into four principles, each in their own way emphasising identity recovery as a distinct theme:

The first theme was our people are our wealth - develop and retain. That meant those from Bulls, Ngati Parewahawaha, knew that was their international headquarters, and those living in Ohau, Ngati Tukorehe, knew that was theirs. The retention had to do with emotional, not geographic, things. It was not saying that people had to live in Bulls or Ohau for the rest of their lives, but that they knew where they were from, knew their identity, hapu, iwi.

The second theme was the reo. We didn't have anyone under the age of thirty able to speak the language, so we needed to revive it as a taonga by which we would reidentify forever.

The third was that the marae is our principal home. We knew when we looked back over our shoulders, that our marae had fallen into disrepair. The ablutions were in bad shape, the kitchen was the same, and mattresses in the meeting house were few and stained.

And self-determination. We had no doubt that it would set our direction and decide where it was we were going, how soon and by what means (Winiata National Radio interview, 2003).

These themes stressed the desire for autonomy and the need to create structures that would serve the needs of local Māori. They also illustrated the process of indigenisation where members reconnected to their own emotional place of connection and undertake social projects from Māori knowledge. This began the 
reorientation of the autonomous self towards lifeprojects within a holistic cosmology.

Research carried out by TWoR has reviewed the critical success factors of the Generation 2000 programme (WRM). Six main determinants are described first in

Te Reo, with their own interpretations beneath:

- Ka uru nga wahanga katoa o te iwi hei Whakatupumau i tona mana Every section of the iwi were involved in retaining its mana

- Ka huraina, ka whakapUmautia, ka whakawhänuitia te MātaurangaMäori

Re-discovered, discovered, restored and extended Mäori knowledge

- Ka whakapakaritia te hunga rangatahi

Rangatahi were involved, strengthened and gained a lot of knowledge

- He oranga wairua to te kaupapa mo te iwi

The kaupapa was spiritually uplifting for the iwi. Oranga wairua was important

- He Kaihautu to te kaupapa e kaha ana kite whakatutuki i ngä mahi

Leaders of the kaupapa were determined for the kaupapa to be successful

- Ka tautokona te kaupapa e ngä kai-whaiputea

Sponsorship from National and International bodies

In respect to Te Māori, Te Aurere, Waka 1990 Celebrations and Te Wananga-o-Raukawa, these six determinants were identified. The model for success predicts that if these determinants are present in kaupapa Māori events, the event will be successful. Whakatupuranga Rua Mano has all of these determinants. All six determinants must be identified in a kaupapa Mäori (Winiata, 2001 p: 34).

The WRM program gained and grew from local leadership support so that local iwi and hapu retained their mana. This early example shows indigenous consciousness and identity constructed not through the relationships to the coloniser or global contexts as theorised by postcolonial researchers but instead within a holistic cosmology recovered through the experience of learning and using Te Reo and Māori knowledge.

Learning and speaking te reo Māori was spiritually uplifting. Knowing how to speak Māori is a special joy that is felt deeply in our wairua [spirit]. Understanding our values and practices has a similar feeling beyond intellectual stimulation (Winiata, 2001 p:34). 
Reflecting the passionately held beliefs in autonomy, the success of the Generation 2000 project is evidencing the importance of a lack of centralised authority.

Whakatupuranga Rua Mano was not centrally driven. Hapu began to take up the ideas and, in the twenty-five years, all but one of the twenty-four or twenty-five marae have been restored. No one centrally said that should happen (Diamond, 2003 p:66).

Winiata stresses the importance of using new technology firmly embedded within the WRM framework to enhance and retain Māori knowledge such as creating the virtual online marae.

Emotional and intellectual retention, in the absence of geographical closeness, are vital. Information technology and telecommunications could be used to advantage. Emergent information technology and telecommunications, and video conferencing in particular may create virtual marae on line. We must have a view about our future that is cradled within our own view of the world (Winiata, $2000 \mathrm{p}: 142$ ).

This use of internet technology illustrates the adaptation to new technologies that Māori have been capable of since settler contact but within a recovered holistic cosmology. Whereas neocolonial influences within globalisation have undermined Māori knowledge and identity, Winiata sees new technology as an avenue of possibility and expansion within ever increasing global connections. Using the best of external knowledge and practices, but from within a Māori knowledge cosmology has been a theme for Winiata.

\subsubsection{Professor Winiata: The 'Generation 2000’ Visionary}

In his study of Māori leaders including Winiata, Diamond (2003) describes how

Winiata has been termed a 'deep radical' which Winiata disputes.

Things don't look radical to me if they look right. I know the term is used and, I think, used to mean 'hard to achieve', and things are. It may also be used to express doubt, 
perhaps that's just the same, its about making progress. But the things that I've been involved in, I see them as sensible - this is a way to deal with issues that have been around for a long time, that are not going to go away unless those proposals that are termed 'radical' are adopted (Diamond, 2003 p:67).

Winiata uses power sharing partnerships to create sites of self-determination to facilitate the economic development required for ongoing survival.

I think self-determination is essential. We'll get there, we'll see Māori with selfdetermination, that is, at least in the sense of a partnership in this land, where they have much greater influence over their prospects and prosperity than they do now (Radio New Zealand National, 2003).

Winiata illustrates the imbrication that hindered many young Māori in their early schooling in the pākeha system. His principal in Levin asked what he wanted to do after leaving school. When he said a doctor or lawyer, there was a pause, before the answer was written, indicating a doubt "[the Principal] thought 'I'd better write it down anyway'. I didn't like that" (Radio New Zealand National 2003).

When an opening in accountancy came up Winiata applied, having had previous experience handling money for his father. This led to a position in Wellington with public accountants and part time study for the Undergraduate Degree of Commerce at Victoria University - the first in his family to attend a tertiary institution. Winiata became a partner in 1958 and became increasingly interested in wider economic and social systems. A scholarship in 1960 allowed Winiata to be Associate Professor at British Columbia University. Winiata continued the study of social and political systems, becoming more aware of the potential for change within this engagement. 
Our time in the US strengthened and deepened the confidence. I had a better understanding of how society worked. I didn't know much about economic and political systems before I went to the US. Those were probably contributing influences to looking forward, and deciding it was going to take time, but could be achieved if it was planned (Radio New Zealand National, 2003).

In 1974 Winiata became involved in rebuilding the tribal Marae in Otaki whilst on sabbatical leave. After this Winiata and his family returned permanently to Otaki to continue the rebuilding by adapting what they had learned in America, but within mātauranga Māori frameworks. The Generation 2000 project quickly evidenced this learning and adaptation.

Whakatupuranga Rua Mano, Generation 2000, has an affinity, I suppose, to Americanisms - being on that continent for fifteen years give rise to the naming of a programme that way (Diamond, 2003 p:63).

Winiata's vision was to develop and maintain core Māori values, exampling how indigenous knowledge underpins his leadership and management practices. With the success of the 25 year experiment he articulated a future vision that goes well beyond 25 years in maintaining and transmitting indigenous knowledge continuities for the survival of the people:

If the iwi is to be identifiable in a thousand years there's some pretty important work to be done in terms of establishing the values by which we will be known, and teaching our offspring (Radio New Zealand National, 2003)

For Winiata, Pākeha imbrication tried to devalue this visionary timeframe: "I find that Pākeha people get quite impatient with that sort of timeframe - they think it's meaningless" (Radio New Zealand National 2003). In Diamond's (2003) biography Winiata describes how he tries to get this vision across in Māori contexts, indicating the role of symbolic leadership.

The way to counsel iwi and hapu, is to have ideas associated with you, and then be seen on marae, at ngihanga, sometimes there's an opportunity to talk, but you don't need that necessarily if you're there. I was called the twenty-five-year, Whakatupuranga Rua Mano man, once they'd got the name in their minds. They'd see 
those who were associated with the programme, including myself, at a tangihanga here, land hui there, at a Māori Council or Māori Congress meeting. It's the presence, being seen and heard occasionally, writing things, that hapu take up (Diamond, 2003 p:65).

One of the central strategies of this recovery was the decision to form a Māoribased university to teach and embellish Māori knowledge within a Māori framework. TWoR as a concept was born, legitimated by being in continuity with prior Māori centres of learning.

\subsubsection{TWoR: Māori Knowledge Recovery and Embellishment}

Following the WRM Generation 2000 assessment, TWoR was formally established in 1981. The original purpose of TWoR was 'for the advancement of knowledge and for the dissemination and maintenance of knowledge through teaching and research' (TWoR Charter File Copy, personal communication, p:1). The charter states that the inspiration of TWoR is an ancient Māori institution legitimising TWoR as having lineage from the Whare Rangiātea of ancient Māori origins: 'TWoR is a reformulation of an ancient institution, the whare wānanga, the most senior of which is Rangiātea' (TWoR Charter File Copy, personal communication, p:1). The purpose, agency and inspiration for TWoR draws from Māori knowledge for the betterment of not only the local Māori communities but also wider Māori and non-Māori alike:

Te Wananga will facilitate scholarly activities which are of direct relevance to the enhancement of teaching and research rooted in Mātauranga Māori and to the needs of the people of Te Atiawa, Ngati Raukawa and Ngati Toarangatira and, more generally, to those people who wish to advance their educational interests within tikanga Māori (TWoR Charter File Copy, personal communicaton, p:3). 
Winiata describes the statement that inspires much of the work of TWoR, which conceives of Māori as not necessarily essentialist in the form of having 'Māori blood' but synonymous with Māori knowledge, or those that follow Māori values and practices. Māori have a worldview which is handed down from previous generations, and broadcast from Rangiātea, implying an exposure to, and enacting of, inter-subjectively constructed and transmitted indigenous knowledge:

There is a very well-known expression, which we have on our letterhead and signage, 'e kore au e ngaro, he kãkano i ruia mai Rangiātea' - 'I won't be lost, a seed distributed or broadcast from Rangiātea', wherever that was. That a statement about forever, kore au e ngaro. That reference has to apply to Māori, and will continue to be the case if people continue to follow values and practices that are Māori and have a world-view that is Māori (Radio New Zealand National, 2003).

This holistic cosmology is not conceived as a fixed state of ancient knowledge,

but as a mystic knowledge continuity which is adaptive and open to enrichment.

The values, practices and worldview must be in a constant state of enhancement, enrichment, expansion and broadening, on the condition or within the context, of a continuity of mātauranga Māori, mai i te ao Māori from the beginnings of time (Diamond, 2003 p:65).

In the context of the global knowledge economy, Winiata sees the use and adaptability of Māori knowledge as the basis of Māori distinctiveness on a global

scale. The Māori renaissance articulates a Māori vision expressed in global terms.

With the knowledge economy, or knowledge society that we are entering, Māori will adjust to that quite readily, they'll take their mātauranga, knowledge, values, practices, their wellbeing with them. That will make them distinctive on the cultural stage of the world (Diamond, 2003 p:65).

This global confidence is articulated in the aspirations of TWoR:

That statement - e kore au e ngaro - is our contribution to the world scene, and it is the prescription that is embodied in that expression. It's a statement about the future, forever. A major justification for this place is to find those ways in terms of values, practices and worldview to contribute to the long-term survival of Māori (Diamond, 2003 p:65). 
The goal of this knowledge recovery is for iwi and hapu recovery 'Ratonga

Tautok Ki Nga Iwi: developing, maintaining and supporting initiatives for the further development socially, economically and politically of Hapu and Iwi' (TWoR Charter File Copy, personal communication, p:2).

In 1981 TWoR began to with one degree, a Bachelor of Māori Administration, two students, and kiawhina [voluntary staff] who gave their time and knowledge for free. In 1984 TWoR was formally incorporated. In 1993 TWoR was finally recognised as a formal educational provider under the new Educational Amendment Act, bringing government EFTS funding for students, but without support for capital investment. Physical expansion came from older buildings being gifted and relocated to TWoR, as well as needing to rely on kaiwhina to deliver programmes.

Professor Winiata said the wananga was dealing with a funding crisis. "Being a growth institution, we are constantly under-funded,". TWoR was heavily dependent on the help of 130 volunteer teachers. Wananga had to develop their facilities using only their annual EFTS funding, and community assistance (Milne, 1999 p:6).

The Māori community donated buildings, while offering work to upgrade their structures. The original Māori Boys College, built in 1905, stands centrally decorated with carvings, as one of the staff members told me:

it symbolises the connection with the Church Rangiātea which has a lot of significance to this area....it was built to bring Christianity to this area.... it's not coincidental that it is looking across at the rebuilding site of the Church Rangiātea which has been built as the same philosophy or structure as a meeting house. It is very ornately carved, one style of tukutuku panels called purpuru pete ...that literally means stars in the night... the belief was that when you died you became a star in the heavens.. so that there are millions of stars, which is representative of our tipuna which have passed on ... Rangiātea Church is currently being rebuilt, using the best current methods, to the traditional design...that's what always been done...if we had a crane in the original building, we would have just used that (TWoR Staff Member Interview, 2003). 


\subsubsection{TWoR Today}

TWoR delivers education programmes which encourage students toward learning about and being involved with their own marae, hapu and iwi. Locally-defined capability building is based on a mātauranga Māori framework. Māori knowledge is defined and emphasised in continuity with 'traditional' Māori knowledge, indicating the central significance of both knowledge and continuity which underpins notions of organisational identity. Not only that, but defining what Māori knowledge, as an act, creates, updates and extends Māori knowledge as a living stock of knowledge, a process centrally articulated in this vision:

Mātauranga Māori is a body of knowledge that is continually flowing and evolving over a period of time and space.... The 'continuum of Māori knowledge' = Traditional Māori Knowledge + Māori Knowledge post 1769 (Te Wānanga o Raukawa, 2004).

Within the organisational vision statement, the focus on Māori knowledge is central, where both the knowledge and methods used to teach this knowledge, comes from within the holistic cosmology:

The vision of Te Wānanga-o-Raukawa is to be a high quality institution of learning that increases knowledge and understanding through teaching and research.

TWoR is a unique centre of higher learning devoted to the world of Māori knowledge, (mātauranga Māori). The method of teaching at Te Wānanga-o-Raukawa is based upon knowledge and wisdom passed on by our ancestors. Through our holistic approach to teaching and learning, you will experience a new and exciting journey into knowledge.Courses are based on group learning or 'hui', rather than through individual learning. Ultimately, you will learn about you! (TWoR Vision Statement, personal communication, March 2003, p:1).

This vision statement encapsulates the journey of healing that TWoR understands students to take through reconnecting to their own knowledge and identity, a theme which will be unpacked in greater detail in the next chapter. TWoR's growth has continued unabated. In 2002 for example, TWoR had 1800 + students, 
with the campus requiring ongoing physical and student expansion. There were 5 certificates, 21 diplomas, 13 degrees, 5 post graduate diplomas, 6 Post graduate courses and $1 \mathrm{PhD}$ programme, with numbers continuing to grow year on year.

\subsubsection{A Tikanga Māori Institution: Enhancing Māori Knowledge}

Winiata, together with the staff, have placed TWoR at the forefront of reversing the losses to Māori knowledge, as some of the incongruities within the colonial and globalist encounter:

Philosophical exploration of mātauranga Māori was stifled with the passing of the Tohunga Suppression Act. Te Wananga-o-Raukawa is obliged to encourage investigation into the depth and breadth of Mātauranga Māori and its future (Winiata, 2001 p.2).

The embellishment and application of Māori knowledge is still central to the identity of TWoR. The statement of objectives, 2002-2004 identifies the core vision of TWoR as:

Kia rangatira te tuu o Te Wananga-o-Raukawa hei whare ako, whakatupu hoki i te mātauranga: let Te Wananga-o-Raukawa be an institution of excellence in teaching and in the creation of knowledge (Te Wānanga o Raukawa Statement of Objectives, 2002-2004 personal communication, p:1).

Rather than knowledge being a limited and fixed objective property, Winiata (2001) conceives of Māori knowledge as having its own 'whakapapa' a continuous genealogy which is both historically located and enacted in an ongoing enterprise of knowledge construction and embellishment. This is presented in stark contrast to the losses to Māori knowledge from the Tohunga Suppression Act named above. 
Mātauranga Māori is a body of theory that seeks to explain phenomena by drawing on concepts handed down from one generation of Māori to another. Accordingly, Mātauranga Māori has no beginning and is without end. It is constantly being enhanced and refined. Each passing generation of Māori makes their contribution to mātauranga Māori. The theory, or collection of theories, with associated values and practices, has accumulated mai i te Māori/ from Māori beginnings and will continue to accumulate providing the whakapapa of Mātauranga Māori is unbroken (Winiata, $2001 \mathrm{p}: 2)$.

In this way, the preservation and continuity of Māori knowledge supports the preservation of the Māori people by facilitating new generations into a profound relationship to this knowledge. Developments have included the creation of Kohanga Reo: Māori immersion primary and secondary schools where: 'the thinking is from kohanga to wananga - we want as much of a chance as possible to, to teach the mokopuna [children] in Te Reo in a Māori way. We've got people employed in TWoR who came through Kohanga Reo' (TWoR Staff Interview, 2003).

From Winiata onwards, actors at TWoR have set and enacted purposes to reverse the incongruities of the colonial encounter. Actors have created a new alternative for the conception and embellishment of Māori knowledge which maintains authentic continuity with the inter-generationally transmitted knowledge from mythic origins, dynamics suggested in the literature (Fischer, 1999). Authenticity is maintained within indigenous knowledge continuities and not colonial subjective power relations as also proposed in the literature (Gunew, 1994; Spivak, 1987ab). From the founder and purposes of TWoR, the focus now shifts to the IC. 


\subsection{Iona in Context: Columban Celtic Mission}

In this section I examine archival, secondary and for pragmatic purposes fuller primary sources to construct the history and purpose of the IC, since few archival documents remain presenting the founding of the community in 1938 .

The IC presents as a central site in the emergence of the Scottish nation by claiming lineage with the mission that Columba founded in 563 A.D. on Iona. In the 2003 IC Island Programme (as distinct from the mainland work of the IC), the then current Leader, Kathy Galloway, describes themes of community, and nation building, stressing education and high cultural expression. She stresses the Celts as educators and civilisers, not the barbarians of the colonial imbrication. The role of the monks is presented as an educative and economic one, improving the resources of the whole region.

The monks improved practices in agriculture, fishing and building. What they brought was not just a religion, but big elements of an economy, skills that were involved in maintaining life (Galloway Interview, IC Island Programme 2003).

The Leader emphasises the cognitive status and worth of the early settlement, the high art and Celtic culture found there.

The Columban settlement became quite sizeable with several hundred people here from all over Europe. The Monks were educators. People came to be educated. Sons of the aristocrats. It was like the Oxford of The North. The worshipping life carried on. It developed skills in terms of words, poetry and prayer. It was a part of a high artist culture. The stone crosses have stood there for a thousand years. (Galloway Interview, IC Island programme, 2003).

Celtic writers such as Bradley (1999, p.211) claim the IC as one of two of the most important sites for Celtic Christianity in Britain today. In the IC's most recent prayer and readings book, Bradley claims the worship on Iona has 'an 
authentic mark of the continuing presence of Columban Christianity on Iona' (Paynter 2002, month2,day13). This authenticity is based on the continuity of a Celtic holistic cosmology and the themes therein. I next explore the original purpose that the founder, The Rev George MacLeod envisioned in constructing Celtic to pursue urban and community rebuilding while intentionally drawing on Iona's ancient Columban imaginary, overcoming urban squalor from the highland clearances outlined earlier.

\subsubsection{The IC: Claiming Columban Mission in the Urban Context \\ The $[\mathrm{IC}]$ is mostly a Lowland community and it started in Glasgow not in Iona (Galloway Interview, 2003).}

From its inception, the IC has sought to be an experiment in new mission. The IC claims evangelical missionary principles from its Celtic Christian past and reworks them to find new ways to touch the hearts of all seeking a contemporary expression of a holistic way of living, which emphasises the wholeness of life with care for creation and work towards issues for justice and peace. The original purpose of the IC, as expressed in their own historical story portrayed on their website, is one of mission to the contemporary context:

The [IC], founded in 1938 by the Rev George MacLeod, then a parish minister in Glasgow is an ecumenical Christian community that is committed to seeking new ways of living the Gospel in today's world. Initially this purpose was expressed through the rebuilding of the monastic quarters of the mediaeval abbey on Iona and pursued in mission and ministry throughout Scotland and beyond (Iona Community, 2004b).

George MacLeod began what he described as a church 'experiment'. Taking 20 students each summer he had them working alongside the unemployed artisans 
and industrial workers of Govan and elsewhere to rebuild the Abbey. For IC member and writer Peter Miller, this historic environment must have affected the members deeply. Despite this, Miller resists the internalised imbrication members have that such histories are 'romantic'.

The IC couldn't have rebuilt the monastic buildings on Iona without being imbued with something that had gone on that island a thousand years before but I resist romanticising that (Miller Interview, 2003).

Writer Ian Fraser was a member of the original senior management team with MacLeod. Fraser was in no doubt about the Celtic influence which he drew from in leading the very first worship in the Abbey for the new IC, drawing themes of an authentic Celtic Christian cosmology.

When the community started in 1938 I got in touch with it. I remember between 193940 taking the first service in the cathedral. I was full of Celtic. I can remember talking about the wild animals in the hills, the birds among the branches and the wings against the sky. All that being gathered into the praise that we'd offer, not on our own behalf, but on the behalf of creation, where it could only be offered by the mountain being what it was or animals communicating the way they could.... We had to make that praise to God.... to have the whole of Creation involved was just part of the framework in the 1939-40 period (Fraser Interview, 2003).

For Ian Fraser, the IC from inception was an indigenous Scottish project, but containing the highest ideals of Ecumenism:

Indigenous had to be about belonging to the land, Iona. That is the way it started. You need your roots. It was also worked out that the community should be open and ecumenical and should report through a board to the general assembly every year. That was very good because it was a Scottish development. We all worked on the rebuilding of the Abbey. It was an indigenous development (Fraser Interview, 2003).

Having rebuilt the Monastery, shown in Figure 9 (over) the IC sought the rebuilding of the common life. A central part was the Columban missionary aspect begun, and claimed, by the IC.

I love that idea of the missionary intent in the modern IC I think our mission is different and the world is different but there is a central truth that we're claiming (Fraser Interview, 2003). 
Figure 9: The Iona Abbey, MacLeod Centre, Refectory and Guests

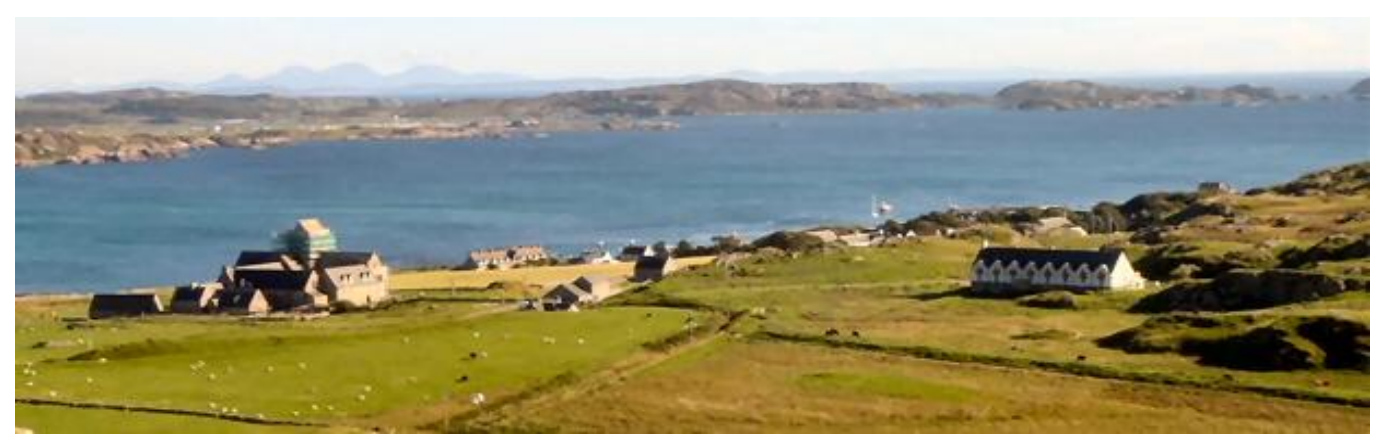

(Fieldwork Photograph, 2003)

The Abbey refectory (left above and below) and Mac courtyard (right, above and below) with guests who form community.
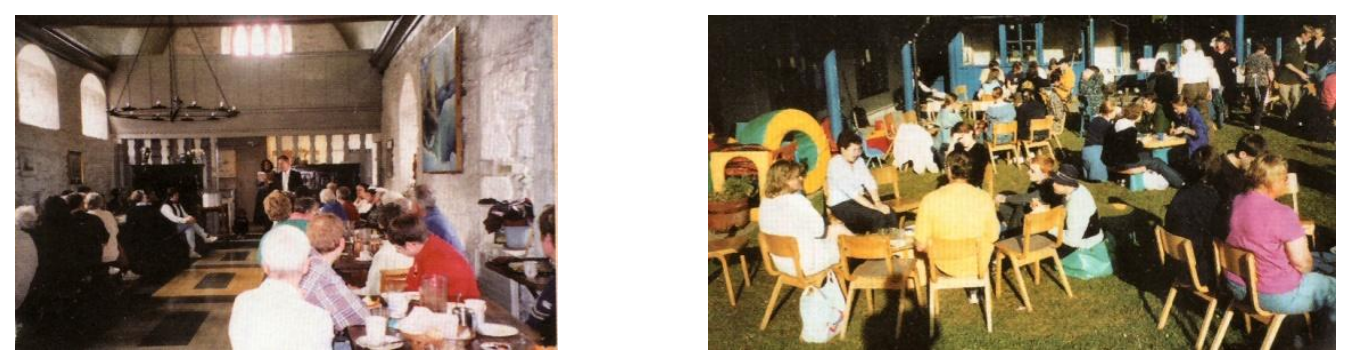

(Images from Iona promotional material, personal communication, 2003)

\subsubsection{A Celtic Institution?}

Continuity between the current IC and its ancient Celtic ancestor is neither clear nor unanimously claimed throughout the IC. Tensions such as this exist within the life of the community, which Miller sees not as a failure of the IC, but the best sign of health. These are tensions that have existed in the life of the founder.

If the tension doesn't exist then the IC should cease to exist. That's its life giving blood between a movement and a community. What's the relationship between its Scottish-ness, and its full members coming from many other places? What's its link to Scottish interests? There's an area of discernment in Scottish interests and wider interests (Miller Interview, 2003). 


\subsubsection{George MacLeod: The Visionary Celtic Environmentalist}

Founder of the IC, Lord George MacLeod was born in 1895 and lived until 1993. MacLeod's life reflected the inherent pressures and contradictions that were bound up with Scottish identity as a whole throughout the $19^{\text {th }}$ and $20^{\text {th }}$ century (Ferguson, 1990). For members of the IC, notions of Celtic represent contradictions that are inherently bound up with incongruities and colonising influences, which are reflected in the life and identity of MacLeod himself.

George MacLeod is a fascinating example of the contradictions (of Celtic) within himself. Here is someone that comes out of a Gaelic tradition a couple of generations back in Fuinary but so much of his foundation is in public school makeup of Winchester. He was a combination of that. He was a collision in his own make-up (IC Member Interview, 2003).

Despite this, MacLeod used Celtic principles and practices from a holistic cosmology in his leadership and management: "he did have something that comes through very strongly in his writings is that he saw the Celtic vision as a way to hold together the material and the spiritual” (IC Member Interview, 2003). Fraser suggests MacLeod sought to reunite spiritual elements that had been riven, placing the work of the community into political and economic life: "George did a major job in making politics the domain of the church... helping to put together the things that had been pulled apart" (Fraser Interview, 2003).

For Miller, MacLeod had a visionary and mystic zeal to relocate the Celtic in the modern context, connecting to the land and the sense of the sacredness, which was inspired by the ancient Celtic monastic institutions and a holistic cosmology. 
He was empowered by the land and the sacredness. That is Celtic. George tried to put it in the 20th Century language but he aligned it to a vision and a kind of second sight that he had which was Celtic... I would say these people [the Celtic Monks] did [the original mission] and they've empowered us like his wee group going in 1938 to try and look and see if they could start the rebuilding (Miller Interview, 2003).

\subsubsection{Founding Purposes and the Celtic Imaginary}

MacLeod created a vision to recover a Celtic holistic cosmology and apply it in practical solutions to the poverty and urban squalor after the clearances: 'it would be the modern counterpart of St Columba's original intention: the new light of Protestantism would be lit to meet our day, as his lamp met his' (Ferguson, 1988 p:59). MacLeod's biographer and IC member Ferguson (1988) directly quotes MacLeod's original IC proposal written in 1938. MacLeod drew intentionally and strongly from the Celtic experience of Columba and Celtic leadership models to reclaim a holistic vision, as the language of the time testifies.

How up to date was the enthusiasm of the early Celtic Church to infuse with the Christian spirit every department of life; how like the most modern foreign mission station was the early Celtic community with its expert craftsmen, its expert agriculturalist, its educationalist and doctor as well as its Anamchara and presiding minister. How much again, is the world not in need of that sense of Universal Church, which was so profound a belief in our Roman days (Ferguson, 1988 p:60).

The original proposal forged the intentional use of Celtic knowledge and leadership models from the earliest founding document. As Ferguson (1988) notes, this use of Celtic was to inspire the indigenous Scottish consciousness, but also made life complex: 'the IC's association with the inspiration of Iona and the Celtic tradition - with what that meant in the latent memory of Scotland... meant that the [IC] could never be simply categorised' (Ferguson, 1988 p:61). This Celtic continuity resonated in the emotional experience of early members: 'it felt right to be living in community on Iona, in continuity with the Columban and 
Benedictine communities' (Ferguson, 1988 p:63). Galloway knew MacLeod from

her birth. As a visionary, she recalled this how a holistic Celtic cosmology

underpinned his leadership.

It was both a mystic and practical vision. In reading his prayers it is mystic, 'the whole earth shall cry glory' but he had this cosmology of the sacramental nature of creation. If you were to look for a comparable figure within the church worldwide it would be Teihard de Chardin. George was a Gael himself, even if slightly aristocratic and detached...

He spoke about the land in the way other Gaels would understand?

Yes, exactly. Even more so, but he connected that with his particularly form of Christianity. He loved the Celts oral storytelling. He was a great opportunist as well. He was a great storyteller. Alistair Campbell had nothing on him for spin. I think that that was part of the highland tradition. You embroider and embellish a story to persuade. It's the culture and the oral tradition. He used that and genuinely believed it (Galloway Interview, 2003).

Galloway describes how MacLeod intentionally wove the relationships between the indigenous Celtic worldview and his own incarnational theology. In so doing he was embellishing his own indigenous, geographically located tradition.

George himself was a Highlander. He was a mystic in lots of ways. He was a poet or a mystic more than a theologian. A Celtic Seer. He was much more that a theologian than a historian. It was a very different kind of process (Galloway Interview, 2003).

However Galloway claims any continuity is very difficult, given the incongruence of history.

It is almost impossible to say to what degree something is continuous. The Celtic period finished at the latest (in historical terms) in the 10th Century, particularly with Malcolm Campbell and Queen Margaret. But the Gaelic culture continued. It took many forms. It was very mainstream - Roman, then there was The Reformation. If you go to the strongest Gaelic speaking areas of Scotland they are the most Presbyterian in a very harsh austere form (Galloway Interview, 2003).

The concept of the community or rebuilding the common life was formed as a response to the experience of urban poverty and moral and social fragmentation that was Glasgow in the 1930s. "A lot of it came out of the ugliness, the 
brokenness, the division of Govan of the 1930s: poor, sectarian, dirty, ugly" (Galloway Interview, 2003).

Ferguson (1990) also suggests MacLeod was reacting to the urban squalor, but intentionally turning to the Celtic knowledge tradition for answers, using what he calls the inborn MacLeodian instincts - referring to the highland family ministry tradition of which MacLeod came (Ferguson, 1990 p.121). Ferguson (1990) suggests that a formative experience in MacLeod's early ministry life was experiencing the drama of the Russian Orthodox Church on an overseas educational visit, which appealed to the Celt in him. This experience found expression through his intentional use of the Celtic imaginary in his personal theatre of Iona Abbey. Fraser clearly recalls that MacLeod's purpose intimately connected to the land, Iona and Scotland as a whole.

I once got hold of George and said to him "What is at the root of all this?" He thought for quite a while and then said, "I think that it is the Island of Iona". There are places that are a resource. Iona is a place that has hope. I had come to see that there were things in places that were like this. George said at the end the importance was Iona itself. You need your roots. (Fraser Interview, 2003).

Like later leaders, MacLeod wasn't necessarily creating an 'authentic Celtic' community in terms they would understand it then, but using what means were necessary to develop and maintain the emerging community project:

Often when you are the founder and the person who is the developer you don't know what you are doing. All of us were given a bit to do and we didn't know where it was going to lead. You may not know yourself where things were going but George was a magnificent initiator. I don't think that is anything against him. I think George did what was needed in his time (Fraser Interview, 2003). 
For others too, George was just being pragmatic in his use of the Celtic: "George was a pragmatist... he'd use the Celtic, but he'd also use the Orthodox, or the Roman. If it's there, and it works, then we use it, he wasn't a historian" (IC Member Interview, 2003).

Voluntary lavour supported the physical and community rebuilding project, exampling agency in the face of global effects. Craftsmen donated time and resources. This 'new experiment' made ministers the servants to the volunteer craftsmen. They formed community on the tiny Hebridean Isle, in preparation for their eventual placement in the urban and industrial housing schemes of Scotland, a pattern that continued well into the $1960 \mathrm{~s}$.

We lived 6 weeks on Iona and then 6 weeks in a community house. There were six of us. We all had to get a job at a factory, I had a job in a plumbers warehouse. The idea was that we went out into the community to work during the day and then came back and prayed together at the end of the day. We would have a number of meetings in the week and then end it in a reflection session (IC Member Interview, 2003).

This focus on the mainland revolved around Community house, exampling the political engagement that the members sought at the social level.

Community house was in Glasgow. It was a power house in the 1960s. It ran a lot of meetings and trade unionists in the weekends. The community was very involved in industrial missions. Industry was very much a huge force. That has changed over recent years (IC Member Interview, 2003).

In the mainland IC members continue to work for social justice. 


\subsubsection{The IC Today}

The IC references the history and location of the Columba, but it also more strongly gives ecumenical expression in and through individuals in their own current contexts, remaining underpinned by an integrated worldview that is undeniably inspired by the integrated vision of a Celtic holistic cosmology.

The Community today remains committed to rebuilding the common life, through working for social and political change, striving for the renewal of the church with an ecumenical emphasis, and exploring new more inclusive approaches to worship, all based on an integrated understanding of spirituality (Iona Community, 2004b).

The IC has some 200 members and 1400 associates spread throughout the world, none of which are based on Iona.

The IC has also been a community in dispersal. There used to be a poster in the Isle of Mull, go to Iona and meet the IC. My understanding is that IC is not Iona. Iona may be a focus but the community is where the members are (IC Member interview, 2003).

The IC emphasises not escape but engagement, where members live in areas of community concern and collectively seek to combine prayer and politics to build local community (Ferguson, 1988; Shanks,1999). The IC still celebrates in ritual and worship Celtic themes of the interconnectedness of life and issues of poverty and social justice. In the Strategic Review carried out in 2003, Galloway summarises the tensions between this history and tradition, and the ever growing and changing nature of the community as understood through the members own experiences.

The Review asked us to focus on our common task. What do we understand to be our primary purposes and goals? There is an extremely high degree of consensus on six key areas of our task: the centrality of The Rule; the commitment to Justice and Peace; the importance of our Island centres as places of community, hospitality, challenge, communication and inspiration; the role, revitalisation and renewal of worship; the importance of Family Groups; and the ecumenical and inclusive nature of the Community (Strategic Review, Personal Communication, July $15^{\text {th }}$ 2003). 
This historic continuity with Iona is in creative tension with ever-increasing growth and an increasing percentage coming from England. For some, the IC is

'too exclusively Scottish' in their agenda:

One group thinks we should stop worrying about our size! Related to this is the perception of a few groups south of the border that issues only seem to matter, or be fully incorporated into the Community's life, if they're Scottish (Strategic Review, Personal Communication, July $\left.15^{\text {th }} 2003\right)$.

The changing nature of the community has evolved away from its Scottish base.

The Review Group identified some areas of tension and imbalance. These include: Between the Community gathered and dispersed. The importance of Family Groups, and of being the Community locally and individually is clear. But how do these relate to our collective structures and identity?

We have moved from being a Scottish, mostly Church of Scotland community with specific tasks and goals (the rebuilding of the Abbey, the renewal of community in urban Scotland, the renewal of the Church of Scotland) to being a British (and beyond) community, which is ecumenical and has wider, and less clearly defined goals (Strategic Review, Personal Communication, July $15^{\text {th }}$ 2003).

The IC has grown past its unique history and identity, to less clearly defined organisational but ecumenical goals. Despite this, Scottish IC members expect the

IC to enact its original founding ethic and create change in and for Scotland.

Because of its longer history in Scotland, because of the nature of its institutions, but mostly just because of its much smaller size, members in Scotland have a much stronger experience and expectation of the Community being able to make a significant impact, not just on the church in Scotland, but on Scottish secular society, politics and institutions (Strategic Review, Personal Communication, July $15^{\text {th }} 2003$ ).

For new members south of the border this expectation is less present, and indeed

the purposes of the community drive innovation in forms of worship:

It's much harder to do this in England, which is ten times the size, and where our membership is much more dispersed. Conversely, one could argue that outside Scotland, the Community's main impact has been in the area of church renewal, especially worship (Strategic Review, Personal Communication, July $15^{\text {th }} 2003$ ).

So differences emerged over what the community is taken to be, and how that should best be expressed: 'One English response wanted to recognise that it is 
primarily the Island work and that of the Wild Goose Resource Group which presently communicate the ethos/identity of the [IC]' (Strategic Review, Personal Communication, July 2003). These expectations have resulted in the IC being constructed in different ways by actors reflecting and seeking their own indigenous identity through the work of the IC.

This is not the experience or perspective of the Scottish groups, some of whom express their reservations...those in the IC who have been drawn into it mainly through its political and peace witness, and those whose introduction has been primarily through the Island centres and worship outreach. There is a clear geographical difference here (Strategic Review, Personal Communication, July $15^{\text {th }}$ 2003).

However tension exists in how the IC looks to new areas for engagement, also remaining true to the original ecumenical vision, such as advancing the dialogue to Muslim communities.

The following emerged with considerable support:

Much greater emphasis on interfaith engagement, especially Christian-Muslim.

Two groups suggested we should be moving to become a multi-faith community, while one wanted to emphasise our distinctive Christian identity.

Increased opportunity for creative, corporate theological reflection

Greater engagement with ecological issues

Possible mainland programme/'drop-in centre' at Glasgow base

The possibility of rediscovering our past role in lay and clergy training, especially given the imminent demise of the Scottish Churches Open College. (Strategic Review, Personal Communication, July $15^{\text {th }}$ 2003).

Despite these tensions, and the evolution away from the 'purely' Scottish project, Galloway's view as Leader of the IC in 2003 suggested it remains indelibly influenced by the holistic cosmology of the Celtic, which is profoundly Biblical but also seeks to integrate in the global context of fragmentation.

How central is the Celtic vision to the IC?

It is very central. Definitely. We wouldn't necessary express it in a Celtic way because lots of members live in the inner city of Glasgow and elsewhere but it is there. The Rule is designed to counter the individualisation and fragmentation and separation in our lives. 
We are accountable to one another for our lives we are bound up with one another. We need to talk about how we use our money, time and our justice and peace commitment We believe that costly reconciliation is at the heart of The Gospel and the reconciliation, the unitary vision in Iona, is about bring together what has been opposed.. it is a different way of being human, of organising human life that's not driven by economics or profit.

What is it driven by?

It's driven by a love of and for the Earth, and for specific places. A desire for a different way of being human that's not based on principles of domination and subordination, a culture of peace. (Galloway Interview, 2003)

In a contrary view which avoids a gloss of consensus, another ex-leader suggests

Celtic spirituality does not drive the vision of the IC, and is little more than one historic influence which remains just that. Despite suggesting a Celtic holistic cosmology still exists, free will and Biblical principles and not essentialism propel action.

I am not sure that it [Celtic] has ever been a huge thing. What has prompted and impelled the IC is the Gospel here and now. The challenge of touching hearts of all in today's society. It is not constrained by one historical emphasis or another.

It may be influenced in a historical sense but it is influenced by the people, not by a philosophy or even spirituality. It is all about an engagement. I think Celtic spirituality is about engagement, but we engage because we are called to do so. That is what the Gospel wants and our understanding of it points us towards. We do not engage because Celtic spirituality or any other form of spirituality tell us that that's what we're do to (IC ex-Leader, 2003).

In a context based difference, the IC places no emphasis on the survival and enhancement of Gaelic. The language and identity fragmentations were brought by globalising and colonial pressures.

I think that the collapse of the Gaelic culture in the inner isles is a long story that does not have much to do with the community. I think there was a long period of the suppression of the language. The language was separated from the population. Also I think that a lot of communication such as television damaged it as well (IC Member Interview, 2003).

Given the recent context of emergent Scottish nationhood, and the resurgence of interest in things Celtic, those coming to the Island centres over recent years 
expressed some degrees of bitterness about a confusion and de-emphasis of Celtic

within the community.

I was running a group at the Mac centre and felt quite a strong indifference from the group to things Scottish and even, from one Member, a strong feeling that as so many Members are now English the HQ should be in England. It is as if Iona's Scottish-ness itself was being contested. There was only 1 Scot in the group of 50 (mostly English and German church groups). He turned up in a kilt on the first day, but put it away thereafter (McIntosh Interview, 2003).

For Alastair MacIntosh, Scottish writer and activist, and an associate of the IC, the tensions to de-emphasise the Celtic has resulted in a lack of respect from the Community not only to what is indigenous within their own history, but towards

the local indigenous villagers also:

All can become indigenous to a place, but that process requires 2 -way respect. It requires that incomers respect the hospitality they are being shown. There has not been enough of this in Scotland generally and on Iona in particular. This is why some of the locals resent the Community. At the core of the cultural difference is the distinction between cultures predicated on competitiveness and those predicated on co-operation. It is a very deep problem, but, in my view, one that is central to the Christian challenge (McIntosh Interview, 2003).

For McIntosh, the IC misses the indigenous Celtic which results in a blindness to the cultural tradition and heritage which is very rich.

As for Celtic spirituality, I think it is very real and deeply indigenous but in a universal manner. However, one requires eyes in the soul to see it, and those whose eyes have been put out or have closed their eyes miss the self-evident before them (McIntosh Interview, 2003).

Fraser suggests that the notion of openness and ecumenism actually comes from, and not against, a sense of respect for a Christian Community's own traditional

roots.

Christian communities become ecumenical because they value their traditional roots. It grows into a larger understanding of the church as its core. That is what happened with the IC as well. That is why you have people from all over the world, even New Zealand, coming into the IC and becoming members (Fraser Interview, 2003). 


\subsection{Discussion}

In beginning to answer the thesis question 'what is an indigenous organisation in global contexts,' I have examined the history and purposes in each organisation and their relationship to both globalist practices and holistic cosmologies. Each is discussed in turn.

The organisational history of TWoR is legitimised and inspired by the indigenous institution the Whare Wānanga of Rangiātea containing the sacred origins of Māori knowledge. Winiata developed a purpose which aims at the advancement of Māori knowledge, embedded with the ART confederation. TWoR is legitimised as being in authentic continuity with ancient and holistic Māori knowledge which is enacted to contribute to the wellbeing and health of Māori in order to promote Māori survival and growth. This counters impacts on community health directly relating to globalising pressures, which concurs with the effects theorised by OS researchers outlined in Chapter 2 (Banerjee, 1999; Banerjee and Linstead, 2001, 2004; Henare and Lips-Wiersma 2000; Jaya, 2001; Whiteman and Cooper, 2000).

For the IC, its history is presented and legitimised as being in continuity with the Columban mission, a central inspiration and purpose articulated by the founder MacLeod who reclaimed and sought to enact an indigenous Celtic Christian holistic cosmology. The IC's purpose today has evolved out of continuities with a Celtic holistic cosmology, to rebuild the common life underpinned by an 
integrated understanding of spirituality. Remaining true to the inclusive nature of that worldview, however, has resulted in significant identity confusion for the IC members whose desire to remain open and accepting has created a more loosely defined set of organisational goals. Despite this, many members remain expectant of and working towards the recovery of an integrated way of being, which is based on this indigenous cosmology enacted mainly, but not exclusively, within the life of the Scottish nation, with many members taking active political positions. The integrative qualities of a Celtic holistic cosmology also overcome globalising fragmentation, as suggested in the literature, and in the previous historic context (Fischer, 1999).

Despite this, many influences of neocolonial fragmentation remain, again similar to the negative effects posited in the literature (Banerjee and Linstead, 2001, 2004). No emphasis on Gaelic language is found, and notions of 'indigenous' and Celtic history and influence are often downplayed, in favour of Christian and Gospel influences stripped of any indigenous continuities, much to the consternation of those seeking an 'authentic' indigenous expression in the IC. Table 8 (over) summarises these last two chapters and places the two indigenous organisations side by side in historic and current contexts. 
Table 8: Indigenous Communities of the Scottish Celtic and Māori Compared

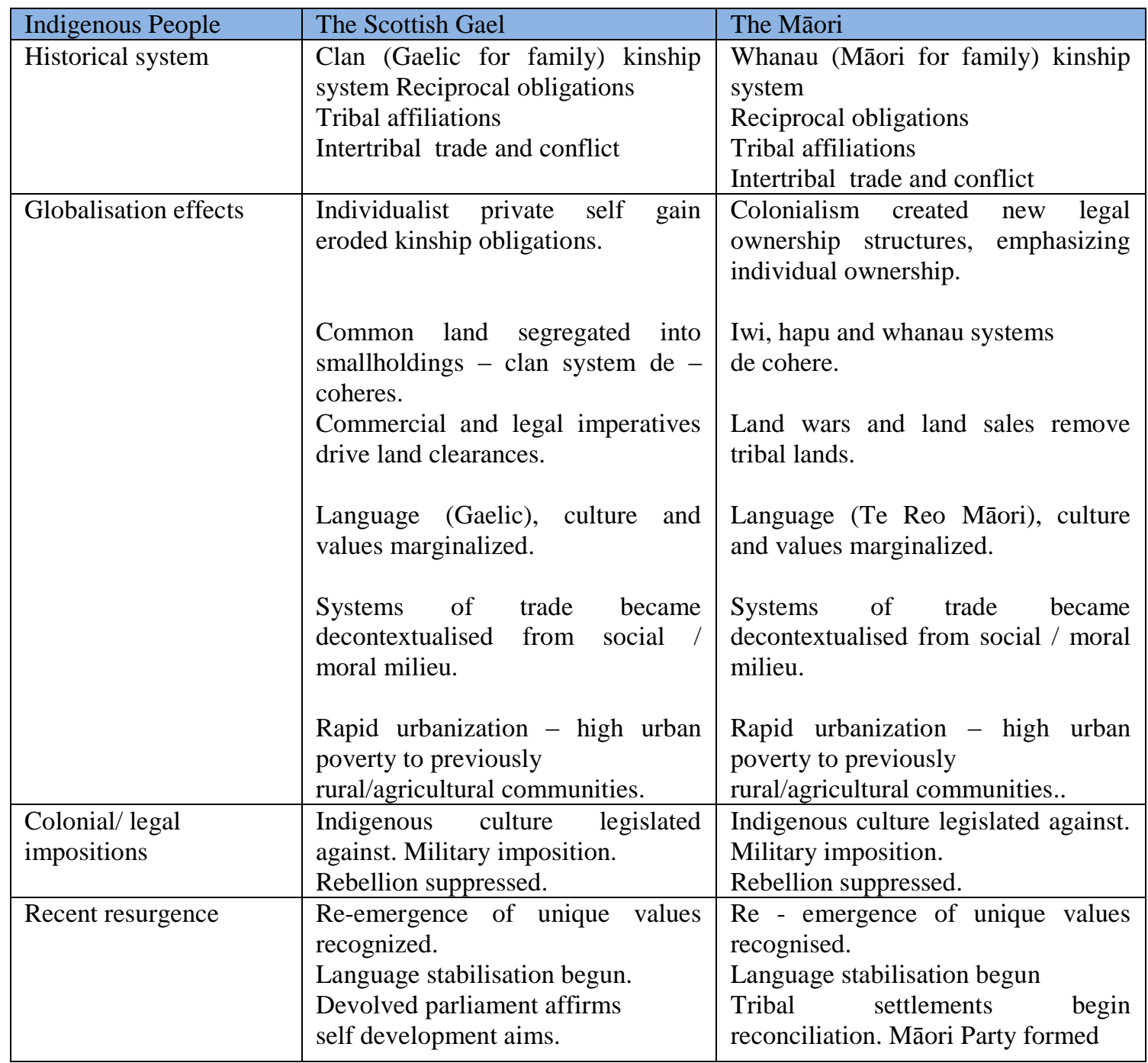

\subsection{Summary}

In this chapter I have begun to explore both similarities and differences in the indigenous organisation using secondary and where necessary primary sources. Contextual case similarities illustrate the histories which each case constructs. The organisational visions and purposes illustrate the profound roles leaders have had in forming and articulating context-based visions of each indigenous 
organisation from indigenous knowledge. Differences illustrate how the purposes of each organisation draw from indigenous knowledge to inspire their own unique aims and goals. These organisational purposes emerged from very different contexts and affect the ways that indigenous knowledge is interpreted, developed and enacted by each organisation. For example TWoR as a reformed Māori University: claims lineage with Rāngiatea; emphasises Te Reo Māori as a core component; and embellishes Mātauranga Māori (Māori knowledge) in teaching and research projects to aid in Māori iwi and hapu capacity building. The IC, as a reformed Celtic Monastery claims lineage from Columban Celtic Mission and uses Celtic knowledge to support Celtic Christian worship and community rebuilding in the context of urban fragmentation and places no focus on the recovery of the Gaelic language.

Having established how an indigenous organisation constructs histories and purposes in lineage with ancient indigenous institutions to overcome neocolonial fragmentations, in the next three chapters I further explore indigenous organising by examining rules and boundaries at individual, organisational and social levels using the Clegg and Hardy framework (1996). I adapt this framework to explore not just knowledge, but how indigenous knowledge is phenomenologically defined, experienced and enacted through the organisation as a whole. 


\section{Chapter 7: Defining and Enacting Māori Knowledge}

\subsection{Introduction}

This chapter is the first of two which examines at the individual level how boundaries and rules support actors to enact indigenous knowledge. This knowledge creates polyvocal definitions of indigeneity in the face of fragmenting

globalist practices. This chapter begins with the Māori context, and ethnographically describes how I developed some levels of cultural competence before approaching TWoR. I describe how local actors define Māori knowledge and worldviews specifically and indigeneity generally. I describe how boundaries and rules support positive identity and life projects of members. I also cover members' experiences of fragmenting globalist practices, and of colonialism and postcolonialism. I describe this and later chapters in an auto-ethnographic present day confessional account to aid reader comprehension of the framing of the organisation and the programmes therein, as well as to convey the immediacy of my research presence and the vitality of the research setting (Van Maanen, 1998).

\subsection{Preparing Cultural Competence}

My access to Māori holistic cosmologies begins before fieldwork at TWoR, with a Te Reo Māori Language Class, gaining prior ethnography (Lincoln and Guba, 1985). Over a number of weeks I am introduced to the basics of Māori language elements, and introductions such as the 'mihi mihi' which reconnects me to my own family and land background, as a formal introduction to the group. From the outset I find myself learning how the Māori language creates positive identity. At 
the language classes (held through Te Wananga-o-Aotearoa) I hear of the TWoR instructors and their reputations for excellence. We practice our 'mihi mihi'. I feel a familiar but strange experience of being somehow relocated within and among my family, ancestors and own Scottish tribal lands. It is an experience I share with members of the group. I also meet and casually chat to other Te Reo learners, mostly Māori, but Pākeha students too.

Sitting with a friend in Wellington, I talk of the challenges involved in finding a Māori organisation that works from a base of Kaupapa Māori. He remarks that the Māori University TWoR at Otaki could be an ideal candidate. As Winiata is an educationalist, he would be open to this type of research. I note the details down and subsequently make contact.

Kia Ora Professor Winiata, my name is Steven Finlay, I'm a PhD student at Victoria University seeking to study indigenous organisations. I've been told by [named colleague] that TWoR could be open to this type of research.

I remember the Kaupapa Māori protocols that Linda Smith recommends, and the importance of face-to-face meetings:

I was wondering if I could come up and meet with you, to show you my research proposal, my questions, and discuss the ethical protocols I will be using to ensure cultural safety. I have discussed my research with Professor Graham Hangingaroa Smith and with The Hon John Tamihere.

Yes that might be possible. My secretary can arrange a date (Winiata interview, 2003) 


\subsubsection{Approach to TWoR}

I drive towards TWoR. The wind blows off the hills on the Otaki coastline of New Zealand. My mind races with the appropriate protocols, research agreements, mihi mihi, and steps that the literature suggests I take, all quietening as I turn off the Otaki roundabout and drive towards the beach. I think about the perceptions of some of the Pākeha community as I approach, of comments that I heard in passing as I previously told those interested of my $\mathrm{PhD}$ topic. "Māori management? You must be joking", was one of the stronger negative opinions expressed. "Governance is an ongoing issue" said another. I think that some Pākeha don't have much faith in Māori processes (Tremaine, 1990). I also think of the Enron scandals and the trust and governance issues that have recently plagued such organisations. I don't think Western Management has shown itself to be hugely ethical or accountable of late.

I have a mental picture of the large multinational corporations which fill most undergraduate textbooks: tall, gleaming metal and stark glass against the landscape - statements of dominion and modernist power fighting for space, and competing for size against the urban backdrop of some anonymous cityscape. As I approach I notice how in harmony with the natural environment TWoR is: without knowing it was there one could easily miss it. It is spread out, nestled between the famous Māori Church of Rangiātea on one side and Otaki beach township beyond a few fields on the other. The white weatherboard buildings look gleaming and clean, washed by the now passing shower, and illuminated by the 
slowly emerging sun, with no buildings rising past the height of the beautiful mature kauris ringing the property. All the buildings seem in good condition. From the road, some buildings seem in the process of being modernised. I feel the adrenaline mix with fear. A variety of 'what ifs' whiz through my mind, the most immediate of which is 'what if they say no?' I think of the trouble to establish another connection, of the knock back I'd feel. The next one to follow is 'what if they say yes?' My elementary grasp of Te Reo, begun only a few months before, seems suddenly painfully inadequate. Standing at the entrance of the site is a group of 6 or so young Māori, smoking. They eye me cautiously as I drive past them. I feel aware of my whiteness. I notice the sign of a cross, entwined with a Māori koru at the entrance, and think about the Celtic crosses standing in welcome to Iona Abbey, stone crosses similarly carved with Celtic interwoven strands. Despite being aware of the negative impact Christianity has had on the Māori cosmology, I feel strengthened by this commonality. The Celtic Christian worldview had not a small impact on me, and it was through Iona that I'm suddenly here, in New Zealand, getting to study in beautiful locations such as this.

I notice the intricate carvings which adorn what looks like a central building and platform to my left. They look old. I park the car opposite what looks like the main glass fronted building and step out into the sunshine, which has now emerged from the rain clouds. I think of the the definitions the literature suggests are 'indigenous', and how the realities here seem already very far away from both 
the themes of colonial imbrication and the standard management theory principles and practices we were taught at undergraduate level.

I take my shoes off and leave them outside the door, alongside the other shoes there. I walk into the building, with a mixture of pride and self-consciousness as my family Farquarson kilt which I am wearing is eyed by those walking close to me. While I wait for Professor Winiata, I feel a familiar sense of being on 'revered ground'. The air seems still, and I look past the stained glass windows, with red koru designs on them to the long grass blowing softly in the fields beyond. The deep green carpet and polished wood interior adds to the sense of the sacred. I'm offered coffee and wait next to his secretary. Māori language radio filters through the air with an upbeat Māori waiata [song], blending ancient rhythms and Māori chanting with digital effects. I feel sorry I couldn't have learned more of the language, since I'm already missing both context and content of a culture I'm here to try and build a 'partnership' with. This is a culture which has been on the receiving end of many partnerships, and, beyond any efforts I make at sharing my non-Pākeha status, with a slightly self-conscious kilt and all, I still feel like a bit of a cheat. I'm still a white male researcher from the city, with pen and fieldnotes in hand, seeking for the great Māori chief, and I'm suddenly feeling very small. I sit next to neat piles of papers and reports on TWoR, trying to blend in too. Professor Winiata comes in and greets me with a kind smile, a hongi and a softly spoken "tena koe". 
Figure 10: TWoR and Professor Winiata

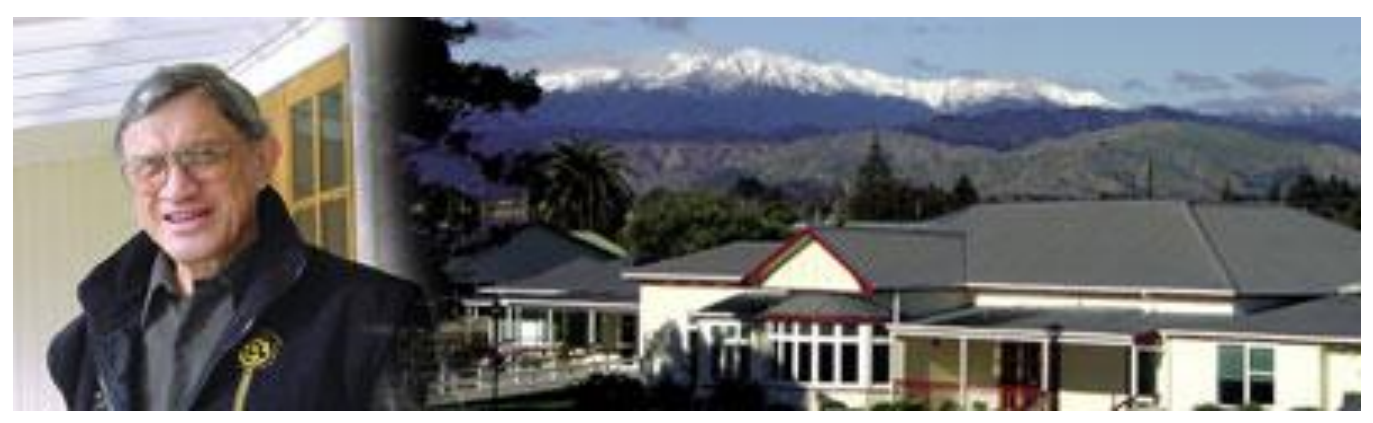

(Image from Te Wānanga o Rauwaka, 2003)

The hongi, (the traditional Māori greeting) is done with placing nose to nose and sharing that most sacred of Māori essences, the breath. Our eyes meet up close and I feel an overwhelming sense of both grace and depth. 'Welcome, welcome' he says, in the same gentle tones. 'Tena koe, ke te pehea koe,' I stumble, using a Māori greeting I have practiced, and feeling very awkward about it. 'Ke te pae, ke te pae'. I have managed at least to ask him in Māori if he is well, and yes, he is. After sharing the plan with his secretary of our movements we sit in his office and I introduce myself and my research context.

We are very intrigued as to your interest in us here.

Since going through my undergraduate study in Scotland we were asked a question: 'What is the Scottish identity, what is a Scottish organisation? I spent three years working with the IC: a Celtic Christian community off the West Coast of Scotland and it really intrigued me.

I met my wife there and she introduced me to some Mäori concepts. When I came to New Zealand I got a job in Wellington of Ecumenical Chaplain at Victoria. I had a chance to meet with Māori during that time, including a visit to the Marae at Parihaka. That really had an impact on me, we seemed to have a connection. I began to see some real similarities between our journeys.

When that finished I did some research work before getting a scholarship at Victoria University in Management. I am asking what is an indigenous organisation from within its own knowledge base? How is that defined and enacted? 
I show him my research proposal, and cover the ethical protocols of the research. My information sheet carries the research questions, processes and expectations of the study. Professor Winiata takes time to go over the detail of the introduction, noting my mis-spelling of some of his Māori colleagues. Looking up from the paper, he says:

Well, I like the way you've laid this out. We generally haven't welcomed Pākeha researchers here since there generally seems to be a failure of understanding or accommodating our worldview but I think this type of international research is the type that we need to be interested in. I think that there will be a lot in your Scottish experience our people will be intrigued to hear.

I notice the emphasis on the word worldview. I feel myself relax as I am given formal permission to begin the study.

I feel very blessed to get the opportunity, and I also am aware of the responsibilities that go with this.

I manage, feeling an increasing sense of ineptitude and knowledge of Māori customs. Gently Winiata responds:

I can understand your sentiments, Steven, but the blessing is all ours.

We then walk outside to the grounds. As we walk I am reminded of the similarity of gentleness and mannerisms that I found when I first met Norman Shanks, leader of the IC. Winiata tells me of the visits he has made to Scotland, and especially Dundee. We walk around the well laid out campus, past computer rooms where middle aged Māori look like they are being instructed on the internet - finding resources for their whakapapa [genealogy] I later find out - before we enter the food hall, where we will have our meeting. It is a large, well-maintained and very clean long hall, with what looks like audiovisual equipment at one end, 
and a servery at another. Winiata introduces me to all the kitchen staff by name, and I get a chance at practicing Māori greetings again.

Steven is doing a comparison between two indigenous cultures: the Māori and another.

Some say Aborigine, others Pacific Islands. 'Scotland' he says, with a gleam in the eye. I point to my kilt and say:

I try not to hide the fact I'm Scottish.

Many of our people can whakapapa back to Scottish.

We move into the hall. Again I am offered tea or coffee, fruit or cakes, all laid out exquisitely on the table. While we prepare our drinks, I am told of the music which plays softly in the background. One of the staff had a dying wish that the canteen becomes smoke free, as she had cancer. The music soothes the people after meals. I tell Professor Winiata of my father's work in health in the Scottish community, of the many health issues that plague the Scots people. I am introduced to his wife Gracie, who also offers a hongi. She sits to my left, while Professor Winiata sits opposite me. I offer to begin by talking of some of my background, my whakakpapa, and, apologize for the lack of fluent Māori. I am told not to worry, most will appreciate my efforts at trying. I offer my mihi mihi.

Tena koutou,

ko Doon toku awa

ko Iona toku maunga

ko Farquarson toku iwi,

ko Finlay toku hapu

ko whare tipuna toku marae kei Falkirk, Scotland,

ko Jock Finlay toku tipuna

ko Margaret Finlay toku tipuna,

ko Drew Finlay toku matua

ko Barbara Finlay toku mama

ko Susan Finlay toku wahine,

ko Lili Grace Finlay toku tamahine

ko Steven Finlay toku ingoa

tena koutou katoa 
I ask if I may talk of my Scottish background. They are gracious. I explain of my Clan, Farquarson, of my grandmother, Maggie Finlay. I tell of her standing in the small Scottish village she comes from, of the challenges that faced them as a family. Professor Winiata is intrigued by the challenges that faced our community - of the similarities in health issues and diet, and of the disconnections that the Scots have faced in finding ourselves as a people: "It will serve you well to remember your Scottish experience here, as our people suffer with a variety of health issues too". Winiata promises to give me some papers he delivered to a hui on health. His next meeting is looming. I proceed with the interview.

\subsubsection{Defining Māori Knowledge - Māori Worldviews}

I begin with Winiata, acknowledging the 'mana' of the first interviewees, including the leader-as-guarantor (as explained in Chapter 4, leader-selected interviewees are named throughout the text). Winiata conceptualises a worldview underpinned by Māori knowledge and how the ongoing formation of Māori knowledge, Mātauranga Māori, is defined and enacted in TWoR.

The definition of Mātauranga Māori are explanations of phenomena - all that there is around us - draws on concepts handed down from previous generations. That vision is consistent with the formation of worldviews that Māori Marsden brought to us in helping us to develop an appreciation of the origins of knowledge and of philosophy as he perceived these things (Winiata Interview, 2003).

Winiata explains the phenomenology of Māori knowledge, where experience is reflected on, named and inter-subjectively constructed:

It starts with experience - the human mind cannot resist trying to explain and out of that comes patterns of explanations, so there is a patterning - certain elements of it find acceptance by the community, being Māori in this case. With that you have what he called a worldview formed (Winiata interview, 2003). 
Winiata describes how the dynamic relationship to context recreates, embellishes

and updates a worldview which is inter-subjectively constructed and experienced.

The worldview is constantly changing and the thinking - at least amongst some of us - is that a Māori worldview won't stand still. It will be in a constant state of change, enhancement, embellishment, refinement, enrichment. We have to look inside to find the links with the earlier generations the explanations that draw on concepts that have come to us from them (Winiata interview, 2003).

Winiata emphasises how in the teaching of Māori to Māori they maintain what he previously called the 'whakapapa of knowledge' or the unbroken line of Māori knowledge continuity which traces back to Rangiātea.

The idea of a knowledge continuum - te kaka moe te muia e Rangiatia: I will never be lost a seed broadcast from the pacific - they brought their knowledge, the seed, and each succeeding generation have refined that knowledge, modified it, but the links remain and the language is an essential part of the link (Winiata Interview, 2003).

I ask others how the Māori worldview and identity is formed which reveals the constant connection to a spiritual cosmology which contains covenantal relationships. Protection and care of the environment are central features.

We have to go back to the very beginning, that's where our worldview is. If I look outside we have tane manutu - the god of the forest - we see that everyday. Everything comes from Papa-tu-anuku but part of that is held with rangiui- with sharing the environment, so we have 70 different gods. Those gods have different departments that they are each responsible for (TWoR Staff Interviews, 2003).

By seeking the wisdom and advice of the male and female tribal elders, who are holders and transmitters and intercessors for and on behalf of the Māori community, knowledge of the world and covenantal relationships within the environment are effectively managed.

We have tohunga, or experts, in different fields, that communicate with the Gods through karakia, through ruruku [gatherings] and they communicate, and these experts, in the old days, they would, approach them, and seek guidance and get advice from these experts, passing on advice. That's in the past. Through the generations this advice has passed on, down and down, until now. 
Roopu tuku iho in terms of the Māori worldview are those people that hold that type of expert knowledge that has been passed on.. Who do they consist of for us? Kaumatua [elders] and Kuia [elderly women]. To enable something to happen in the whanau or the hapu, where is the best place to go? To generate support, the best place to go, is to approach the kaumatua and kuia (TWoR Staff Interviews, 2003)

\subsubsection{Defining Indigeneity - Constructing Identity}

I ask a number of students at TWoR about their definition and experience of indigeneity at the individual level, with emergent themes emphasising a profound connection to the land through ancient habitation and a holistic cosmology which constructs indigenous identity.

Indigeneity for me is about our sacred connection to the land. Our marae, our Maonga [Mountain].W e say we are 'Tangata Whenua, the people of the land'. We are the first people here, the people of the land. We're born from the land.

I've been told stories of our old people and that they can whakapapa back to the land, to the sacred grasses and rocks of their land. That's what the people of the land is.

The big picture is that [Māori] got to come back to the land, the people and where we are from. You got to show your identity. You can't hide it. That's always going to be a part of your life.

It wasn't until I started getting into the adult world and I learnt that those things led to spirituality and then started going to, back to our Marae that's where I found more.

Tangata Whenua is interesting because of the meaning of the words. Whenua is the placenta, the afterbirth but its' also the land, for us they are one and the same thing that's why we bury our placenta in the ground. It's where we are from (TWoR Student Interviews, 2003).

Not only does Māori identity come through this ancient relationship to the land, it is expressed through whakapapa, which places Māori identity within a continuity between their ancestors and their children, and places an onus on them to embellish and transmit the best Māori knowledge and practice to their children, processes which TWoR aid:

It's not until I got to be adult and had children of my own. I can see their future and my past connected. You only find those things in places like these, and you can only go through them to help the next generation (TWoR Student Interviews, 2003). 
This whakapapa and identity also seeks to overcome some of the colonial Christian Missionary imbrication which has fragmented and devalued Māori identity, by bringing Christianity but devaluing indigeneity.

For Māori people we have a whakapapa. You hear lot of Māori people say in the churches 'I may look brown but I'm really white inside, you know, I'm not Māori I look brown but I'm really just a Pākeha Christian' and its really hard because then they don't know who they really are (TWoR Student Interviews, 2003).

Students connect to Māori knowledge through the processes of indigenisation which reorients then to their own knowledge and overcomes colonial identity fragmentation. This is replaced by a reconnection to a holistic spirituality, interwoven with the search for identity. The guidance and prompting of family at events like tangi [funerals held on Marae] enables this.

They'll still feel a connection although they may not acknowledge it. Something will come along like a tangihanga [funeral] and then there they are. Whanau will take them back to where their tupuna [ancestors] have come from. There is always going to be that whole wairua [spirit] which is going to be searching. Who am I? What am I? Where am I? Who are my people?

I've always believed that it is cool to be Māori.. It's awesome. It's who we are. Its something that you can always sort of like wake up the next day and it's always going to be there. It's not going to run away. Like you said like people trying to close the door and it's like always going to be there (TWoR Student Interviews, 2003).

The guiding aspects of Māori knowledge, whakapapa and wairua [spirituality] directed agency in a very positive way. Members also commented on my own

\section{Scottish tacit knowledge.}

My father's Kiwi but he trained in your country [Scotland]. A lot of what made him, and influenced him through his life, influences mine. He has a love for your land. He knows it well, I don't. I intend to though. Knowing my heart I want to know what that feels like. Ain't gonna never read it in a book, ain't gonna find it in a photo. Those things are there to see and aspire to but you got to actually get there.

Same with wairua, they give you a determining vision and the strength of that is what will lead you there. Its making you put your feet forward all the time. Its not making you take no backward steps neither (TWoR Student Interviews, 2003). 
I also ask other staff members about indigeneity and Māori identity, which is variously defined as self values, beliefs, being of the land, walking the values of the land, within an overarching holistic cosmology.

What does the word mean for me... indigeneity?

Being strong in your own self -boundaries, beliefs and values,holding strong to who you are. I am Māori first, Anglican second. My being is Māori. All I know is Māori. I have Scottish ancestry which I don't know. I've been raised in Aotearoa as a Māori.

Indigeneity to me is being of the land based on the land walking the values of the land.

As indigenous people we are in touch with our spiritual lives. Ever since I was a child I was fascinated about the American Indians, I think it was the way they respected the land although it is a physical bonding there is also the spiritual bonding of the indigenous people that although we don't understand the language we feel the spirituality behind it.

Whether it be Gaelic, Aboriginal, American Indian or whatever there is a language beyond which is the spiritual language, when the Scottish do their prayer or karakia or invocation there is that spiritual language of understanding (TWoR Staff Interviews, 2003).

Another definition emphasises how the values of the land emerge, and how indigeneity is strongly linked to survival in a colonised context.

Indigenous relates to the way in which a group of people who have only the land to support them develop stories which reinforce the need to hold together, the defining qualities are the ones that protect the community and enable it to survive rather than further some of the interests of the individual. It is a problem how to retain indigenous in a colonised country lke Scotland or New Zealand where there have been shocks which put the people off course (TWoR Staff Interviews, 2003).

This relationship between the person, the land and a holistic cosmology contains a contract of covenantal protection and guardianship, called kaitiakitanga. By exhibiting continual protection of the land, the status of guardianship of the land is bestowed:

Part of indigeneity is being a guardian of the land.. we call it kaitiakitanga...

Is indigeneity and kaitiakitanga the same?

To be kaitiakitanga of the land the inference is that you are the original inhabitor and that you've picked up this whenua [land] and you then pass it on to the next generation of your descendents... so the common link between kaitiakitanga and indigeneity is 
the land... we've just taken the term of kaitiakiatanga and extended it to other aspects but to me the basic element between them is the land.

Does that relate to whakapapa?

Whakapapa links the people together and you can whakapapa back to the land itself ... Mana atua, mana whenua, mana tanagata that's all linked in together. The common bond between them is whakapapa, in my mind anyway.

If you go through whakapapa and you take it right back to the whenua and then take it back even further you'll end up at Io matua - a supreme being... an indigenous person is a person who has the rights and responsibilities of kaitiakitanga, and they've acquired that through whakapapa.. Kaitiakitanga is guardianship. They don't own it, they just look after it, and enhance it, and pass it on if they can, if not in a better form than they had it, at least not in a worse form for succeeding generation (TWoR Staff Interviews, 2003).

Learning Te Reo wasn’t sufficient in developing a Māori identity. Learning Māori knowledge brought a sense of fitting in a Māori worldview, one that is whanau, hapu and iwi-based and holistic.

You can learn Te Reo, but it doesn't make you Māori...Coming here for over three years gave me that extra bit to make me understand how I personally fitted within the world of Māoridom... how I became a part of where my whanau was, where they fit within the hapu, where the hapu fits within the iwi, and what that means in the world of Māori. The Reo on it's own doesn't do that, it enables you to communicate within an indigenous language but it's just a small part of the whole, and you need it all to get that whole (TWoR Staff Interviews, 2003).

In the staff and students of TWoR, the notions of indigeneity relate specifically to

a sacred connection to the earth, within a holistic cosmology in profound connection to land. This cosmology may be learned as knowledge, but the status to claim this is passed through the notions of 'Tangata Whenua', containing whakapapa: genealogies that maintain the sacred connection to the land which pass on rights to kaitiakitanga status.

I am advised by Winiata to approach writer and musician Dr Te Ahukaramu Charles Royal, ex-director of the postgraduate research programme at TWoR, and 
relative of Bishop Māori Marsden, the philosopher Winiata indicated was instructive in helping shape TWoR's thinking. I am told by staff at TWoR that Bishop Māori, who was himself schooled in a traditional wānanga, personally schooled Dr Royal in Māori knowledge. Dr Royal tells me of his research, which sought to ask:

What vision of the world of life is contained with indigenous knowledge and Māori knowledge? In 2001 I had to define what I meant by indigenous, so I did. It is a very deliberate attempt to define indigeneity and indigenous cultures outside of this post colonial social justice paradigm. An indigenous culture to me is one that sees a divinity in the world (Royal Interview, 2003).

For Royal, contrasting Pākeha and Māori notions of 'indigenous' are useful to illustrate the notion of a sacred connectedness with the land, longevity or Te Ahika, the lit flame. Importantly Royal indicates there are other definitions not put forward, and the complexities of the issue for Māori and Pākeha.

My Dad is Māori, my Mum is English and Scots. If I look to the Pākeha side of my family why can we not them as Tangata Whenua? This Tangata Whenua seems to me in New Zealand terms as the real icon of indigeneity in New Zealand.

When I look at what is the criteria to be Tangata Whenua on the Māori side, one is burying the dead in the land, second thing is spilling blood on the land, a third thing is what is called ahika, the lit flame, that is longevity of dwelling in a place. There are others, but we're talking about the spiritual connection with the land.

I look at the Pākeha side of my family, they've got that. But we still feel reluctant to say that Pākeha are tangata whenua. Now there's lots and lots of complex answers to this question, but Pākeha do not ritualise their connection with the landscape. Whereas the Māori are talking about mountains, and seas. We can't shut up. Such and such, my ancestor,the seas, the rivers, the lakes. And even when a forest has been absolutely rent asunder we keep on saying that's our forest (Royal Interview, 2003).

Despite this difficulty, for Pākeha to claim Tangata Whenua Royal proposes that everyone is indigenous to where they are born.

We can't ever help by being indigenous to our environment, even if we don't know it. My physiology is very much indigenous to the lower North Island of New Zealand. I was bought up in a rural/urban environment. I am an urban dweller. I suggest that people who grow up in Manhattan are indigenous to Manhattan and London and so on. You can see it in their language (Royal Interview, 2003). 
So for Royal, indigenisation is a method of sensitising oneself to whatever local context all people find themselves and the inevitable influences which emerge from, and are constructed in that context. I next plot the organisational boundaries and rules at TWoR.

\subsubsection{Boundaries and Rules: The Theory of Wānanga}

Plotting the boundaries and rules within TWoR illustrates how Māori knowledge overcomes colonising influences on health. Winiata describes the Theory of Wānanga, and how the boundaries and rules are concepts developed from Māori knowledge including the Māori notion of Rangatiratanga, have lessened the negative effects of neocolonial identity fragmentations.

The theory of wānanga looks to concepts of mana enhancement and rangatiratanga to help explain the way we behave. 'Te kawa o te ako' is an example of drawing on a concept for the new generation to help explain and influence behaviour.

Te kawa te ako is a requirement that students avoid activities which will impede their ability to learn and our ability to teach. We haven't said that drugs and alcohol are banned. The protocols and the behaviour required in a place like this is to avoid actions which will impede learning or impede teaching.

It was te kawa te ako that was introduced when we were beginning to have difficulties with drugs and alcohol. Students who were supposed to be studying were smoking marijuana in the hotels. Staff became really frustrated and deeply worried about that. (Winiata Interview, 2003).

Winiata emphasises how successful drawing and adapting ideas from earlier generations has been.

With a concept handed down to explain behaviour, we have found that it hasn't been a problem. We have been able to get rid of drugs and alcohol. One really important byproduct of the introduction of te kawa te ako is that sexual harassment has come pretty close to zero. We had one case last year, one the year before, that one the year before that. Prior to 1999 and earlier they were becoming a regular feature following a noho.

Drawing on and modifying ideas from earlier generations are providing the opportunity to enhance and enrich our understanding of behaviour (Winiata Interview, 2003). 
I am also told how the holistic worldview of Māori is interwoven with wairua

[spirituality] and how external symbols such as moko [tattoos] need to be backed

by agency or 'walking the talk'.

We were saying about the Māori spirituality and culture, how the two are one and the same? People who believe in ta moko, which is the carving of the face, which is having a resurgence, that's saying if you are really going to follow the teachings of our tipuna and you are going to have your body adorned with carvings you are going to need to live the true spiritual life that goes with it, you don't swear, or any of that, like the ten commandments. It's the tikanga associated with having your face adorned. If you follow the path truly you have to take on everything that's involved with it (TWoR Staff Interview, 2003).

\subsubsection{Theory of Wānanga Session}

The session presents the history, aims and the underpinning behaviours expected of guests and new students. The video presentation begins with a high quality multimedia presentation backed by a modern Māori waiata [song] showing scenes from Rangiātea Church and TWoR, played to the 100 or so tribal guests sitting at tables in front of the large screen. The presentation begins by underpinning practices and boundaries that emerge from Tikanga Māori:

Te Wananga o Raukawa strives to operate following tikanga Mäori for Tikanaga Mäori Students are assisted to see the world through Mäori eyes and are encouraged to behave accordingly. This is a BIG CHALLENGE Te Wananga o Raukawa strives to operate following tikanga Mäori (Theory of Wananga, personal communication, March $15^{\text {th }} 2003$, umlauts and Caps in original).

The introductory slides lay out TWoR's commitment to Māori knowledge and practices, emphasising the journey of healing that comes from students exploring their own identity, whanau, hapu and iwi within the holistic cosmology used to underpin teaching methods at TWoR:

At Te Wananga o Raukawa you will study yourself in the context of your own Whänau, Hapü and Iwi. Iwi and Hapü Studies is the vehicle for your personal journey Te Reo Mäori is essential to this journey Your Specialisation will illustrate the journey The journey will be - W.E.H.I. (awe inspiring) Wonderful, Exciting, Healing and Internal. For some, the journey will be a continuation of earlier experience. 
For others, the journey will involve entering the world of their extended Whänau, Hapü and Iwi for the first time. We need each other to succeed.

For some, Te Wananga o Raukawa will be easily understood.

For others, Te Wananga o Raukawa will be difficult to understand.

We must help each other to ease the uncertainty and discomfort (Theory of Wananga, personal communication, March $15^{\text {th }} 2003$, umlauts and Caps in original).

The presentation articulates a set of principles and practices which legitimises the university and its purposes as a Māori institution to the students. It shows how Māori knowledge underpins lifeprojects for the members, which enables reconnection to iwi and hapu, and overcomes globalist practices. TWoR and their staff are placed within the guiding principles and knowledge of Māori practices, using a notion of tikanga [rule]:

tikanga Mäori refers to ordinary or normal practices that are Mäori

Tikanga Mäori in this presentation, refers to the staff and students of TWoR who observe these practices. TWoR strives to operate following tikanga Mäori for Tikanga Mäori (Theory of Wananga, personal communication, March $15^{\text {th }} 2003$, umlauts in original).

The identity of TWoR as a Māori institution is created and sustained through principles and practices which are presented as rules and frameworks to follow. These develop and maintain the mana of the students and the university. They avoid activities which lessen the mana of either. For students, Māori knowledge creates coherence to develop a learning journey within clearly expressed boundaries. "They just laid the foundations here today. You have to have really good foundations to start from. They couldn't have done it better" (TWoR Student Interview, 2003). 


\subsubsection{Māori Knowledge and Life Projects in Social Context}

In the 'Theory of Wananga' workshop, themes of encouraging connection to

whanau, iwi and hapu emerge as goals for life-projects of the students, interwoven

with learning more of their own whakapapa, building Māori identity. However

access back to the Marae wasn't without its own constraining power structures:

You been goin' to a Marae for 20 years. You done the dishes, peeled the spuds, you done the hangi hole and the Uncles will say 'Hey, you're not a Māori because you weren't there for this day'. That's why I'm trying to get on to it for myself and for my iwi... So then I can go back to the young people. How are you going to find that out? Unless you go to the place you come from.

Your uncles say 'I've done the back, the legwork at the back for 10 years now, I want to get up on the paepae' [speaking space on the Marae]. I've learnt how to do that as well. And they say 'Aw nah you're too young.' But you've got whakapapa haven't you? Your whakapapa says you earned the right to sit on that.

TWoR really keeps your identity your Māoritanga. What was said about iwi - that's where I want to end up. (TWoR Focus Group, 2003).

Participants seek to reconnect their family, hapu and iwi to Māori knowledge,

which is far more valuable than the logics of globalisation.

Do you have a vision for where you'd would like to take this journey?

It starts with your whanau.From whanau to hapu to iwi. Cause you don't miss out on anybody, the young, the old, the infirm, sedentary all of them. Build it up from the ones that are close to you then expand. You give up too soon you're going to lose some of them...

If you're not willing to turn around and provide for your people who the hell will? The same as the children, if you're not able to give them the best you got, which isn't just your money or your shoes, or your car... its your aroha [love], your wairua, your mana, respect.

Teaching them the qualities of learning. That's how to earn it. It's not about commanding it, it's about what you got to give in this life. That's why I like coming here, these people got plenty (TWoR Focus Group, 2003)

The participants speak of the role of TWoR in their lives, of imparting the tools that allow them to reconnect to their own knowledge at the iwi and hapu level and pass it on to the next generation in their whanau. 
The book will always still stay open of questions.. That's why I come to the wananga. It's taken me three years to get here and I'm hungry. I've come here with my kete [knowledge basket] to be filled up, then I've got my next kete, fill that up too. Until I got all these ketes and give them back out to my tamariki [children] so that it will continue to carry on. That's our future (TWoR Focus Group, 2003).

Gaining Māori knowledge from the tribal elders enables a positive construction of Māori identity for current and future generations. This reverses the losses to Māori knowledge that recent generations have suffered, exampling how Māori knowledge is still devalued and de-legitimised.

Usually there's people who'll laugh at Māoritanga. I go to a house and talk about it they go 'chuck you out of the door'. I go to another house they sit w' you for 5 minutes (TWoR Focus Group, 2003).

This is contrasted with tribal elders who still maintain, uphold and pass on indigenous knowledge.

You go to an old kaumatua they'll stay there all day. They just enjoy just that feeling of people asking for that knowledge. So then they've told someone that's going to take that in, grasp it with two hands. Put it straight in their heart. It might take me one week it might take me my whole life.. I know where I'm coming from (TWoR Focus Group, 2003).

TWoR encourages students to reconnect to iwi and hapu, through the Marae Based Studies (MBS), a compulsory paper: "its scary for them to go back but it has reconnected them back to where they're from. It's given them a link back to their marae. Giving energy back to the marae" (TWoR Staff Interview, 2003).

I am told about how students on the MBS programme build Marae capacity:

MBS taught them to develop a plan for 'The Virtual Awa' at Parakino which is a cyber café in the middle of Wanganui River. And now they are venturing out in to greater ideas (TWoR Staff Interview, 2003). 


\subsubsection{Experiencing Colonialism and Postcolonialism}

In discussing student's experience of Māori knowledge, themes of colonial internalised imbrication and devaluing Māori knowledge through the education system and in the global environment emerged.

We weren’t taught anything Māori at school. Being Māori meant sitting at the back of the class, not fitting in.

When I left my iwi I left a place where people cared for me, looked after my physical needs. When I got to school nobody cared how I was, or what I needed.

When I was at school I was labelled as a troublemaker and told the only thing I'd be good for was prison. It's no surprise that's where I ended up. It's pretty crazy that the only place you'd be taught anything about Māori culture then was in prison.

I didn't have much of a Māori upbringing. Our parents didn't want us to learn that. They did teach us a bit of the things that I'm learning today like whanaungatanga [familiness], manaakitanga [mana enhancing behaviour].

My parents even though they didn't bring us up in the Māori world they couldn't help but show us how to be Māori because they are Māori themselves. I was learning the wairua [spirit] without it being spoken (TWoR Focus Group, 2003).

For many, the imbrication of Māori by the Christian missionary orders has created identity confusion, but also for some a source of strength.

My mother was Catholic and my father was Anglican so the religion that was taught to us but in a Māori concept. A lot of cultures that Christianity impacted on, they tried to meld them together.

When I became an adult I asked where is my identity as a Māori? I'm in this faith so how do I become Māori and Christian? How can the two come together? I am on this whole big journey as Māori and Christian, not only for myself but I bring up my kids in the faith and as Māori. I want them to learn two sides.

It plays as big part as being Māori. We've seen a lot of Māori people in the churches today say 'I am no longer Māori I am just Christian'. Being Māori is no longer just all the bad stuff (TWoR Focus Group, 2003).

For the participants the limits of this knowledge needed to be completed by accessing Māori knowledge which foundationally supports the development of their identity, as knowledge continuities going forward. 
What happens if those things aren't taught?

There's no fulfilment, just a sense of loss. When my babies come to me say 'Where am I from?' then I don't know.

I think that hill up there belongs to you or something like that. That's not explaining it to them. It just gives them a half of the person that they really are. They're lost. Its not a completeness, its not a closing to who they are.

And the great shame is that when you need them, they won't be there for you. When you really need them now that's your moment of truth.

Anybody can stand tall in the light of day but they still shiver in the dark (TWoR Focus Group, 2003).

The group saw TWoR as a guardian of Māori knowledge, illustrating the role of symbolic universe maintenance and enabling identity. Members contrasted the knowledge they were receiving from TWoR with the identity and agency associated with globalist practices which decohered Māori whanau values, and replaced identity with a constant quest for material acquisition.

People out there know nothing of who they are. It's places like this where you get it. You don't get it out there, all you get out there is just the KFC culture.

My nephews and nieces next to my kids they're like, they can work hard they can make lots of money but they can't bother to sit down and have, be a whanau and just be...hug each other.

They can go and make money and drive flash cars all they want. But these are the things I need to teach them..

My nieces they have no identity, their identity is just to go to work and come back with flash things they'd rather have KFC instead of boil up [traditional Māori broth] (TWoR Focus Group, 2003).

Postcolonial perspectives do not have any precedence, despite the ongoing need to manage the effects of globalist practices on health.

The word colonial is eschewed here... we generally don't like the term.. if you are interested instead in what we call an 'indigenous worldview' then you should speak to Charles Royal, who has done a lot of work on defining indigenous worldviews for us here (Winiata Interview, 2003). 
Royal was also eschewing discussion about colonisation, avoiding what he saw as an undue focus on colonialism and all its' derivatives.

I resisted the whole theme of colonisation in the discussion about indigenous world views. I'm not keen on the topic at all. Too much of our knowledge has been transformed through the lenses of colonisation, decolonisation postcolonisation.

I know it's an ideal and I know you can't leave it $100 \%$ it's, there's no such thing as a pure source of Māori knowledge or indigenous knowledge, but it was a very deliberate attempt to try and not to define concepts through our experience of colonisation (Royal Interview, 2003).

Postcolonial theory which enables the 'voice of tribals' to speak back, as Spivak (1987ab) suggests in the literature, has been supplanted by TWoR defining and enacted their own Māori holistic cosmology.

\subsubsection{Māori Knowledge at Individual Levels}

This chapter discussed actors' and communities' orientation to Māori knowledge. Organisational leaders encourage members' indigenous identity through the requirement to learn whakapapa (genealogy) which supports the reclaiming and rebuilding of Māori identity, emically constructed within revalued knowledge which includes, but is not limited to, aspects of covenantal cosmologies which Fischer, (1999) found in the Mayan context. Interwoven with this knowledge, and the carrier of it, is the Māori language, Te Reo Māori, which is also a requirement of members. Exposure to knowledge, carried by the Māori language, has substantially affected members' own self definition, raising their own notions of identity from those devalued by the colonial context, to identity based proudly on family connections to prior and longstanding indigenous settlement. Identity is not based on consumerism or individualism as Banerjee and Linstead (2001) and 
Friedman, (1994b) proposed in the literature, but instead on connectedness to whanau, hapu and iwi, and the social projects which develop and enhance this identity, an orientation Friedman (1994a) suggests in the literature is central to the foci of indigeneity. These social projects eschew individualism and aim at the development of community capability and survival, as Henare and Lips-Wiersma (2002) identify in their own OS research on Māori organisations. Boundaries assist in overcoming neocolonial fragmenting health issues which were also found in the research of the Aboriginal contexts (Banerjee, 1999 ; Cunningham and Stanley, 2003).

\subsubsection{Indigeneity Defined and Enacted in a Māori Context}

For the Māori people of the ART confederation constructing Māori as indigenous did not focus on the consequences of colonial imbrication. However the effects of this imbrication were inexorably present. Local definitions of indigeneity emphasised 'Tangata Whenua' the 'people of the land' as occupiers and guardians of both sacred knowledge and sacred land, each to be protected, developed and transferred for the use of future generations, concepts supported by constructionist anthropological definitions outlined earlier. Placed at the centre of their consciousness of indigenous were notions of Tangata Whenua within a covenantal holistic cosmology that is passed from previous generations and constantly lived and updated, echoing the themes of indigeneity that were earlier introduced in Chapter 2 (Fischer, 1999; Friedman, 1994a). These covenantal relationships include Māori Gods that require acknowledgement and consultation with through 
Māori elders. Identity is constructed within ancestral family (whanau) and tribal (iwi and hapu) relationships. Essential notions of whakapapa holds as sacred the very essence of Māori identity in the blood lines that whakapapa contains. Not only is tribal identity based on blood and kin based notions. The relatedness of showing good actions towards people and tribes creates whakapapa: the ongoing construction of sacred relations between people. As I learned, this happens in the formal context of a powhiri [tribal welcome] where the mihi mihi constructs both the sacred relations with the land: "this is my mountain, this is my river" through selected whakapapa. Other polyvocal definitions of indigeneity were articulated. These included notions of Māori identity being directly related to Māori knowledge, of whakapapa and the other interconnected elements of a Māori worldview. They also contain notions of Māori identity that is formed through relatedness to a tribe or people, and the ability for non-Māori to be given Māori names and adopted into tribes. Within broader indigenous definitions are a universal and expansive definition of indigenous that understands as central notions of guardianship or stewardship of the environment, but maintained through whakapapa. Notions of indigenous have been extended by Royal to be inclusive and can be used to apply to all humanity, not just Māori, relating to our own places of origin, and the worldviews therein. Experiencing Māori knowledge had a profound impact on staff and students alike. They explored this cosmology through making connection with family and tribal members, a process of indigenisation actively encouraged by TWoR. Indeed, connecting with this knowledge is presented and experienced as healing, overcoming the colonial and 
globalising influences that are seen to decohere indigenous knowledge, values and practices. Instead positive indigenous identity is developed as are connections back to iwi and hapu, where the agency of active contributions for iwi and hapu survival and development are encouraged.

\subsection{Discussion}

Indigenous identity is found not to be constructed by colonial imbrication as postcolonial theorists propose in the literature of Chapter 2 (Banerjee, 1999; Rattansi, 1997; Spivak, 1988), but instead constructed by reference to 'mystical' transmitted knowledge in relation to sacred land, as suggested in other studies (Banerjee, 1999; Banerjee and Linstead, 2004; Henare and Lips-Wiersma, 20002; Whiteman and Cooper, 2000). Authenticity in this context relates to the strategic use of indigenous knowledge to underpin consciousness and therefore subjectivities, including identity, without the primacy of marginalising power relations or social structures (Friedman, 1994a; Gunew, 1994). This knowledge is not essentially fixed (Fuss, 1989) nor is consciousness fragmented in the use of knowledge (Calas and Smircich, 1999; Spivak, 1987a). Instead indigenous knowledge is inter-generationally transmitted and enacted, creating coordinating and unifying functions, while being constantly updated as proposed in the constructionist anthropological literature (Fischer, 1999). 


\subsection{Summary}

In chapter summary, the 'tikanga' of mātauranga Māori involve principles and practices that uphold the 'mana' of the people, and the university. For TWoR, what works in their context involves embellishing and enhancing Māori knowledge to support many organisational aims, not least of which is excellence in teaching of Māori for Māori students, within Māori frameworks. Part of this teaching at the earliest stage involves the compulsory classes Te Reo and Marae Based Studies (MBS), which reconnects students with their own whanau, hapu and iwi. Within these whakapapa are 'Tangata Whenua' relationships, which maintain ancient and sacred connections to the land, within the cosmological relationships of the Māori worldview. These whanau, iwi and hapu connections construct stable identity patterns which are inter-generationally transmitted. They also act as a social guide for life - projects: staff and students take an active part in the rebuilding of Māori community at local, regional or indeed national levels.

In this chapter I have ethnographically described how Māori knowledge is defined, phenomenologically experienced, and enacted at the individual level exploring definitions and experiences of indigenous Māori knowledge. I next do the same exploration within the IC, and the Island Centre of Iona. 


\section{Chapter 8: Defining and Enacting Celtic Knowledge}

\subsection{Introduction}

This chapter is the second of two which examines at the individual level how boundaries and rules support actors to enact knowledge and how this action creates polyvocal definitions of indigeneity in the face of fragmenting globalist practices. It ethnographically describes how actors define and enacts Celtic knowledge and indigeneity in the context of the Iona Island Programme in 2003. It shows how IC has sought to recover and enact Celtic Christian knowledge, which supports the life projects of members to rebuild community and overcome fragmenting globalist and historic practices which have impacted Celtic Christian knowledge.

\subsection{Iona Programme 2003: On the Move}

This programme is run by the leader, Kathy Galloway. For myself, my wife and our two small children, forming the community begins unintentionally on the ferry leaving Oban for the IC programme in July 2003. This programme is typical of those run in the MacLeod Centre, as it is focussed on family life and community building. We sit next to another young family, and find out that they too, are coming to Iona for the family programme, and that they too, are working on research. Eileen's topic is on Celtic worship in American churches, and how, with the ever-increasing interest in things Celtic there, how Celtic liturgy works in that context. 
What brings you to Iona?

We're studying Celtic worship.

Really? I am studying Celtic things too. Maybe there will be no authentic visitors on the island, just researchers. What's your topic?

I'm studying the transfer of Celtic worship, in the US, where we live. We have research support from our seminary to pursue our study.

What is Celtic for you?

It is where churches use Celtic liturgy which has themes of connectedness, where all things are sacred, especially sensing the sacred in the environment.

So the fuller Celtic model builds community?

Definitely. I'm going to Iona to see how they do that (Guest Interview, 2003).

Eileen tells me of how Celtic worship acts as a 'gateway' to encourage connectedness to the environment, and how the fuller model has an intentional focus in community building and less on individualism. We sail on, arriving at Mull. I feel the internal gears slowing down, as the laid-back island bus drivers wait casually to pick us up and take us the one-hour trip across the single-track road over Mull. Once on the bus I feel a familiar rush of excitement. I enjoy taking in the rugged Mull landscape as a precursor to the renewal of my relationship with the Iona Island and the Community. Across the moors the old pilgrim walking routes appear, semi-hidden, lined with the occasional stone marker or 'waymark', small standing stones which point the way towards discovering God's presence in the world (Miller, 2000). The small single track road traces around many hidden bays. The sense of journeying West, to the edge, increases until, without warning, we emerge over a small hill to be faced with the last short ferry ride, and the presence of the Iona Abbey, nestled as it appears beneath Dun I, the highest point on Iona. Once on the ferry we sail gently over the 
last stretch, before disembarking on the jetty. As we walk up past the Abbey I feel an immediate resonance with history, knowing as I do that Scottish Kings and saints are buried here. The depth of connection to the past seems almost overwhelming, as do the towering Celtic Crosses, carved in stone, and standing tall against the racing clouds. As I look again at St Martin's cross, I see the thousand-year-old interweaving pattern.

\section{Figure 11: Iona Abbey}

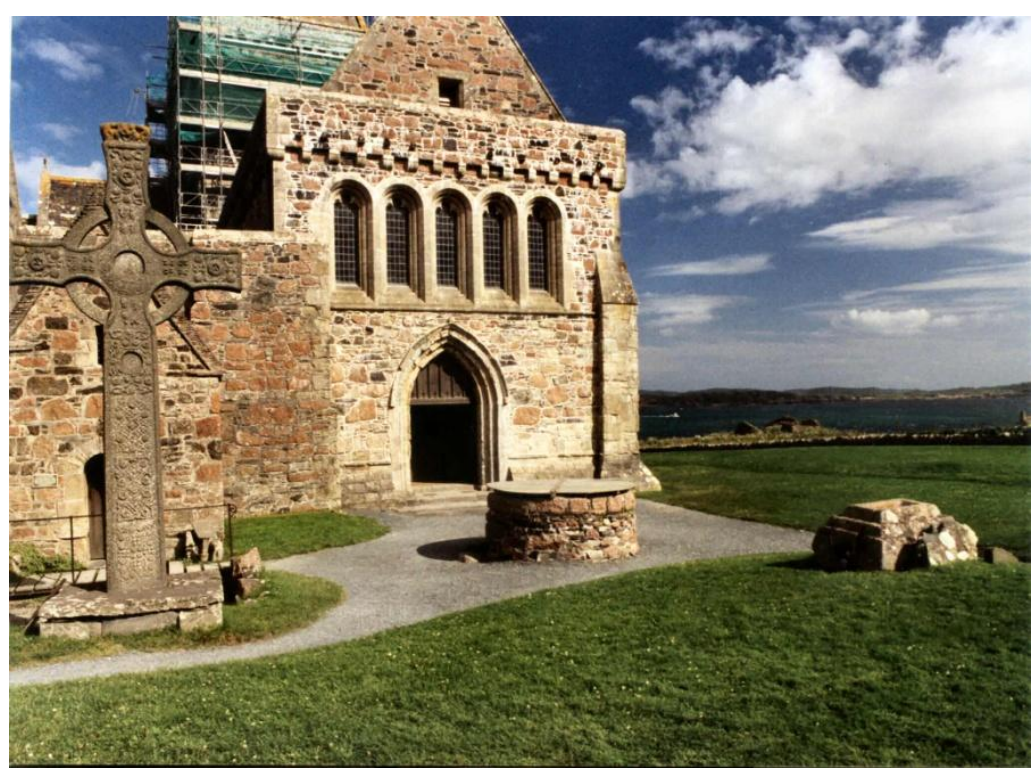

(Fieldwork Photograph, 2003) 
We arrive at The MacLeod Centre named after its founder and designed to be a meeting and programme space where people from all backgrounds can gather and experience 'family'.

\section{Figure 12: Appraching the MacLeod Centre}

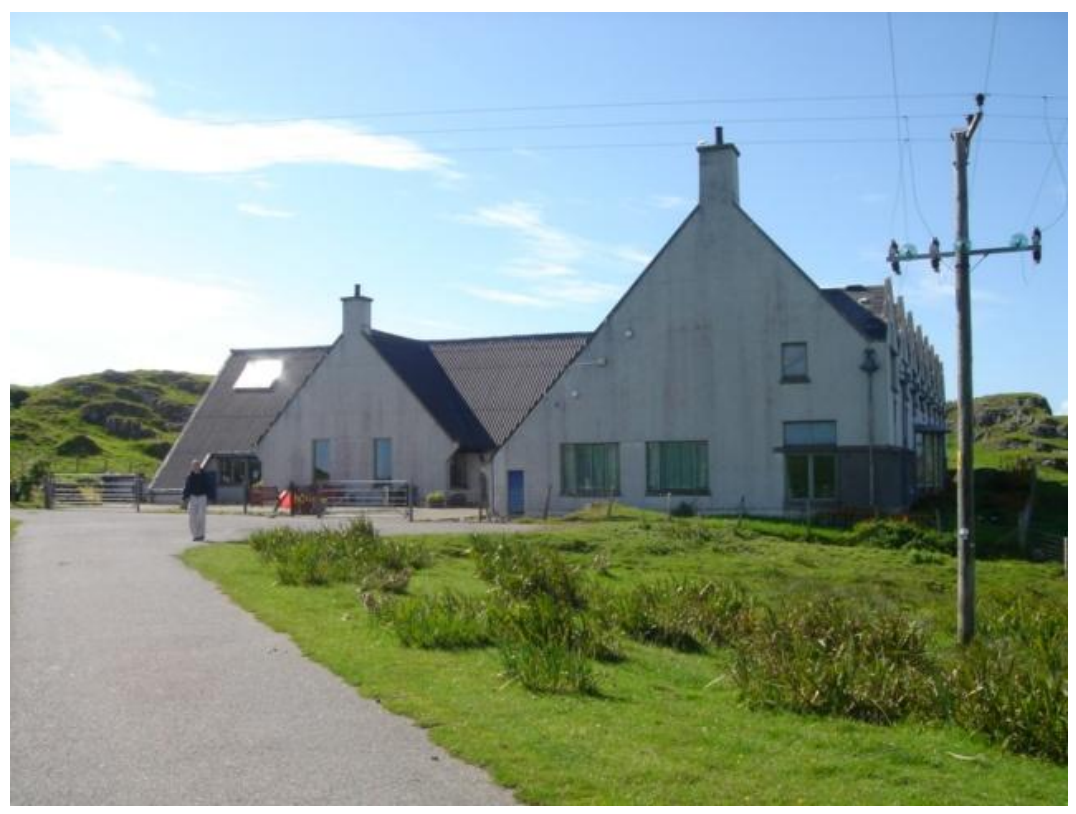

(Fieldwork Photograph, 2003)

We are welcomed, shown to our separate dorms, and introduced to the leaders over a welcome tea and biscuits, before the evening meal. At the first meal I seek to gently probe as to why people have come: "what brings you to Iona?" "I had heard of Iona through so many people that I wanted to experience it for myself" (Guest Interview, 2003). For many the connection is through the music of John Bell: "I have sung the songs often enough and just wanted to experience something deeper" (Guest Interview, 2003), or simply it is a break in the busyness of life: "we came to take a break and to take time out" (Guest 
Interview, 2003). The journey is also part of a profound journey of healing and renewal that has taken years. I am told stories of pain and brokenness, surprising and challenging in their frankness given how little we know of one another. As a guest put it to me: "In the world you get to know people from the outside in, here it's the inside out" (Guest Interview, 2003). The reciprocal question is asked of me: "I first came here as a volunteer in 1994, as a management student, and worked at Camas, the IC youth centre on Mull. I then met my wife here”. Introducing my wife Susan, and our two children, I tell people of my research, and feel able to build trust and rapport when they know that I have spent some time here before. We gather for the beginning programme and introductory session, called 'On the Move'. Kathy Galloway introduces the theme, after introducing a Jerusalem song, in which we all join:

We are a people on the move. We journey as a people from a whole variety of backgrounds, and I'd like to invite you to go round the group, saying your name, and telling us something that happened to you of significance on your journey here (IC Programme Fieldnotes, 2003).

We go round, being introduced to each other through hearing from where people have come, and some insight into an event that happened to them on the way.

Hello, this is Susan, my wife, and Lili and Skye, my children. I'm Steven and we came from New Zealand. We got on the ferry at Oban, seeing another young family seated in good seats. As we sat we learned that they were coming here too, and both studying things Celtic, showing how the journey and the experience often begins before we even arrive!

Conversation is safe, yet revealing. The group then close again with a song, and Kathy invites us to the service of welcome at $9 \mathrm{pm}$. The opening programme is a lovely mix of safety and risk. The introductions help us locate one another, and 
gain a sense of where we've come from, the journeys we are all on. Kathy comes over, after the programme, offering hugs of welcome. We tell her of our recent experiences in New Zealand, after talking about the ethical protocols of the research. She is really interested in the research. With conversations going late into the evening I get a chance to introduce myself, and my research, to a number of guests.

\subsubsection{Celtic Knowledge - Celtic Liturgy}

I awake in the male dormitory to find another roommate arrived later the previous evening, an Anglican Minister who journeyed all day from South England to be here. We exchange introductions, and I tell him of my research. 'What brings you to Iona?' I ask.

I'd heard a lot about it, and been singing the songs of John Bell for years, so I wanted to experience something of it for myself'

What do you find on Iona that's distinctive?

I've been to quite a few Hebridean Islands, so there's the closeness to nature that you tend to get in the islands, but on Iona there is the Celtic liturgy and worship which makes it very special.

What is Celtic for you?

Well, they said it last night in the worship - the focus on an ecological awareness, which is tied in to a reverence for creation. The other thing that struck me was the notion of work and worship - that making one's work an act of worship -that seems quite unique to Iona. The other theme that I got was of interconnectedness, that all things are connected. That seems quite Celtic (IC Programme Guest Interviews, 2003).

We go to the morning meal, where the guests are split into their assigned teams and share the common tasks of living together. We help by clearing the tables, sweeping the floor and clearing the dishes. This gives the group a common task. 
After breakfast we make our way down to the Abbey, for the Sunday worship, which is a communion service led by Galloway. Her sermon is the high point of the service, and also symbolically the high point of the week. I gained a personal copy of this sermon, and reference it throughout. It contains many of the broad themes of Celtic Christianity, and Celtic knowledge, beginning with the premise of the goodness of creation as it exists in itself, in contrast with a typical Western view.

[The Celts held] a conviction of the goodness of the whole creation, not goodness in a moral sense, but ontologically, the goodness of being. All is good, not by virtue of its value to others, or by its resourcefulness or its efficiency, but simply in the fact of its being. (Galloway Personal Sermon Notes, Iona Cathedral, July 2003)

She also articulates a belief within this worldview of the holistic nature of existence contained in the Celtic Cosmology: "the conviction, not only of the intrinsic worth of the creation, but of its interconnectedness. The whole universe exists in a delicate yet complex web of relationship, an integrity of creation" (Galloway Personal Sermon Notes, Iona Cathedral, July 2003). For Galloway the miraculous is to be found in the everyday: "the conviction that nothing is more miraculous, more wonderful, more worthy of reverence, than the ordinary" (Galloway, Personal Sermon Notes, Iona Cathedral, July $15^{\text {th }} 2003$ ). It is through the world that the 'self communication' of God can be found:

The [IC] holds to the sacramental character of the whole creation, which does not makes distinctions between the sacred and the secular, but believes in the active selfcommunication of God in and through the things of this world (Galloway Personal Sermon Notes, Iona Cathedral, July $\left.15^{\text {th }} 2003\right)$. 
In the sermon Galloway legitimises both Celtic scholars and a Celtic worldview, including references to sacred knowledge held within a holistic cosmology which extends beyond, but is deeply imbued within the physical:

The 9th century Irish theologian, John Scotus Eriugena said: 'every visible and invisible creature can be called a theophany, an appearance of the divine.' And the Christian Celts of Scotland used to refer to God's little book, the Bible, and God's great book, the creation, and read God in both...

There is nowhere that God's love has not extended - to the invisible as well as the visible world, to the things unknown as well as known, to the dreaming world as well as the waking one, as the Celtic poets had it (Galloway Personal Sermon Notes, Iona Cathedral, July $\left.15^{\text {th }} 2003\right)$.

Galloway describes the IC's belief in sacred people being in a sacramental or covenantal relationship with the Earth, and each other, within this Celtic Christian holistic cosmology. Galloway calls Christians to act within a covenantal awareness, to be in 'right relationships' both with the Earth, and each other as stewards of creation: "To be creatures in the covenant, to be citizens of heaven, it is not only to be required to be in right relationship with our own human kind, but with the whole creation. Justice is also eco-justice"(Galloway Personal Sermon Notes, Iona Cathedral, July $\left.15^{\text {th }} 2003\right)$.

\subsubsection{Defining Indigeneity}

For Galloway, indigeneity relates directly to what is native to a land and the sense of historical continuous occupation in a place. The Scots language Gaelic is also intimately connected to such a notion:

It's about being native to a land - I think of myself as being an indigenous Scot born in Scotland raised in Scotland and all the generations of my family that I am aware of at least to the early 18th Century are entirely Scots. They probably are 
before that as well. If they are not Gaelic speakers in the latter generations they are much more likely to be in the earlier ones (Galloway Interview, 2003).

Galloway describes the sacred relationships to land that indigeneity involves, what she calls the sacred landscapes of the heart, emphasising profound connectedness to people and place, what she terms culture and nature.

I have done a huge amount of travel and I love other landscapes but they are not the landscapes that are my inner landscapes. Not just Iona but the West of Scotland is my inner landscape. That includes Glasgow, both culture and nature (Galloway Interview, 2003).

However Galloway also relates how indigenous is a term that is difficult to use in Scotland, since the Scots aren't a marginalised group within their own notion of nation:

Indigenous means different things in different places. Scotland hasn't been recently colonised. It's a different thing in Canada where Indigenous Peoples are more easily distinguishable. I don't know if you would call me an indigenous person in Scotland, but I am indigenous to Scotland (Galloway Interview, 2003).

Throughout the programme, and travelling around Scotland, I interview many guests, volunteers, staff and members about their definitions of indigeneity.

These are summarised below.

Indigenous is that which is unique to a particular community, the values and story of that community, I don't know if it's totally linked to a race, for some people its multi-ethnic, for others it's totally linked to a race, it resonates about where generations have lived in that same place (IC Programme Guest Interview, 2003).

Extending the idea of values or story, other guests conceive of the notion of indigeneity as being in a sacred relationship to the land within a holistic cosmology;

Indigenous means coming out of the local people. It's a sacred connection to the land. It doesn't have any meaning unless there's some kind of history or tradition in the back of it. It implies cultural, social and religious roots tied to a particular place. 
So there is a spiritual component there?

Yes absolutely it has to be. I would put that under the heading of cultural. I definitely would put that in or otherwise it is empty (IC Programme Guest Interview, 2003).

Indigenous is also defined by American guests as being related to the land, through direct ancient territorial occupation. On that basis the Iona villagers are identified as more indigenous to the island than recent IC members, who are transitory, but themselves part of a long tradition of pilgrim visits to the Island:

How old or how long do you have to be here to be indigenous? It has been a site for pilgrims for a long time, so its very indigenous to this village to have an influx of non-locals, mixing the Christianity along with their own beliefs.

There are also people who belong here because they are attached to the land. The young man that gave us a tour of the Abbey yesterday was born and christened there and grew up running around the pews. So there are people who are indigenous in that sense. There are families who can trace back their heritages to places.

I think that part of it is the rootedness in the land. I don't know if his family are land workers? He has made a choice as his forbearers to stay here. When there are so many temptations and reasons not to stay. That is part of it (IC Programme Focus Group Interviews, 2003).

Miller locates both Celtic beliefs and the worldviews of other indigenous groups as reflecting similar themes, being the sacredness of the world, and the sacredness of the human person:

As in many ancient traditions, I think it is the same in the Aboriginal traditions of Australia that span many thousands of years (much longer than the Celtic ones), is that it is a sacred world and that we are sacred in it. That the image of God in us is a sacred image (Miller Interview, 2003).

Indigeneity is associated with a profound relationship to the history and the land, to place, language and tribal customs, as opposed to consumerist notions for composer and member John Bell. 
Indigenous means rooted in the land and the history of the place in which we presently stand. McDonald's is not indigenous to Scotland, but the name McDonalds might claim to be Scottish. Culture and language define one place from another certainly if you go to PNG you would find 360 languages which all involve and express a variety of tribes (Bell Interview, 2003).

Indigeneity is also conceived of as people being grounded in their own

knowledge, place and time, and a profound connection to community and to

nature, again contrasted with superficiality of imported globalist practices.

Indigenous has to do with a rootedness to place and to it's history. That doesn't mean that every indigenous expression is an ancient expression but that it comes out of people's sense of being grounded in this culture in this place in this time. It's a feeling for what throbs at the heart of community or at the heart of nature and calls out for expression. That's a different thing from a plastic culture which is imported and which comes kind of gift wrapped, often from across the Atlantic (Bell Interview, 2003).

Another writer and ex-warden of the Abbey, Phillip Newell is working to compare Celtic spirituality with other indigenous traditions:

I'm exploring the relationship between Nature and Native. Being Canadian one of my interests has been to observe the resonance between native North Americans and Celtic spirituality.. I was blessed by some opportunities to get some dialogues with the First Nations community of Canada (Newell Interview, 2003).

Indigeneity describes what is at the centre of the self, and of nature. This is in

direct contrast to globalist practices that seek to place the emphasis on

knowledge and traditions which are 'other' and away from one's own place and

knowledge tradition.

So what is native and what is nature? Both words are derived from the Latin word natus - which means born. What we find in so many native spiritualities is this celebration of what we are born into and are a part of; creation and culture.

It is also about celebrating what is deepest in ones own birth. The whole approach to grace in spiritual life is not away from the sacredness of nature that we are born into and are part of. Nor is it about developing away from a culture and the essence of a people or place (Newell Interview, 2003). 
Newell describes the healing journey that comes from seeking one's own knowledge tradition that places a value on what he terms 'inner' knowledge, valuing the knowledge traditions of place.

It is more of a journey that heals and takes us deeply into the treasure that we were born into... The primary image of indigenous is an emerging from within. It's a flowering of what is deeply rooted within us, not what is imposed from the outside (Newell Interview, 2003).

For other IC members, indigeneity relates directly to a history of place and the tribal peoples associated through length of living relationship to the land: "Indigenous is rooted in the life, culture and expressions of a particular people and the place that they made their homes as well. Groups certainly moved from Ireland and Scotland" (Iona Member Interview, 2003). For these members, the high crosses represent the Indigenous totems of Scotland:

There is something about the carvings of the high crosses and the illuminated manuscripts of the period that have become for many people that's our 'native art'.

That is our indigenous artistic expression (IC Member Interview, 2003).

\subsubsection{Defining Celtic}

In exploring notions of Celtic, guests emphasise profound relatedness to the goodness of the human person and the goodness of Creation, or the notion of the dignity and worth of the individual, in relation to self and other:

Celtic is somehow about the dignity of the individual, the ability to respect each person for the individual they are, and to have respect for yourself and your own journey, for your own sense of who you are (IC Programme Guest Interview, 2003).

Celtic also relates to a covenantal relationship to the environment, expressed as awareness and sacred celebration of life, affirming the notion that the environment contains within it a sacred element: 
The creating of a space between activity and the necessities of life is also of value, an awareness of the landscape. We've seen it in beautiful sunlight in early mornings and late night sunsets. It's a sense of being able to celebrate the creation around us. (IC Programme Guest Interview, 2003).

For other guests, Celtic is the local tribal particular of the rubric of indigenous, as it belongs to the cultural spiritual and historic tradition of the Western Isles of Scotland.

[Celtic] is definitely indigenous, no question about it. Put it this way my only exposure to things Celtic has been on Mull and here. They qualify absolutely because they are a spiritual tradition that also has a cultural and a social component, within the history of Iona and the Western Isles (IC Programme Guest Interview, 2003).

For others too, Celtic is understood as being especially about a sacred connection to nature, and sacred knowledge. This living knowledge is being updated and played out in the post-modern context, where authenticity involves reclaiming identity through knowledge within a holistic cosmology but in an open and pluralistic context.

Celtic is influenced by an ancient form of spirituality that is integrated in with nature, natural theology, tribal notions - Celtic shows a hunger from various Christian traditions. It is an attempt to reclaim a more holistic and spiritual place. It is almost a post-modern phenomenon - ancient Christianity dealing with the multiple truth claims of modern life. There is certainly an emphasis on environmentalism and mysticism in a dominant form (IC Programme Guest Interview, 2003).

Volunteers in the Iona Islands context define Celtic as relating directly to the twin notions of a sense of sacredness of creation, and the sacredness of people, which is located directly within Scots' history.

Celtic means something very beautiful and sacred. A sense of the sacredness of creation, and the sacredness of people. I think it is related to Scotland historically...it is the ancient spirituality of the Western Isles (IC Volunteer Interview, 2003). 
Musician, writer and theologian John Bell defines Celtic Christianity as having

some main elements, namely a holistic cosmology, which is also an inclusive

Biblical tradition, alongside living in close relationship to nature.

I see Celtic as a historical expression of Christian faith which for me at least has the singular qualities of being holistic, it deals with all of life and it sees no division between the spiritual and the material.

It's also a Biblical tradition - and the thing which I find continually mesmerising is how both the monks and the illiterate lay people who followed in their steps were amazingly well versed in the stories of scripture - so that in their writings it just permeates them.

The third thing is its inclusive spiritual tradition - inclusive of men and woman, inclusive of ordained and unordained, inclusive and embracing of the world and its creatures as well as its humanity (Bell Interview, 2003).

For Galloway Celtic contains its own internal cultural logic, which was

legitimate in and of its own accord, not the 'dimwits' of colonial imbrication:

The Celtic cosmology had in it its own logic. We all essentially have an 18th century Enlightenment cosmology. They didn't have that. They had their own logic. They weren't unthinking. They weren't stupid (Galloway Interview, 2003).

In seeking to define Celtic Miller locates this tradition in a place - being the

Highland oral tradition of Scotland, as redefined by Carmina Gadelica.

The little book "Carminica Gedelica"-songs of the Gaels was brought together by Alexander Carmichael who was a civil servant in the 19th century. It was prayer, saying and songs from country folk. It was from the oral tradition that these prayers came down to them. This is in the West of Scotland... how I understand them is that they have an understanding of the Celtic worldview running through them (Miller Interview, 2003).

Bell discussed how the Celtic worldview was kept alive and orally transmitted by illiterate tradesfolk which Carmichael surveyed in beginning to redress the inferiorisation of the highlands.

The basic tenets of Celtic Christianity were kept in play by illiterate tradespeople, the fisherwoman who in their own remote island homes and in their own dialects and cultural forms managed to retain something of the theology and the spirituality which had been first taught them a thousand years earlier by monks (Bell Interview, 2003). 
For Miller at the heart of these orally transmitted social stocks of knowledge is a sacred cosmology:

If we take this initial opening response- "Thanks be to you o' God that we have risen this day to the rising of this life itself". That immediately takes us into one of the central convictions of the insights or wisdom of Celtic people. That this is God's moment, not our moment. That we rise and fall in it (Miller Interview, 2003).

This holistic cosmology encourages actors to reconnect to a sacred and mystical connection between themselves as a community, God and land.

The central connection is between God, the Earth and the people that we're with. It seems to be a repeating theme in all the Celtic world; the naming of nature is actually the naming of ourselves and also the naming of God. Each one is not that in itself, it is much wider. The significance of the naming is beyond itself.(Miller Interview, 2003).

The notions of sacred connection to both God and the land pervade the holistic Celtic worldview. Miller discusses his writings, which emphasise both wholeness and a notion of the continuum of knowledge within this holistic cosmology.

The prayer goes on to say "O' God that has brought us to the bright light of this new day bring us to the guiding light of eternity". If we are talking about the Christian Celtic vision this idea that I have written and talked about for years, is not a disconnected religious or spiritual experience but the idea of the continual (Miller Interview, 2003).

Miller discusses the nature of prayer interwoven in all life, and also the sacred naming of, and living with the land. This closeness, rather than some romantic environmental notion, is borne out of the experience of poverty and a communal need to survive.

The Celtic Christians had prayers for their rising, for their animals, for sleeping at night. All these prayers were all held in the natural world. Every mountain, hill and valley had a name. 
The nature of life was provisional - the idea that it came out of struggle, out of poverty, out of uncertainty about life and death, all these things (Miller Interview, 2003).

However also centrally for Miller is an unselfconscious communal social order, which was both an unquestioned reality and the source, from which the Celtic cosmology derived.

All this arose, even the Christian faith, out of community. There was no other possibility, people didn't even think about community. They didn't think about how or try to create it. There was no other reality. Everything was a communal experience, not an individual one (Miller Interview, 2003).

This sense of communal awareness is not something that is self conscious, since the very notion of 'self' and the individual were not fully present in this cosmology.

This world wasn't being seen from individual, self-projecting, self-enclosed eyes of the modern world. There could be no feeling as "How does it affect me?" or "How does it affect you?" That is something that came much later in human consciousness.

This is where it is very important not to appropriate either the Celtic worldview or the views of traditional wisdoms just lock-stock and barrel into our own age (Miller Interview, 2003).

For others Celtic Christianity is undeniably indigenous, which was marginalised by mainstream processes:

Celtic is not exclusively Christian but the Celtic Church is a particular expression, which is an indigenous expression of Christianity in terms of having a form of organisation and form, which was different from that which became the norm (IC Member Interview, 2003).

For writer Newell claiming knowledge continuities with 'Celtic' knowledge is very important, and rather than emphasise the fragmentations or difficulties of seeking a recovery, Newell has intentionally sought the appreciative and integrative aspects of Celtic knowledge which are both valid and enacted today. 
More important than saying what had gone wrong in the Celtic recovery was to say what is right and giving shape to it in today in this part of the world...

So much of my writing reflects the experience of trying to understand what this tradition of spirituality offers us today (Newell Interview, 2003).

Celtic is defined as containing two central characteristics, one being the goodness of people, of the child from the moment of conception, as opposed to the Augustinian tradition which views the human condition as being one of escaping sin through grace.

What is deepest in us is the image of God and the grace and nature relationship is an important distinction to that.

Some of the Celtic teachers speak of the true naturalness of being, the true natural, the truly human. It is not dominated by the doctrine of original $\sin$ as it has developed in Western tradition.

The theme that runs through Genesis 1 is that it [creation] is good. God looked at what he made and it was good. Of course creation is not something that happened at one point in the past. Creation is something that is forever coming forth (Newell Interview, 2003).

Celtic is thus conceived as being a continuity of tradition as he describes in his book: 'a selective review of the history of Celtic spirituality is valuable in itself, providing as it does some continuity of perspective, it also demonstrates that this spirituality has been tried and tested over time' (Newell, 1997 p:7). Celtic is constructed in contrast to notions that emphasise fragmentation, and instead viewed as a living knowledge tradition that is viewed as a historical continuity whose validity today stands on the grounds of its status as valid, working knowledge. Given the particular locating of Celtic as the indigenous knowledge of Western Scottish islands, discussion turns to the contentious issue of if and how the IC is Celtic. 


\subsubsection{IC: Recovering and Enacting Celtic Knowledge}

Newell describes MacLeod's defining beliefs that make him distinguishable as 'a modern day Celt' in continuity with the Celtic tradition: 'the major characteristics of Celtic spirituality can be found in MacLeod's mysticism...[this] was his conviction of the essential goodness of creation and of the image of God in humanity' (Newell, 1997 p:86). Newell clearly conceives of Celtic as a knowledge tradition in historical continuity with the ancient sources of Celtic beliefs. This is able to be learned and enacted by modern day 'Celts' such as MacLeod, the exemplar:

My own interpretation is pretty clear in the chapter I give to MacLeod. He saw, lived and experienced a richness that was coming out of the Celtic tradition. You can look at his prayers and find a resonance and a parallel between his prayers and the Carmena Gadelica tradition and the St Patricks breastplate (Newell Interview, 2003).

Newell's experience of leading programmes in the IC shaped his own life project and became a source for his own Celtic expression, indicating the notion that non-indigenous Scots, when enacting these beliefs, are part of this living tradition:

My time in Iona was so important for me. It was filled with a lot of inspirational pain and struggle that shaped me. I have tried not to mimic or romanticise what that was, but it has some important gifts for us today. Part of what people hear through someone like me is the IC is an expression of this ancient tradition for today (Newell Interview, 2003).

I ask guests about their experience of the Islands programme. They are seen as Celtic through raising the value of everyday life to the sacred, alongside an ecological dimension. 
The language of taking the things of everyday life, and recognising the value in them.... God having a purpose for people, people trying to recognise what that is.....but also an ecological awareness.... some of that awareness was brought home on the pilgrimage (IC Programme Guest Interview, 2003).

Environmental awareness is also a strong theme for this guest, where the Community encouraged personal responsibility in dealing with the ecological crisis.

You have to start by thinking what you are doing yourself, somewhere along the line the scale of things is so massive that we can make a difference and small personal adjustments can make a difference. The sense that the responsibility for this has to begin with us and how we live our lives (IC Programme Guest Interview, 2003).

The IC is seen by others also as indigenous, conceived as enacting a cultural and spiritual knowledge tradition, which can be enacted as knowledge separately from notions of continuity of habitation. In this way, the IC articulates a 'Celtic' indigenous worldview, which draws pilgrims to the Shrine of Columba, nestled within the Abbey buildings. In this way The IC and Celtic Christianity are indelibly intertwined:

It gets its grounding from these elusive ancient notions. Part of their power is they are not overly understood or defined...

Iona is as good an example of what modern Celtic religion is. It does not try to be a re-enactment of the past, but it comfortably tries to hold the old (IC Programme Guest Interview, 2003).

They are indigenous, they are continuing with the life that began here with Columba and continues today. That's what Ian Bradley writes about.

What about the language, do they need to speak Gaelic or to have been from Iona?

No, just because they aren't all speaking Gaelic or from Iona themselves....I think its more about living a faith tradition, you can have Gaelic speakers that don't live the faith in any way like the IC do, it depends what you see Celtic as (IC Programme Guest Interview, 2003). 
American guests, on the other hand, reflect the sense of the IC's ecumenism: although being grounded in 'ancient notions' these notions are not exclusively presented. As such, Iona is seen more as a synthesis of indigenous - it has these traditions within it, but it creates the space for many more 'voices in the mix'.

Iona is not overly indigenous. This is more a synthesis. I don't think that is bad. I would not call Iona an indigenous phenomenon. It has a high respect for its history. I am glad that it is not indigenous, because it means that there are a lot more voices in the mix. There is a lot more cross-fertilisation. It does not mean that there isn't a heavy strand of that (IC Programme Guest Interview, 2003).

Other visitors to the island challenge any notion that the IC is indigenous. "From what I know of the IC they emphasise far more the justice and peace and ecumenical components, and even downplay the Celtic" (Visitor Interview 2003). Guests were also aware of the tension and paradoxes between the IC and the villagers of the island. A temporary community exists on the most sacred site on the Island. They do not stay and yet claim Columba alongside the Govan site as their inheritance whilst being seen to have ignored and even marginalised the indigenous villagers on the Island. "I sensed some tension on the island, between the Abbey and the villagers on some unspoken level" (Guest Interview, 2003). Villagers sum up the view that they see the community as bossy newcomers, and at the extreme end of views 'religious fanatics'.

Many of us think they are just a bunch of religious fanatics, and sure, they bring in the visitors, but they ignore us and turn away many of the folk that come here....

The islanders think it's just a middle class hotel or retreat centre for stressed English folk...

[The IC] and MacLeod acted terribly when they first came here.. we already had a minister on the island. MacLeod just elbowed him out (Village Resident Interview, 2003). 
Early contemporaries of MacLeod made links with the local villagers by speaking Gaelic, smoothing the feathers of those ruffled by MacLeod.

George was part of the establishment. They saw him of some kind of interloper. He was starting services in the Abbey and there was already a Church on Iona. Uist MacDonald moved among the people speaking Gaelic. That was hugely important. Uist made contact with the Iona people. That allowed things to happen that might have resulted in raw edges (IC Member Interview, 2003).

Despite Galloway's view on the question of Celtic being an undeniable influence on the vision and throughout the community in 2003 (described in Chapter 6), this is not a unanimous view. As Newell suggests, many mixed signals have emerged from the Community leadership over this question, suggesting over time, and in marked contrast to the early leaders, the recent leadership significantly downplays any Celtic connections.

There are some signals that baffle people... I had a group from North America last summer, and on the train they happened to sit with someone from the IC leadership who said that there is no such thing as Celtic spirituality and was offering a critique that those of us who were trying to recovering this tradition were doing a 'fanciful recreation' with no basis in history. So clearly people are getting mixed messages (Newell Interview, 2003).

Proponents of this view are very clear in their view that the IC was, is not, and never will be a Celtic Community.

What we are doing is not in any way, in any way, an attempt to be a Celtic community - we are not trying to do that and I would challenge anybody who says we are. We are not interested in that and that's not our purpose. Our purpose is to find new ways to touch the hearts of all (Ex-Leader Interview, 2003).

In this way within the IC claims to Celtic, and indeed indigenous are delegitimated in favour of the urban Glasgow history to Iona. Despite this position, writer Newell describes how people see Celtic themes in the work of John Bell and the Wild Goose Worship Group who, amongst others, articulate this living 
tradition, without being limited to a repressive authenticity that limits the authentic to a historic period, devaluing any contemporary relevance.

Some people feel an indigenous link through the works of John Bell. He is very happy to make that explicit link between what has been and the new creativity.

He is not trying to go back. He is clearly delving into that treasure house and using those rituals today. What are the characteristics of the body of Christ today? Some of the major markings of the body, the new outline have come through MacLeod's vision are consistent with these characteristics of the Celtic tradition (Newell Interview, 2003).

For Newell and others, the IC specifically stands in continuity with this Celtic tradition, and is very significant in being a living strand in the search for knowledge to nourish indigenous identity.

The rebuilding on Iona, this creation of the community springs or flows from this or is part of this creative stream of [Celtic] spirituality. It is part out inheritance. It is part of who we are (Newell Interview, 2003).

In this way the influence of Celtic as indigenous knowledge directly supports and constructs identity. In the IC programme as a whole, Celtic knowledge and beliefs seem to inform many aspects of the life of the IC, within the inescapably Celtic history and location of Iona. From the pilgrimage that takes guests through the most sacred sites on the Island, Columba's Bay, the Hermit's Cell, The Nunnery to the themes expressed in worship and liturgy, the IC's Island Programme is intricately interwoven with both the history and the landscape of Iona. 


\subsection{Experiencing Celtic Knowledge and Plotting Boundaries}

I ask Scottish volunteers both present and past how they had experienced Celtic. Volunteers report life-changing and healing experience of Celtic notions through the community programmes on Iona, specifically being valued as a 'sacred self', in sharp contrast to the 'worldly' relations constructed under notions of consumerism.

It has profoundly changed my life...

I came here feeling that no one valued me or anything I did. No one would give me a leg up. But when I came here I felt so loved and accepted for just being who I am... no labels, or facades. People encouraged me with the gifts that I've got. I'm doing things now that I would never have done, on the mainland. I've got so much more confidence now (IC Volunteer Interview, 2003).

Volunteers emphasise how spending time on Iona and as part of the Islands programme promotes identity recovery associated with both colonising and globalising pressures. Colonising pressures are named 'cultural cringe' or what I take to be carrying a deep sense of inferiority, constructed as an internalised negative self perception in contrast to the 'ruling powers' to the South.

Before I came here I thought of us Scots and Scotland like as a bunch of alkies [alcoholics] and druggies. A total bunch of no hopers. Just like, just like Trainspotting [laughs]. Total cultural cringe ken?... like they say [in the film] we've been colonised for too long and we're no hopers [laughs] (IC Volunteer Interviews, 2003).

Part of this negative self-perception involved a redefinition of identity and involved recovery from alcohol and drug issues, brought about through the effects of poverty and poor opportunities experienced in urban Scotland.

I really needed alcohol just to go out.. just to be social.. now I feel able to live and to do things without the need for this. 
Others I know had real issues - poverty, social stuff that comes from that... both Scottish and Irish... they've all had to face stuff here about who they truly are and what they do... at times it is really hard (IC Volunteer Interviews, 2003).

Experiencing Celtic knowledge was transforming the self-perception and releasing self-inhibited inferiorisation.

When I came here, it, it just completely changed my view of being Scottish and Scotland itself... here is a place where people come to from all over the world and are transformed, being with these really gifted Scots people, ministers and community workers and artists and poets, and its in Scotland.. That really blew me away that we have places like this in our culture.

It made me rethink and revalue what being Scottish is. I realised what a great race of people we are, not how we're portrayed at all... like the backward North.. Everything I've done since, is, is because of Iona. if they can do that, then so can I. You're never told that on the mainland.. It's just constant put downs (Iona Volunteer Interviews, 2003).

This re-legitimised Celtic Scottish knowledge is a source of continued inspiration and growth for a number of Scottish volunteers, in contrast to globalist logics.

When I left the IC I went on to study Scottish philosophy at University because of the IC.. I couldn't believe all this knowledge in Scots history and Iona and Columba, how could I not have known that before?

It transformed how I saw myself and my country. I saw how valuable our own cultural history is.

It's about finding your roots. It is so different to just buying the latest thing, the latest gadget, having the latest mobile phone or whatever society says you're meant to have (IC Volunteer Interviews, 2003).

In her own writings Galloway places the search for Celtic as being a key part of the recovery from one's own internalised self-marginalisation, reflecting her beliefs and experience of feminism and exampling indigenous leadership from the female perspective transcends issues of gender and also supports identity recovery. 
It's a rediscovery. There is something that has been in your history and you have been disconnected from it. Sometimes by yourselves, sometimes by history.

Because this element is missing there is a need to find that again. It's been the thinking behind feminism and a lot of liberation theology, the need to liberate yourself from your own internalised negative idea of yourself (Galloway Interview, 2003).

For Galloway this internalised negative image implicates English Imperialism and imbrication directly, which also denigrated the Gaelic language.

Some of the reasons why Gaelic was lost was because people were forbidden to talk it.

Was it outlawed or banned for a period?

Yes, even after it was banned, then it became the uncivilised language. If you wanted to get on you had to learn English. People would discourage their children from speaking Gaelic. It was a tragedy. It was the imperialism of England... The Scots internalised it, they took on that kind of internalised subordination. Getting rid of that is very important (Galloway Interview, 2003).

For staff and volunteers working with guests, healing derives directly from the Celtic notion that, like the Community Member Morag suggested, there is, in each person, the image of God as complete, "a place that cannot be tarnished" as it was put, at the centre of all people, exampled often most strongly through the Community's adventure camp 'Camas', on Mull, whose purpose is providing adventure based education specifically aimed at inner city youth, who carry with them many of the negative effects of urbanisation and negative imbrications.

We get people at Camas [ IC's adventure camp] that bring issues, some try and do here what they do at home, especially the Royston [Glasgow] groups...

We have often had issues with drugs and alcohol.... we do a tough love you'd call it...

We try and see God in each person and encourage them to do the same, if that means thinking beyond the drink and drugs, then that's what we do..

Try and see the potential for their life. It can be really hard (IC Volunteer Interview, 2003). 
One volunteer at Camas described powerfully the low sense of trust that these groups brought from their own experience, and how that changed over time at Camas.

We ran programmes to encourage the group to see something sacred and valuable in each other, even in a five day programme... it was hard work...

We did trust exercises with a Royston group. One guy said it was the first time he had dared himself to trust anyone. He said before that the only thing he could trust was "the hit" from drugs. I could see he was really moved. He was a gang leader too (IC Volunteer Interview, 2003).

\subsubsection{Boundaries - Drawing from the Benedictine}

Whilst trying to remain open to all, the IC attempts to establish the boundaries to alcohol and drugs before volunteers, guests and residents arrive on the Island. The bringing of alcohol or drugs, or of inappropriate sexual behaviour on the island is noted as an area of concern for the community. Framing these boundaries in ancient Benedictine terms, the resident information pack (p.12) states that:

We expect a chastity from people in our life. The chastity of understanding that our indulgence in sex, or alcohol, or drugs will be seen and noted; by people who live on the island, and to whom we represent the [IC]; by young, impressionable people who come, sometimes from a background of sexual and drug abuse; and by one another, who may not be helped by such things. It is the chastity of sensitivity, perhaps of denying ourselves freedom we might legitimately expect elsewhere, for the sake of others. The discipline of chastity in one's private life is not easy (Iona Volunteer Information Pack, Personal Notes, July $15^{\text {th }} 2003$, p.12).

These rules and boundaries draw intentionally from prior Benedictine spiritual traditions of the $12^{\text {th }}$ Century. These boundaries are not the only intentional attempts to enable healing. Liturgy draws directly from the ancient Celtic and Benedictine imaginary to create space for healing. In his book the ex-leader 
Shanks summarises this experience as being transformational, and directly related to issues of identity construction within a sacred cosmology.

The Iona experience is one of transformation.. it is an experience involving grace and generosity, hospitality and, vulnerability. In the course of which minds are challenged and hearts are touched (Shanks, 1999 p:84-87).

Shanks (1999) describes how individuals become re-orientated toward and generate agency within life-projects supporting notions of community all placed within a holistic cosmology emphasising relationships within and between sacred people and the sacred earth.

It is an experience involving basic issues of identity... Belonging, values and priorities that recognises the spiritual reality that individual fulfilment is to be discovered only in community... that self development cannot be achieved apart from a concern for one another and the world around us [and] that all this is embraced and caught up in our relationship with God (Shanks, 1999 p.84,87).

Enabling others to experience this cosmology is a direct and intentional enacting of the missionary legacy of Columba and Celtic Christianity, framed for the current context.

Our hope is that.. in however small a way in the IC experience their lives may be touched and transfigured by the Risen Christ. They may glimpse afresh the plans and purposes of God...In so doing we see ourselves sharing in the legacy of Columba in the pilgrimage towards tomorrow that is the missionary priority for today (Shanks, 1999 p. 84,87).

\subsubsection{Celtic Knowledge: Building Community}

Within members' work programmes, Celtic knowledge contained within the Rule is enacted for situated social action, what I term indigenous agency. IC members enact their own individual interpretation or area of interest within the 
IC's five fold Rule ${ }^{10}$ which provides a framework for accountability for members.

Our five-fold Rule calls us to:

1. Daily prayer and bible-reading

2. Sharing and accounting for the use of our money

3. Planning and accounting for the use of our time

4. Action for justice and peace in society

5. Meeting with and accounting to each other.

Corporately and individually members pursue the concerns of the Community.

Despite much diversity there is a strong emphasis on community building within

a holistic cosmology.

The whole thing is all about rebuilding a common life, about affirming mutual interdependence, about helping people, about affirming the worth of every individual. It is about people sharing their gifts and developing their capacity.

How do members do that?

It is about exploring the life of community, and discovering new skills and living together in a different sort of way. Within the community we try to share jobs around. There are structures and processes involve sharing responsibility. Underlying it all is a commitment to social inclusion means that we are committed to empowerment and principles of community development (Ex-Leader Interview, 2003).

Members work for change within the social and political dimensions of Scottish

life. However in an effort to remain inclusive Shanks remains cautious of too

close a link to any cohesive notion of nation, instead reflecting the fragmented

spiritual and social fabric that the church seeks to engage with.

What is the role of the IC in the Scottish national project?

What does that mean? The IC has a role in the evolving life of the church. To an extent the church has a role in the national project. That begs questions of

${ }^{10}$ A full copy of the Rule is available online at http://www.iona.org.uk 
denominational tradition and the place of the Church of Scotland, in relation to national life here.

What nation are we talking about? Is the national project about the new British Empire? Is it to find a way of integrating Britain more closely into the life of Europe and the European Union? Is it to built on the moves to give Scotland a greater say in its own life. Or is the national project not political? Is it to rebuilt a life and nation in a deeper spiritual/ social way. I don't know. We are involved in that way too. That is what the church is all about and we are part of the church. (Shanks Interview, 2003).

Despite this caution, Shanks concedes that there remains a strong majority working towards community building through political engagement on Scottish life more broadly.

Over $60 \%$ of us live in Scotland. I think that we are all interested and committed to politics. This means that we are interested in that. To an extent the IC's agenda has involved relating to that. We still have various working groups with political agendas. These are clearly linked to the national political project (Shanks Interview, 2003).

For other members, the IC membership has an unambiguous relationship to

Scotland and issues of autonomy - a theme consistent with other indigenous

groups (Muehlebach, 2001), in this context expressed as supporting the

Devolutionary argument.

Lots of people in the community are very involved in politics. It's been stronger in the past. We are committed to local community building, community encouraging... members work very hard in that area.

The community has always supported the devolutionary project. People voting for parties or encouraging it wherever we can.. It is active engagement for Devolution (IC Member Interview, 2003).

However Shanks seeks to downplay any consensus.

I'm not sure to what extent that we are deliberately doing that as a corporate thing. I think that we may be doing that through our membership of political parties - some of us have been or are involved in local government, government council and members of social, political committees. Some of it has been church involved, others haven't (Shanks Interview, 2003). 
Members stress the importance of individual interpretation of the IC Rule, and the strong consensus on working towards devolution and Scottish community development.

\section{Is there a role for the IC in nation building now?}

Well I think there is. I don't quite know how up front that is. We have members who are heavily involved in Scottish constitutional convention. The community has always been pro-Devolution

Has that always been quite strong? Why is that?

Well the Church of Scotland has a long history of supporting devolution. I don't know the reasons. I think that the community's argument would be that the community held the belief that Westminster was too remote, but in general the closer government is to the people the better (IC Member Interview, 2003).

Concerns were expressed for the limitations that too strong a national allegiance might bring.

Is there a vision of IC in Scottish life?

There's a tightrope to be walked here. One of the gifts of Iona has always been that its an ecumenical place where you are liable to meet people from anywhere across the globe. I think that becomes particularly important in terms of the community's concerns about justice, the kingdom. (IC Member Interview, 2003).

Scotland is framed here in ecumenical and inclusive terms: with themes that the

IC mirrors, and therefore represents.

One of the concerns that some of us would have is that people who tend to come to the Abbey come from South of the Watford Gap [English].

I think the community must never be exclusively Scottish, because I don't think Scotland's story is a story of exclusion, it is a story of inclusion. We've always had different people coming here (IC Member Interview, 2003).

Being a Church organisation too closely identified with a nation state is a very dangerous notion, calling to mind other Church sponsored national projects.

You hear fairly disastrous stories of national churches such as in the First World War. The German Christians believing they had God on their side. It just becomes 
very dangerous. My generation grew up with a very healthy fear of churches and nationalism.

having said that is there a place for this kind of conversation, that Iona can give something?

I've been involved a wee bit in the sectarian debate as part of the Church's nation committee and one of the very interesting questions is how do you give people permission to cherish and develop their own historical and cultural traditions in a way that isn't exclusive or divisive (IC Member Interview, 2003).

Despite this tightrope focussed on the need to remain open and ecumenical, and the debate about cherishing and developing historical and cultural traditions, concerns were strongly expressed about the Community itself losing (and by extension therefore having) a Scottish identity, expressed as being it's 'Scottish roots'.

There's a debate going on in the community at the moment about how the community continues to reflect its Scottish roots.

With the growth of the number of members in England? Is there fear there that something might be being lost?

Could be,yes... (IC Member Interview, 2003).

Some members were reserved and cautious about exploring what was being threatened in this discussion. Others less so. Another member recalled his vocal opposition to the IC Council (of which he was a member) relocating to England to appease the growing English membership.

For a while I was a member of the council of the IC. I was at a meeting and the next meeting of the council was being arranged to take place in Manchester. At that point I rather drew the line and said 'This is a piece of nonsense.' (IC Member Interview, 2003).

This member based his challenge to the English call firmly on the grounds that for him, the IC has its history and identity firmly on Iona and Glasgow and by extension in Scotland. 
The working community of Iona and its staff are in Glasgow. The emotional, physical and spiritual roots of the community are in a small Island off the West Coast of Scotland. I really don't care how many members of the IC live in England this is a Scottish based community (IC Member Interview, 2003)

The member articulates a defence of the indigeneity of the IC in the face of, for him, the possibility of losing touch with the roots of the community.

What is it that you were protecting?

I think a feeling that if the membership of the IC, which is broad, if it becomes less Scottish I think that it loses touch with its roots...

That is not to say that is can't be open, but I think it has to be open to people that are prepared to understand that and live with that. There have been many members of the IC from England who have not found that difficult that all (IC Member Interview, 2003).

This member rejects the possibility of the community becoming a British or a world community through this increasingly diverse membership. Such a position threatens the very core identity - and distinctiveness - of the community, which ultimately comes from its historical roots to Iona and the Columban Church. These roots, for this member, are centrally a discussion and defence of indigeneity.

We are hearing the voice of people who have no roots in Scotland or in Scotland's Church. They do not understand the roots of the IC. We are talking about indigenousness in a sense now, in a way that is important to me.

I don't want the IC to become a world organisation or a British organisation. It seems to me that it will lose its distinctive voice if it does that (IC Member Interview, 2003).

Iona, the island and its history are firmly located as the source of the IC's identity, formed intentionally by MacLeod as the source from where the IC's identity is confirmed and renewed, and from which the ecumenical spirit to go out emerges from. 
Iona is the place where we gather and from which we take our identity, but it is not the place that we work. We go out from there and going there, it is a place of affirmation and reformation....

How important is that history to that identity?

I think that is fundamental in the sense of identity. MacLeod didn't go anywhere. He went to Iona because what Iona was and what it stood for (IC Member Interview, 2003).

The roots of Iona encompass more than the Celtic, which is located as a subset of the Scottish identity and the IC's history, alongside the Benedictine, from which the Community also draws on for its formation of rules and boundaries.

So there was an intention to connect back into that Celtic?

Yes, with the origins of the Church of Scotland which happened to be Celtic. After all the Abbey that we now occupy and identify with is a reconstruction of the Benedictine foundation, not the Celtic one (IC Member Interview, 2003).

The Island is sacred in the spiritual history of Scotland, and the source of renewal for a distinctive Scottish identity, as opposed to an identity subsumed within the British Union.

Having spent time as a member of the resident group and worked on Iona reinforced my sense of Scottishness as distinct from my sense of Britishness. I think that it does do that (IC Member Interview, 2003).

The relationship between Iona and the emerging Scottish nation is experienced with pride, but also with a self-consciously non-romantic manner, suggesting the current imbrication that exists with constructing Celtic.

What was it about Iona that did that?

It was being somewhere with a deep historical significance in the life and formation of the nation of Scotland, as distinct from the United Kingdom, the nation state that we now belong.

I was being back in touch with that in a non-romantic and non-sentimental way. A great deal of Scottishness is like that today. That is how it works for a lot of people. I find this difficult to speak about. 
I find that my feelings about it are not very PC and the Iona Committee has become very PC (IC Member Interview, 2003).

The holding together of the national and the global is a balancing act that requires constant attention, but brings benefits.

The IC can play a helpful role where the people meet the community either on Iona or elsewhere in the life of Scotland or in the life of the World Church, I think it's the holding together of Scotland and the world church that prevents either one being exclusive (IC Member Interview, 2003).

Enacting Celtic knowledge is not without challenges. Celtic knowledge has gone through a number of incongruities that have riven Scots and Gaelic history and made recovering and defining Celtic knowledge problematic.

\subsubsection{Historical and Neocolonial Impositions on Celtic Knowledge}

The disjunctures of history that have riven the Celtic worldview challenge concepts of knowledge continuity and are illustrative of forces at work in fragmenting Celtic knowledge. These range from the Viking invasions to globalising mass media. For Bell, this rupture is not small: "we are dealing with a rupture of a 1000 years - this rupture is manifold" (Bell Interview, 2003). Globalist practices transformed and fragmented the collective Scottish imaginary, from their communitarian origins into hierarchies and structures imposed from without.

The forms of Christian expression which had been nurtured in us by Celtic monks on a communitarian basis from the 5 th to the 10 th Century was no longer requisite.

We had to move from this interactive model to a much more structured and hierarchical model when the Rome centred Church came in with it's Diocesan structure (Bell Interview, 2003). 
Not only were the mental models ruptured, the physical artefacts of this culture were removed as trophies for the invaders:

We had a rupture of tangible artefacts of the Celtic expression being continually taken away by the Vikings. We still have the Celtic Crosses, but there's a whole lot of other things that are just no longer there because they are in a museum in Trondheim (Bell Interview, 2003).

On top of this comes the Reformation, resulting in Celtic - now Catholic ministers going into hiding to avoid persecution.

We had the rupture of the Reformation onto a Celtic tradition which has been subsumed into the Roman Church now undergoing a second discontinuity. The Roman Church which had been strong going into hiding in the Western Highlands. No priest was able to articulate what the doctrine was. People were living in fear of their bigger protestant neighbours (Bell Interview, 2003).

The loss of language was part of the emerging Protestant Reformation, which together with universal education, emphasised and imbricated 'the modern' as opposed to the 'backwards North', which was assimilated within the Empire language of English.

We have the rupture of Gaelic which was the medium for Celtic mission, along with Latin for the liturgy and Gaelic which the Catholic Church had espoused. Gaelic is taken over by Protestants but as the $19^{\text {th }}$ Century encroaches and as universal education becomes mandatory it is to be in English. Therefore the very linguistic devices which enable to story of your people to be transmitted are under threat (Bell Interview, 2003).

Finally the imposition of Western consumer culture fragments and dominates local culture: "in the 20th Century we have the smallest islands feeling dominated by the media cultures of urbanised Britain” (Bell Interview, 2003). These disjunctures have caused a profound dislocation for the intergenerational transmission of Celtic knowledge for the Scottish imaginary, where the sacred knowledge holders were fragmented and the interests of the clan diverted from their communal base. 
Because of the Reformation we do not have arbiters of cultural theological and spiritual truth. We do not have the gurus who say these are the things that we must pass on.... because the gurus who were the monks and priests have been taken from the local clan chieftains who don't necessary have that as a primary interest.

It is a much more fragmented process whereby people just remember poems and stories and truths that their grandparents told them and transmit that from one generation to another, so who are the people who hold the yardstick of what is the wisdom of the ancients that has to be delivered to our descendants? Scotland has never had that (Bell Interview, 2003).

Bell describes how even within Scotland's own spiritual tradition outside knowledge and practices have been incorporated. This creates identity confusion about being authentically Scottish actually is.

The Celtic preaching tradition was not there before the Reformation and the Celts and the Gaels will talk about their great Psalm singing tradition. They will start up this thing that is very moving but this came from England. It was imported for illiterate people around about the $17^{\text {th }}$ Century. It is not an indigenous art-form. It quite clearly comes from Post Reformation England when they got a Psalter and a meter and found that it was no use because nobody could sing so they had to devise a way (Bell Interview, 2003).

Acknowledging the fragmentations is important, making an exclusive 'theme park Celtic' almost impossible to achieve if even desirable, against notions of repressive authenticity instead favouring 'expressions and offshoots' of the

Celtic heritage, as opposed to defining any 'essentially Celtic' elements.

I don't think we need to go back to the theme-park stuff which is what would go in the theme-park which is essentially Celtic not with the ruptures and the fragmentations and so on, no. I think the more we can put in that area which is being expressions of, offshoots of the Celtic heritage the better (Bell Interview, 2003).

\subsubsection{Celtic Knowledge at Individual Level}

This chapter explores how indigenous is defined in the Iona context. Indigeneity indicates notions of the goodness (the divine source) of the people alongside the goodness (divine source) of the Earth. All these are constructed within a Celtic 
Christian holistic cosmology, which is claimed by the proponents of Celtic, to be in knowledge continuity with both Columba and MacLeod. Scottish volunteers experience this Celtic knowledge - interwoven with the Biblical tradition - as creating a positive identity. This is in contrast to the imperial imbrications that created the cultural cringe of the Scottish putdown or posited consumerist logics which Friedman (1994b) proposes in the literature as the ultimate aim of the globalist project. Using rules and boundaries which drew from the Benedictine spiritual tradition of the Abbey enhances the Celtic notion of the worth of the person, and both polices and encourages the abstinence from colonising health influences, again alcohol and drugs as found in the Aboriginal contexts (Banerjee, 1999; Cunningham and Stanley, 2003). The Community encourages life projects which define more stable identity in relation to community connectedness and development, in the context of a Celtic holistic cosmology, which supports the proposition Friedman posits for traditional identities generally in the literature (1994b).

\subsection{Discussion: Indigeneity Defined and Enacted in a Celtic Context}

This chapter describes the definitions of indigenous that Scottish members and guests self attributed. These refer to the knowledge, customs language and 'ways of being' which derive from place. This profound connection to place is exemplified in Celtic notions of the sacredness of the earth, and the sacredness of people. While Gaelic language remains outside the arena of the IC, these Celtic themes pervade the community at all levels. Enactment of indigenous 
knowledge is continually reinforced through Celtic themes that pervade the services, symbolically maintaining a canopy of universe meaning: the 'Celtic Christian' indigenous knowledge tradition, despite pressures on the leadership which results in a de-emphasis on the influence and effect of 'Celtic' themes in favour of the Christian. This is in contrast to Chapter 5 which shows how 'Celtic' peoples have been imbricated as Barbarians, by the 'civilising' Greek and later 'developing' Imperial powers whose identities were, in part, created by such a contrast. Later globalist pressures also fragmented the Gaelic language and Celtic worldview, devaluing the mythic status of indigenous knowledge. Despite this, the worldview and language survived through the Western Highlands of Scotland in particular (MacArthur, 1996; MacInnes, 1994). Chapter 6 showed how the formation of the IC by MacLeod used the 'Celtic imaginary' as a collective notion underpinning the Scottish nation, which Anderson (1983) proposes as a common instrument in the literature, to legitimise the fledgling project within an ancient Celtic knowledge tradition, which the first and later preachers intentionally drew from for sermons in the Abbey, and founding purposes.

\subsection{Summary}

In chapter summary, in the Celtic context notions of indigenous are defined as being the story and the values of a particular community, linked to a greater or lesser extant to race, but more significantly to place. These stories and values are also expressed as a social, cultural, and religious tradition, which is located in, 
emerges from, and is in direct profound relationship with, a place. Polvyvocal definitions of indigeneity relate to that which is 'at the living heart of a people, and the heart of nature'; the inner and local awareness and Celtic knowledge transmitted inter-generationally in the Western Isles of Scotland.

Celtic is seen as conveying the twin notions of valuing and respecting the goodness and uniqueness of the individual, as well as valuing and respecting the goodness and uniqueness of the environment, and enacting profound relationships of respect, a covenantal cosmology, to each.

These elements were seen as being collectively an ancient form of sacred knowledge, a spirituality which is completely integrated with nature, but are ecumenical and open to others. IC Members defined Celtic as knowledge which survived and was transmitted through the oral tradition as was collected by Carmichael (MacInnes, 1994) despite the major disjunctures which have affected the intergenerational transmission of this knowledge system.

The IC is seen as an indigenous Celtic organisation on the grounds of the articulation and enactment of Celtic principles through worship and themes which emerge over various parts of the Islands programme. However it is also viewed as more of a synthesis since it allows more voices in the mix. In this sense it is aware of its past. It tries to hold the old but also to be adaptive and open to other traditions. Despite this, deep questions were asked about the extent 
of Celtic elements which were downplayed, and also the relationships the community had fostered over time with people in its' own Islands home.

Members and ex-leaders of the IC challenged notions of both Celtic and indigenous, claiming a great deal of scepticism about each. This position suggests that the IC might have very little relevance to anything historically Celtic, and that with a growing English membership of the IC, any historic influence is lessening. Some IC members and ex-leaders rejected the Celtic claim, stating that all the roots to the IC come from Glasgow and not Iona, questioning what influence Iona and a historical spirituality should have over the IC.

Supporters of the indigenous Celtic worldview claimed authentic knowledge continuities between Columba, MacLeod and the current IC. Enacted Celtic knowledge enabled positive self, community and national identity formulation and development. For Scottish volunteers, their own sense of identity was reordered from one of identity fragmentation and cultural cringe which was associated with negative behaviours, English domination, negative imbrication and consumerist consumption, to one of increasing pride in Scottish, and Celtic knowledge and history. Boundaries drawing from past spiritual traditions on Iona as well as the Celtic notion of the goodness of all people assist the guests and volunteers to enact potential, by overcoming negative behaviours and internalised inferiorisation. 
Celtic knowledge also directs action in projects, exampled as the work programmes of the IC Members, most of whom take an active and political part in building community in the broader Scottish national project. A strong position of support was expressed for devolution, despite increasing English membership. However members felt that the IC identifying too strongly with the national project could become exclusive or dangerous in the extreme, and the community needed to become more open to increasingly diverse and English membership, to the point of relocating the council to England to be accommodating. These positions were bitterly critiqued by other members seeking a deeper indigenous legitimacy and living presence of Celtic, which they felt were being denied by this anti-Celtic voice which was too PC. Celtic supporters insisted that the history, roots and source of identity for the IC remain with both Glasgow and Iona, and that the IC should remain a Scottish based Community. Being 'too PC' meant potential for a serious watering down of the distinctive indigenous Celtic roots that refresh and sustain both the community's identity and spirit of ecumenism. 


\section{Chapter 9: Organising with Indigenous Knowledge}

\subsection{Introduction}

This chapter examines actors' indigenous organising processes in situ, but viewed in social and global contexts. The chapter illustrates how leaders' strategies and practices encourage members to create and enact an indigenous organisation which overcomes knowledge challenges. These organising practices encourage the departments and family groups to define, enact and update Māori and Celtic knowledge respectively through the organisation, as well as supporting the construction of a Māori and Celtic holistic cosmology at the social level. The data on indigenous organisational identity as seen in global contexts is discussed and compared with extant literature.

\subsection{Māori Organising: Constructing a Tikanga Māori Organisation}

Within TWoR much debate has surrounded the issue of how TWoR is a tikanga Māori organisation referring to the means by which members take the organisation to be an authentically Māori organisation. At the organising level addressing this issue has taken significant amounts of time and energy for TWoR: "The effort to develop and strengthen the tikanga Māori basis of our institution over the years has been considerable" (Te Wānanga o Raukawa, Charter, 2003 p.1). For staff interviewed, this is also a key issue.

Since the mid-1990s that's been a constant issue for Te Wananga Raukawa. Something that's really important for TWoR is for it to maintain it's distinctiveness and to be autonomous. (Huia Winiata Interview, 2003). 
From the outset TWoR has set about establishing itself as a reformulated Māori institution, claiming authentic Māori lineage.

Te Wänanga-o-Raukawa was established in April 1981 as a Centre of Higher Learning for the Confederation of Te Äti Awa, Ngäti Raukawa and Ngäti Toarangatira, as part of the tribal development programme of the Raukawa Trustees, called Whakatupuranga Rua Mano. Te Wänanga-o-Raukawa has always described itself as a reformulation of the ancient whare wänanga (Te Wānanga o Raukawa Charter, 2003 p.1, umlauts in original).

Through this lineage TWoR classifies itself as a Māori institution, using notions of 'tikanga Māori' [principles or practices that are Māori]. I plot this use of tikanga Māori as an organisational rule which is used in situ to identify as authentic its distinctive Māori status: 'As such it has also described itself as a tikanga Mäori institution, another unique and fundamental characteristic' (Te Wānanga o Raukawa, Charter, 2003 p.1).

I was invited to attend a one-day hui on setting the strategic direction that took place in April 2003, in effect the event that created and shaped the 2003 Charter $^{11}$. This hui gave me privileged insight into the construction of Māori organising in-situ. While data transcription from the full 8-hour event was impossible, I gathered copious fieldnotes before and during the day.

This day does not act in isolation from the ongoing activities of TWoR, but I use it to exemplify how Māori organising constructs a Māori organisation, revealing

\footnotetext{
${ }^{11}$ An updated version of this document is available online at http://www.twor.ac.nz
} 
multiple legitimating strategies and uses of indigenous knowledge. I also describe the role that Winiata took, encouraging autonomy and Māori knowledge application. The purpose of the hui was understood by one of the key participants, as

The wananga is going to have its own hui to look at its tikanga Māori nature and all the departments were asked to write up what they think are their tikanga Māori practices (Pakeke Winiata Interview, 2003).

The organisational rule of 'tikanga Māori' is encouraged by the Tumuaki where departments can reflect and account for the authentic actions which draw from Māori knowledge. Whilst reflecting on these actions and knowledge behind TWoR is not new, there has been an increasing sense of urgency in articulating the policy.

Te Wānanga-o-Raukawa for most of its existence has operated without a substantial policy base. Tikanga Māori has been the base. In the last 12 months however there has been a desire amongst management to develop a policy base for the Wānanga to guide its decision-making (Te Wānanga o Raukawa Charter, 2003 p:21).

\subsubsection{Overcoming Knowledge Challenges}

While accounting for Māori knowledge is use may appear straightforward, in actuality I am told how difficult this might be, since Māori knowledge is often seen as legitimate, or valid 'only on the Marae', having no practical value or working use in 'everyday life' indicating notions of repressive authenticity, held by both Pākeha and Māori.

For a long time mātauranga Māori has been ringfenced inside the Marae, and once you start talking about mātauranga Māori being in an institution like this, or VUW, people start saying 'isn't that stuff just for the Marae' how come your talking about it here (Pakeke Winiata Interview, 2003). 
I am told that: "some Māori have perpetuated the idea that Māori knowledge serves no purpose and has no relevance outside the marae environs" (Pakeke Winiata Interview, 2003). In an interview with one member, their central challenge relates to this idea: "what use will Mātauranga Māori be to students once they leave the wananga? They need to be taught how to make it in the real world, not just on the Marae" (Staff Interview, 2003). Here the cognitive validity of Māori knowledge is devalued in use 'beyond the Marae,' where Western knowledge is claimed as the only valid knowledge in use. The insidious nature of what TWoR calls 'tikanga Pākeha' practices are also seen as a constant threat, claiming universal best practice status, which devalues indigenous knowledge in use by claiming a different philosophy: '[Formulating policy] is a bold step, as the potential to move away from tikanga Mäori and take on board other philosophies and ideas is great' (Te Wānanga o Raukawa Charter, 2003 p:3 umlauts in original).

Globalist knowledge is seen by some as more valid in use within the organisation. "TWoR needs to take on board the best practices from other institutions; otherwise it will be left behind. If it's going to be a quality institution, it needs the best of what other universities are doing" (Staff Interview, 2003). I am told of debates over the validity of Māori knowledge to operate at the organisational level, as opposed to 'universally applicable best practice', imported from Western legitimated institutions. 
I had quite a lengthy debate with one of my colleagues here, talking to me about management and about HRM management models we should be investigating , those by Harvard or Oxford. There was some doubt expressed about whether or not Mātauranga Māori would have anything to say about HRM (Pakeke Winiata Interview, 2003).

Members maintain a faith in Māori knowledge to 'work', based on its use in past and current contexts.

A place like this should be trying to exhaust what Mātauranga Māori would say about management. I would have thought taking an entire population of people and moving on small canoes from island to island to island and eventually establishing themselves in this new land, and developing into a robust population in Aotearoa would have required some quite considerable HRM skills. It is those kinds of things we need to be addressing (Pakeke Winiata Interview, 2003).

To counter these knowledge challenges, Winiata encourages autonomy for each department to define what Māori knowledge underpins organising in each context. Within the hui itself in TWoR, a model is proposed and presented, (developed by Royal) to describe organisational action which derives from knowledge which is accountably Māori.

This paper argues that Mātauranga Māori can continue to inform and guide Te Wānanga-o- Raukawa in its policy development and decision-making. The paper does not only relate to personnel policies and practices, but rather the whole modus operandi of the institution (Guiding Principles/ Kaupapa of Te Wānanga-o-Raukawa, Personal Communication March $15^{\text {th }} 2003^{12}$, p.1).

The model proposed is represented below from the charter, and was presented in the hui to the Academic Board by Pakeke Winiata.

${ }^{12}$ An updated version of this document is available at: http://www.twor.ac.nz/docs/pdfs/Guiding\%20Principles.pdf 


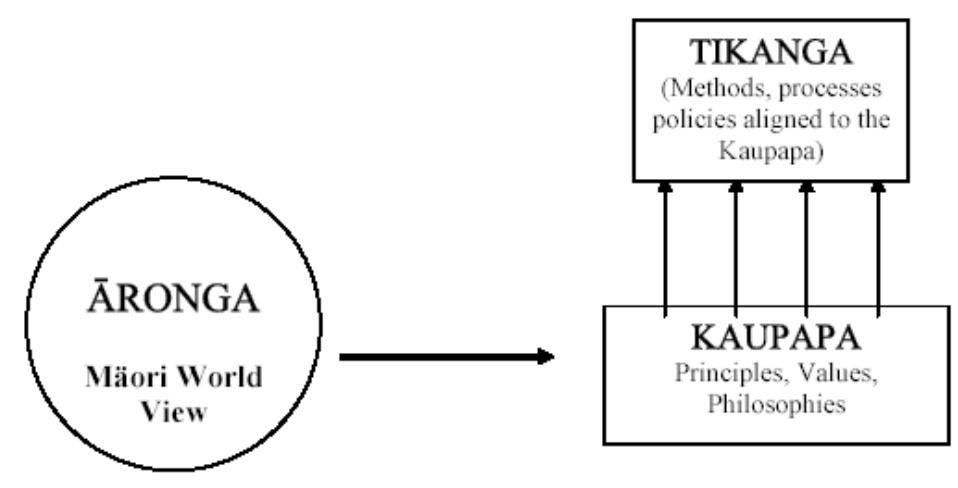

(Te Wānanga o Raukawa, 2003 p:24)

For the tikanga to be identifiable, Māori knowledge is reiterated as being formed through the conscious application of Māori knowledge to each context, in and through the very reflective act of organisational members:

Mātauranga should be the foundation for our contemplations, developments and future directions. Mätauranga Mäori is a knowledge tradition within which is contained explanations, perspectives and views on the nature of the world, views and explanations that have arisen, and continue to arise, according to the experience of those endowed with it. (Te Wānanga o Raukawa Charter, 2003, p:3 umlauts in original).

The Māori cosmology (as Chapter 7 demonstrates) operates within an understanding that places a primacy on the continuity of Māori knowledge, and 'eshews colonialism'. In accounting for this model the academic board described how a Māori knowledge continuum creates the very culture for Māori as a whole from which actions, or 'Tikanga' emerge, principles which apply to the broader Māori population as a whole.

The basic idea is that through Püräkau, Karakia, Möteatea, Whakatauki and Whakapapa our World View is described and a set of Kaupapa are drawn from which the culture is founded. These are the bedrock, the foundation of the culture. Growing from within the Kaupapa are our tikanga, just like a tree springs from Papa-tüä-nuku. The tikanga are actions, methods, processes, policies etc that are aligned and 
consistent with the foundation Kaupapa. All tikanga purporting to be Mäori should find their bases in Kaupapa. (Te Wānanga o Raukawa, Charter, 2003, p:24, umlauts in original).

Māori knowledge is therefore used as the primary legitimator for the very existence of TWoR, and Tikanga Māori are the means through which notions of knowledge continuity are recognised, made accountable and validated.

\subsubsection{Autonomy in Decision Making: The Academic Board}

Against the context of battling for knowledge legitimacy the board maintain the investment in the cognitive status of Māori knowledge, trusting that this knowledge tradition itself has cognitive and practical worth in use whilst delegitimising Pākeha knowledge and practices lessening the cognitive worth of these 'insidious' practices.

We need faith in ourselves and our mātauranga. We should not revert to tikanga Pākehā practices and philosophies because we are unsure of what to do at times. Nor should we necessarily hold as near and dear those things that a university or polytechnic management group would. What they may consider as important may not be where our priorities are (Guiding Principles/ Kaupapa of Te Wānanga-o-Raukawa, Personal Communication March $15^{\text {th }} 2003$, p:2).

The board locate the organisation as authentically Māori by being a tikanga

Māori organisation.

In the case of Te Wänanga-o-Raukawa, the model could be considered as the conceptual framework for the development of a tikanga Māori institution. We ought to be able to demonstrate how the tikanga of Te Wänanga-o-Raukawa are consistent with Kaupapa Māori, which themselves are consistent with the Māori World View (Guiding Principles/ Kaupapa of Te Wānanga-o-Raukawa, Personal Communication March $15^{\text {th }}$ 2003, p:5 umlauts in original)

Authenticity is based primarily in relation to indigenous knowledge, on the intersubjective Māori knowledge reflection and construction, without either power 
relations or subjectivities as the central element. Nor is indigenous consciousness in this context fragmented. The strategic use of indigenous knowledge enables action across the organisation. For example, the 2003 charter describes how the claim to tikanga Māori is based on observable actions derived from Māori knowledge in the day to day activities of the wānanga. Here the charter becomes a sensemaking device to itself reflexively guide or make accountable actions within the organisation.

Such lofty descriptions however are of little value if, on a day to day basis, the Wänanga is operating like any other tertiary institution. The tikanga Māori nature of this place is an essential part of the justification for the existence of Te Wananga-oRaukawa. (Guiding Principles/ Kaupapa of Te Wānanga-o-Raukawa, Personal Communication March $15^{\text {th }} 2003$, p:1 umlauts in original).

To this end the charter notes the strenuous efforts that have occurred at articulating and reflecting the basis by which organisational actions are predicated on indigenous knowledge, legitimated within the organisation by the principles of autonomy which were established within the Generation 2000 project led by Winiata. 'We have regularly called on the Purutanga Mauri (itself a tikanga Māori concept) for guidance. The four principles of Whakatupuranga Rua Mano have been regularly invoked' (Te Wānanga o Raukawa, Charter 2003 $\mathrm{p}: 21)$.

Members of the wānanga were given freedom to articulate what their own practices are that are consistent with tikanga Māori, illustrating at the organisational level the autonomy that the leadership has strived to vest in the departmental groups. 'I wrote that paper and each of the departments were then 
asked to come up with what they think are their practices that are aligned with and consistent with tikanga Māori’ (Pakeke Winiata Interview, 2003).

Most members found this 'directed' freedom helped strengthen and nourish Māori knowledge, rather than be an imposition of power which limits the functioning of the organisation: "Mātauranga Māori, Māori knowledge has been facilitated greatly by having freedom to develop courses that nurture Mātauranga Māori" (Huia Winiata Interview, 2003). This autonomy is a critical part of the organisational accountability, where 'tikanga Māori' practices are made accountable by being indexed from the local historic tribal Māori knowledge tradition, which, at the same time, reflexively constructs, and maintains, the knowledge tradition from this very context.

Something that contributes to our distinctiveness has been clear is as a tikanga Māori institution. For the three founding iwi it's the tikānga of those three iwi that are maintained. Our belief is if we maintain a tikanga Māori institution and that its consistent with the tikannga of the ART confederation: Awa, Raukawa, Toa Rangatira, our distinctiveness will be apparent.. Autonomy is about giving the power to make sure that happens (Huia Winiata Interview, 2003).

So autonomy in the context of the academic board contributes directly to the contextual survival and embellishment of Māori knowledge which helps reflexively construct and indexically maintain Māori as a people.

Whata talked about the wananga's role in survival of Māori as a people, I always put a little twist on that phrase because this department has a responsibility to contribute to survival of Māori as a people through contributing to the survival of people as Māori, and that's where what we teach here is about cultural practices, Tikanga.

But we never stop there, the idea of mātauranga Māori being a knowledge continuum, its up to us in this generation to find its application and to be really lateral and expansive in our thinking about its application (Pakeke Winiata Interview, 2003). 
This example illustrates the power of indigenous knowledge continuities in overcoming globalising colonial pressures which attempt to devalue Māori as a people and instead directly contribute, through the use and embellishment of Māori knowledge to the maintenance and development of Māori identity as a whole. For the organisational members of TWoR, claiming knowledge continuities enhances Māori identity within a Māori cosmology whilst overcoming knowledge fragmentations from historical colonising influences. Imbrication and repressive authenticity is overcome through organisational identity formation within indigenous knowledge. Continuity is ensured through Mātauranga Māori being 'valid' knowledge in use through the ongoing and open horizon to ultimately add to and maintain the survival of Māori as a people, processes of symbolic universe maintenance. The processes of organisational autonomy allow both the use and survival of Māori knowledge and Māori people in the current context. However maintaining the knowledge validity of Mātauranga Māori may mean overcoming internal self-imbrication as a product of colonialism.

Some of us may need to get past our training and / or thinking that leads us to doubt our own knowledge base as being informative. For some, moving out of our comfort zone will be difficult, especially where that zone is founded on Päkeha methodology and principles (Guiding Principles/ Kaupapa of Te Wānanga-o-Raukawa, Personal Communication March $15^{\text {th }} 2003$, p:1 umlauts in original).

\subsubsection{Māori Knowledge: Continuity and Adaptiveness}

The members at TWoR are committed to the expansive teaching and embellishment of Māori knowledge, a task that has occurred since the arrival of 
the Māori people in Aotearoa, in creating new knowledge to be valid in changing contexts.

Each generation has a responsibility to teach, to maintain and preserve, and to create knowledge, and we have become very focussed on the teaching and the preservation, and not really sure about what is the process of creation of knowledge.

We could have a fairly consistent worldview and a fairly consistent set of principles and philosophies, but their application could well be different in each generation (Pakeke Winiata Interview, 2003).

However creating and updating Māori knowledge was challenging due to external and internal pressures, and to be authentic in the knowledge that is created, presenting an internalised repressive authenticity.

Mātauranga Māori is a body of knowledge expanded through creation of explanations. In class how do we know we are using authentic and appropriate processes for creating knowledge? This worldview is something that the people who created knowledge in previous generations had that worldview.

For many Māori today understanding what a worldview is hard enough let alone living one. For most of us the Māori worldview is more of an academic intellectual concept rather than a living one that we are operating. When you have this fairly tenuous attachment to a worldview it does make you a little bit nervous about the prospect of being able to create things and being confident that you are being consistent (Pakeke Winiata Interview, 2003).

Whilst momentum and progress for TWoR is important, it must always remain interwoven with the development of the surrounding region.

Us who are from this confederation, and have a long association with Te Wananga, are always mindful of the need to be seen to be contributing to the ART confederation, to make sure those three iwi don't get lost in our development (Pakeke Winiata Interview, 2003).

This places the emphasis on development within a holistic cosmology emphasising connection and social obligation which supports the enhancement and embellishment of indigenous knowledge. The Marae Based Studies (MBS) programme for example contributes to iwi and hapu development, using 
expansive use of Māori knowledge but also tools gathered from the external

environment.

The MBS paper is to provide a model that will help ensure the survival of the iwi or hapu. Its also looking at the environment that that they're in. We're in a non-Māori world as well. In line with the Treaty of Waitangi we take the best of their world to bring it in to Te Ao Māori and keep it within the confines of Tikanga to the betterment of both non-Māori and Māori if its done properly. I know it's idealistic but that's what we should be aiming for (TWoR Staff Interview, 2003).

These measures create the framework for ideas to further ensure the survival of

the hapu or iwi, exampling rangatira or qualities of indigeneity.

When we show the iwi or the hapu 'this is the best way to survive' the reaction is interesting.. it's challenging them. I could almost see them stiffen up because it means giving away something for them. It is the risk of losing the identity of the hapu or the iwi. But through [tools of MBS] they get the people back and we contribute. We used my paper as the basis for a discussion of what we do next. I now take an active part of the strategic view of the hapu (TWoR Staff Interview, 2003).

Despite the percieved threats of losing a distinctive Māori identity in using

external tools MBS encourages a vision which primarily focuses on the people.

Marae Based Studies is about creating a platform for the long-term survival and prosperity of that hapu or that marae who are nothing without people. Te whakatauki he aha te mea o te Ao - he tangata he tangata he tangata.

So even though we can look at the whenua and say its hugely important without people its nothing because it needs the people to keep it alive so to speak.

MBS is one tool of assisting and ensuring they will be around in 2610. It's empowering those people. The trick is to ensure that they in turn pass that empowerment on to the generations that follow. And the empowerment doesn't mean they've got power. It means they've got the power of knowledge, the power of understanding. (TWoR Staff Interview, 2003).

This adaptation to settler contact is nothing new, as the oft-quoted historic

phrase from Apirana Ngata is used to illustrate.

e tipu e rea mo nga ra tou ao

ko tou ringa ki te rakau a te Pākeha hei ara mo tou tinana

ko tou ngakau ki nga taonga a o tipuna Māorihei tiki tiki mo tou mahunga

ko tou wairua ki te atua, nana nei nga mea katoa (Winiata, 2000 p. 134).

[grow and flourish for the time (alloted you) in your world

grasp the tools of the Pākeha- as a guide on the pathways of your temporal journey 
your soul to collect and remember the gifts of your forebears

worn as a plume within the topknot of your head

your spirit to the Creator, who created all that is]. [Translation - TWoR Staff Member, 2003]

For Winiata, whilst this prescription remains valid, recent developments have

lifted the confidence Māori should have in their own knowledge.

We have moved beyond the prescription of the second line. We are not limited ki te rakau a te Pākeha to sustain ourselves. We have discovered opportunities to provide for ourselves based on mātauranga Māori (for example in education, in communications, in clothing manufacture and design, in entertainment, in many areas of art and so on) and on mātauranga from origins beyond Pākeha (Winiata Interview, 2000 p:135).

Updating this knowledge for Winiata means having the confidence to adapt even the most sacred Māori knowledge which is used to develop tikanga, that of kawa.

Plenty of people see it that way, originating with view that kawa comes straight from the gods or the god and is a gift that isn't to be amended or changed. I don't think we need to be that rigid - te aroha matataua - we can still retain the notion of kawa and tikanga has uses and meanings that are fairly closely related (Winiata Interview, 2003).

Winiata describes the vision that TWoR has in the ongoing work on enabling the tangible social structures of Māori beyond knowledge, of enabling iwi and hapu development, towards which his model of Māori power-sharing model has been accepted and trialled in the Anglican Church.

\subsubsection{Māori Knowledge Coordinates Organising}

For TWoR, from its earliest inception onwards, the goal has been a reclaiming and revitalising of Māori knowledge as a living world of valid and sacred knowledge. In this chapter I have explored how this emphasis on Māori 
knowledge occurs within the organisation as a whole. Within the everyday meaning making processes of organisational members Māori knowledge is enacted and updated in living relationship to context. In this way both the validity of existing Māori knowledge is maintained, and the construction of new knowledge achieved. Within this knowledge-context relationship lies competing pressures to revert to other knowledge formulations, to do 'what works' from Western sources, which are overcome through a profound belief in Māori knowledge, which is used to police and account for the use of Māori knowledge. In this way, Māori knowledge has been the most significant attribute, and source of, indigenous organisational identity for TWoR, which has become in the process a protector and guarantor for the quality of Māori knowledge, in Professor Durie's estimation (Durie, 2003). Autonomy allows Māori knowledge to guide action and buld Māori organisational culture (Alvesson, 2002). For example within the academic departments autonomy allows authentic identity to be constructed. Within these inter- subjective accounts the everyday construction of 'a Māori department' is located and confirmed as being in authentic lineage, and enactment of The Rules of 'tikanga Māori'. Here Māori knowledge also acts as an accounting sense-making device, where checks of knowledge validity ensure that what is proposed as 'Māori knowledge' has its source in bodies of oral Māori history. 


\subsubsection{Māori Organising at the Social Level}

The task of TWoR from the outset has been one of recovery, continuity and embellishment of indigenous knowledge. The very actions of TWoR, as viewed from a social phenomenological perspective, centrally underpin and support this knowledge survival, from these first actions and self definition onwards. For example, even conceiving of TWoR as being of the category 'wānanga', formed and located within the organisational charter, is an action which both maintains the categorical use of the notion of 'wānanga' and at the same time locates TWoR as within it: defining the living reality of a 'wānanga' for the current context. That this process extends to actions of the organisation as a whole indicates the symbolic importance of TWoR, one which supports and ultimately constructs a contextual part of Māori reality, of symbolic 'universe maintenance' as Berger and Luckmann (1966) propose in the theory literature. Such actions have required at the least, and in stark contrast to the historical context faced by Māori, faith and belief in their own knowledge, that is to know that such knowledge is itself of high cognitive status, and that it is able to be 'valid' for use in each context. This investment in the status of knowledge applies to its application across an expansive and open horizon of use, as Holstein and Gubrium (1994) suggest in the application of theory. Whereas neocolonial pressures influence actors to have little faith or belief in the worth of Māori knowledge, the leadership of TWoR from inception and through the evolution of the organisation have sought the recovery, application and expansion of Māori knowledge to guide and underpin organisational action, legitimising the 
aims and purposes as continuity within ancient Māori histories, findings which support other OS research (Henare and Lips-Wiersma, 2002; Henry and Pene, 2001; Jaya 2001; Wolfgramm, 2001).

At the social level organisational projects are encouraged and supported using currencies of measurement ('mana') that emerge from Tikanga Māori practices and suggest organisational action that create and sustain regional community development, whilst acting in sacred relationship to the environment, and one another. These actions include developing and maintaining spaces for the reflection and enlargement of the application of Māori knowledge within external bodies such as theology, economics and politics, indicating the broader political and social engagement which Banerjee (1999) and Henry and Pene (2001) point to as sites for both indigenous resistance and positive engagement. Indeed the development of political agendas which supports the enlargement of Tikanga Māori practices to reconceptualise pathways for social justice and effective representation, including political transformation, at the national level are major undertakings for TWoR overcoming repressive authenticity and a deeconomised indigenous, themes which other OS researchers have alluded to in other contexts (Banerjee and Linstead, 2004; Wolfe, 1999). Māori knowledge, which has been reinvested with cognitive status, links individuals and staff members with the organisation as a whole, which is itself intimately connected to the survival, maintenance and development of the surrounding social context. In this way the focus for meaning making within TWoR was, from the first, seen 
as the embellishment and maintenance of Māori knowledge for the benefit and identifiable survival of Māori 'as a people' of the surrounding ART Confederation and wider, in the face of neocolonial imbrications which challenge the very existence of such a people.

\subsection{Summary}

For TWoR, the authenticity of the actions of their strategic decision-making was predicated on their ability to create and maintain accountability structures and accounts which articulate 'Tikanga' behind their organisational actions, which are themselves based on, come from and add to the broader Māori holistic cosmology. In this way this knowledge is legitimated as authentically in continuity with Māori ancestry. Despite Schutz' (1970) claim that in it's constitutive sense-making role the stock of knowledge is taken for granted, given the fragmentations that have affected the retentions and transmission of the Māori worldview, this stock of knowledge is instead distributed according to length of time learning firstly Te Reo and secondly the concepts and values contained within the worldview. So instead of being an assumed or taken for granted source of meaning making, Māori values, and language, are highly prized and consciously articulated processes which play a vital and significant part in collectively constructing a Māori organisation. I next examine the Scottish context to explore indigenous organising in the context of the IC. 


\subsection{Celtic Organising: The Rule of the IC}

Within the Scottish context, how does the IC coherently constitute itself? In this section I address how notions of identity and continuity of meaning making processes or indigenous organising co-exists within and alongside organisational change. I begin with what the community understands to be its primary collective purpose and goals, as it was established through a democratic review of member's views on exactly this. Within the review of strategic priorities carried out in 2003 the IC affirmed that: 'there is an extremely high degree of consensus on six key areas of our task, especially the centrality of the Rule' (Strategic Review, Personal Communication, July 15 ${ }^{\text {th }}$ 2003). Reflecting this review, Galloway described the cohesive function that the Rule plays in the life of the members, suggesting how Celtic or Benedictine accountability structures guide and direct action in the life-projects of the members who, taken together, enact and constitute the IC.

The Rule hasn't changed. In our review of strategic priorities that is the thing that is most central to the life of the members, The Rule has not changed, it is the unifying factor, it is like the spine that holds everything up (Galloway Interview, 2003).

The Rule as the accountability framework of the IC is the major commitment that members make, and through which, become accountable to each other in their lives, as they meet in family groups.

There is a spiritual aspect, which is very simple. It requires daily attention to scriptures and prayer. They are the basic building blocks of our faith, so that is not that unique. There is The Rule of fellowship - of associating together. Obviously you can't have a community without them. There is the economic discipline, which is quite formative because while it does not reduce us to poverty it does make us pay attention. We also tithe, which is rare in the mainline church these days, but is common in Anglican churches. We tithe not to report to the church but to reach out to those who are in need. We have a discipline of time, for the people in the ministry, that who it 
was designed for. There is the peace and justice discipline was is very basic to the ethos of the community and its particularly brand of Christianity, which is politically left wing and activist (IC Member Interview, 2003).

The Rule evolved from Benedictine as well as Celtic notions which members draw on, to account for their own work programmes.

To some extent there the roots [of the Rule] are not necessarily Celtic but in the Monastic tradition. The Benedictine as much as the Celtic, because the Benedictines worked very hard. Some of the earliest economic organisations that you can analyse are in Benedictine monasteries (IC Member Interview, 2003).

For other members, the Rule remains indelibly imbibed with Celtic principles.

It tries to enact [Celtic] through the 5 fold Rule. We wouldn't say this is a Celtic rule but the idea of listening to the scriptures, of accounting for certain things, of accounting to one another has a Celtic feel about it about, but again we can take this into a realm where it isn't there, but there are some threads of that I think. A commitment to the world which is inside The Rule too, is a Celtic theme (Miller Interview, 2003).

For Galloway, the Rule covers the major aspects of IC members' lives: "this is about our prayer, the way that we use our currencies of time and money" (Galloway Interview, 2003). It also is imbued with notions of Celtic knowledge, however these are individually interpreted: "It's about the goodness of the world including the earth. It's about the way that we are together with one another- it is about everything, it's a Rule of life" (Galloway Interview, 2003). For Galloway the Rule is the major unifying factor that creates a cohesive unity and suggests an integrative canopy' of meaning or of legitimisations where the whole self is understood within a holistic cosmology, with individual actions placed within this knowledge framework: "it takes little bits from every aspect of your life and tries to bring them into harmony, if not always harmony at least creative tension" (Galloway Interview, 2003). Further and significantly the Rule is seen 
then, not only as the cohesive 'glue' that holds the community together, but also the vehicle by which the knowledge and beliefs that direct action are able to be enacted individually in a variety of local contexts, creating Celtic organisational culture.

The Rule of the community operates in widely divergent contexts, one member is Dean of a College in Oxford, others who are shop workers or teachers or artists, they take The Rule and work it in each context (Galloway Interview,2003).

For other members the Rule is a guide to life to be lived in a range of contexts. For Miller new situations can be met which allow sense making processes to occur where the vision of the IC can be individually and autonomously interpreted in and through members own lives, bringing dynamic and open, if at times challenging, life to the vision of the IC in each context.

I feel that the Rule empowers me to travel round just now these endless journeys I'm making but I feel encircled by the community or held by them, every year we account for our disciplines, and I had a beautiful note from Kathy, I was saying that there are some of the things I find difficult in the Rule, she put it beautifully about trying to say these are difficulties, but the vision is there, the Rule is sort of, in any community, a vision statement, it's not supposed to be an arrival point. (Miller Interview, 2003).

In this way the Rule remains the thread of continuity for the members "the Rule is unchanging, which is not a tension, but its the expression of the Rule in the modern world and the areas of discernment which change every 5 or 7 years" (Miller Interview, 2003).

Although the Rule itself does not adapt, its application to each context does require the rethinking of how it should apply, indicating at a cognitive level the ongoing and interpretive processes at work between knowledge and context.

The way that the Rule would lead us to think about things changes. Take human sexuality for instance, these issues weren't discussed when George MacLeod was 
around, you say there was a direct link between that discussion and The Rule, or our liturgies have evolved (Miller Interview, 2003).

For Galloway too, the Rule reflects and challenges widely accepted Western consumerist notions in the wider culture, replacing these with notions and processes that stress connection and community accountability.

The Rule is designed to counter individualisation and fragmentation and separation in our lives (Galloway Interview, 2003).

For other ex- leaders, this vision pulls people into the life of the IC, and through the Rule, onto enacting change to develop community at many levels, not least national.

The vision remains finding new ways to touch the hearts of all. People are not finding in the life of the Churches a project that satisfies them sufficiently. They need an experience that is deeper and a vision that is broader and has a sharper cutting edge. It has to do with being touched by the possibility of all things being made new and the vision of a better world.

People see within the life, the structures, and the commitment of the IC a way of being part of it. It has to do with taking part in going back to the national project - playing a part in reshaping the life of the church, the life of the nation and even the life of the world (Shanks Interview, 2003).

This vision seeks not only transformation of the surrounding context, but also transformation of the self, both in dynamic relationship, which is ultimately for Miller, profoundly Biblical and Celtic.

Biblical faith is prophetically relevant to everything that happens in the world. So you would need that conviction to move into the IC. I think that is Celtic, that prophetic vision. That prophetic vision is what calls us to be more than we are (Miller Interview, 2003).

In the IC the Rule provides a cohesive focus for the members. It also contains within it what some members at least see as the major tenets of Celtic knowledge, intimately intertwined with the IC vision, to be enacted by 
individuals in each context. As covered in the previous chapter, individual interpretations of this Rule directly inform the work programmes that members undertake, many of which seek to rebuild community at national levels. In this way, the Rule provides for continuity of knowledge enactment and identity through guiding individual community member's work programmes, which enact Celtic knowledge tenets (respecting the earth, working for social justice, etc) within a Benedictine inspired accountability framework. IC members constitute and enact indigenous Celtic organising in each context. I next address internal and external knowledge delegitimisations to Celtic knowledge.

\subsubsection{Challenging Celtic Knowledge inside the IC}

Within the IC the notions of Celtic being at all central to the life have been vociferously expressed, as noted in previous chapters.

I defy anyone to suggest the IC is a Celtic Community. Its roots are in Govan Glasgow and not Iona. Iona just used the story of Columba as a helpful peg to hang stuff on. If there is any continuity it is merely this, that The IC today uses the Bible the way Columba used the Bible to evangelise, to find new ways to touch the hearts of all. If there is any similarity between them, it is because they were reading the same book, nothing else (Ex-Leader Interview, 2003).

Challenging views such as this for Newell means claiming direct knowledge continuities to both MacLeod and Columba, as previously described. As Galloway also reiterates, the Celtic vision is very much at the heart of the IC, propelling its vision on into the 21 st century, despite members not speaking Gaelic.

How central is the Celtic logic to the vision of Iona? 
It is very central. I would say so. We wouldn't necessary express it in a Celtic way because lots of members live in the inner city of Glasgow. Nor are we Gaelic speakers. But it is there, absolutely. (Galloway Interview, 2003).

So for leaders and members claiming authenticity is based on notions of intersubjective experience with Celtic Christian knowledge which challenges and critiques external power relations for their equity and social justice. However, other pressures also exist at the social level which challenges the authenticity of the IC.

\subsubsection{Challenging Celtic outside the Community}

Indicating notions of repressive authenticity, academics claim the IC has made no connections to the Gaelic language, rendering it inauthentic and implying Celtic knowledge cannot exist separately to Gaelic.

Scottish academics like Donald Meek suggest anything Celtic can only be really claimed through speaking one of the Celtic languages. Also traditional Celtic organisations were very hierarchical. But George MacLeod was educated as a lowlander despite himself coming from a highland tradition.

As such he was schooled at Winchester, and was a very public school Victorian gentleman. So the IC has more of the lowland traditions, it tries to be more democratic and egalitarian, with leadership based on open elections and the position held on a rotational seven year term.(Galloway Interview, 2003).

Others describe how notions of repressive authenticity try to challenge or limit the use and understanding of Celtic knowledge.

The critics tell us there is no such thing as Celtic spirituality or missionary. This is because no historical Irish missionary would have described themselves as a 'Celtic spirituality teacher'.

Of course that's right, that is not how he would have understood himself. Although there are references invariably to the Irish missions, these great historic teachers of that we now refer to as Celtic spirituality or Celtic Christian tradition, would have seen themselves as part of the one Holy Catholic Apostolic Church (IC Member Interview, 2003). 
For Newell, claiming knowledge continuities has been plagued by the desire not to be romantic as repressive authenticity has imbricated.

When I very consciously began to write and appropriate within this tradition, I was aware that one of the misunderstanding and criticisms that we were going to get was that there was no such thing as the Celtic tradition. That it was romanticism (Newell Interview, 2003).

Bell discusses the profound sense of connection that many feel to Celtic knowledge, describing even in an Australian context the sense of closeness that people felt when he articulated the underpinning ideas of Celtic knowledge, indicating how knowledge delegitimisations are overcome through intentional reconnection to holistic cosmologies which, in the Scottish context, exist separately from the Gaelic language.

The first time I went to Australia I was asked to do a seminar on Celtic Spirituality. There was a conference of Roman Catholic religious priests. I spoke to them and I could not believe the silence and also the degree to which people wept. These big sturdy four letter swearing tough Australian priests were moved. I was telling no emotional stories but there was something in this that spoke to something in them. It is maybe the almost primordial thing that taps into basic yearnings for community and for wholeness and for depth (Bell Interview, 2003).

Bell describes how arguments of repressive authenticity hold no sway because

the history of Celtic knowledge has always been one of confident and expansive movement, rather than remaining in any strictly ancient location.

I take issue with Meek because Celtic's genesis was not in Ireland, it was in France. Before then it was the Desert Fathers and the Celtic tribes like the Keltoi which came from the middle of Germany.

They were not particularly related to Ireland or Scotland and they did not Mission just to themselves. If they came into places like Kilwinning and Kilmaurs and Kilmarnock and all these places where Irish names dominated as well as the North of England Durham, and Lindesfarne, Whitby, Celtic sites - they don't speak Gaelic there but they were all Celtic sites.

You cannot say it's all to do with the Celtic language because from the Seventh Century it stopped being Gaelic.(Bell Interview, 2003). 


\subsubsection{Celtic Knowledge: Continuity and Change}

The Rule evolved during the IC's early formation, "the most important thing in the 1940s was to establish a discipline that we would agree to and hold on to. We didn't know what we were doing at the time" (Fraser Interview, 2003). Rather than play a facilitating role engendering change MacLeod was a major barrier, being able to manipulate and control IC Council meetings. As a result the IC evolved a decision making structure that sought to reflect autonomy in the family groups.

George could manipulate plenaries but he couldn't manipulate small communities. That was the basic cells of the IC Church. It would bring fresh blood in and give people confidence to contribute more if they met in family groups and not only in plenaries (Fraser Interview, 2003).

MacLeod's views reflected many of the attitudes of the time, for example, insisting that the early community was a male only affair. Fraser recalls the tactics MacLeod used to block agenda items he didn't agree with, for instance Fraser's won proposal to make the community more balanced and open.

George was a clergyman. Somewhere in the 1950s I had a motion at last accepted on the agenda that we have more laity and women. George raised a great storm over the nuclear issue being the thing that really mattered. It didn't get to my item in the agenda (Fraser Interview, 2003).

Because of this, advances in opening up the community to laity and women only occurred once MacLeod had formally left leadership: "It had to be when George gave up the leadership that we could break open into more laity and women in particular. Of course now the whole thing is much more balanced" (Fraser Interview, 2003). So change evolved through the gradual adoption of communal decision-making processes, which supported autonomy and gender equity and 
away from the early and charismatic leadership and direction of MacLeod. The

Community has since steadily grown from its early 12 members to encompass

over 240, and from a few associates to over 3000. At its core is the same

theological notions that were worked into the Rule, which underpin the values

and identity of the community today.

The theological underpinning has remained broadly the same: the integrated spirituality; the incarnational spirituality; God in the whole of life; worship and work; religion and politics; prayer and social commitment; all being part of the same thing. I think that has remained (Miller Interview, 2003).

However whilst these core beliefs remain, enacting these in differing contexts

calls for members to model change in the settings that they choose to work.

This question relates how best to contribute to change. I think that it is probably recognised that most of us do that individually. Change involves modelling something new whether it is done within or without. So essential to the whole thing, to the continuing base on Iona, is the justice and peace and the Christian treatment of the whole thing. Worship is also part of that (Shanks Interview, 2003).

With changes in the wider context, especially for example an increase in individualism, the core commitments of the community have taken on a new significance, and articulation, to challenge globalist practices, and instead emphasising the open and adaptive nature of the Rule in each context.

The significance of the communal dimension has become more important as society has become more individualistic. How that is expressed has changed. Both the Rule and the structures of the community have developed over time. They reflect and are a response to changes in society (Shanks Interview, 2003).

While society has changed, the IC organisation itself has also had to adapt.

[The IC] has become much more organised. It had to be, because of lots of reasons. It is a medium sized charity now. It is not just a random collection of people who have a commitment to peace and justice. It is like a business, a charity with a budget of more than half a million pounds and about 50 people. You have to organise that (Shanks Interview, 2003). 
Such adaptation isn't without its tensions, however. "There is a tension in an organisation, I have argued that a movement has to be organised. As an organisation we have to move. The two are not mutually incompatible or contradicting" (Shanks Interview, 2003). This adaptation involves increasing its professionalism by establishing structures to comply with legislation and to meet the professional needs of the staff:

I think that we are more structured and more organised. The constraints, we now have to take in to account health and safety regulation, environmental health legislation and child protection legislation many other policies and practises that didn't exist before. They impact on members of the organisation in different ways (Shanks Interview, 2003).

Staff are required to be increasingly professional and qualified, indicating the Community's desire to upgrade its competencies through its employment processes:

We have to employee managerial positions, in catering and maintenance, we can no longer be somebody who is interested in joining or likes cooking. People have to have more than that: experience as well as training and qualifications. We find and employ people like that (Shanks Interview, 2003).

To avoid conflicts between worldly competence and the values of the organisation, a commitment - or at a minimum sympathy with the IC's ethos - is also required, indicating spiritual values which underpin professional competence, as opposed to rejecting globalist skills altogether.

We do want them to a show an interest in what the community is all about. I think that is essential. It is advantageous that people have some connection with the community but not essential. Some of the best employees are the ones who come out of nowhere and have seen something in the community that they are quite happy to commit themselves to (Shanks Interview, 2003).

Leadership in this context is very different to the traditional autocratic model and is conceived of as not particularly focussing on any individual or properties 
of any one 'guru' leader, but as qualities vested interchangeably in the group. In the IC leadership involves a nurturing role in enabling and sustaining the community, in binding together, and being accountable to the members and associates in the context of symbolically maintaining the beliefs of a Celtic holistic cosmology.

The leader has a pastoral nurturing role in supporting and relating to the 26 family groups which exist thought Britain. The leader has to associate with not only the members but also the associate members - there are 1500 of those.

It is affirming the significance in people and treating people well; respecting and encouraging mutual respect; developing a team, a corporate approach; building and rebuilding a common life (Shanks Interview, 2003).

This binding together perhaps does symbolise one tradition from MacLeod - that of the notion of the Wild Goose which has been picked up and used to express the essential qualities of the Holy Spirit, and of leadership within the IC today. "the wild goose flies in formation - it takes turns in leading in flight, the rest of the birds following in close formation... that's how I see the wild goose in the Iona leadership" (Iona Associate Interview, 2003). MacLeod used this symbol in the storytelling oral tradition to create mythic imagery, even if his historical accuracy is at times dubious.

George brought this thing in about the wild goose being the Celtic symbol of the Holy Spirit. When George read Ron's pamphlet he asked "where did you get that thing about the Wild Goose from?" Ron said "From you!" It was something that George had written in Coracle in 1941 that he had completely forgotten about. Ron picked it up. Where George got that from nobody knows. He can't even remember. He would have come across it somewhere and it was gotten in there (IC Member Interview, 2003).

From the beginning Miller suggests that a communal leadership model was actually informally operating on Iona, despite MacLeod's visionary status: 
From the beginning there was a communal leadership. Yes George was the visionary he appeared to be leader and he appeared to go round raising all this money but somehow or other that was also linked or married there was this working out with Ian Fraser and others, how it came about. There needs to be a lot more written about the other people who made the IC possible (Miller Interview, 2003).

\subsubsection{Constructing the Celtic Christian Holistic Cosmology}

The leader today also takes a role today in communication and symbolic representation of the values and ethics of the community to its many publics, a

function of the transmission of the stock of knowledge through representation.

The leader has a function to represent the community. A lot of engagements with meeting and greeting. I was asked to speak on a number of occasions as a leader of the community. It involved recognising the community's political insights, experiences and approaches to things that people might find helpful and stimulating. So in a sense the leader embodies the vision and the values of the community in fulfilling the representative function (Shanks Interview, 2003).

Other management practices involve modelling ethical and environmental responsibility showing the Celtic beliefs through actions, or what Galloway calls 'voluntary self restraint' in the everyday choices that can, collectively, reduce the use of limited and valuable resources, in the process respecting the environment and marginalized or exploited groups.

Every aspect of our life on Iona has a reason. It is in the very small things like using fairly traded goods, promoting trade justice. Its about our economics, it's about our politics, its about our culture, its about our spirituality, its about everything (Galloway Interview, 2003).

For other members too the Community has tried to walk the talk with regards to environmental awareness.

What role does Iona the community itself play in environmental concerns?

We have been quite an important a lobbying organisation on environmental matters. As an expression of the faithful stewardship of the created order which is the duty of the Christian. I think the more sensitive people become to the extent that we are not in the right relationship with our world the more there is a tendency to look back to models which are counter to that (IC Member Interview, 2003). 
This environmental awareness is not an aspect that is new to the IC, as one member recalled from his time on the island:

We were using biodegradable detergents 25 years ago. There has been a number of heating experiments. The first solar panel I saw was the one that went up at the youth camp, before it gave way to the Mac. They had a heat exchange system for heating the Abbey using pipes.

The Herb garden wasn't there when I first started. Now we are growing things for our own consumption on the doorstep rather than bringing them from far away (IC Member Interview, 2003).

However for other members this focus on environmentalism is underdeveloped:

We pay lip service in our liturgies to that. It is an interest of the members. A few people have been involved in environmental issues in a big way. We've thought that this was a major aspect of our time, and we need to work more effectively in this area.

Young peoples' environmental concerns such as global warming, gas emissions. We've not got workings groups on that yet. However it is something that we should pay more attention too. (IC Member Interview, 2003).

The ability of the IC to change, whilst maintaining its core beliefs, is one of the main reasons for its continued survival. Change requires bringing in the best external knowledge and practices that are compatible with the Community's values, and embedding them within its own holistic Celtic cosmology underpinning organisational culture.

It is a dynamic process. Thing have to keep changing. We have a member who has done a lot of work in management consultancy and is a Professor at Strathclyde University. He is now convenor of the council. He has been on the finance committee in the past. On our IC video, the last word is his, which is the need to be open and the need to continue to change.

The reason the community has lasted this long is that is has been ready and able to change and been responsive for the need for change without losing sight of its fundamental Christian commitment and the commitment for working for a better world (Shanks Interview, 2003). 


\subsubsection{Celtic Knowledge Coordinates Organising}

At the organisational level the community has developed the Rule which Garfinkel suggests in the literature of Chapter 4 is a sensemaking and accounting device to aid everyday organising (Heritage, 1984). Applying this general principle suggests the Rule guides the living out of Celtic Christian principles in a range of contexts. These principles draw from the surrounding culture and from inside the Celtic Christian history of Iona and the region, and are adapted and updated by use in each context. Within the organisation, however, knowledge delegitimisations exist which have to be overcome. These propose that any connection to Celtic knowledge is tenuous at best, and that instead it is merely a vehicle through which an evangelical Christian mission can be legitimised and claimed. At the social level, processes of repressive authenticity were identified, as proposed in the literature (Banerjee and Linstead, 2004; Wolfe, 1999). Critics claimed Celtic knowledge is only valid if it is held and spoken by a Gaelic speaker, reflecting the profound dislocations that have riven the Celtic Scottish history, as noted in Chapter 5. Overcoming this, through the strategic review process in 2003 the Iona leadership encouraged the expansive use of Celtic Christian knowledge. This has underpinned the validity of this knowledge, reflected and embodied in the Rule throughout the organisation. This enactment also builds Celtic organisational culture using stories and themes as resources which Alvesson (2002) suggests in the literature helps form organisational culture generally. The leader in 2003 and members of the community also conditionally claim knowledge continuity with the ancient 
Celtic cosmology, and posit that it relates to the vision of the community, and to the Rule.

\subsubsection{Celtic Knowledge at the Social Level}

At the social level the Rule encourages actors to engage in devolution within the national legal political structures, as well as critiquing structures against principles of social justice. Alongside this, the calls for ecological sustainability, whilst undeveloped at the organisational level, remain a passionate area of community concern reflecting themes common to other indigenous organisations (Whiteman and Cooper, 2002). Taken together, these leadership and organising processes help enact and update a Celtic Christian holistic cosmology in the wider social context, overcoming globalist practices.

\subsection{Summary}

In chapter summary, I propose the notion of authentic indigenous organising is based on notions of organisational authenticity, which I take to be the creation and enactment of indigenous knowledge of members and the knowledge continuities which underpin this. An authentic indigenous organisation appears to be based on indigenous organising or sensemaking devices based on indigenous knowledge which fulfils a number of strategic functions, drawing from knowledge which is updated, and therefore not fixed. In the Māori context indigenous knowledge legitimates the organisation as authentic through the intentional use of tikanga Māori across the organisation. From boundary setting 
activities to constructing the organisation's charter, Māori knowledge is indexically constructed, that is, its usage is dependent on, but also constructs, the local context, to guide action for members. For example, creating the TWoR charter relies on Māori knowledge traditions articulated in situ. When interpreted, this organisational artefact constructs the context and directs sensemaking action for organisational members. In this way, indigenous knowledge experts construct, and define as legitimate, their own reality. The organisation not only ensures the continuity of indigenous knowledge in this way. Members are encouraged, from the leadership down, to use and create new knowledge, where the validity of Māori knowledge is proven through its use in each generational context. Māori knowledge adapts through the open horizon of use, where ongoing knowledge use creates adaptability within changing contexts. Tests of authenticity carries policing and sensemaking functions where knowledge which is deemed inauthentic and its supporters are challenged and excluded from legitimate organising processes, eventually to leave. These actors themselves challenge the ontic worth of indigenous knowledge claiming its use has no relevance or value in the real world. Overcoming this, processes of autonomy operates to allow departments within TWoR to reflect on action and self identify their own indigenous Tikanga Māori practice, enabling entrepreneurialism and reducing cultural dissonance.

In the Scottish context, the IC maintains its sense of coherence within a Celtic Christian framework using the Rule to focus and directs action towards peace 
and social justice. Autonomy also operates at the organisational level, allowing community members to flexibly respond to changing areas of community concern. These include working towards environmental sustainability; working to build community capabilities; and to support notions of a fairer and more just Scottish life, whilst supporting arguments for increasing devolution within the United Kingdom. Finding new ways to touch the hearts of all indexically draws from the wider culture and reflexively constructs a Celtic Christian cosmology. However the definitions of both Celtic Christian and indigenous are neither agreed within nor outside the life of the IC. Whilst the leadership in 2003 and many organisational members actively support the notions of Celtic Christian and indigenous being centrally present, others do not share this view. Those supporting this position argue for knowledge continuities between the ancient worldview, the Iona founder and current life of the Community. However others strongly argue for 'Celtic' being marginal to the life of the community at most and the only continuities with the earlier Celtic community being the Biblical tradition. External pressures also seek to delegitimise the Community as being not Celtic enough, having no living relationship to the revitalisation of Gaelic. Having compared indigenous organising in each context in the next and final chapter I return to the thesis question and theorise the functional dynamics of the indigenous organisation placing the empirical explorations of both cases more fully back in the context of extant literatures, discussing findings and implications in light of the empirical research. 


\section{Chapter 10: Indigenous Organising In Global Contexts}

\subsection{Introduction}

This chapter theorises polyvocal definitions of indigeneity integrating constructionist literatures with empirical data from the two case studies. I then describe the key elements and processes of each indigenous organisation which are enacted from recovered holistic cosmologies in the face of fragmenting globalist practices. I synthesise these cases to generate a theory of indigenisation which illustratres indigenous organising as a process. I show how leaders maintain the validity of indigenous knowledge and encourage broader processes of indigenisation, which supports the recovery of individual and organisational identity, and a wider holistic cosmology. This theory of indigenisation is compared with the OS literature at three levels, and with assumptions contained in globalist literature. Limits of this research and a social phenomenological approach are noted. Future research agendas are proposed.

\subsection{Defining Indigeneity from Holistic Cosmologies}

This section theorises Māori and Celtic notions indigeneity by synthesising the constructionist definitions of indigeneity with the case study data. In each case notions of indigenous identity have been constructed from cultural logics which re-inscribe individual identity within social projects. These projects support the strategic reclamation of indigenous practices and territorial claims through principles within indigenous holistic cosmologies. These projects and 
communities transcend the 'synthetic solution' of new social movements to provide stable identity structures which ascribe both self and status by reference to the continuity of community within a broader holistic cosmology, as suggested by Fischer (1999) and Friedman (1994b). Identity becomes based on increasing internalisation and enactment of indigenous knowledge, carrying with it all 'the force of social relations that transfer propositions about the world from one person or position to another' (Friedman, 1994b p.207). A symbolic universe of meaning in fully differentiated terms is increasingly realised as it is increasingly enacted (Berger and Luckmann, 1966, p.199). In these terms the 'running self-identikit' which Spivak (1987a,b,1993) proposes is not based on a need to 'fully recover' the source of self identity before the self is enacted, but rather the indigenous self is enacted and developed in and through adaptive cultural logics which are known by different members to differing degrees, as is knowledge from any quarter (Berger and Luckmann, 1966; Schutz, 1967, 1970).

The construction of indigenous identity in both cases is enacted from 'covenantal cosmologies' which Fischer (1999) identified in the Mayan context, but I posit that these cosmologies provide a source of not just identity, but reality definition within which identity is constructed, as posited by Berger and Luckmann (1966). These cosmologies contain notions of the sacredness of people and the sacredness of the Earth positing covenantal relationships of care to each. While increased exposure to indigenous knowledge deepens identity, those with limited exposure may still construct identity just as powerfully, but 
through symbolic consumption as a marker of identity (Banerjee and Linstead, 2001; Lash and Urry, 1994). In simple terms, the adornment of a Māori or Celtic tattoo may be a powerful marker of indigenous identity recovery, which carries with it the obligation to 'walk the talk'. These social expectations require increasing working familiarity with indigenous knowledge. These markers become sites of authentic indigenous knowledge membership which are policed. Identity of the emergent indigenous self is both nurtured and policed by the community as individuals enact community obligations, thus iteratively rebuilding both identity and community. 'Authentic' indigenous identity is conferred by the community based on observable indigenous paractices. Thus the conferring of indigenous identity may begin with what appears to be symbolic identity consumption of the autonomous subject. Over time the construction of indigenous identity is enabled and conferred by the indigenous community, overcoming individual alienation which Friedman (1994b p.218) discusses as one cause of the new social movements.

Table 9 below summarises how indigeneity has been self-defined in two contexts, contrasted in Table 10 with a constructionist assessment of these against the literatures of Chapter 2. 
Table 9: Self Definitions of Indigeneity in Two Contexts

\begin{tabular}{|c|c|c|}
\hline Indigenous Knowledge & Celtic Knowledge (CK) & Māori Knowledge (MK) \\
\hline $\begin{array}{l}\text { Conception of personhood: } \\
\text { Sacred notions of self, } \\
\text { developed in deep relationships } \\
\text { to sacred community and land. }\end{array}$ & $\begin{array}{l}\text { "To be creatures in the } \\
\text { covenant, to be citizens of } \\
\text { heaven, it is not only to be } \\
\text { required to be in right } \\
\text { relationship with our own } \\
\text { human kind, but with the whole } \\
\text { creation." (Galloway Sermon, } \\
\text { 2003) }\end{array}$ & $\begin{array}{l}\text { "Whakapapa (geneology) links } \\
\text { the people together and within } \\
\text { Māoridom you can whakapapa } \\
\text { back to the land itself ... Mana } \\
\text { atua, mana whenua, mana } \\
\text { tanagata power from God, } \\
\text { power from land, power from } \\
\text { people, that's all linked in } \\
\text { together..." } \\
\text { Interviews, 2003) }\end{array}$ \\
\hline $\begin{array}{l}\text { Conception of land: } \\
\text { Stewardship of sacred resources } \\
\text { all held within covenantal } \\
\text { cosmology which guides action }\end{array}$ & $\begin{array}{l}\text { "[the Celts held] a conviction of } \\
\text { the goodness of the whole } \\
\text { creation, not goodness in a } \\
\text { moral sense, but ontologically, } \\
\text { the goodness of being. All is } \\
\text { good, not by virtue of its value } \\
\text { to others, or by its } \\
\text { resourcefulness or its efficiency, } \\
\text { but simply in the fact of its } \\
\text { being. Justice is also eco- } \\
\text { justice..." } \\
\text { (Galloway Sermon, 2003) }\end{array}$ & $\begin{array}{l}\text { "an indigenous person is a } \\
\text { person who has the rights and } \\
\text { responsibilities of kaitiakitanga } \\
\text { and they've aquired that } \\
\text { through } \\
\text { Kaitiakitanga is guardianship } \\
\text { they don't own it, they just look } \\
\text { after it, and enhance it, and pass } \\
\text { it on if they can, if not in a } \\
\text { better form than they had it, at } \\
\text { least not in a worse form for } \\
\text { succeeding generation" (Staff } \\
\text { Interviews, 2003) }\end{array}$ \\
\hline $\begin{array}{l}\text { Conception of indigenous: } \\
\text { Continuity of guardianship } \\
\text { traced back to ancient } \\
\text { settlement or deep communion } \\
\text { with the land. }\end{array}$ & $\begin{array}{l}\text { "Indigenous has to do with a } \\
\text { rootedness to place and to it's } \\
\text { history... it comes out of } \\
\text { people's sense of being } \\
\text { grounded in this culture in this } \\
\text { place in this time, and feeling } \\
\text { for what throbs at the heart of } \\
\text { community or at the heart of } \\
\text { nature and calls out for } \\
\text { expression" } \\
\text { ( Bell Interview, 2003) }\end{array}$ & $\begin{array}{l}\text { "indigenous for me is about our } \\
\text { sacred connection to the land.. } \\
\text { our marae, our Maonga } \\
\text { [Mountain] ...we say we are } \\
\text { 'tangata whenua, the people of } \\
\text { the land'... we are the first } \\
\text { people here... the people of the } \\
\text { land. we're born from the } \\
\text { land..." } \\
\text { "I've been told stories of our } \\
\text { old people and that they can } \\
\text { whakapapa back to the land, to } \\
\text { the sacred grasses and rocks of } \\
\text { their land... that's what the } \\
\text { people of the land is"(IC Staff } \\
\text { Interviews, 2003) }\end{array}$ \\
\hline
\end{tabular}


Table 10: A Constructionist Assessment of Indigeneity

\begin{tabular}{|c|c|c|c|c|}
\hline Context & $\begin{array}{l}\text { Sample } \\
\text { Definitions }\end{array}$ & $\begin{array}{l}\text { Source } \\
\text { knowledge }\end{array}$ of & $\begin{array}{l}\text { What knowledge } \\
\text { Does }\end{array}$ & $\begin{array}{l}\text { How knowledge relates } \\
\text { to social structures }\end{array}$ \\
\hline $\begin{array}{l}\text { Māori } \\
\text { Of } \\
\text { A.R.T. }\end{array}$ & $\begin{array}{l}\text { 'Tangata } \\
\text { Whenua' } \\
\text { 'Kaitiakitanga' } \\
\text { Iwi and Hapu } \\
\text { identities }\end{array}$ & $\begin{array}{l}\text { Rangiatea } \\
\text { Sacred tribal } \\
\text { origins of } \\
\text { metaphysical } \\
\text { nature }\end{array}$ & $\begin{array}{l}\text { Protects indigenous } \\
\text { status. Rebuilds } \\
\text { positive identity and } \\
\text { social status, lessens } \\
\text { negatives. Reasserts } \\
\text { guardianship of the } \\
\text { land }\end{array}$ & $\begin{array}{l}\text { Reconnects members } \\
\text { to iwi and hapu } \\
\text { through whakapapa, } \\
\text { provides integrative } \\
\text { symbolic canopy of } \\
\text { meaning within tribal } \\
\text { relations through land }\end{array}$ \\
\hline Celtic & $\begin{array}{l}\text { Goodness (divine } \\
\text { source) of people } \\
\text { Goodness (divine } \\
\text { source) of Earth } \\
\text { 'living heart at the } \\
\text { centre of a people' }\end{array}$ & $\begin{array}{l}\text { Celtic Christian, } \\
\text { Desert fathers, } \\
\text { St Martin of } \\
\text { Tours and } \\
\text { others, (all based } \\
\text { on divine } \\
\text { revelation) }\end{array}$ & $\begin{array}{l}\text { Builds positive } \\
\text { identity, lessens } \\
\text { negatives, } \\
\text { encourages sacred } \\
\text { connection to Earth } \\
\text { and environmental } \\
\text { awareness }\end{array}$ & $\begin{array}{l}\text { Reconnects members } \\
\text { to spiritual notions of } \\
\text { community, } \\
\text { Seeks to build local } \\
\text { church capabilities, } \\
\text { provides integrative } \\
\text { canopy of meaning } \\
\text { within Christian } \\
\text { tradition }\end{array}$ \\
\hline \multirow[t]{2}{*}{ Literature } & $\begin{array}{l}\text { 'Native' } \\
\text { 'Tribal' } \\
\text { 'Subaltern' }\end{array}$ & Postcolonial & $\begin{array}{l}\text { Devalues indigenous } \\
\text { knowledge, legitimises } \\
\text { 'development' } \\
\text { Points to colonial co- } \\
\text { construction }\end{array}$ & $\begin{array}{l}\text { Maintains status quo of } \\
\text { Colonial supremacy, } \\
\text { co-constructs colonial } \\
\text { superiority } \\
\text { Creates space 'at } \\
\text { margins' for } \\
\text { indigenous voice }\end{array}$ \\
\hline & 'Indigenous' & $\begin{array}{l}\text { Anthropological } \\
\text { Activism }\end{array}$ & $\begin{array}{l}\text { Suggests socially held } \\
\text { knowledge }\end{array}$ & $\begin{array}{l}\text { Reflects or supports } \\
\text { Indigenous claims }\end{array}$ \\
\hline
\end{tabular}

Without a single definition implied or expected, a constructionist assessment of indigeneity asks who is defining indigeneity, for whom, and for what purpose? The table above compares the self definitions in two contexts with the definitions provided in Chapter 2. 


\subsection{Comparing and Theorising Indigenous Organisations}

Indigenous knowledge in each context is used to critique the social justice of existing legal national structures and to empower community development in social or economic terms. This indicates the self-directed focus of indigenous development which is in no way limited to ecological principles, despite these themes being present. Instead these organisations reclaim universal domains of application of indigenous knowledge which sustains their holistic cosmologies. Contextual differences between cases illustrate the expansive uses to which each set of indigenous knowledge has been put. In the context of a Māori teaching and research institution, Māori knowledge supports the activity of knowledge embellishment for teaching and research. Recast to support a Christian Community, Celtic knowledge supports Biblical centrality, evangelisation and missionary zeal, drawing from the imaginary of the Celtic founder, St Columba. Table 11 below describes the compentents of two indigenous organisations and their respective functions.

Table 11: Components of the Indigenous Organisation

\begin{tabular}{|l|l|}
\hline $\begin{array}{l}\text { Component of } \\
\text { Organisation }\end{array}$ & Function \\
\hline Histories & $\begin{array}{l}\text { Tells story of indigenous knowledge: Relegitimates indigenous } \\
\text { knowledge as valid working knowledge in context. }\end{array}$ \\
\hline Purposes & $\begin{array}{l}\text { Establishes organisational identity and strategy within indigenous } \\
\text { organisational lineages. Encourages use of indigenous knowledge. }\end{array}$ \\
\hline Boundaries & $\begin{array}{l}\text { Draws from indigenous knowledge to negate fragmenting influences } \\
\text { and recover identity. }\end{array}$ \\
\hline Rules & $\begin{array}{l}\text { Draws from indigenous knowledge, operates to coordinate actions } \\
\text { across the organisation as a whole within multiple contexts, changing } \\
\text { contexts updates knowledge. }\end{array}$ \\
\hline
\end{tabular}


Histories reclaim indigenous knowledge as valid knowledge in context. Purposes aim to overcome globalist effects and enact indigenous knowledge as intentional strategies. Boundaries discourage individual behaviours associated with globalist practices such as identity fragmentation, consumerism and alcohol or drug abuse, while sensemaking rules guide members to enact, account for, and update indigenous knowledge across the organisation as a whole, and wider context, ensuring the survival of their holistic cosmology.

\subsubsection{The Indigenous Organisation in Global Contexts}

Based on social phenomenology and constructionist OS, it can be said that an indigenous organisation is enacted where the formation and ongoing interpretation of purposes and histories, boundaries and rules directly draws

from indigenous knowledge, to overcome fragmenting global practices and increase the expansive use of indigenous knowledge. These sensemaking processes work to legitimise the indigenous organisational aims and goals to rebuild community and develop indigenous autonomy at the national level, whilst critiquing existing national legal political structures for their social justice. 
Table 12: Two Indigenous Organisations Compared

\begin{tabular}{|c|c|c|}
\hline Feature & The Iona Community (IC) & Te Wānanga-o-Raukawa (TWoR) \\
\hline Established & $\begin{array}{l}\text { Regional churches } \quad \text { support } \\
\text { rebuilding programme in } 1938 .\end{array}$ & $\begin{array}{l}\text { Runanga confederation creates } \\
\text { Wānanga (house of learning) } \\
\text { 1975. }\end{array}$ \\
\hline $\begin{array}{l}\text { Globalising } \\
\text { Response }\end{array}$ & Overcoming urban squalor & Overcoming disarray \\
\hline $\begin{array}{l}\text { Underpinning } \\
\text { knowledge }\end{array}$ & $\begin{array}{l}\text { Seeks a commitment to a holistic } \\
\text { understanding including the } \\
\text { spiritual in areas of community } \\
\text { concern. }\end{array}$ & $\begin{array}{l}\text { TWoR is a unique centre of higher } \\
\text { learning devoted to the world of } \\
\text { Māori knowledge, (Mātauranga } \\
\text { Māori). }\end{array}$ \\
\hline $\begin{array}{l}\text { Source of } \\
\text { indigenous } \\
\text { knowledge/ } \\
\text { stated } \\
\text { worldview }\end{array}$ & $\begin{array}{l}\text { An integrated understanding of } \\
\text { spirituality - seeking to rediscover } \\
\text { and rearticulate strands of ancient } \\
\text { Scottish (Celtic) spirituality and } \\
\text { knowledge in a modern and } \\
\text { postmodern environment. }\end{array}$ & $\begin{array}{l}\text { The "continuum of Māori } \\
\text { knowledge" = Traditional Māori } \\
\text { Knowledge }+ \text { Māori Knowledge } \\
\text { post 1769. To see the world } \\
\text { through Māori eyes- Mātauranga } \\
\text { Māori is a body of knowledge that } \\
\text { is continually flowing and } \\
\text { evolving over a period of time and } \\
\text { space. }\end{array}$ \\
\hline $\begin{array}{l}\text { Inspired by } \\
\text { ancient } \\
\text { indigenous } \\
\text { organisation }\end{array}$ & $\begin{array}{l}\text { The IC is a recreation of an ancient } \\
\text { Celtic institution (monastery),which } \\
\text { were the tribal and spiritual centres } \\
\text { of learning. (St Columba's } \\
\text { monastery; St Mungo established } \\
\text { Glasgow University) }\end{array}$ & $\begin{array}{l}\text { TWoR is a reformulation of an } \\
\text { ancient Polynesian institution } \\
\text { known as the whāre wānanga } \\
\text { which were tribal centres of higher } \\
\text { learning. }\end{array}$ \\
\hline Membership & $\begin{array}{l}\text { Open to all with an interest in } \\
\text { integrated Celtic spirituality } \\
\text { volunteer immersion programmes }\end{array}$ & $\begin{array}{l}\text { Open to all with desire to explore } \\
\text { Māori language and knowledge }\end{array}$ \\
\hline
\end{tabular}




\subsubsection{Indigenous Organising as a Process}

Indigenous organising as a process is defined as situated organisational action from actors who enact and update indigenous knowledge, overcoming globalist practices. This definition draws from social phenomenology (Schutz, 1970;

Weick, 1979) to describe the organising processes out of which the indigenous organisation unfolds and is enacted. Figure 14 below and Figure 15 over illustrate processes of indigenous organising in each context.

\section{Figure 14: Māori Organising as a Process}

\begin{tabular}{|c|c|c|c|c|}
\hline History: & Purpose & Accounting with MK: & Inside Org: & Outside Org: \\
\hline $\begin{array}{l}\text { TWoR is a } \\
\text { reformulation of the } \\
\text { whare wananga, } \\
\text { the most senior of } \\
\text { which is Rangiatea }\end{array}$ & $\begin{array}{l}\text { Advancement } \\
\text { Of Knowledge } \\
\text { Enhancement of } \\
\text { teaching \& } \\
\text { research rooted in } \\
\text { Matauranga Maori } \\
\text { and needs of ART } \\
\text { confederation } \\
\text { To contribute to the } \\
\text { development and } \\
\text { wellbeing of Maori } \\
\text { in order to promote } \\
\text { Maori survival and } \\
\text { prosperity }\end{array}$ & $\begin{array}{l}\text { Charter } \\
\text { Principles: } \\
\text { Manaakitanga } \\
\text { [Mana enhancing } \\
\text { behaviour] } \\
\text { Rangatiratanga } \\
\text { [Attributes of a rangatira] } \\
\text { Whanaungatanga } \\
\text { [Familiness:being part of a } \\
\text { larger whole] } \\
\text { Kotahitanga } \\
\text { [Unity of purpose and } \\
\text { direction] } \\
\text { Wairuatanga } \\
\text { [Nurturing spirituality] } \\
\text { Ükaipötanga } \\
\text { [Nurturing places and } \\
\text { senses of belonging] } \\
\text { Pukengatanga } \\
\text { [Nurturing traditions] } \\
\text { Kaitiakitanga } \\
\text { [Care of treasures] }\end{array}$ & $\begin{array}{l}\text { Tikanga: } \\
\text { Principles } \\
\text { Applied in each } \\
\text { Department: } \\
\text { Builds Maori } \\
\text { organisational } \\
\text { culture } \\
\text { Directs use of } \\
\text { Maori Knowledge } \\
\text { outside org }\end{array}$ & $\begin{array}{l}\frac{\text { Individual }}{\text { - Te Ao Maori }} \\
\text { - Whakapapa } \\
\frac{\text { Social }}{\text { - Iwi \& Hapu }} \\
\text { Recovery \& } \\
\text { Growth } \\
\text { - Power } \\
\text { Sharing } \\
\text { Models } \\
\text { - Maori Party } \\
\\
\text { Knowledge and practices } \\
\text { from context: } \\
\text { 'Global' Knowledge, } \\
\text { Technology, } \\
\text { Skills \& Behaviours }\end{array}$ \\
\hline & & $\begin{array}{l}\text { Organisational } \\
\text { Boundary } \\
\text { Protection \& } \\
\text { Adaptation }\end{array}$ & & \\
\hline
\end{tabular}


Figure 15: Celtic Organising as a Process

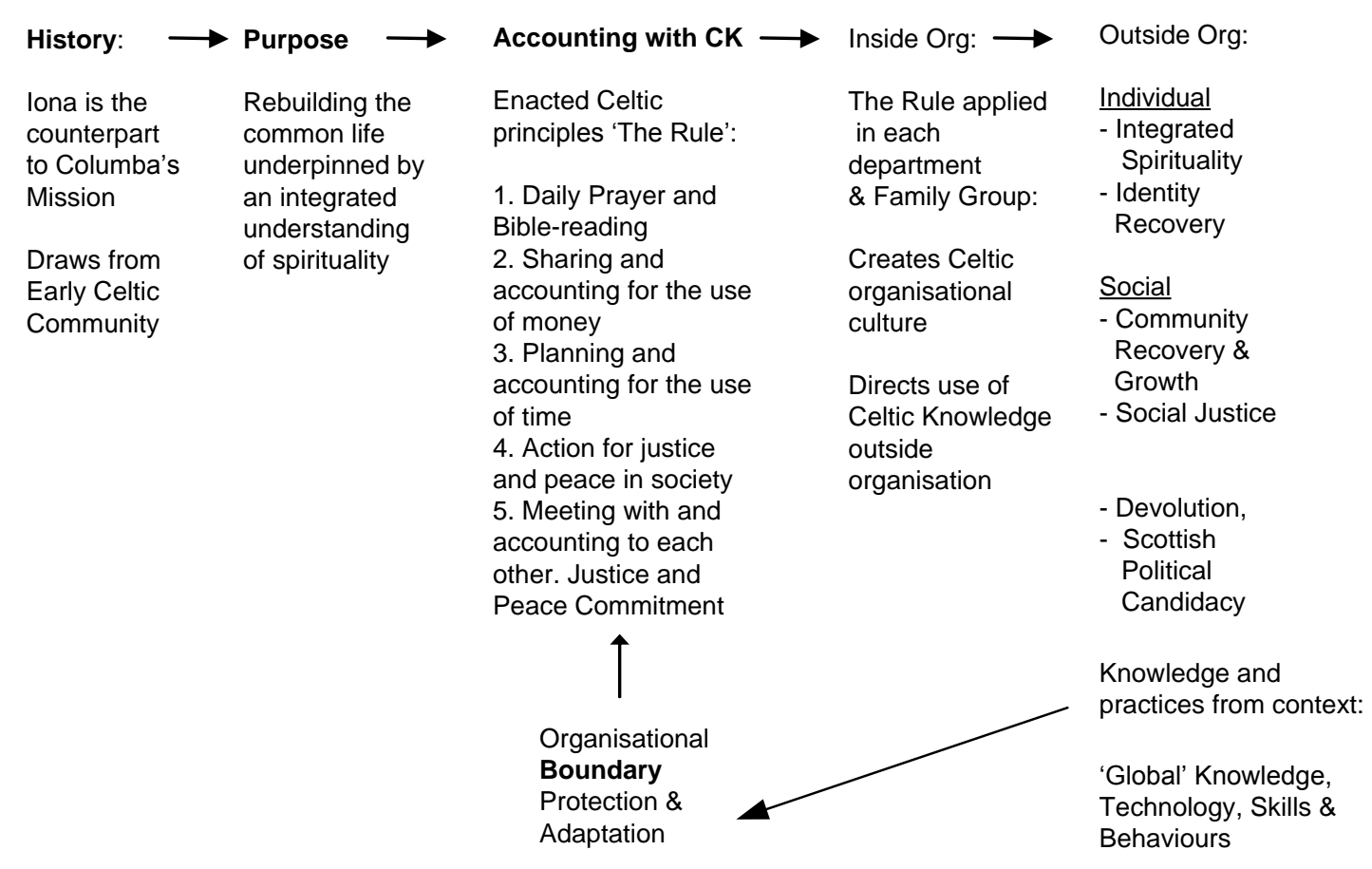

In the context of each organisation studied, indigenous knowledge continuities provide members with authentic and coherent organisational knowledge, recovered as working knowledge in their own historic contexts, and revalidated through application in the current. This knowledge-enacting process is synthesised from both cases and illustrated in Figure 16, below. 
Figure 16: Indigenous Organising as a Process

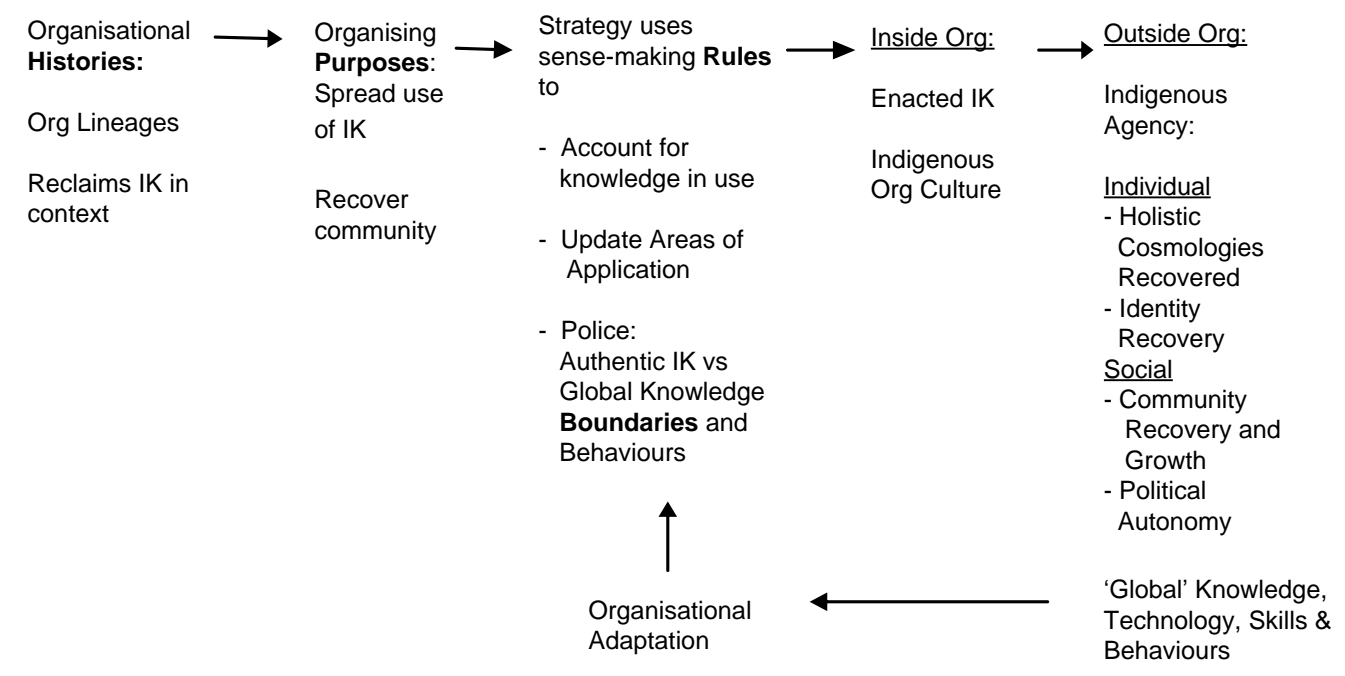

Synthesising the processes found in two case studies, I theorise a process of indigenous organising and a theory of indigenisation whereby the indigenous organisation is interpreted from indigenous knowledge to guide the continued enactment of indigenous knowledge by organisational actors (Figure 16, above). This theory illustrates the key role of indigenous knowledge in underpinning strategy and leadership. I submit that this theory also illustrates and integrates new understandings of knowledge, strategy and leadership in OS. Organisational strategies aim to use indigenous knowledge to underpin organising and to overcome repressive authenticity. Indigenous leadership enables this by vesting these knowledge sets with validity, modelling indigenous knowledge in current contexts. Management ensures the strategy is achieved, by enabling and updating indigenous knowledge in use. Autonomy using sense-making rules provides the means by which the organisation as a whole enacts indigenous 
knowledge to fulfil purposes in changing contexts. In this way indigenous organisational culture is enacted indigenous knowledge inside the organisation. Outside the organisation the enacted strategy is conceived of as indigenous agency which works to fulfil the organisational purposes and rebuild community in the face of fragmenting globalist effects. Indigenous agency is defined as indigenous knowledge which directs the life projects of individuals and which works to reverse the effects of globalist practices and towards the recovery and progression of Indigenous Peoples.

Indigenous organisational strategy places the organisation within its wider context where the enactment of indigenous knowledge ensures its growth, while it is adapting to broader contexts. Sensemaking rules drawing from indigenous knowledge account for the enactment of indigenous knowledge inside the organisation, building indigenous organisational culture. These rules also guide the enactment of indigenous knowledge outside the organisation, which is defined as indigenous agency which works to recover individual indigenous identity, which is the individual enactment of holistic cosmologies. This agency also supports social projects which recover indigenous organisational networks which are embedded within local communities. Indigenous autonomy in these networks attends to political autonomy.

For indigenous organising to remain as valid knowledge, social phenomenology also suggests the ongoing and open horizon of use, in an ever-expanding domain 
of reflexive linguistic application, drawing from local epistemologies. Indigenous organising emphasises the significance of knowledge being proven in the context of application. These organisations must themselves survive in changing contexts, and need to adapt working practices and technologies from each context in order to do so, maintaining and updating organisational and broader social competencies in the process. However I also suggest that this knowledge-context application works indexically to co-create the social contexts through which these 'universal canopies' survive, as theorised by Berger and Luckmann, (1966). What works for these organisations is based on the legitimacy provided by the survival and development of wider communities who construct individual, community and national identity through local epistemologies, and confer guardian status to these organisations as knowledge protectors.

Part of this legitimacy is based on how these organisations empower deep cultural change in social contexts which can err towards reification of deep cultural norms. In this way, the survival and updating of communities supported by these organisations is also maintained despite ongoing external pressures to leave behind such living knowledge as 'irrelevant' or internal pressures to avoid change in the process of knowledge protection. This suggests that indigenous organisations exhibit and build expertise within their own indigenous epistemologies. However openness is also required to the competences and capabilities from outside which might serve the organisation. Such use of 
external competencies does not necessarily imply the loss of any indigenous identity, but demonstrates the ongoing story of adaptation within a holistic cosmology, as exists, and has existed within their own stories from first settler contact.

\subsection{Indigenous Leadership}

Indigenous leadership enables indigenous knowledge to be enacted, from the first forming of purposes onwards. This presupposes proficiency with indigenous knowledge as well as the means to enable organisational members to themselves enact indigenous knowledge in ways that work for them. This illuminates indigenous management practices, which deal with how management ensures the aims and goals of the organisation are met, i.e. how each organisation enacts indigenous knowledge for the furtherance of their own communitiy. This management-worker dialectic may appear to be naively unitarist in its approach but I submit that, with open processes of conflict management as well as the emergence of rotational leadership models, cohesion does appear be maintained between the aims of management and those of the members, to the point where management 'bind the people together' in their growth. As guardians of this knowledge, founding leaders have modelled the integrity they recovered in indigenous knowledge, illustrating in case form how management practices can enable indigenous organising. However, confusion or mixed messages from the leadership can also powerfully limit the application of indigenous knowledge, as the Celtic case reveals. 


\subsubsection{Māori Leadership: Rangatiratanga}

Without the imposition of external notions of 'leadership' on TWoR, their own conception of Rangatira indicates how chiefly actions of leaders bind the people together to ensure their survival and encourage their development. From the formation of organisational purposes onwards, Winiata has represented the actions of TWoR as an example of cohesion and unity, and of possibility in the sense of "a laboratory" of what is possible in the recovery and enactment of Māori knowledge. Displays of unity and cohesion did indeed exist at TWoR in the smallest of interactions through to the largest. He was talked of warmly and as having a great deal of 'mana' by almost all. Of course no organisational site is free from dissensus, and this is no exception. I have sought to represent a flavour of this through the previous chapter, illustrating the tensions and competing agendas that I encountered at TWoR. These tensions cast valuable light on what is delegitimised within these organisations, rendering the research sites open to the selfsame critical gaze with which I engaged the external historic and theoretic sites. However, what was at stake for TWoR was the authentic identity of the organisation itself, and nothing less. To surrender strategic position to socalled external Western knowledge experts would be to admit to the inability of Māori knowledge to engage with a site of importance, the outcome of which would be a direct internal devaluation of Māori knowledge itself and the loss of potential for Māori knowledge to grow in the process. What I experienced instead was the gentle guiding and encouragement from Winiata and other Māori knowledge experts to always be expansive in the use and application of 
Māori knowledge. As Winiata said in one meeting "it is enough for mātauranga Māori that it has been thought by a Māori mind". Referring here to Māori notions of entrepreneurship, Winiata sees no area which is 'off limits' to the conceptualisation and engagement of Māori development. In this way, adaptation to each context is through political and economic engagement with social structures, in the process recasting them as valid territory for the ongoing embellishment of Māori knowledge by Māori people. For the members of TWoR, survival of Māori knowledge presupposes the survival of people as Māori (contrary to whatever external delegitimisations exist). Indigenous identity and indigenous knowledge, in the context of TWoR, are inseparable. The seed sown from the Rangiātea is indeed not lost, but grows in each context for each new generation.

\subsubsection{Celtic Leadership}

Celtic leadership in 2003 defined their functions, beyond the administrative, as allowing the differing voices of the community to emerge, and to guide these voices into a process to support the growth of the community as a whole, such as through the strategic review process. The leader played a strategic role in maintaining the political agendas of the community to wider publics, with whom the community also sought to serve and build community. The leadership of the community was also vocal in challenging some of the traditional stereotypes associated with male-dominated institutional practices and encouraged 
democratic practices within the community, supporting rotational leadership. However, the position of the Celtic leader had significantly changed between 2003 and 2009, delegisimising any claim that the Community was indeed Celtic, and reflecting the pressures that past leaders have managed, and conclusions reached, against which critics have baulked. This starkly illustrates the challenges of managing competing internal and external pressures on what Celtic is, and whether or not the IC is Celtic. I submit this thesis as evidence that themes remain but do not completely define the IC. However, denying their influence completely is equally problematic. Actors within and outside the IC have identity positions intimately bound up with this debate, and they deserve and expect symbolic leadership which can support their own integrative canopies of meaning which encompasses and supports their own Celtic worldviews. That the founding leader and original senior management team of the IC drew so strongly from the Celtic imaginary must suggest there is a rich history which remains to be explored and potentially redefined, without the IC being overwhelmed by it.

\subsubsection{Indigenous Leadership Enabling Knowledge and Organising}

The founding leaders have articulated prophetic visions of how indigenous knowledge can powerfully ensure the survival of the people and contribute to the recovery of holistic cosmologies. As agents of universe-maintenance the leaders modelled both continuity and change of indigenous knowledge, ensuring its adaptation and survival. 
To do this the leadership supports the inter-subjective experience of organisational groups which are given autonomy, defined as decision-making ability by Muehlebach (2001), to create and sustain knowledge-context interaction or 'indigenous organising'. To facilitate this, organisational adaptation occurs through knowledge-context interaction. Through this interaction the leadership encourages actors to reform the organisational purposes and to engage with new areas of concern based on autonomous reality definition. This iterative cycle of organising is renewed through engagement with, and feedback from, organisational members in each context (Figure 17).

Figure 17: The Iterative Cycle of Indigenous Adaptation

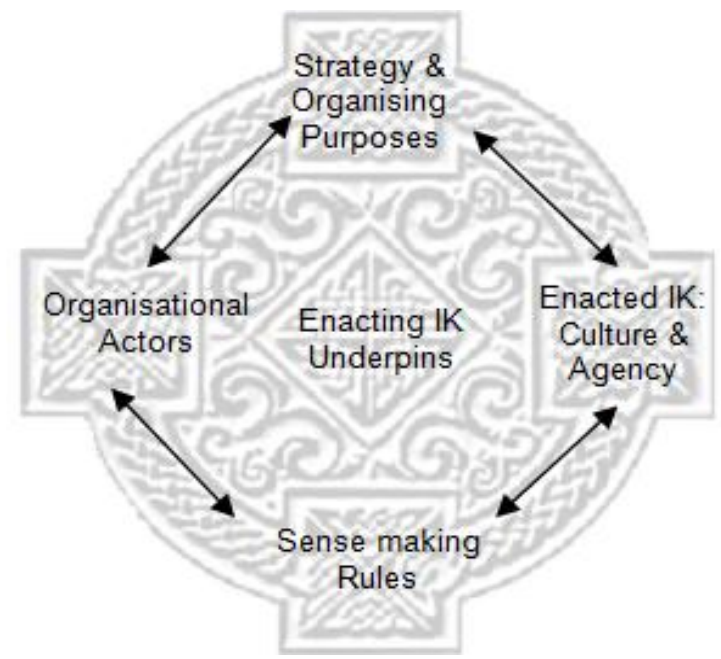

Organisational autonomy is connected to reality definition and contextual adaptation, a relationship also suggested in the constructionist anthropological literature (Fischer, 1999; Muehlebach, 2001), and social phenomenology (Berger and Luckmann, 1966; Schutz, 1967, 1970). I underscore the importance of reality definition and example in case form for its operational dynamics, 
suggesting autonomy as a central feature at the organising level, reflecting the political agendas of the social and national projects within which each case is embedded. That each community can define their own reality is an obvious but necessary condition for the ongoing survival of these realities, through the ongoing construction of and adaptation between the indigenous stock of knowledge and its context of use. Where these realities are denied at the social level, through knowledge de-legitimisation, threats to the ontic existence of the constructed reality must surely follow.

In this way, in giving the departmental groupings of TWoR and the family groups of the IC freedom to define their experience for themselves, the leadership creates the very means by which members' own experience of their contexts changes and updates the organising areas of application. In this sense leadership 'binds the people together' by enabling their growth in and use of indigenous knowledge. This use extends the stock of indigenous knowledge, contributing to its application both within and beyond the indigenous organisation, enabling indigenous reality construction and transmission in the wider milieu, or the expansion of the holistic cosmology itself.

The leadership itself is legitimised by enacting and articulating indigenous knowledge. This requires familiarity with and proximity to these knowledge sets, which may be oral or written, partial or more completely recorded in either folk memory or historic literature. For example, IC members' experience of 
changing social contexts has contributed to updating of the areas of concern. Within TWoR, the experience of students in creating new mātauranga Māori and enacting the Tikanga updates the application and acceptable use, or validation, of this knowledge.

Of course, differences between these indigenous epistemologies affect how they are constituted, emphasising the importance of context. For the IC the Rule does not connect in any intentional way to the ongoing use of Gaelic as a language, but it does connect to the ongoing survival and use of Celtic Christianity. Indeed, many authors take the ongoing Celtic Christian worship as a living example of the indigenous epistemology as it survives in the Western Isles. Within TWoR, the use and development of concepts through and within Te Reo is fundamental to the ongoing survival of Māori as a people as Te Reo Māori gains in resurgence. This resurgence is partly driven by TWoR and their organisational aims and goals.

\subsubsection{Enacting Indigenous Knowledge - Antecedent Conditions}

For indigenous knowledge to underpin organisational action, some antecedent conditions appear to have been required in each case. These conditions illustrate the significance of the founders in forming and shaping organisational purposes in terms of indigenous knowledge. Firstly, and as a theme throughout the thesis, such indigenous knowledge is required to be 'close at hand' in Schutz's (1970) 
terms. For founding leaders and visionaries of indigenous organisations, this has meant intimacy with, and familial connections to, indigenous epistemologies. In the organisations studied here at least, the founders have led the revitalisation of indigenous knowledge by demonstrating a profound belief in the ability of indigenous knowledge to transform individuals and communities. The leaders of both organisations have come from backgrounds where closeness to this knowledge has gone hand-in-hand with an awareness of, and passionate desire to overcome, globalising fragmenting influences. Secondly, such knowledge has been intentionally reconstructed at the organisational formation phase. Ancient indigenous institutions have been willingly drawn on as 'imaginaries' to propel and legitimise organisational visions and 'sacred' mystical origins, legitimising and claiming the 'mythic realm' as the underpinning inspiration for organising. This process has been described in an Australian Aboriginal context (Wolfe, 1999). Lineages and knowledge continuities within ancient and mythic institutions establish and legitimise the organisational purposes, when they are recast in current terms. Such purposes have become significant in the maintenance of meaning-making at the organisational level. These purposes, rather than becoming organisational 'artefacts', become sites for the ongoing renegotiation and reconfiguration of organising activity, ensuring the ongoing validity of purposes in each context. To facilitate this, principles of autonomy support changes to indigenous knowledge through the authentic experience of organisational members as they themselves engage with wider social and political structures, in order to progress their collective agency. 


\subsubsection{Challenges to Indigneous Knowledge}

The validity of indigenous knowledge faces internal and external challenges to their cognitive status and worth. In the Celtic case, internal challenges suggest that any Celtic influence itself does not exist or is marginal at best, despite being present in the activities and actions of the founders, with themes pervading 'The Rule' and so on. Allied to this claim is the threat that indigenous knowledge will overwhelm the missionary focus of the organisation. External challenges suggest that any notion of the reconstructed Celtic to be found through the Community is not authentic enough, indicating notions of repressive authenticity (Banerjee and Linstead, 2004; Wolfe, 1999).

MacLeod initially hindered such flexibility, insisting on a tightly defined purpose within strictly 'traditional' terms, reflecting his own formative Victorian context. Organisational members themselves later sought to recast these purposes through the creation and enlargement of 'The Rule' which was, in 2003, confirmed as the first priority, but always to be applied flexibly to ongoing or new areas of concern. Connections to the Celtic language through the IC have been marginal or non-existent, also reflecting the differing context of organisational formation and MacLeod's own 'Victorian gentleman' heritage. This illustrates colonial or imperial fragmentation in the Scottish context where language, spirituality and identity have been profoundly riven through (amongst other things) Enlightenment historical legacies. While Gaelic is reviving (however fragile this may be), connections between indigenous language and 
indigenous spirituality as expressed through the IC remain to be made, and at present seem highly unlikely. Proponents of the non-indigenous view remain committed to a de-Celtified IC. Through time, the leadership has also come to support this view, much to the chagrin of other members for whom Celtic knowledge continuities are central to notions of both indigeneity and identity with Iona.

In the Māori case, themes of repressive authenticity also pervade. Internal challenges to knowledge validity seek to suggest mātauranga Māori 'doesn't work' beyond the confines of the institution, that Māori knowledge should be kept 'on the marae'. These claims are forcefully made in the external context as are challenges to the notions of Māori as a people as well as challenges to the cognitive status and worth of mātauranga Māori. Against these challenges in the Māori context the Tumuaki has supported the fluidity and expansive reconceptualisation of knowledge interwoven with the recovery of Māori language.

\subsubsection{Indigenisation in the Context of the Global}

The underpinning assumptions of two indigenous organisations have very different outcomes in relation to Indigenous Peoples than do globalist practices which have been theorised to dislocate indigenous knowledge and instead promote and promulgate individualism. 
The fragmenting effects of globalist and neo-colonial practices are represented schematically below, where a colonial 'globe' acts to separate indigenous actors (and their identity) from their community, land and indigenous knowledge (IK) (Figure 18). Context-derived examples of these fragmenting effects are presented in Table 13 (over). As a counter to the above effects, indigenisation describes and accounts for the authentic recovery of holistic cosmologies and the social projects which overcome alienation.

Figure 18: Effects of Globalist Practices on Indigenous Knowledge

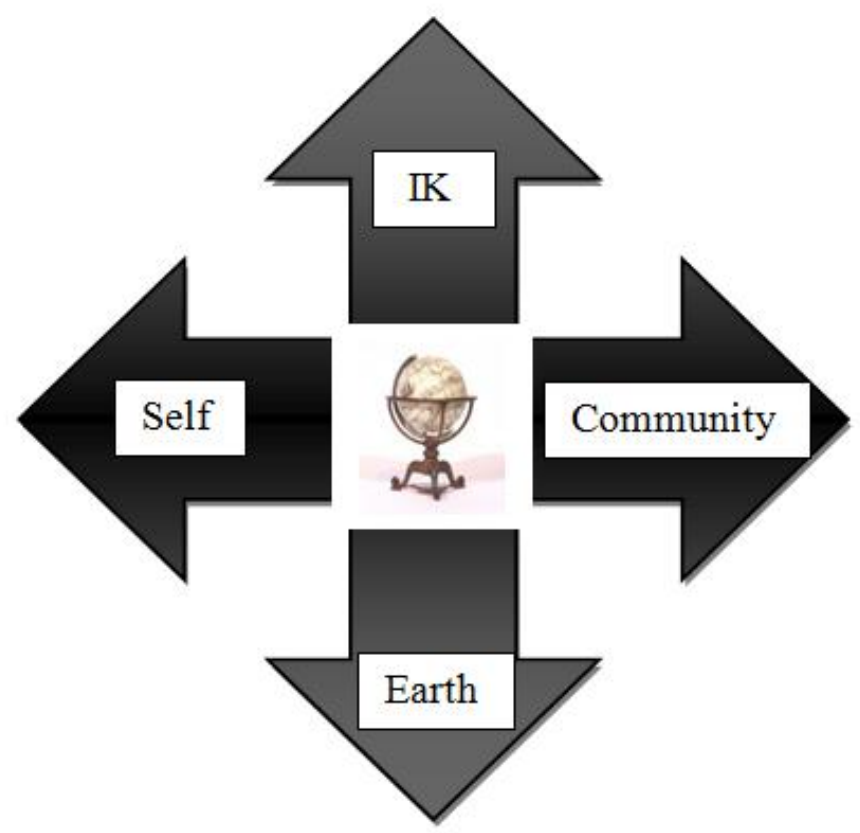


Table 13: Effects of Globalist Practices on Two Indigenous Communities

\begin{tabular}{|c|c|c|c|c|}
\hline $\begin{array}{l}\text { Key } \\
\text { Element }\end{array}$ & Globalist Practice & $\begin{array}{l}\text { Effect on Indigenous } \\
\text { Community }\end{array}$ & Māori Example & Celtic Example \\
\hline IK & $\begin{array}{l} \\
\text { Language control. } \\
\text { English as } \\
\text { 'universal } \\
\text { language'. }\end{array}$ & $\begin{array}{l}\text { Devalues IK as } \\
\text { 'mythology', science } \\
\text { and rationality is } \\
\text { 'what works'. }\end{array}$ & $\begin{array}{l}\text { Tohunga Act } \\
\text { makes Māori } \\
\text { knowledge experts } \\
\text { illegal, Māori seen } \\
\text { as 'savage' in need } \\
\text { of English } \\
\text { education. } \\
\text { Māori language } \\
\text { legislated against } \\
\text { until 1970s. }\end{array}$ & $\begin{array}{l}\text { Celts seen as } \\
\text { uncivilised } \\
\text { 'Barbarian'; } \\
\text { 'feckless and dim' } \\
\text { and 'the lazy and } \\
\text { backwards North' } \\
\text { in need of } \\
\text { civilising. } \\
\text { Gaelic language } \\
\text { legislated against. }\end{array}$ \\
\hline Self & $\begin{array}{l}\text { Consumerism; } \\
\text { Private self gain. }\end{array}$ & $\begin{array}{l}\text { Self formed in } \\
\text { relation to economy } \\
\text { as resource or } \\
\text { consumer. }\end{array}$ & $\begin{array}{l}\text { Māori 'taught' } \\
\text { greed by early } \\
\text { colonial settlers; } \\
\text { Māori 'taonga' or } \\
\text { treasures } \\
\text { appropriated for } \\
\text { colonial gain. }\end{array}$ & $\begin{array}{l}\text { Clan chiefs } \\
\text { eschewed clan } \\
\text { obligations in } \\
\text { favour of new } \\
\text { economic } \\
\text { orthodoxy of } \\
\text { individual wealth. }\end{array}$ \\
\hline Community & Individualism. & $\begin{array}{l}\text { Fragments reciprocal } \\
\text { ties. Asserts rights } \\
\text { and property of } \\
\text { individual. }\end{array}$ & $\begin{array}{l}\text { Māori land resold } \\
\text { as individual } \\
\text { holdings. Early } \\
\text { vote limited to } \\
\text { those who 'owned' } \\
\text { land. Tribal } \\
\text { ownership negated. }\end{array}$ & $\begin{array}{l}\text { Highlands and } \\
\text { Islands communal } \\
\text { structures replaced } \\
\text { with individual } \\
\text { smallholdings. }\end{array}$ \\
\hline Earth & Material resource. & $\begin{array}{l}\text { Removes ancient } \\
\text { connections to land } \\
\text { Creates land as } \\
\text { commodity. }\end{array}$ & $\begin{array}{l}\text { Land Wars a result } \\
\text { of forced land } \\
\text { sales. Many tribal } \\
\text { lands sold to } \\
\text { colonial settlers. }\end{array}$ & $\begin{array}{l}\text { Highland } \\
\text { Clearances in Mull } \\
\text { and elsewhere } \\
\text { cleared crofting } \\
\text { culture to make } \\
\text { way for more } \\
\text { profitable options. }\end{array}$ \\
\hline
\end{tabular}

I submit that processes of indigenisation encourage the healing and reordering of identity within recovered cosmologies and connections previously rendered separate by globalist practices. This theory describes how these cosmologies and social projects fully supports the orientation to place that has been identified as a critical factor in rejecting globalist practices (Ralston Saul, 2005). 
The four key elements of indigenisation are Indigenous Cosmology, self as Indigenous Peoples, Community and Earth, illustrated below. The effects of indigenisation on each key element are presented in Table 14 and their interactions are shown in Figure 19 (below).

Table 14: Indigenous Knowledge Effects on Indigenous Peoples

\begin{tabular}{|c|c|c|}
\hline Key Element & Indigenous knowledge & Effect on Indigenous Peoples \\
\hline $\begin{array}{l}\text { Indigenous } \\
\text { Cosmology }\end{array}$ & $\begin{array}{l}\text { Recovers cosmology as working } \\
\text { knowledge }\end{array}$ & $\begin{array}{l}\text { Worldview regains 'nobility' and } \\
\text { pride; encourages language } \\
\text { recovery }\end{array}$ \\
\hline $\begin{array}{l}\text { Self- } \\
\text { Indigenous } \\
\text { Peoples }\end{array}$ & $\begin{array}{l}\text { Sacred essence of being in } \\
\text { relation to cosmology; } \\
\text { community and creation. }\end{array}$ & $\begin{array}{l}\text { Creates ethical and moral } \\
\text { framework for behaviour; lessens } \\
\text { negative behaviours }\end{array}$ \\
\hline Community & $\begin{array}{l}\text { Source of self identity including } \\
\text { family continuity; location of } \\
\text { status }\end{array}$ & $\begin{array}{l}\text { Builds connection to and } \\
\text { strength of community }\end{array}$ \\
\hline Earth & $\begin{array}{l}\text { Guardians and stewards of } \\
\text { creation. Identity profoundly } \\
\text { connected to place }\end{array}$ & $\begin{array}{l}\text { Relation of self and community } \\
\text { held in relation to place and } \\
\text { cosmology }\end{array}$ \\
\hline
\end{tabular}

Figure 19: Indigenisation in Globalising Contexts

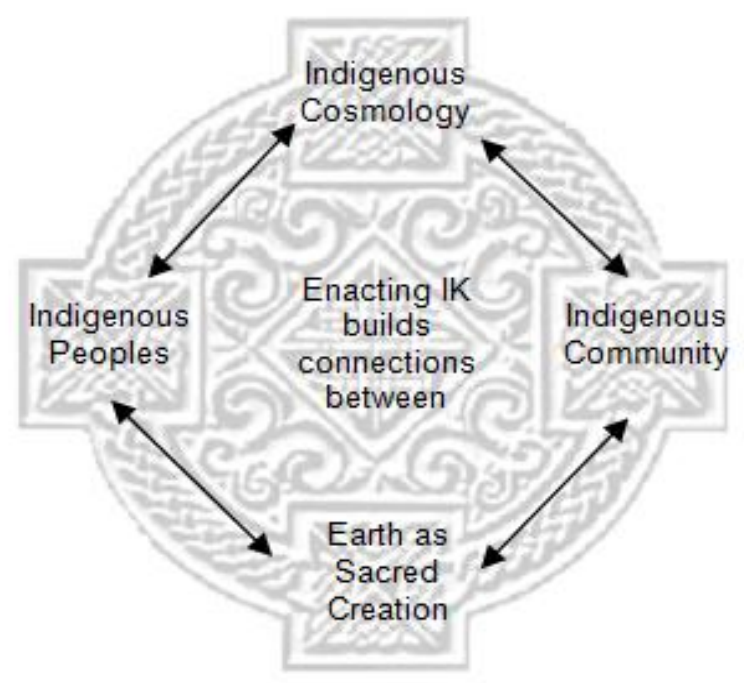


Indigenisation reorients individuals and groups to their own knowledge, histories and communitarian projects which culminate in the search for national autonomy. That these groups have used globalisation's technology to do this does not reduce the effects of globalist practices on holistic cosmologies. Indeed, the level of investment and effort required to recover cosmologies and overcome globalist practices indicates their pervasive power and reach. The contrasting assumptions of indigenisation and globalisation are compared in Table 15 below.

Table 15: Assumptions of Indigenisation and Globalisation Compared

\begin{tabular}{|c|c|c|c|}
\hline $\begin{array}{l}\text { Organising } \\
\text { Context }\end{array}$ & Māori & Celtic & Global \\
\hline $\begin{array}{l}\text { Organising } \\
\text { Knowledge }\end{array}$ & Mātauranga Māori & $\begin{array}{l}\text { Celtic / Benedictine } \\
\text { 'Rule' }\end{array}$ & $\begin{array}{l}\text { Consumerist } \\
\text { Individualist (Friedman, } \\
\text { 1994a,b; Ohmae, } \\
\text { 1995a,b) }\end{array}$ \\
\hline $\begin{array}{l}\text { Situated } \\
\text { Organising } \\
\text { Actions }\end{array}$ & $\begin{array}{l}\text { builds positive identity } \\
\text { builds iwi and hapu } \\
\text { social development } \\
\text { develops autonomous } \\
\text { national structures }\end{array}$ & $\begin{array}{l}\text { builds positive identity } \\
\text { builds community } \\
\text { capacities and } \\
\text { development } \\
\text { develops autonomous } \\
\text { national structures }\end{array}$ & $\begin{array}{l}\text { fragments identity } \\
\text { devalues community and } \\
\text { replaces with } \\
\text { individualistic motives } \\
\text { (Friedman,1994b) }\end{array}$ \\
\hline $\begin{array}{l}\text { Relationship to } \\
\text { Self }\end{array}$ & $\begin{array}{l}\text { Defines self in relation } \\
\text { to whanau, iwi and hapu, } \\
\text { within a Māori } \\
\text { cosmology }\end{array}$ & $\begin{array}{l}\text { Defines self in relation to } \\
\text { sacred community, and } \\
\text { planet within Celtic } \\
\text { Christian cosmology }\end{array}$ & $\begin{array}{l}\text { Defining self in relation } \\
\text { to cohort product } \\
\text { affiliation and Western } \\
\text { notions of 'development' } \\
\text { (Friedman,1994a,b; } \\
\text { Ohmae, 1995a,b) }\end{array}$ \\
\hline $\begin{array}{l}\text { Relationship to } \\
\text { Context }\end{array}$ & $\begin{array}{l}\text { Builds intergenerational } \\
\text { affiliation and Māori } \\
\text { knowledge enactment } \\
\text { and transmission } \\
\text { Reflexively constructs } \\
\text { and strengthens } \\
\text { Māori capability } \\
\text { building and search for } \\
\text { Māori power sharing }\end{array}$ & $\begin{array}{l}\text { Builds community and } \\
\text { social affiliation and } \\
\text { Celtic knowledge } \\
\text { enactment and } \\
\text { transmission } \\
\text { Reflexively constructs } \\
\text { and strengthens Scottish } \\
\text { 'nationhood' and } \\
\text { autonomy }\end{array}$ & $\begin{array}{l}\text { Devalues context \& } \\
\text { replaces false claims of } \\
\text { homogeneity } \\
\text { (Ohmae,1995a,b). } \\
\text { Replaces devalued } \\
\text { indigenous with the } \\
\text { always incomplete need } \\
\text { for 'global' knowledge } \\
\text { and products (Banerjee } \\
\text { and Linstead, 2001, } \\
\text { 2004; Friedman 1994a; } \\
\text { Jaya, 2001). }\end{array}$ \\
\hline
\end{tabular}


Indigenisation describes the orientation towards and enactment of indigenous knowledge. On a broader canvas, supra-organisational processes attend to the greater recovery and enactment of indigenous holistic cosmologies. Indigenisation as a process more adequately unifies and describes not only the construction of indigenous identity with reference to indigenous knowledge, but also how this knowledge locates and supports social projects in which the locus of identity is more firmly grounded in holistic cosmologies than the fragmenting effects of consumerism which Friedman (1994a,b) has identified.

However, much attention has been paid to the questioning of large scale economic doxa as the sole vehicle of development (Lash and Friedman, 1992; Ralston Saul, 2005). Indigenisation suggests that rather than the wholesale abandonment of economic practices, it is the adoption of economic practices within these recovered cosmologies which enables development, and, further, that economic development alone continues to fragment indigenous knowledge. The implications of this may be that development agencies and those involved with Indigenous Peoples may need to consider how best to enable the recovery and enactment of indigenous knowledge, before and beyond the economic imperatives alone (Banerjee and Linstead, 2001; Henare and Lips-Wiersma, 2002). That notions of autonomy are encouraged by these cases is a principle to be understood if more effective development partnerships are to be attempted. Such a position is a radical reworking of previous colonial and assimilationist policy (Wolfe, 1999). Indigenous community recovery may also help to resolve 
what Ralston Saul (2005, p.259) argues are the effects of near sighted historic colonialism which has helped to create negative nationalism. Further this theory of indigenisation more fully details the processes that are involved with the 'identification with place' (Ralston Saul, 2005 p.212) which often remains obscured within notions of nationalism alone. Instead, indigenous knowledge as detailed in these cases contains many moral and ethical principles which guide behaviour towards not just those people and projects within the community and locality, but projects at the social level and beyond.

\subsection{Credibility Criteria of Research Findings}

This thesis has sought to address the stated credibility criteria of authenticity, plausibility, criticality and reflexivity, as promulgated by other exemplar naturalistic theorists (Altheide and Johnson, 1998; Golden-Biddle and Locke, 1993). I submit this research has critically challenged traditional definitions and applications of indigeneity. Assumptions of globalist practices have also been interrogated, to reveal their effects on indigenous holistic cosmologies. To achieve this, the insights from a wide variety of authors have been integrated as artefacts which have aided this research project in each context.

From these insights, I have sought to develop a working theory of indigenous organising which illuminates how actors use indigenous knowledge to recover indigenous identity and underpin organising. This agency redevelops the concept 
of community in the face of globalist practices whose logics continually seek to fragment. Using this theory I have sought to authentically convey the vitality of everyday life in the research settings, illustrating the living dynamic realities, aspirations and visions constructed by each community, and the external and internal pressures they experience and which they need to manage as part of their organising processes. However it is the views of the communites themselves that adjudicate authenticity and pausibility.

With regards to 'fit', a presentation of the theory to the academic board of TWoR on October 2006 resulted in the Tumuaki, Winiata, stating that "if the test of a good theory is that it is recognisable to the people, then this is a good theory." Others commented that while the model presented (Figure 14, p.323) of Māori organising may seem straightforward, it has taken over 25 years of deepening confidence to get to this point, which still remains a beginning point. Others suggested that if the theory remains descriptive and not prescriptive, then it may indeed be useful to other indigenous communities, fulfilling Kaupapa Māori guidelines (L. Smith, 1999, 2000). However, the theory was not without criticisms. Members commented that knowledge continuities "go much further back" than Rāngiatea, and critical comments challenged how notions of "cultural logics' can 'fit' to the experience of teaching Mātauranga Māori, with a prominent member commenting he was: "off now to teach 'cultural logics' to the kids at the Kura". Despite these criticisms, I was invited to formally present the first full public articulation of the theory at a conference: 'Ma te rango te 
waka ka rere: Exploring a Kaupapa Māori Organisational Framework', at TWoR on the $3^{\text {rd }}$ and 4 th of November, 2006, which also first published the full theory (Finlay, 2006).

In 2009 an identical Power Point presentation as delivered to TWoR was presented to the senior leadership leam of the IC, with Galloway as current IC leader and to previous leaders, when I was able to return to the UK. While much of the content was strongly supported, any notion that the IC was and is Celtic was strongly rejected. This view directly contrasts with the data gathered from Galloway in 2003, and illustrates the pressures on the IC from those from within and outside who challenge how Celtic they are. As Galloway put it in 2009, "like repressive authenticity, we are continually forced to fit into an idea of being Celtic that we are not." I was cognisant that the session included the previous leader, who also maintained the same view, which was consistent with his data gathered in 2003. This added evidence to the defensive stance that IC leaders have to take over time, as illustrated by Galloway's 2009 position, which contrasts directly with her early views as new leader in 2003. My hope remains that, with time, the IC can resolve this tension by accepting and celebrating its own history and tradition, without being constrained or overwhelmed by it.

I have sought to represent the actors' point of view in each case. But like any 'pure fit' between one researcher's interpretations, and the life world of others they seek to reflect, the fit remains inevitably incomplete, since changes in the 
research context also occur over time, as the feedback received from both cases illustrates (Holstein and Gubrium, 2000; Schutz, 1967). However I do claim an authentic case study representation of the material to which I was given access at the time of the research. It remains for the reader to judge the coherence of this interpretation and the conclusions drawn.

\subsection{Conclusion}

This thesis has implications for the communities studied and also for the specific OS researchers and wider literature covered in Chapter 2. For the communities studied this thesis has sought to portray a supportive analysis of the working uses of indigenous knowledge. These organisations do not require any external legitimisation for the journeys they have undertaken. Nor does this analysis fully capture the breadth of their work. Instead I have sought to authentically portray a snapshot of the vitality of life in each of these two settings, with competing and diverse views of both knowledge and indigeneity.

The IC sits in a difficult position. If the tensions both within and outside the organisation are to be resolved, my suggestions below may increase coherence. Their key challenge for the IC remains how to accept their own Celtic history without being overwhelmed, not by globalisation, but by the resurgence of interest in things Celtic. As the current tenants on the Isle of Iona, to deny this Celtic history and tradition seems to cause more challenges than to graciously accept its influence, however it is defined, and to move forward to new 
articulations of what it might mean in a missionary Christian context. By comparison, TWoR has maintained a much stronger understanding of its own identity and purpose, supported by passionate advocates who keenly police Māori knowledge in use but who are also aware of its fragility. They are worthy knowledge guardians (M.Durie, personal communication, March $15^{\text {th }}, 2002$ ).

At the individual level I theorise that polyvocal notions of indigeneity are located in continuity with ancient knowledge from mystic origins in both the Celtic and Māori contexts, as has been suggested by Wolfe (1999) in the Australian Aboriginal context. Both of these knowledge continuities have been subject to fragmenting effects of globalist practices, which are interwoven with imperialism and colonialism, and which supports the work of Banerjee (1999) and Banerjee and Linstead (2004).

Despite this fragmentation, each indigenous organisation has provided guiding principles which encourage the reconnection to indigenous holistic cosmologies, which have integrative properties (Friedman, 1994a), and draw from holistic spiritualities (Henare and Lips-Wiersma 2002; Whiteman and Cooper, 2000).

Enacting this knowledge, with support from rules and boundaries, encourages the powerful reconstruction of individual indigenous identity. Life projects of members enact indigenous agency which powerfully connects to land and strategically builds community and political projects, reflecting an authentic and 
strategic essence (Friedman, 1994a; Muehlebach, 2001). These political projects support the development of national imaginaries, as Anderson (1983) has theorised. None of these strategic essentialisms or identity claims are fragmented in these contexts, unlike in the postcolonial setting as documented by Calas and Smircich (1999) and Spivak (1987ab). Consciousness is neither wholly or fully constructed by the coloniser but based on indigenous knowledge continuities, which require ongoing enactment to remain as valid working knowledge. This suggests that indigenous consciousness is fully recoverable but subject to ongoing policing to ensure that indigenous knowledge is referred to and grown in an open horizon of use. These practices are supported by principles within social phenomenology (Schutz, 1967, 1970, 1973) and described within the definition of cultural logics in the Mayan context (Fischer, 1999).

At the organisational level, the founding leadership in the Māori and Celtic contexts have not been overwhelmed by globalising forces in the same way as Banerjee (1999) found in the Australian Aboriginal context. Instead they held a powerful belief in the legitimacy of indigenous knowledge and a deep sense of connection to the land. This concurs with the findings of Whiteman and Cooper (2000) in the Cree context. Their early visions and enabling strategies suggest that autonomy and social justice are key themes, illustrating indigenous leadership practices which can continually overcome ongoing globalising forces. These are indigenous biographies which balance a profound love of the land and ecological and covenantal principles, as Fischer (1999) found in the Mayan 
context, with an equally powerful awareness of fragmenting globalising effects, as Banerjee (1999) has found in the Australian Aboriginal context. These effects can be mediated and overcome through an expansive enactment of indigenous knowledge, as an exemplary assessment of indigenous leadership, as Jaya (2001) has called for, and illustrating practices which overcomes repressive authenticity, as Wolfe (1999) found in the Australian Aboriginal context.

Processes of indigenous organising illustrate how leaders provide strategies for indigenous knowledge to coordinate action across the organisation as a whole, confirming and extending the insights of Henare and Lips-Wiersma (2002) and Wolfgramm (2001) who suggest that Māori organisations contain principles of spirituality which draw from the wider context. This research shows how indigenous leaders can also construct the wider context and their holistic cosmologies through their symbolic leadership actions. The in-depth case studies illustrate a whare wānanga that Henry and Pene and I (Finlay, 2001) introduced to the OS community in 2001, and present a full case study of the IC, as a Celtic organisation, which was introduced to the strategy community by also Johnson and Scholes and myself (Finlay,2001) in 2001, and to the OS community more fully in my own emerging analyses (Finlay, 2001, 2002, 2003, 2005, 2006, 2008). This work also illustrates and integrates new understandings of knowledge, strategy and leadership in OS. 
At the social level, the processes of organisational adaptation suggest that Wolfgramm's (2001) hybrid traditionalists can reduce cultural dissonance and increase the social contract through adapting tools and techniques which are useful to the indigenous organisation, if policing and accounting strategies maintain indigenous knowledge as the central organisational kaupapa or purpose. In the Celtic case, the later leadership lost the central focus and confidence in the Celtic imaginary, creating cultural dissonance and tension as Wolgramm (2001) suggests. These cases also theorise non-capitalist forms of globalisation (Banerjee and Linstead, 2001).

My findings also suggest that the globalist dialectic continues to powerfully fragment and delegitimise indigenous knowledge. Economic and migratory pressures have historically affected indigenous rural communities, alongside an expanding global media which continues the fragmentation of indigenous language, deepening and legitimising globalist logics as 'what works' (Banerjee and Linstead, 2001, 2004; Friedman, 1994b). This continuity of neocolonial 'positional superiority' is aided and abetted by the increase in speed, reach and intensity of knowledge networks under the rubric of globalisation.

In spite of this, indigenous communities have quickly adapted new technologies to develop their own projects. Here, new media present many opportunities to enable the recovery and use of indigenous knowledge and language. Further, new technology and the internet have allowed for 'glocalisation' or connections 
between indigenous communities at the national and international levels (Gopal Willis and Gopal, 1999; Robertson, 1995). The internet also facilitates the ability to search for, and development of indigenous identity such as Māori researching whakapapa through online genealogy records, and for the storage and distribution of oral taonga or histories and records.

Despite the almost overwhelming penetration of globalist logics, intentional cooption of technology does aid in the recovery of indigenous knowledge. Whilst certain globalist practices, knowledge and skills are incorporated into the operational and environmental routines of the organisation, rules and accountability structures ensure that indigenous knowledge remains the dominant knowledge set. The recovery and enactment of holistic cosmologies directly reverses the fragmentation from globalist practices described in Chapter 2. Within these case studies, actors' use of indigenous knowledge in each context radically recovers the profound connections to their holistic cosmologies, land and communities which were riven by globalist and colonial or imperial practices. Processes of indigenisation illustrate actors' reorientation away from the ongoing effects of globalist practices, and towards the orientation of local ancient knowledge sets, explaining how indigenous knowledge and identity is enacted and updated in each context.

Further, indigenisation details profound 'senses of belonging' (Ralston Saul, 2005 p.280) which adapts and extends indigenous knowledge in changing 
contexts. While many theorists ascribe components of indigenous knowledge in fixed pre-modernist terms, processes within indigenisation recover and enact multiple ontic realities, effectively updating indigenous knowledge whilst coupling to carefully selected globalist processes and practices. Thus, while containing many of the features of pre-modern societies such as integrative canopies of meaning indigenisation also incorporates features of both modernist and post-modern landscapes. Indeed, the continuities and adaptabilities of indigenous knowledge suggest that future features of developing social landscapes will also be adapted to, if the breadth and depth of holistic cosmologies are transmitted through future generations. In this sense, indigenous organisations transcend etically imposed academic notions (Alvarado, 1996).

Globalist practices have unquestionably had a profoundly negative effect on indigenous knowledge and identity, which has been subsumed under economic solutions of development. These solutions have profoundly fragmented holistic cosmologies, to be replaced with consumerism. Economic logics have been used to legitimise the separation of indigenous people from communally held land and have created notions of individualism which have delegitimised holistic cosmologies and worked to separate connections to community (Banerjee, 1999; Banerjee and Linstead, 2001; Friedman, 1994a,b; Lash and Friedman, 1992; Ralston Saul, 2004, 2005). 
If the claims made by theorists are warranted, namely that globalist practices have reached their zenith and that differing worldviews are re-emerging, then this thesis conditionally supports, illustrates and extends these claims, illustrating the dialectic as a whole (Friedman, 1994ab; Lash and Friedman, 1992; Ralston Saul, 2004, 2005). While Friedman (1994b, p.215) has theorised how modernity dissolves pre-modern social structures and commercializes the network of obligations of kinship, indigenisation describes how indigenous social structures are reclaimed within broader cosmologies. Indigenous knowledge reorders the network of obligations displaying currencies contained in cultural logics which preserve and enhance metaphysical balance (Fischer, 1999 p.488). Hence, action is based on what is good for community, creation and cosmology, rather than notions of private self gain. This evidence suggests globalist practices remain a pervasive influence, but one overcome by the effects of indigenous knowledge. However, the insidious presence of globalist practices seems a long way from completely dissipating, given the undeniable scope of the globalist project, as Banerjee and Linstead (2001) caution. It remains to be seen how many interconnected indigenous cosmologies themselves recover, an assessment well beyond the remit of a single thesis, however well the full dialectic is described. Table 16 (over) summarises the contribution of this thesis at individual, organisation and social levels. 
Table 16: Summary of Thesis Contribution at Three Levels

\begin{tabular}{|c|c|}
\hline $\begin{array}{l}\text { Level: } \\
\text { Individual }\end{array}$ & Specific Topic of Contribution \\
\hline 1. & $\begin{array}{l}\text { Polyvocal definitions of indigeneity are in continuity with ancient knowledge from } \\
\text { mystic origins (Wolfe, 1999). Both of these knowledge continuities have been } \\
\text { subject to fragmenting effects of globalist, colonial and imperial practices } \\
\text { (Banerjee, 1999, Banerjee and Linstead, 2004). }\end{array}$ \\
\hline 2. & $\begin{array}{l}\text { Each indigenous organisation provides guiding principles which encourage } \\
\text { individuals reconnection to indigenous holistic cosmologies which have integrative } \\
\text { properties (Friedman, 1994a), and draw from holistic spiritualities (Henare and } \\
\text { Lips-Wiersma 2002; Whiteman and Cooper, 2000). }\end{array}$ \\
\hline 3. & $\begin{array}{l}\text { Individual indigenous identity is reconstructed by enacting indigenous knowledge } \\
\text { with support from rules and boundaries. Political projects build community and } \\
\text { national political agency, reflecting an authentic and strategic essence (Friedman, } \\
\text { 1994a; Muehlebach, 2001) and building a national indigenous imaginary } \\
\text { (Anderson, 1983). }\end{array}$ \\
\hline 4. & $\begin{array}{l}\text { Unlike the postcolonial setting (Calas and Smircich, 1999; Spivak, 1987a,b) } \\
\text { consciousness is neither wholly or in part constructed by the coloniser, but based on } \\
\text { indigenous knowledge continuities. }\end{array}$ \\
\hline 5. & $\begin{array}{l}\text { Indigenous consciousness is fully recoverable but subject to ongoing policing to } \\
\text { ensure that indigenous knowledge is referred to and grown in an open horizon of } \\
\text { use (Fischer, 1999; Schutz, 1967, 1970, 1973). }\end{array}$ \\
\hline \multicolumn{2}{|r|}{ (2) } \\
\hline 6. & $\begin{array}{l}\text { The founding leadership held a powerful belief in the legitimacy of indigenous } \\
\text { knowledge and a deep sense of connection to the land (Whiteman and Cooper, } \\
\text { 2000). }\end{array}$ \\
\hline 7. & $\begin{array}{l}\text { Indigenous leadership practices can continually overcome ongoing globalising } \\
\text { forces, including those of repressive authenticity (Banerjee and Linstead, 2004, } \\
\text { Wolfe, 1999) through expansive enactment of indigenous knowledge. }\end{array}$ \\
\hline 8. & $\begin{array}{l}\text { Indigenous organising illustrates how leaders provide strategies for indigenous } \\
\text { knowledge to coordinate action across the organisation as a whole (Henare and } \\
\text { Lips-Wiersma, 2002; Wolfgramm, 2001). }\end{array}$ \\
\hline 9. & $\begin{array}{l}\text { Indigenous organising illustrates how indigenous leaders construct holistic } \\
\text { cosmologies through symbolic leadership actions. }\end{array}$ \\
\hline 10. & $\begin{array}{l}\text { In-depth case studies illustrate a whare wānanga (Henry and Pene, 2001) and a } \\
\text { Celtic organisation (Johnson and Scholes, 2001). }\end{array}$ \\
\hline 11. & $\begin{array}{l}\text { Indigenous organising illustrates and integrates new understandings of knowledge, } \\
\text { strategy and leadership in OS. }\end{array}$ \\
\hline \multicolumn{2}{|l|}{ Social } \\
\hline 12. & $\begin{array}{l}\text { Wolfgramm's (2001) hybrid traditionalists can reduce cultural dissonance and } \\
\text { increase the social contract through organisational adaptation tools and techniques } \\
\text { which are useful to the indigenous organisation. Loss of confidence in indigenous } \\
\text { knowledge increases cultural dissonance and tension. }\end{array}$ \\
\hline 13. & $\begin{array}{l}\text { Indigenous organising theorises non-capitalist forms of globalisation (Banerjee and } \\
\text { Linstead, 2001). }\end{array}$ \\
\hline 14. & $\begin{array}{l}\text { Globalist logics continue to powerfully fragment and delegitimise indigenous } \\
\text { knowledge, aided by the increase in speed intensity and reach of new technologies } \\
\text { (Banerjee and Linstead, 2001). }\end{array}$ \\
\hline 15. & $\begin{array}{l}\text { Indigenous communities have quickly adapted new technologies to develop their } \\
\text { own projects enabling 'glocalisation' (Gopal Willis and Gopal, 1999; Robertson, } \\
\text { 1995). Technology enables the storage and distribution of indigenous treasures. }\end{array}$ \\
\hline
\end{tabular}




\begin{tabular}{|c|l|}
\hline 16. & $\begin{array}{l}\text { Processes of indigenisation illustrate actors' reorientation away from the ongoing } \\
\text { effects of globalist practices, and towards the orientation of local ancient } \\
\text { knowledge sets, explaining how indigenous knowledge and identity is enacted and } \\
\text { updated in each context. }\end{array}$ \\
\hline 17. & $\begin{array}{l}\text { Indigenisation details profound 'senses of belonging' which adapts and extends } \\
\text { indigenous knowledge in changing contexts (Ralston Saul, 2005). }\end{array}$ \\
\hline 18. & $\begin{array}{l}\text { Indigenisation recovers and enact multiple ontic realities, updating indigenous } \\
\text { knowledge whilst coupling to carefully selected globalist processes and practices. }\end{array}$ \\
\hline 19. & $\begin{array}{l}\text { Economic logics have separated indigenous people from land, notions of } \\
\text { individualism have delegitimised holistic cosmologies and worked to separate } \\
\text { connections to community (Banerjee, 1999; Banerjee and Linstead, 2001; } \\
\text { Friedman, 1994a,b; Lash and Friedman, 1992; Ralston Saul, 2004, 2005). }\end{array}$ \\
\hline 20. & $\begin{array}{l}\text { Globalist practices have reached their zenith and that differing worldviews are re- } \\
\text { emerging (Friedman, 1994ab; Lash and Friedman, 1992; Ralston Saul, 2004, 2005). }\end{array}$ \\
\hline 21. & $\begin{array}{l}\text { Indigenous knowledge reorders the network of obligations displaying currencies } \\
\text { contained in cultural logics which preserve and enhance metaphysical balance } \\
\text { (Fischer, 1999 p.488) }\end{array}$ \\
\hline
\end{tabular}

\subsection{Limitations of the Research}

In line with social phenomenology and constructionist OS researchers, this thesis has not proposed a fixed definition of indigeneity to be applied universally, as a potential limitation of the research. Instead, a process-based approach has sought to illustrate how local actors draw from ancient and local but previously fragmented holistic cosmologies to rebuild positive identity, agency and the organisation, in the context of globalising practices.

I acknowledge my own self application of the definitions of indigeneity I have used for pragmatic purposes in this project. This is how social phenomenology defines knowledge, and also assumes that these processes are common to all groups. I submit that there is merit in acknowledging our identities, and communities are in part formed from the knowledge transmitted from our local contexts and in part from how we define ourselves as individuals. Free will dictates which identities serve our own lifeprojects, and the effects of our 
choices on us (Schutz, 1970). However, I also acknowledge that not all groups would commonly agree to a collective self-definition of indigeneity. Neither of the two groups studied in this research did. That does not limit the application of this research, but sharpens its contribution. Again, without a single definition implied or expected, a constructionist focus shifts to asking who is defining indigeneity, for whom, and for what purpose. This illuminates the tacit knowledge and lifeprojects which build the political and practical positioning of actors who seek to define indigeneity, and the processes of consensus building, and as outlined in Chapter 1, and elaborated on in Chapters 2, 3 and 4. I submit my own researcher positioning as sufficient explanation and justification for this self-defined use, as recommended by Māori researchers (L. Smith, 1999), and have included constructionist assessments of indigeneity in Tables 6, 7, 10 and 11.

Having established my position, I reflect on its limits. My self understanding of my own Celtic knowledge tradition has been immeasurably enriched through a culturally safe engagement with tangata whenua. I have not claimed tangata whenua status, nor would I do so. I have (hopefully) built a mana-enhancing relationship with tangata whenua, and seek to continue to do so.

I am indigenous to the West Coast of Scotland, and can trace my genealogy back to the proud Clan Farquarson. I yearned for a reconnection to a Celtic holistic cosmology and experienced a recovering of my own identity through enacting 
lifeprojects in the context of the IC, with boundaries. I have learned how Celtic knowledge has been inter-generationally transmitted and updated, and have applied the working definitions of Friedman (1994a,b) and Fischer (1999) to my own history.

As with all knowledge and definitions, there are gaps. These definitions, along with the definitions of Celtic, did not reflect the views of all the members or guests of the IC. Indeed, I have sought to represent a full flavour of the discord and confusion in seeking a 'standard or universal' definition of Celtic, and of indigeneity. Nor can these definitions contain or fully reflect the reality of my own family history and experience, let alone anyone else's. Can they pragmatically help? For the purposes of this project, I can say yes.

I have found genuine learning in reflecting on both Celtic and Māori knowledge traditions, and how these are being used in new ways. Could we share a dialogue by reflecting on our common experiences of our own knowledge traditions, aspirations and visions? I would submit that this thesis is evidence of the deep face-to-face dialogues that can develop, when culturally safe practices are followed, as has been suggested eslewhere (L. Smith, 1999). These protocols protect the mana of all parties. The literature in Chapter 4 has evidenced the negative results of working without protocols. However going too far beyond them is also equally damaging, and risks a subtlety of identity claim which 
verges on neocolonialism. The definitions provided, but also not revealed by Royal in Chapter 7 also maintain cultural safety for Māori.

What are the limits of theorising the indigenous organisation using social phenomenology? This process-based approach has not provided a simple organisational structure which can be taken and applied universally, assuming an objective and unproblematic organisation. Instead I theorise the power of knowledge to organise. I suggest knowledge is what an organisation is, not what it has, placing the focus on the roles, scripts and stories of organisational actors and the strategies used to manage knowledge and enact the organisation. These strategies and the documents which reflect them can construct not just the organisation, but also can support the construction of the wider world which we all tacitly accept has been created by someone else.

\subsection{Areas for Future Research}

A working theory of indigenous organising as a process describes how indigenous communities in two global contexts have ensured the survival of their unique knowledge sets through organisational agency, thus fulfilling the hope expressed at the beginning of the thesis. OS researchers can explore in greater detail and in a range of contexts the working theory which has been proposed here, and the organisational topics underpinned by knowledge which have been outlined in the thesis. Researchers paying due weight to their own local conditions, contexts and conversations, can generalise for themselves how 
a working theory of indigenous organising can be adapted or updated to build theoretic depth (Lincoln and Guba, 1985; Kuhn, 1996).

Taking the notions of knowledge and new theory in OS further, I have initially theorised how actors use indigenous knowledge to construct a framework of an indigenous organisation. I suggest that new possibilities exist to develop this theory and cases of indigenisation, illustrating new of ways of organising which may emerge from other communities and societies, as Ralston Saul (2005) has suggested in Chapter 2.

I propose that this theory and the insights gained can also be extended to rethink knowledge management and organising in organisational theory. This thesis provides evidence that knowledge is not just what an organisation has, but the resources from which actors construct the very organisation itself. My own future work in OS seeks to develop this framework of organising knowledge to retheorise leadership and knowledge management. To develop new knowledge, there is much to relearn. 


\title{
Appendix: Sample Information Sheet
}

\author{
VICTORIA UNIVERSITY OF WELLINGTON \\ Te Whare Wananga o te Upoko o te Ika a Maui

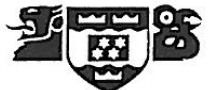 \\ Steven Finlay \\ PhD Scholarship Student \\ Room Rutherford House RH 912 \\ P.O. Box 600 Wellington \\ Steven.finlay@vuw.ac.nz \\ Tel: 64-04-463-5143 Fax: 64-04-463 5253
}

\section{PhD Research: Indigenous Organising}

The goal of this research is to explore organisations drawing from historical cultural and spiritual traditions - comparing the Maori and Scottish cases: The Iona Community on Iona, Scotland and Te Wananga O Raukawa at Otaki. Given that most organisational theory is written from an American perspective I am keen to explore alternative understandings which are more locally based, drawing from two communities who intentionally have created organisations from an older spiritual tradition.

I am drawing from an intellectual tradition which seeks to explore how the experience occurs within the lifeworld of the members of a community - therefore questions will be asked about your own experience. If you agree to take part in this research I will be seeking to interview you about your own cultural and spiritual tradition and this organisation. The interview will last for about one hour.

I am seeking to explore two aspects : 1) a historical view and 2) a current view:

1) historical: in thinking about your sense of your own cultural and spiritual tradition - how did you or didn't you experience this?

Have there been any barriers or blocks to the survival of this tradition? What are they?

2) a current view : asking about your sense of your own cultural and spiritual tradition today - how is this meaningfully expressed and fulfilled for you today?

Does the organisation support this. If so, how? Are there any barriers or blocks

to the survival of this tradition today? If so, what are they?

I am also seeking to explore how you came to the organisation, and what it was like when you connected with the organisation. What changed? How was connecting with this organisation different from a broader mainstream organisation?

You can decide whether I tape record the interview, video or take notes. You can have the notes and any material recorded back at any time. Whilst I have obtained the permission of Professor Whatarangi Winiata to pursue the study, you have the right to refuse. There is no obligation on any individual to collaborate if, for whatever reason, you are not comfortable. 


\section{RESEARCH AGREEMENT}

- This is a personal research agreement. Whilst the leader has given consent it is up to you.

- Your individual identity will be confidential. Whilst the organisation will be named, no individual attribution will be made without your permission.

- No one will be given access to any material except the researcher.

- You can have as much information as you want about the research, including a copy of the current proposal.

\section{PARTICIPANT'S STATEMENT}

I have been provided with adequate information relating to the nature and objectives of this research project, I have understood that information and have been given the opportunity to seek further clarification or explanations.

I understand that I may withdraw from this study at any time before the final analysis of data: specifically by Nov 2003 without providing reasons and without incurring any consequences. If I withdraw I expect to have all data returned to me. I understand that lack of withdrawal up to, and after, this period will be taken as consent.

I consent to information or opinions being anonymously attributed to me within the thesis, and future publications, in standard academic form: for example: discussing indigeneity, "Judy" spoke of "the need to maintain cultural control" (Finlay,S. 2003, fieldnotes).

I understand that the information I have provided will be used only for this research project. I understand future publication of data will occur after analysis. Consent is also sought for publication, anonymously, in the above form. I understand that when this research is completed the information obtained will be destroyed or returned.

Any extra comments or conditions?

\section{Participant Name:}

Signature:

Researcher:

Date: 


\section{Māori Glossary}

aroha [love]

hapu [sub tribe]

iwi [tribe]

kaitiakitanga [care of treasures]

kaumatua [elders]

karakia [prayers of welcome]

kawa [practices]

kawanatanga [governorship]

kete [knowledge basket]

kiawhina [voluntary staff]

kohanga Reo [Māori language learning nests]

korero [conversations]

kotahitanga [unity of purpose and direction]

mana [spiritual pride]

manaakitanga [mana enhancing behaviour]

maonga [Mountain]

matauranga Māori [Māori knowledge]

powhiri [tribal welcome]

pukengatanga [nurturing traditions]

rangatira [chiefs]

rangatiratanga [chieftainship - attributes of a rangatira] 
runanga [tribal authority]

ruruku [gatherings]

taa moko [facial tattoo]

tamariki [children]

tangi [funerals held on Marae]

taonga [treasures]

tapu [the state of being sacred]

Te Reo Māori [Māori language]

tikanga Māori [Māori principles]

tino rangatiratanga [full chieftainship]

tohunga [knowledge experts]

tumuaki [chairperson]

tupuna [ancestors]

turangawaewae [ground of standing]

ukaipötanga [nurturing places and senses of belonging]

utu [reciprocal return, either positive or negative]

wānanga [Māori universities]

waiata[song]

wairuatanga [nurturing spirituality]

whanaungatanga [familiness:being part of a larger whole]

whakapapa [genealogy] 


\section{Bibliography}

Adler, P. A., \& Adler, P. (1994). Observational techniques. In N. Denzin \& Y. Lincoln (Eds.), Handbook of qualitative research (pp. 377- 392). California: Sage.

Altheide, D., \& Johnson, J. (1998). Criteria for assessing interpretive validity in qualitative research. In N. Denzin \& Y. Lincoln (Eds.), Collecting and interpreting qualitative materials. California: Sage.

Alvarado, F. (1996) Concerning postmodernity and organizations in the third world: Opening a debate and suggestions for a research agenda Organization Science Vol 7. no 6. 667-681.

Alvesson, M. (2002). Understanding organizational culture. Thousand Oaks, California: Sage Publications.

Alvesson, M. \& Deetz, S. (2000) Doing critical management research. Thousand Oaks, California: Sage Publications.

Amin, A. (2004). Regulating economic globalisation. Transactions of the Institute of British Geographers, 29(2), 217-233.

Anderson, B. (1983). Imagined communities: Reflections on the origin and spread of nationalism.London: Verso.

Angrosino, M. V., \& Mays de Perez, K. A. (2000). Rethinking observation: From method to context. In N. Denzin \& Y. Lincoln (Eds.), Handbook of Qualitative Research (2 ${ }^{\text {nd }}$ Ed, pp. 673-714). California: Sage.

Arnold, B., \& Gibson, D. B. (Eds.). (1996). Celtic chiefdom, Celtic state. Cambridge: Cambridge University Press. 
Banerjee, S. B. (1999). Whose mine is it anyway? National interest, indigenous stakeholders and colonial discourses: The case of the Jabiluka uranium mine. Paper presented at the Critical Management Conference, Manchester. Retrieved online in Dec 2001 from http://www.mngt.waikato.ac.nz/ejrot/cmsconference/default.htm

Banerjee, S. B., \& Linstead, S. (2001). Globalization, multiculturalism and other fictions: Colonialism for the new Millenium. Organization, 8(4), 683- 722.

Banerjee, S. B., \& Linstead, S. (2004). Masking subversion: Neocolonial embeddedness in anthropological accounts of indigenous management. Human Relations, 57(2), $221-247$.

Barber, B. (1996). Jihad vs. Mcworld: How globalism and tribalism are shaping the world: Ballantyne Books.

Bartunek, J. (1984). Changing interpretive schemes and organisational restructuring: The example of a religious order. Administrative Science Quarterly, 29, 355372.

Bartunek, J. and Necochea R. (2000). Old insights and new times: Kairos, Inca cosmology, and their contributions to contemporary management inquiry. Journal of Management Inquiry, 9(2), 103-112.

Belich, J. (2001). Paradise re-forged: A History of the New Zealanders From the 1880s to the year 2000.Auckland, N.Z.: Allan Lane; Penguin, 2001.

Berger, P., \& Luckmann, T. (1966). The Social Construction of Reality. Middlesex, England: Penguin. 
Berking, H. (2003). 'Ethnicity is everywhere': On globalisation and the transformation of cultural identity. Current Sociology, 51 (3/4), 248-264.

Beteille, A. (1998). The idea of indigenous people. Current Anthropology, 39(2), 187191.

Bradley, I. (1994). The Celtic Way. London: Darton, Longman and Todd.

Bradley. I. (1999) Celtic Christianity: Making Myths and Chasing Dreams. New York: St. Martin's Press.

Bragg, M. (2003). Voices of the powerless. In S. Taylor (Producer) BBC Radio Scotland, July $20^{\text {th }}$.

Brun, P. (1996). From chiefdom to state organisation in Celtic Europe. In B. Arnold \& D. B. Gibson (Eds.), Celtic Chiefdom; Celtic State. 140-187 Cambridge: Cambridge University Press.

Burrell, G., \& Morgan, G. (1979). Sociological Paradigms and Organisational Analysis. London: Heinemann.

Calas, M., \& Smircich, L. (1999). Past postmodernism? Reflections and tentative directions. Academy of Management Review, Oct, 24(4) 649-672.

Carruthers, G., \& Rawes, A. (Eds.). (2003). English Romanticism and the Celtic World. Cambridge: Cambridge University Press.

Casey, C. (2002). Critical Analysis of Organisations-Theory, Practice, Revitalisation. London: Sage.

Chapman, M. (1978). The Gaelic Vision in Scottish Culture. Guilford, Surrey: Biddles. 
Charmaz, K. (2000). Grounded theory: Objectivist and constructionist methods. In N. K. Denzin \& Y. S. Lincoln (Eds.), Handbook of Qualitative Research (2 ${ }^{\text {nd }}$ ed.). London: Sage.

Childs, J. B., \& Guillermo Delgado, P. (1999). On the idea of the indigenous. Current Anthropology, 40(2), 211-212.

Chun, A. (2000). Introduction: (Post)Colonialism and its discontents, or the future of practice. Cultural Studies, 14(3/4), 379-384.

Clegg, S., \& Hardy, C. (1996). Introduction. In S. Clegg, C. Hardy \& W. Nord (Eds.), Handbook of Organisation Studies. London: Sage.

Cliff, B. (1996). Essentialism, accessed June 2004, from http://www.emory.edu/ENGLISH/Bahri/Essentialism.html

Comer, L., \& Sundakov, A. (2003). Māori Economic Development. Wellington: New Zealand Institute of Economic Research.

Cramm, F. (2001). Rangahau Māori: Tona tika, tona pono -The validity and integrity of Māori research. In M. Tolich (Ed.), Research Ethics in Aotearoa: Context, Practice, Critique (pp. 35- 52). Auckland: Longman.

Crossley, N. (2003). Even newer social movements? Anti -corporate protests, capitalist crises and the re-moralisation of society. Organisation, 10(2), 287-298.

Cunningham, C., \& Stanley, F. (2003). Indigenous by definition, experience or worldview. British Medical Journal, 327, 403.

Curtise, J., McCrone, D., Park, A., \& Paterson, L. (2002). New Scotland, New Society? Edinburgh: Polygon. 
Czarniawska, B. (1997). Narrating the Organisation: Dramas of Institutional Identity. Chicago: University of Chicago Press.

Davies, O., O'Loughlin, T., \& Mackay, J. (1999). Celtic Spirituality. New York: Paulist Press.

Deetz, S. (1996). Describing differences in approaches to organisation science; Rethinking Burrell and Morgan and their legacy. Organisation Science, 7(2), 191-207.

Denzin, N. (1997). Interpretive Ethnography: Ethnographic Practices for the 21st Century. London: Sage.

Derrida, J. (1976). Of Grammatology (G. C. Spivak, Trans.). Baltimore: John Hopkins University Press.

Devine, T. M. (2000). Scotland: The History of a Nation: 1700 -2000. London: Penguin.

Dhaouadi, M. (1994). Capitalism, global humane development and the other underdevelopment. In L. Sklair (Ed.), Capitalism and Development: pp 140 165.

Diamond, P. (2003). A Fire In Your Belly: Māori Leaders Speak. Wellington: Huia.

Durie, E. T., Stanley Latimer, G., \& Basil, P. (1986). Te Reo Māori Claim (3.1.4.), accessed July 2004 from http://www.knowledgebasket.co.nz/waitangi/text/wai011/doc006.html

Durie, M. (1998). Te Mana, Te kawangatanga: The Politics of Māori Self Determination. Sydney: Oxford University Press. 
Durie, M. (2000). Contemporary Māori Development: Issues and Broad Directions working paper. Palmerston North: Massey University.

Durie, M. (2003). Launching Māori Futures. Wellington: Huia.

During, S. (2000). Postcolonialism and globalisation: Towards a historicisation of their inter-relation. Cultural Studies, 14(3/4), 385-404.

Dyer, W. G., \& Wilkins, A. (1991). Better stories, not better constructs, to generate better theory: A rejoinder to Eisenhardt. Academy of Management Review, 16(3), 613- 619.

Eisenhardt, K. (1989). Building theories from case study research. Academy of Management Review, 14(4), 532- 550.

Ellis, C., \& Bochner, A. P. (2000). Autoethnography. In N. Denzin \& Y. Lincoln (Eds.), Handbook of Qualitative Research (pp. pp 733 -767). London: Sage.

Elmes, M., \& Prasad, A. (2005). Resisting in high places: A study of First Nation Mohawk Ironworkers. Unpublished manuscript. Worcester Polytechnic Institute. Department of Management.

Ferguson, R. (1988). Chasing the Wild Goose. London: Collins.

Ferguson, R. (1990). George MacLeod: Founder of the Iona Community. London: Collins.

Fetterman, D. M. (1989). Ethnography Step by Step.California: Sage.

Feyerabend, P. (1996). Against Method. London: Verso.

Feyerabend, P. (1994). Farewell to Reason. London: Verso. 
Finlay, S. (2001). Theorising from the edge: Building bridges of possibility.

Closing the Divide: Australia New Zealand Academy of Management Conference, Unitec, Auckland 2001, pp 1-18. Published on CD Rom Conference Proceedings.

Finlay, S. (2002). Voices from the edge: Framing indigenous organisations in the 21st Century. Management in a Global Context. Prospects for the 21st Century. Brisbane, Australia 2002. 6th ANZAM/IFSAM World Congress, pp 113. Published on CD Rom Conference Proceedings.

Finlay, S. (2003). Critical systems theory and indigenous organising. 3rd Critical Management Studies Conference, Lancaster University. Critical Management Studies 3 Conference Proceedings, pp.1-28. Published online at www.mngt.waikato.ac.nz/ejrot/cmsconference/2003/.../Finlay.pdf

Finlay, S. (2005). 'Enacting indigeneity: Local knowledge, place and identity' in Work, Identity and Locality Conference, Massey University School of Business, Palmerston North.

Finlay, S. (2006). Indigenous organising. Ma te rango te waka ka rere: Exploring a Kaupapa Māori organisational framework, 3rd- 4th November, Te Wānanga o Rauwaka, Otaki. Published in Conference Proceedings, Te Wānanga o Rauwaka, Otaki.

Finlay, S. (2008). Indigenous organizing: Enacting and updating indigenous knowledge. In D. Barry and H. Hansen. (Eds) The Sage Handbook of New Approaches to Management and Organization. pp 528-539. New York: Sage. 
Fischer, E. (1999). Cultural logic and Maya identity. Current Anthropology, 40(4), $473-499$.

Foley, D. (2004). Where do Indigenous Australian entrepreneurs fit into mainstream society? Paper presented at the ANZAM 2004, Dunedin. Published on CD Rom.

Friedman, J. (1994a). Cultural Identity and Global Process. London: Sage.

Friedman, J. (1994b). Consumption and Identity. Chur: Harwood academic publishers.

Fuss, D. (1989). Essentially Speaking. New York: Routledge.

Macpherson J.A, Cunningham M., MacInnes D.J., MacKay D., \& MacSween A., (2000). Gaelic: Revitalising Gaelic a National Asset. Retrieved from http://www.scotland.gov.uk/library3/heritage/gtfr-01.asp\#b5

Geertz, C. (1973). The Interpretation of Cultures. New York: Basic Books.

Gephardt, R. P. (1993). The textual approach: Risk and blame in disaster sensemaking. Academy of Management Journal, 36, 1465.

Gergen, K. (1985). The social construction movement in modern psychology. American Psychologist, 40(3), 266-275.

Gergen, K.(1992). Organisational theory in the postmodern era. In M. Reed \& M. Hughes (Eds.), Rethinking Organisation. London: Sage.

Glaser, B. G. (1978). Theoretical sensitivity - Advances in the methodology of grounded theory. California: The Sociology Press.

Glaser, B. G. (2002). Constructivist grounded theory? Forum: Qualitative Social Research, 3(3), 1-12. 
Golden-Biddle, K., \& Locke, K. (1993). Appealing work: An investigation of how ethnographic texts convince. Organisation Science, 4(4), 595-615.

Gopal A. Willis R. and Gopal Y. (1999) From the colonial enterprise to enterprise systems: parallels between colonisation and globalisation Paper presented at the Critical Management Conference, Manchester. Retrieved online in Dec 2001 from http://www.mngt.waikato.ac.nz/ejrot/cmsconference/default.htm

Greene, S., Banerjee, S. B., Bannister, K., \& Brush, S. (2004). Indigenous peoples incorporated? Culture as politics, culture as property in pharmaceutical bioprospecting. Current Anthropology, 45(2), 211- 240.

Grice, S., \& Fleming, P. (1999). Opening our global (eyes): the (dis)appearing politics narrating globalisation. In N. Monin, J. Monin \& R. Walker (Eds.), Narrative of business and society (pp. 321- 334). Auckland: Longman.

Guba, E. G. (1990). The Paradigm Dialogue. California: Sage.

Gunew, S. (1994). Framing Marginality: Multicultural Literary Studies. Melbourne: Paul \& Co Pub Consortium.

Hammersley, M. (2003). Conversation analysis and discourse analysis: Methods or paradigms? Discourse \& Society, 14(6), 751-781.

Hammersley, M., \& Atkinson, P. (1994). Ethnography and participant observation. In Handbook of Qualitative Research. California: Sage.

Hansen, H. (2002). The construction of organisational stories: The stories behind the stories, University of Kansas. Unpublished PhD Thesis. 
Hansen, H. (2003). Abduction: A (retro)introduction. Paper submitted to the Academy of Management, Conference 2003. Seattle.

Hartley, L. (2004). Ngai Tahu Inc. Unlimited, Jan 2004, 66- 70.

Henare, M. (1988). Nga tikanga me nga ritenga o te ao Māori: Standards and foundations of Māori society. Report of the Royal Commission on Social Policy, April, 1- 40. The Royal Commission, Wellington.

Henare, M. (1995). Differing perceptions of New Zealand history and sovereignty: Wellington School of Māori Studies, Victoria University of Wellington.

Henare, M.(2001). Globalisation: World of darkness or light? Presentation at the Globalisation Seminar, UNESCO, Wellington, June.

Henare, M., \& Lips-Wiersma, M. (2002). Spirituality in organisations; Comparing Western and Māori perspectives. Paper presented at the Academy of Management Conference: Spirituality and Religion Interest Group.

Henry, E. (1994). Contemporary Māori business, and its legislative and institutional origins. In Deeks. J. \& P. Enderwick (Eds.), Business and New Zealand Society (pp 150-174). Auckland: Longman.

Henry, E., \& Pene, H. (2001). Kaupapa Māori: Locating indigenous ontology, epistemology and methodology in the Academy. Organisation, 8 (2), 234 -239.

Heritage, J. (1984). Garfinkel and Ethnomethodology. Oxford: Polity Press.

Hirst, P., \& Thompson, F. (1996). Globalisation in question: The international economy and the possibilities of governance. Cambridge: Polity Press.

Hofstede, G. (1993). Cultural constraints in management theories. The Executive Management Journal, 7(1), 81- 94. 
Holstein, J. A., \& Gubrium, J. F. (1994). Phenomenology, ethnomethodology, and interpretive practice. In N. Denzin \& Y. Lincoln (Eds.), Handbook of Qualitative Research (pp. 262-272). New York: Sage.

Holstein, J. A., \& Gubrium, J. F. (1995). The Active Interview. California: Sage.

Holstein, J. A., \& Gubrium, J. F. (2000). Analysing interpretive practice. In The Handbook of Qualitative Research (2nd ed. pp. 487- 508). California: Sage.

Iona Community (2004a). the Rule retrieved July 2004 from http://www.iona.org.uk Iona Community (2004b). The Story of the Iona Community retrieved July 2004 from http://www.iona.org.uk

Jackson, B. (2001). Management Gurus and Management Fashions. London: Routledge.

Jacques, R. (1996). Manufacturing the Employee. London: Sage.

Jaya, P. (2001). Do we really know and profess? Decolonizing management knowledge. Organization 8(2), pp 227-233.

Johnson, G. \& Scholes, K. (2001) Exploring Corporate Strategy: Text and Cases $\left(4^{\text {th }}\right.$ ed.) London, Prentice Hall.

Joyce, T. (1998). Celtic Christianity. New York: Orbis Book.

King, M. (1997). 1000 years of Māori History. Auckland: Reed.

Kondo, D. (1990). Crafting Selves: Power, Gender and Discourses of Identity in a Japanese Workplace. Chicago: University of Chicago.

Kuhn, T. S. (1996). The Structure of Scientific Revolutions (3rd ed.). Chicago, IL: University of Chicago Press. 
Kunda, G. (1992). Engineering Culture: Control and Commitment in a High Tech Corporation. Philadelphia: Temple University Press.

Ladson-Billings, G. (2000). Racialised discourses and ethnic epistemologies. In N.

Denzin \& Y. S. Lincoln (Eds.), The Handbook of Qualitative Research (Second ed) (pp. 257-277). London: Sage.

Lange, R. (1999). May the People Live - A History of Māori Health Development 1900 -1920. Auckland: Auckland University Press.

Lash, S., \& Friedman, J. (1992). Modernity and Identity. Oxford: Blackwell.

Lash, S., \& Urry, J. (1994). Economies of Sign and Space. London: Sage.

Lincoln, Y. (1990). The making of a constructivist. In E. G. Guba (Ed.), Paradigm Dialogue (pp. 67-87). California: Sage.

Lincoln, Y., \& Guba, E. G. (1985). Naturalistic Enquiry. London: Sage.

Locke, K. (2001). Grounded Theory in Management Research. London: Sage.

Loomis, T. (1998). Indigenous Populations and Sustainable Development: Building on Indigenous Approaches to Holistic, Self - Determined Development. Hamilton: University of Waikato working paper.

Love, M., \& Waa, P. (1994). The pre-European Māori economy. In Deeks. J. \& P. Enderwick (Eds.), Business and New Zealand Society (pp.15-33): Longman.

Love, M., \& Waa, P. (1994). Māori in the Period of Colonisation. In Deeks. J. \& P. Enderwick (Eds.), Business and New Zealand Society (pp. 33-42): Longman.

MacArthur, E. M. (1996). Columba 's Island. Edinburgh: Edinburgh University Press. 
MacDonnell of Leinster (2006) The Evolution of Dalriada Retrieved from http://macdonnellofleinster.org/page_7r\%20The\%20Evolution\%20of\%20Dalria da.htm

MacInnes, J. (1994). Preface. In A. Carmichael (Ed.), Carmina Gadelica: Hymns and Incantations. (pp. i- xx) London: Redwood Books.

Marsden, M. (2003). The Woven Universe: Selected writings of Rev.Māori Marsden. Masterton: The Estate of the Rev. Māori Marsden.

Marshall, C., \& Rossman, G. (1999). Designing Qualitative Research. California: Sage.

Martin, J. (2001). Meta Theoretical Controversies in Studying Organisational Culture. Stanford: Stanford University.

Maykuk, P., \& Morehouse, R. (1994). Beginning Qualitative Research: A Philosophic and Practical Guide. London: The Falmer Press.

McConnell, J. (2004). First Minister delivers speech in Skye. Retrieved June, 2004 from http://www.scotland.gov.uk/News/News-Extras/210

McIntosh, A. (2001). Soil and Soul. London: Aurum.

Meek, D. (2002). The faith of the fringe: Perspectives and issues in Celtic Christianity. In J. Pearson (Ed.), Belief Beyond Boundaries: Wicca, Celtic Spirituality and The New Age (pp. 251-276). Milton Keynes: The Open University - Ashgate Publishing.

Merrett, C. D. (2001). Understanding local responses to globalisation. National Identities, Vol 3,(No 1.) pp 24- 38.

Miles, H., \& Huberman, J. (1984). Analysing Qualitative Research. California: Sage. 
Miller, P. (2000). Waymarks: Signposts to Discovering God's Presence in the World. Norfolk: Canterbury Press.

Milne, J. (July 20 ${ }^{\text {th }}$ 1998). Calls for Māori Parliament won't go away. The Dominion Post, 2.

Milne, J. (February $\left.15^{\text {th }} 1999\right)$. Crown admits to universities' under-funding. The Dominion Post, 6.

Mitchell, R. (1972). Māori Language. On Akona Te Reo: Māori language in State Education 1840-1990. Archives New Zealand Exhibition 2004: The Christchurch Press.

Muehlebach, A. (2001). 'Making place' at the United Nations: Indigenous cultural politics at the U.N. working group on indigenous populations. Cultural Anthropology, 16(3), 415-448.

Munck, R. (1984). Politics and Dependency in the Third World. London: Pitman Press. Munshi, D. (1999). The Business of the Other: Representing the non- West in Management and Media. Unpublished Thesis. University of Waikato.

Mushinski, D., \& Pickering, K. (2000). Inequality in income distribution - does culture matter? Journal of Economic Issues, V 34.(403-412).

Nantson, M. (1970). Phenomenology and Social Reality. The Hague: Martinus Nijhoff. National Library of New Zealand (2001) The celebrated southern chief, Te Rauparaha 1847 , retrieved from http://rangiatea.natlib.govt.nz/TeRauparahaE.htm\#TeRauE3 and Interior of Rangiātea retrieved from http://rangiatea.natlib.govt.nz/HomeE.htm\#homeE1 
Newell, J. P. (1997). Listening for the Heartbeat of God: A Celtic Spirituality. New York: Paulist Press.

Nustad, K. G. (2003). Considering global/local relations: Beyond dualism. In T. H. Erikson (Ed.), Globalisation: Studies in Anthropology (pp. 122-137). London: Pluto press.

O'Connell, B. (1978). Greek and Celtic. New York: Vantage Press.

O'Hogain, D. (2002). The Celts - A History. Cork: The Boydell Press.

Ohmae, K. (1995a). The End of the Nation State. London: Harper Collins.

Ohmae, K. (1995b). The Evolving Global Economy. Harvard: HBS.

Orange, C. (1987). The Treaty of Waitangi. Auckland: Allen and Inwin.

Orange, C. (1989). The Treaty of Waitangi-competing views. In B. Kernot \& A. McBride (Eds.), Te Reo o Te Tiriti Mai Rano: The Treaty is Always Speaking. Wellington: Victoria University of Wellington.

Oxford Online Dictionary. (1988). Second Edition, accessed June 2004 at http://dictionary.oed.com/

Paterson, R. (2003) Highland clearances. The Glasgow Herald, 15 ${ }^{\text {th }}$ August 200315.

Paynter, N. (2002). This is the Day: Readings and Meditations from the Iona Community. Glasgow: Wild Goose Publishing.

Pearson, J. (2002). Introduction. In J. Pearson (Ed.), Belief Beyond Boundaries: Wicca, Celtic Spirituality and the New Age (pp. 1-14). Milton Keynes: The Open University - Ashgate Publishing.

Polanyi, M. (1958). Personal Knowledge: Towards a Post Critical Landscape. London: Routledge \& Kegan Paul. 
Popkin, R. H. (1999). The Pimlico History of Western Philosophy. London: Pimlico.

Porter, M. (2001). New Zealand Competitiveness -The Next Agenda. Paper presented at The Knowledge Wave Conference, Auckland.

Prasad, A. (2003). Postcolonial Theory and Organisational Analyses: A Critical Engagement. New York: Palgrave Macmillan.

Prasad, A., \& Prasad, P. (2002). The coming of age of interpretive organisational research. Organisational Research Methods, 5(1), 4-12.

Prasad, P. (2003). CMS 3 Postcolonial stream discussion. Lancaster: Critical Management Studies Conference. Fieldnotes Journal.

Radio New Zealand National (Producer). (2003) Interview with Whatarangi Winiata. Radio New Zealand National (Producer). (2005, Febuary 6th) 'The reconciliation of two key words in the Treaty of Waitangi: Kawanatanga and Tino Rangatiratanga'. [Audio Podcast] Retrieved from http://www.radionz.co.nz/national/lecturesandforums/waitangi_rua_rau_tau_lec tures (Replay Radio NRP 710).

Ralston Saul, J. (2004). The collapse of globalism. Harpers' Magazine, March, 33 - 43. Ralston Saul, J. (2005). The Collapse of Globalism and the Reinvention of the World. London: Atlantic.

Ramsden, E. (1951). Rangiatea: The Story of Otaki's Māori Church. Wellington: AH and AW Reed.

Ranford, J. (2006) 'Pakeha', its origin and meaning Auckland College of Education informally published essay accessed online from http://www.maorinews.com/writings/papers/other/pakeha.htm 
Rattansi, A. (1997). Postcolonialism and its discontents. Economy and Society, 26(4), 480-500.

Reed, M. (1996). Organisational theorising: A historically contested terrain. In S.

Clegg, C. Hardy \& W. Nord (Eds.), Handbook of Organisation Studies. London: Sage.

Richardson, L. (1994). Writing: A method of inquiry. In Y. Lincoln \& E. G. Guba (Eds.), Handbook of Qualitative Inquiry ( ${ }^{\text {st }}$ Ed pp.516-529). Thousand Oaks: Sage.

Robertson, R. (1995). Glocalization: Time - space and homogeneity - heterogeneity. In M. Featherstone, S. Lash \& R. Robertson (Eds.), Global Modernities (pp. 2544). London: Sage.

Robertson, R., \& Giulianotti, R. (2004). The globalisation of football: A study in the glocalization of the 'serious life'. The British Journal of Sociology, 55(4), pp.545-568.

Rosaldo, R. (1993). Culture and Truth. London: Routledge.

Rose, D., Sanderson, K., Morgan, P., Stuart, G., \& Andrews, G. (1997). Strategies to Facilitate Māori Economic Development Business and Economic Research Ltd.

Royal, T. A. C., Baker, M., \& Simpson, M. (1997). Rangiatea. Wellington: The National Library of New Zealand.

Ruwhiu, D., \& Wolfgramm, R. (2005). Revealing the key to research in indigenous organisations. Paper presented at the 21st EGOS Colloquium Frei Universitat, Berlin. Published on CD Rom.

Said, E. (1978). Orientalism. London: Routledge. 
Said, E. (1994). Culture and Imperialism. New York: Knopf.

Salmond, A. (1985). Māori epistemologies. In J. Overing (Ed.), Reason and Morality (pp. 240-261). London: Tavistock publications.

Salmond, A. (1991). Two Worlds - First Meetings Between Māori and Europeans 1642-1772 Auckland: Penguin Books.

Shafritz, J.M. \& Steven Ott, J. (1987). Classics of Organization Theory New York: Dorsey Press.

Scottish Parliament, The. (2004). About the Scottish Parliament. Retrieved June, 2004, from http://www.scotland.gov.uk/About/Intro/Issues

Schutz, A. (1964). Collected Papers II: Studies in Social Theory. The Hague: Martinus Nijhoff.

Schutz, A. (1967). The Phenomenology of the Social World. New York: Northwestern University Press.

Schutz, A. (1970). On Phenomenology and Social Relations. Chicago: The University of Chicago Press.

Schutz, A. (1973). The Structures of the Lifeworld. London: Northwestern University Press.

Schwartzman, H. (1993). Ethnography in organisations. Qualitative Research Methods, Research Inquiry Series no 27 University of Chicago.

Shanks, N. (1999). Iona - God's Energy: The Spirituality and Vision of the Iona Community. London: Hodder and Stoughton.

Shirres, P. (1997). Te Tangata - The Human Person. Auckland: Accent Publications. 
Shwandt, T. A. (1996). Constructivist, interpretivist approaches to human enquiry. In S. R. Clegg, C. Handy \& W. Nord (Eds.), Handbook of Organisation Studies: (pp339 -356.) California: Sage.

Sillitoe, P. (1998). The development of indigenous knowledge. Current Anthropology, $39(2), 223-235$.

Sklair, L. (2002). Globalisation: Capitalism and its Alternatives. Oxford: Oxford University Press.

Smith, C., \& Ward, G. K. (2000). Indigenous Cultures in an Interconnected World. St Leonards: Allen Unwin.

Smith, G. (2000). Protecting and respecting indigenous knowledge. In M. Battiste (Ed.), Reclaiming Indigenous Voice and Vision (pp.208- 219) Vancouver UBC Press.

Smith, H.(1994). The issues of compatibility between cultural identity and economic development among Native American tribes. American Indian Culture and Research Journal, 18:3 (177-206).

Smith, L. (1999). Decolonizing Methodologies. London: Zed Books.

Smith, L. (2000). Kaupapa Māori research. In M. Battiste (Ed.), Reclaiming Indigenous Voice and Vision (219 -230): Vancouver, UBC Press.

Spivak, G. C. (1987a). In Other Worlds. New York: Methuen.

Spivak, G. C. (1987b). The post-colonial critic. The Book Review, 11(3).

Spivak, G. C. (1988). Can the subaltern speak? In N. C. \& G. L. (Eds.), Marxism and the Interpretation of Culture (pp. 271-313). St. Pierre, E. A.: University of Illinois Press. 
Spivak, G. C. (1993). Outside in the Teaching Machine. New York: Routledge.

Stablein, R. (1996). Data in organisation studies. In S. Clegg, C. Hardy \& W. Nord (Eds.), Handbook of organisation studies (pp. 509- 526). London: Sage.

Stablein, R. (2002). Using existential phenomenology to study a work team. Towards Phenomenology of Groups and Group Membership, 4, 1-26.

Stake, R. (2000). Case studies. In N. K. Denzin \& Y. S. Lincoln (Eds.), Handbook of Qualitative Research (2 ${ }^{\text {nd }}$ ed.) (pp. 435- 452). London: Sage.

Steier, F. (1991). Introduction: Research as self reflexivity, self reflexivity as social process. In F. Steier (Ed.), Research and Reflexivity. London: Sage.

Taepa, H. (1968). The Rangiatea Story. Levin: Kerslake, Billens and Humpries.

Te Puni Kokiri. (2001). National Māori Language Survey, accessed July 2002 from http://www.tpk.govt.nz.

Te Wānanga o Raukawa (2003). Updated and renewed file copies of cited documents: (Note: page numbers may misalign from 2003 file documents cited in text): Charter 2003, updated version avalailabe athttp://www.twor.ac.nz/?q=node/113 Guiding Principles of Te Wānanga o Raukawa, Winiaita, P. (2003) updated version available from http://www.twor.ac.nz/?q=node/113 Images from http://www.twor.ac.nz.

Tolich, M., \& Davidson, C. (2000). Starting Fieldwork: An Introduction to Qualitative Research in New Zealand. Auckland.: Oxford University Press.

Tremaine, M. (1990). Sharing from the baskets of knowledge. In F. Sligo (Ed.), Business Communication: New Zealand perspectives (pp. 48-55). Palmerston North: Software Technology N.Z. 
Van Maanen, J. (1998). Tales from the Field. New York: Sage.

Waitangi Tribunal,The. (2004). About the Waitangi Tribunal. Retrieved July, 2004, from http://www.waitangi-tribunal.govt.nz/about/waitangitribunal

Walker, R. (1989). Māori identity. In D. Novitz \& B. Wilmott (Eds.), Culture and Identity in New Zealand (pp. 35-52). Wellington: Bookprint.

Walker, R. (1992). Models of Māori Leadership. Auckland: Māori Studies Department, University of Auckland.

Wallerstein, I. (1974). The Modern World System: Capitalist Agriculture and the Origins of the European World Economy in the Sixteenth Century. London: Plenum Press.

Watson, G. (1996). Listening to the native; The non-ironic alternative to dialogic ethnography. The Canadian Review of Sociology and Anthropology, 33(1), 7389.

Weick, K. (1979). The Social Psychology of Organizing. California: McGraw Hill.

Weick, K. (1995). Sensemaking in Organizations. California: Sage.

Whiteman, G., \& Cooper, W. H. (2000). Ecological Embeddedness. Academy of Management Journal, 43, 1265 -1282.

Wikipedia, (2005). Book of Kells Folio 32V, (Circa 900 C.E) Retrieved from http://en.wikipedia.org/wiki/Book_of_Kells

Wilson, M. (2001). The Treaty Settlements Parliamentary Speech. Retrieved March 2002, from http://www.executive.govt.nz/speech.cfm?speechralph=37199\&SR=0 
Winiata, W. (2000). Whakatupuranga rua mano: Capability building in practice. Paper presented at the Nation Building and Māori Development in the 21st Century, University of Waikato.

Winiata, P. (2001). Leaders are made not just born- planning for leaders and leadership succession. Paper presented at the Ngati Tatou 2020:Young Māori Leaders Conference. The Foundation for Indigenous Research in Society \& Technology.

Winiata, W. (2001). Mental and social health within Tikanga Maaori. Paper presented at The Mental Health Services Conference of Australia and New Zealand, Wellington.

Wolfe, P. (1999). Settler Colonialism and the Transformation of Anthropology. London: Cassell.

Wolfgramm, R. (2001). Cultural complexities and strategic orientation: An analysis of contemporary Māori organisations. Paper presented at the APRU Doctoral Proceedings Conference, Auckland.

Yin, R. (1990). Case Study Research: Design and Methods. London: Sage. 